\title{
Evaluation of the primary mouse hepatocyte model for the prediction of genotoxicity
}

Citation for published version (APA):

Mathijs, K. (2009). Evaluation of the primary mouse hepatocyte model for the prediction of genotoxicity. [Doctoral Thesis, Maastricht University]. Datawyse / Universitaire Pers Maastricht.

https://doi.org/10.26481/dis.20091209km

Document status and date:

Published: 01/01/2009

DOI:

10.26481/dis.20091209km

Document Version:

Publisher's PDF, also known as Version of record

\section{Please check the document version of this publication:}

- A submitted manuscript is the version of the article upon submission and before peer-review. There can be important differences between the submitted version and the official published version of record.

People interested in the research are advised to contact the author for the final version of the publication, or visit the DOI to the publisher's website.

- The final author version and the galley proof are versions of the publication after peer review.

- The final published version features the final layout of the paper including the volume, issue and page numbers.

Link to publication

\footnotetext{
General rights rights.

- You may freely distribute the URL identifying the publication in the public portal. please follow below link for the End User Agreement:

www.umlib.nl/taverne-license

Take down policy

If you believe that this document breaches copyright please contact us at:

repository@maastrichtuniversity.nl

providing details and we will investigate your claim.
}

Copyright and moral rights for the publications made accessible in the public portal are retained by the authors and/or other copyright owners and it is a condition of accessing publications that users recognise and abide by the legal requirements associated with these

- Users may download and print one copy of any publication from the public portal for the purpose of private study or research.

- You may not further distribute the material or use it for any profit-making activity or commercial gain

If the publication is distributed under the terms of Article $25 \mathrm{fa}$ of the Dutch Copyright Act, indicated by the "Taverne" license above, 
Evaluation of the Primary Mouse Hepatocyte Model for the Prediction of Genotoxicity

Karen Mathijs 
(C) Karen Mathijs, Maastricht 2009

ISBN 9789052788869

Universitaire Pers Maastricht

Omslagillustratie en lay-out: Karen Mathijs

Omslagrealisatie en druk: Datawyse Boekproducties, Maastricht

\section{nutuim}

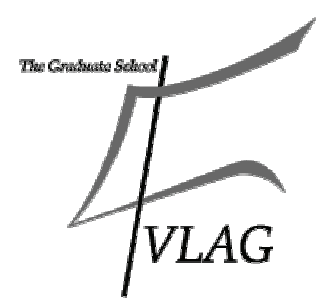

The studies presented in this thesis were performed at the Nutrition and Toxicology Research Institute Maastricht (NUTRIM), which participates in the Graduate School VLAG (Food Technology, Agrobiotechnology, Nutrition and Health Sciences), accredited by the Royal Netherlands Academy of Arts and Sciences. 


\title{
Evaluation of the Primary Mouse Hepatocyte Model for the Prediction of Genotoxicity
}

\author{
PROEFSCHRIFT
}

ter verkrijging van de graad van doctor aan de Universiteit Maastricht, op gezag van de Rector Magnificus, Prof. mr. G.P.M.F. Mols volgens het besluit van het College van Decanen, in het openbaar te verdedigen op woensdag 9 december om 14:00 uur

door

Karen Mathijs

geboren te Neerpelt op 6 april 1981

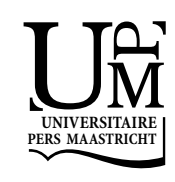




\section{Promotor}

Prof. dr. J.C.S. Kleinjans

\section{Copromotor}

Dr. J.H.M. van Delft

\section{Beoordelingscommissie}

Prof. dr. F.C.S. Ramaekers (voorzitter)

Dr. C.T.A. Evelo

Prof. dr. H. van Loveren (RIVM Bilthoven)

Prof. dr. E.C.M. Mariman

Dr. H. van Steeg (RIVM Bilthoven)

The research presented in this thesis was conducted as part of and therefore financed by the Netherlands Genomics Initiative (NGI), the Netherlands Organisation for Scientific Research (NWO) and the CARCINOGENOMICS FP6 project sponsored by the European Union (PL037712). 
Voor bompa... 

CONTENTS

Chapter 1 General Introduction 9

Chapter 2 Time Series Analysis of Benzo(a)Pyrene-Induced

Transcriptome Changes Reveals Temporary Effects on DNA

Repair, Metabolism and Cell Cycle

Chapter 3 Assessing the Metabolic Competence of Sandwich-Cultured Mouse Primary Hepatocytes

Chapter 4 The Relevance of Primary Mouse Hepatocytes for Toxicity

Profiling: Responses by Benzo(a)Pyrene

Chapter 5 Discrimination for Genotoxic and Non-Genotoxic Carcinogens by Gene Expression Profiling in Primary Mouse Hepatocytes Improves With Exposure Time

Chapter 6 Gene Expression Profiling in Primary Mouse Hepatocytes Discriminates Between True and False Genotoxic Compounds

Chapter 7 Summary and General Discussion

Nederlandse Samenvatting

Dankwoord

Curriculum Vitae 

Chapter 1

General Introduction 


\section{CHEMICAL CARCINOGENESIS}

Of the known carcinogenic agents (viruses, ultraviolet and ionizing radiations, and chemicals), chemicals appear to be of major importance in the induction of human cancers. Cancer is one of the leading causes of death worldwide. Nearly 2.9 million incident cases of cancer diagnosis and 1.7 million cancer deaths were reported in 2004 (1). Cancer can be caused by endogenous agents, like hormones, as well as exogenous agents, like chemical carcinogens and ionizing radiation. There is evidence that a considerable part of cancers is caused by exogenous factors and that these factors account for more than $50 \%$ of the cancer risk (2). Therefore the prediction of the carcinogenic potential of chemicals is tremendously important.

Chemical carcinogenesis is a multistage process. Initiation, the first stage, occurs rapidly and appears to be irreversible, generally as a result from one or more mutations of cellular DNA. When a compound is able to covalently bind with DNA, the formed adduct can be either incorrectly or not be repaired. This will eventually lead to the formation of a mutation $(3,4)$. When these adducts are induced at sites with genes involved in regulation of cell growth and cell differentiation, i.e. oncogenes and tumorsuppressor genes, cancer development can be induced (5). Chemicals which are able to, whether or not preceded by biotransformation, covalently bind to DNA and cause DNA damage, and appear to be able to consistently do this in several in vitro tests, are called genotoxic compounds (GTX). If this genotoxicity actually develops into carcinogenicity, such chemicals are called genotoxic carcinogens.

The second stage, promotion, occurs over a longer period of time. Promotion is a complex process and has been defined as the interruptible or reversible clonal expansion of the single initiated cell, in order that additional genetic/epigenetic changes can occur. It is followed by a progression stage. The proliferation rate of the cells is increased, enhancing the likelihood of genetic errors to occur which make already mutated cells more cancerous. Also a clinically detectable tumor develops into its terminal, often malignant form, which ultimately overwhelms the host, mainly by invasion and metastasis.

Carcinogens which do not demonstrate chemical reactivity with DNA and hence do not form DNA adducts, but rather promote carcinogenesis by inducing effects that indirectly lead to neoplastic transformation or enhance the development of tumors from preinitiated cells, are called nongenotoxic compounds (NGTX). When a carcinogen has both initiating and promoting activities, it is called a complete carcinogen. 


\section{PREDICTION GENOTOXIC AND OF CARCINOGENIC POTENTIAL}

The classification of chemical compounds according to their carcinogenic potential is frequently evaluated through application of chronic rodent bioassays, namely by using rats and mice. These assays are used to estimate cancer risks for humans, but are very expensive and time-consuming as they require the use of many animals and large quantities of the test compound during what is usually a 2-year period of study. These chronic rodent bioassays are also associated with ethical drawbacks. Furthermore the reliability, relevance and effectiveness of these in vivo assays are subjected to many uncertainties with regard to the extrapolation from animal to human risk. Therefore demands to develop a reliable way of predicting in vivo carcinogenicity in humans with a high predictive value by means of in vitro models are increasing (6).

Since many carcinogens are GTX, the testing whether a chemical has GTX properties is the first step in the carcinogenic risk assessment. Most frequently used in vitro systems for the identification of the GTX potency of chemicals are the bacterial Ames test, the mouse lymphoma assay, the micronucleus test and the chromosomal aberration test (7). These systems are relatively simple, accurate and much cheaper for the screening of chemical compounds for their GTX potential. The main disadvantage of these classic in vitro genotoxicity tests, however, is the generation of an extremely high false positive rate when compared with in vivo genotoxicity and carcinogenicity data. (7).

The specificity of the bacterial Ames test, for example was $73.9 \%$, while the mouse lymphoma assay, the micronucleus test and the chromosomal aberration test had very low specificity, even below $45 \%$. Thus the predictive value of in vitro experiments for in vivo effects is poor. In many cases, compounds that are genotoxic in vitro must be further tested using in vivo genotoxicity tests (8). Because of this, a large number of chemicals are subject to additional in vivo testing without the need for that, which thus results in unnecessary experiments on animals. Therefore, new in vitro systems need to be developed which are capable of reliably discriminating chemical compounds according to their GTX potential. This is where alternative cellular models as well as the novel genomics technologies come into the picture.

\section{LIVER MODELS}

The liver is the principal organ involved in the metabolism of many compounds including pro-carcinogens, and also represents a major target organ for chemical carcinogens in vivo $(9,10)$. Therefore the use of in vitro liver systems might be a relevant experimental approach to screen potentially carcinogenic compounds. Hepatic cell lines, pri- 
mary hepatocyte cultures and precision-cut liver slices from various species are well established in vitro systems for these studies $(9,10,11)$ and are presented in Table 1. Immortalized cell lines are used frequently for assessing toxicity in vitro (12-17). However, these cell lines are usually derived from tumors and have adapted to growth in culture: they lack liver tissue architecture, and cell-cell interactions and liver-specific functions tend to vanish as culture time increases $(18,19)$. They often acquire a molecular phenotype quite different from liver cells in vivo.

Because precision-cut liver slices contain all the cell types present in whole liver and maintain their three-dimensional structure and cell-cell interactions, these are thought to better represent the in vivo situation. Therefore they are well accepted as an in vitro system to study hepatotoxicity and biotransformation of compounds $(20,21)$, even after cryopreservation and thawing $(22,23)$. They remain metabolically active for 2 days, so they are more suited for short-term studies (24). However, poor penetration of compounds into the inner cell layers of slices and inter-assay variability due to different preservation of cells in different slices are reported $(24,25)$.

Primary mammalian hepatocytes largely retain their liver-specific functions when freshly derived from the animal and are therefore considered to be the most relevant in vitro model in hepatotoxicity studies (26). Hepatocytes used to be cultured on cell culture plates, but appeared to loose drug-metabolizing enzymes and other differentiated liver-specific cell functions very rapidly (27). As it became evident later on that hepatocytes need cell-cell and cell-matrix interactions in order to survive, cell culture systems were adapted. Cells cultured on a collagen layer, especially in a sandwich collagencollagen configuration, appeared to maintain hepatocyte polarity, bile canaliculae formation and liver-specific functions $(28,29 ; 30,31 ; 32)$.

Thus, for the prediction of in vivo toxicity in humans the use of primary human hepatocytes is preferential. The limited availability of donor material and the large variability between the donors, however, has however hampered the use of human hepatocytes (11) and resulted in the use of primary hepatocytes isolated from other mammals as an alternative to human tissue. One of these alternatives is represented by primary rat hepatocytes. These hepatocytes, however, show a rapid decline in liver specific functions, in particular cytochrome P450 (Cyp450) enzyme activity $(21,33)$. Therefore the use of primary mouse hepatocytes might be an alternative to the rat and human systems. Although information about stability of liver specific functions in mice is scarce, the availability of transgenic mouse models and of the complete sequence of the mouse genome, make primary mouse hepatocytes interesting for the purpose mechanistic investigations (34). 
Table 1 In vitro hepatocyte systems

\begin{tabular}{|c|c|c|c|c|}
\hline System & $\begin{array}{l}\text { Complexity } \\
\text { (level of interaction) }\end{array}$ & $\begin{array}{l}\text { Ability to retain liver- } \\
\text { specific functions }\end{array}$ & $\begin{array}{l}\text { Potential duration } \\
\text { of culture }\end{array}$ & $\begin{array}{l}\text { Ability to control } \\
\text { environment }\end{array}$ \\
\hline Immortalized cell lines & some cell to cell* & poor to good* & indefinite & excellent \\
\hline Primary hepatocyte cultures & cell to cell & fair to excellent** & days to weeks & excellent \\
\hline Liver slices & $\begin{array}{l}\text { cell to cell } \\
\text { (all cell types) }\end{array}$ & good to excellent & good to excellent & good \\
\hline
\end{tabular}

*varies with cell line; **varies with culture conditions

\section{TOXICOGENOMICS}

The development of new, mechanism-based, in vitro assays with a high predictive value for the screening of chemicals for their carcinogenic potential is feasible through the availability of powerful novel technologies for monitoring the complete cellular genome, gene expressions, proteome expressions and metabolite levels. This enables high throughput and multi-endpoints analyses for the effects caused by chemicals, thus presenting opportunities for improved methods to identify and evaluate the carcinogenic potential of chemicals, and for monitoring their effects.

The implementation of these technologies in toxicology together with the required bioinformatics tools is called toxicogenomics and is envisioned to revolutionize current hazard and risk assessment practices. Toxicogenomics provides the opportunity to improve the in vitro-in vivo extrapolation, e.g. by developing "fingerprints", a set of key genes in a gene expression fingerprint for a given exposure to a particular chemical. By defining specific classes of toxicity that need to be discriminated, and by using a range of very well chosen model compounds that are prototypical for those classes, gene expression fingerprints specific for these classes can be generated. The application of microarrays in toxicology is an interesting tool to generate those gene expression fingerprints, which will be useful for prediction of the toxicity of a chemical, such as the carcinogenic potential, and to reveal the mode-of-action of that compound $(14,17,35$ 44).

\section{Microarrays}

The intensive genome-sequencing and subsequent rapid accumulation of genomicsequence data has made it necessary to develop novel methods for the high-throughput monitoring of gene expression (45). The monitoring of expression levels of thousands of genes simultaneously was established by using miniaturised hybridization assays, the microarrays (46). Microarrays consist of a platform on which cDNAs or oligonucleotides are immobilized. 


\section{Chapter 1}

In case of a two-colour experiment (Agilent or Operon) RNA from two cell populations, for instance a test sample and a contol sample, is extracted and each sample is differentially labelled with a specific dye fluorophore, Cy3 (green) or Cy5 (red). Equal amounts of labelled RNA is hybridized to the microarray. The intensity of both fluorophoric signals is measured and used to determine the ratio of expression for each gene in the test sample compared to the control sample. This will result in the relative expression level $(46,47)$.

In case of a one-colour experiment (Affymetrix, Illumina, Agilent) the RNA from each sample or control is labelled, fragmented and hybridized to different microarrays. In this case the absolute fluorescence value is determined and, after normalization, compared with other samples or controls to detect variation of expression $(48 ; 49,50)$. The procedures of both approaches are compared in Figure 1.

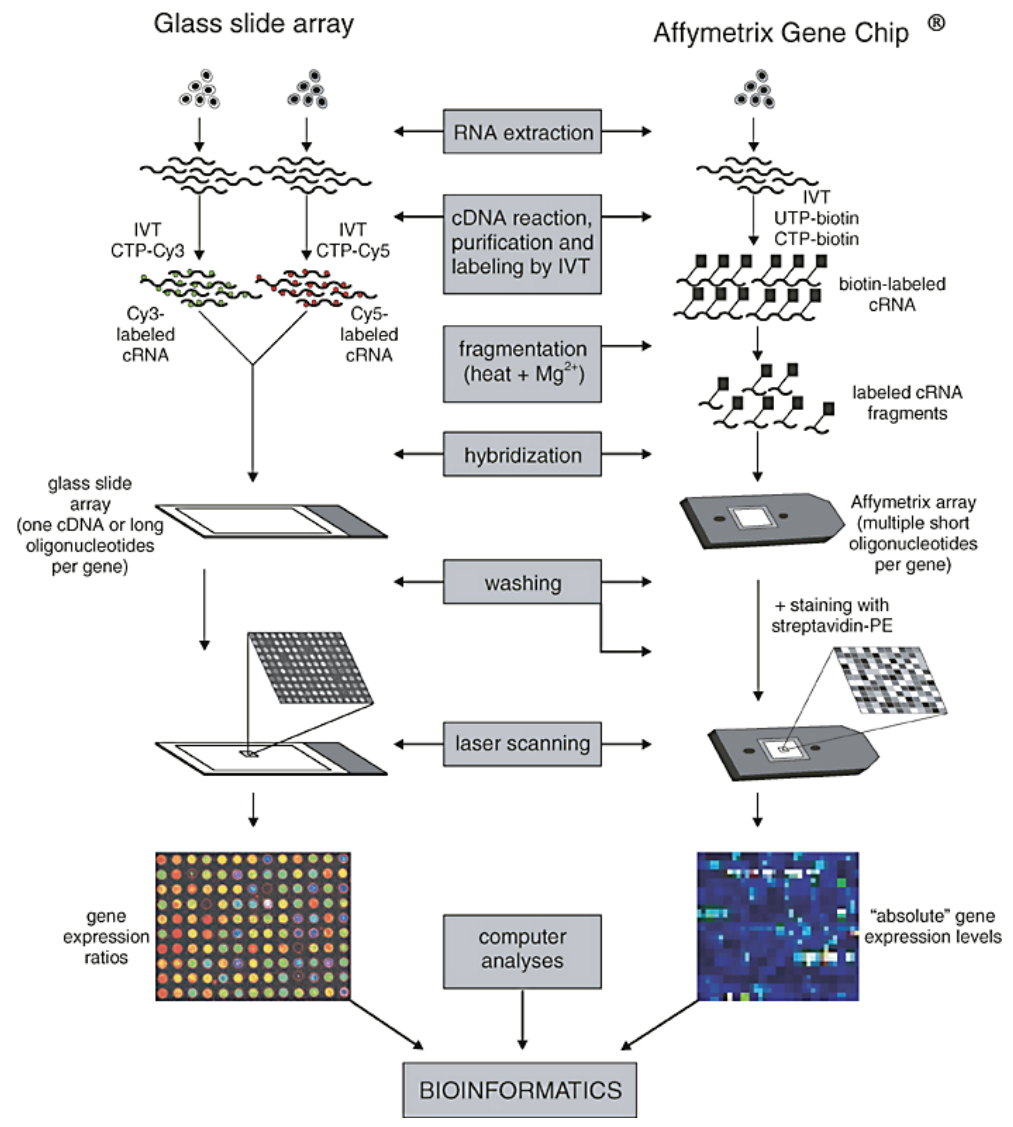

Figure 1 Comparison between a two-colour experiment (Agilent or Operon) and one-colour experiment (Affymetrix). 
Toxicogenomics, which combines classical toxicology with high-throughput genomic technologies like microarrays, is focused on the identification of potential human toxicants and their specific alterations in gene expression patterns and subsequent phenotypic responses of cells or organisms, on the identification of useful biomarkers of disease and exposure to toxic substances, and on understanding the molecular mechanisms of toxicity.

The resulting gene expression patterns, so called transcriptomic fingerprints, can be used for predicting toxic properties of chemicals, such as for classification of GTX and NGTX carcinogens or non-carcinogens $(12,17)$. Furthermore, these gene expression patterns can reveal underlying pathways associated with the compound.

\section{Data analysis}

The amount of the data generated with a microarray experiment is immense. Therefore careful data analysis is essential for interpreting toxicological outcomes (45).

For the Affymetrix GeneChip arrays numerous quality control criteria can be applied, such as normalization quality controls, including scaling factors, average intensities, present calls, background intensities, noise, and raw $\mathrm{Q}$ values. Their values should be within acceptable limits for all chips. Hybridization controls BioB, BioC, BioD, and CreX, need to be identified on all chips and should yield in the expected increases in intensities as described by Affymetrix.

The raw data are then imported into an integrated software system for managing, mining and visualilzing microarray gene expression data. To adjust microarray data for effects which arise from variation within or between chips, data need to be normalized. Most frequently used methods for normalisation are Robust Multi-array Average (RMA) or GeneChip RMA (50). Present-Marginal-Absent calls are used to identify and omit probe sets of poor quality (51). Probe sets are a collection of probes designed to cover a given sequence from a gene. Subsequently, the remaining probe sets are logarithmically (base 2) transformed, corrected for vehicle control if necessary, and subjected to statistical analysis. Identification of differentially expressed probe sets can be by simple foldchange cutoffs or by (complicated) statistical tests. Taking into account the possible false-discovery rate, the chance that a significant finding is false-positive, is crucial for statistical analyses.

Thereafter several methods can be used to interpret and visualize microarray data, including hierarchical clustering, k-means clustering, self-organizing maps (SOM) and principal component analysis (PCA) $(52,53,54,55)$. These methods are used to identify groups of genes with similar expression patterns and are referred to as unsupervised methods. Supervised clustering methods like support vector machines (SVM) or prediction analysis of microarrays (PAM), are used when one has some previous information 
about samples that are expected to cluster together according to their gene expression patterns (56). For the PAM software first a training set is made. This software uses a modification of the nearest centroid method, which computes a standardized centroid for each class in the training set. This is the average gene expression for each gene in each class divided by the within-class standard deviation for that gene. Thereafter crossvalidation was repeated ten times. Cross-validation imitates how the classifier would work on new data. This will result in a list of genes, i.e. classifiers. These classifiers are then validated with a test set and classes are predicted.

Microarray data can also be analysed in a pathway perspective, which can lead to a higher level of understanding of the system. Several tools have been developed for this purpose.

The Gene Ontology (GO) consortium developed an ontology for genes to describe the roles of genes and gene products in any organism (57). Genes can be listed together according to their biology, function and location with GO analysis, but lacks information about the relation between those genes (58). Therefore other methods, which give information about the connections between genes and gene products, are available. An example is MetaCore, which contains pathways and networks derived from text-mining (59). All these methods require individual genes to be significantly up- or downregulated in order to contribute to the score of the significance of overlap between predefined gene groups, like GO categories, and the subset of induced or repressed genes. Recently, new pathway analysis methods have been developed for which no subset of genes needs to be selected prior to analysis. T-profiler is such an example of a pathway analysis tool. T-profiler can score GO categories or other pre-defined gene sets without the need to apply cut-offs to the expression level of individual genes (60). It uses the $t$ test to score the difference between the mean expression level of predefined groups of genes and that of all other genes on the microarray. This method has been shown to be useful in several genome-wide studies (61-66). Another pathway analysis tool which does not require pre-selection is Gene Set Enrichment Analysis (GSEA). This tool takes existing pathways and the entire biomolecular network knowledge into account. It uses the statistical non-parametric Mann-Whitney test to calculate the $\mathrm{P}$ value to indicate significant enrichment scores (67).

\section{MODEL COMPOUNDS}

As mentioned before, the use of well documented model compounds for well specified classes of toxicity is essential to obtain specific transcriptomic fingerprints in order to classify compounds according to their carcinogenic potential.

Based on their mechanisms of action, chemical carcinogens are classified as genotoxic (GTX) or non-genotoxic (NGTX) carcinogens (12). A genotoxic compound may cova- 
lently bind with DNA and cause direct damage to DNA by adduct formation. These lesions may not or incorrectly be repaired which leads to mutations and ultimately to the formation of tumors (3). A non-genotoxic compound, on the other hand, lacks the ability to induce DNA damage directly or indirectly. Because NGTX compounds have different features from GTX compounds, it may be hypothesized that GTX and NGTX induce distinct gene expression profiles which consequently may be used for mechanism-based classifying unknown compounds as $\operatorname{GTX}$ or $\operatorname{NGTX}(68,69)$.

The compounds used in the studies described in this thesis are chosen to cover both GTX and NGTX classes as well as true GTX compounds and false positive GTX compounds, many taken from the Kirkland databases $(70,70,71)$. These compounds and corresponding results from in vivo and in vitro genotoxicity tests are presented in Table 2.

\section{Genotoxic compounds}

\section{Benzo(a)pyrene}

Benzo[a]pyrene $(\mathrm{BaP})$ is a widespread environmental pollutant formed during the combustion of organic products (World Health Organization, 1987) with both GTX and NGTX characteristics. This polycyclic aromatic hydrocarbon (PAH) is a preferred substrate for cytochrome P450 (Cyp450)-dependent monooxygenases (72). Those Cyp450 enzymes, together with epoxide hydroxylase, can convert $\mathrm{BaP}$ into its ultimate genotoxic carcinogen benzo(a)pyrene-7,8-dihydrodiol-9,10-epoxide (BPDE) and forms DNA adducts and DNA damage (73). BaP has been proved to be able to induce both in vitro and in vivo genotoxicity in several studies and clearly introduces DNA adducts (Table 2).

\section{Aflatoxin B1}

Aflatoxins consist of a group of primarily hepatotoxic mycotoxins, produced by some strains of the fungi Aspergillus flavus and A. parasiticus $(74,75)$. The fungi are ubiquitous and grow, under appropriate conditions of heat and moisture, on a variety of agricultural products, like milk and other dairy products, intended for human and animal consumption (76). Aflatoxin B1 (AFB1) is one of the most potent hepatocarcinogens. It requires oxidation of the 8,9-vinyl bond to yield the biologically active AFB1-8,9epoxide, which binds covalently to DNA and thereby forming DNA adducts and chromosomal aberrations (Table 2). Both activation and deactivation of AFB1 are mediated by the microsomal cytochrome P450 system. (77) 


\section{Chapter 1}

\section{2-Acetylaminofluorene}

2-Acetylaminofluorene (2-AAF), a synthetic chemical not generally present in the environment, is one of the most intensively studied of all chemical carcinogens. 2-AAF was produced as a synthetic chemical insecticide in the 1940's until it's toxicity was revealed (78). Now it is extensively used as a model GTX compound.

The metabolic activation of 2-AAF is initiated by the cytochrome P450 dependent Nhydroxylation, leading to the formation of $\mathrm{N}-\mathrm{OH}-\mathrm{AAF}$, which is the main metabolite of $2-\mathrm{AAF}$ in the liver and can already introduce DNA damage in the liver $(79,80,81,82)$. 2-AAF has proven to be genotoxic in several in vivo and in vitro studies and is able to introduce gene mutations (Table 2).

\section{Dimethylnitrosamine}

Dimethylnitrosamine (DMN) is the most simple and widely occurring nitrosamine and has been shown to be an acute hepatotoxic and potent carcinogenic compound (83-85). It is present in many foods such as cured meat, cooked ham, smoked fish, and alcoholic beverages (86). In order to express its toxic potential DMN needs to be metabolically activated to form its reactive metabolite. The major step in this metabolic activation is the cytochrome P450-dependent (Cyp450) oxidative demethylation of the alpha-carbon to the monomethyl nitrosamine, an unstable metabolite which breaks down to the methyldiazonium ion and eventually to the carbonium ion which alkylates the DNA (87, 88). The most important Cyp450, responsible for the activation of DMN is CYP2E1 in humans or mice $(89,90)$. DMN shows genotoxic effects in several in vivo and in vitro studies (Table 2).

\section{Mitomycin C}

Mitomycin $\mathrm{C}(\mathrm{MitC})$ is an antitumor antibiotic frequently used in cancer chemotherapy (91).

Early studies have demonstrated that enzymatic bioactivation of MitC is NADPHdependent $(92,93)$. It has also been shown that NADPH:cytochrome c reductase and xanthine oxidase activate MitC under hypoxic conditions and Cyp450 enzymes might be involved in the anaerobic metabolism of $\operatorname{MitC}(92,94,95)$. Therefore activated MitC can induce a variety of DNA adducts by cross-linkage and covalent binding to DNA. MitC causes DNA damage and is shown to be genotoxic in several in vivo and in vitro studies (Table 2). 


\section{Non-genotoxic compounds}

Cyclosporine $A$

Cyclosporine A (CsA), a neutral lipophilic cyclic undecapeptide isolated from the fungus Hypocladium inflatum gams, is a potent immunosuppressant widely used to prevent rejections after organ transplantation (107). Despite being highly efficacious for this prevention, the use of CsA as an immunosuppressant is limited by severe side effects including nephrotoxicity, neurotoxicity, and hepatotoxicity (96). It has been shown to induce cell proliferation and cancer progression in different cell lines by a cellautonomous mechanism $(97,98)$. However, the precise mechanisms by which CsA stimulates growth of carcinogen-initiated hepatocytes remain uncertain.

\section{2,3,7,8-tetrachlorodibenzo-p-dioxin}

Dioxins, like 2,3,7,8-tetrachlorodibenzo-p-dioxin (TCDD), are ubiquitous environmental contaminants that are inadvertent by-products of various processes including municipal waste combustion and phenoxy acid herbicides production $(99,100,101)$. They elicit a broad range of species-specific biochemical and toxic effects in animals such as xenobiotic enzyme induction, tumor promotion and hepatotoxicity $(102,103$, 104). Dioxins are considered to exert their toxicity by activating the transcription factor AhR,(105).

The precise mechanism of action of TCDD remains unclear, but it is found to target mitochondrial transcription and to induce mitochondrial stress signalling in vivo and thereby promote tumor progression.

\section{False-positive GTX carcinogens}

The false-positive GTX compounds, chosen for this study, are considered to be noncarcinogens, and to show only genotoxicity in in vitro tests but not to induce genotoxicity in vivo.

\section{o-Anthranilic acid}

o-Anthranilic acid (ANAC) is used extensively in electrophoretic separations of oligosaccharides by SDS PAGE (106-108). ANAC is on of the metabolites of L-tryptophan and is excreted in urine after conjugation with glycine or glucuronic acid without further metabolism. However, ANAC can be metabolized to 5-hydroxyanthranilic acid (109) in the presence of NADPH and molecular oxygen, stimulated by superoxide dismutase (110). ANAC has been shown to introduce chromosomal aberrations in vitro (Table 2). Also in the mouse lymphoma cell mutation test (MLA) ANAC is shown to be 
genotoxic. In the chromosomal aberrations test (CA) in vivo, however, ANAC is shown to be equivocal genotoxic in the mouse.

\section{2-(Chloromethyl)pyridine. $\mathrm{HCl}$}

2-(Chloromethyl)pyridine. $\mathrm{HCl}$ (2-CP) is an aromatic heterocycle frequently used as an intermediate in the preparation of various compounds which have one or more of hypocholesteremic, anti-hypotensive, anti-flammatory, analgesic, fungicidal or bactericidal properties (111). 2-CP shows in vitro genotoxicity in the MLA and Ames test and in the CA test, but shows no in vivo genotoxicity in the micronucleus (MN) and CA tests in the mouse (Table 2).

\section{4-Nitro-o-phenylenediamine}

4-Nitro-o-phenylenediamine (4-NP) is a nitroaniline dye that has been used exclusively at low levels in some semi-permanent hair colourings (112). It is a very powerful directacting mutagen and its mutagenic potency can significantly be enhanced in the presence of plant enzymes $(113,114,115)$. Peroxidactic oxidation plays a major role in the mutagen enhancement process and endogenous peroxidase activity such as that associated with the plant cytochrome P450-dependent enzyme systems may also play a role in the activation of 4-NP (115). 4-NP shows in vitro genotoxicity in the MLA and Ames test, but no in the CA test. In the mouse no in vivo genotoxicity was observed in the CA test while equivocal genotoxicity was reported by means of the MN test (Table 2).

\section{8-Hydroxyquinoline}

8-Hydroxyquinoline (8-HQ) is a heterocyclic phenol amine used as cosmetic biocides, fungicides, bacteriocides, and oxidation stabilizers in cosmetics. It is also used as reagents for detection of bismuth and as a chelating agent in analysis of trace metals in industry (116). 8-HQ can be metabolized by Cyp450 enzymes to 8-hydroxyquinoline Noxide or various 8-hydroxyquinoline epoxides. The water-soluble reactive quinoline2,3-epoxide and 8-hydroxyquinoline sulfate are suggested to be the most important intermediates responsible for the genotoxic activity of 8-HQ (117). 8-HQ shows in vitro genotoxicity in the Ames and MLA test. Weak genotoxicity was detected in the CA test. In the in vivo $\mathrm{MN}$ and $\mathrm{CA}$ assays, no in vivo genotoxicity was observed in the mouse (Table 2).

\section{Quercetin}

Quercetin $(\mathrm{Q})$ is one of the most widely distributed flavonoids, present in fruit, vegetables and many other dietary sources. Many beneficial biological and pharmacological activities for human health have been attributed to quercetin, including antioxidant, anticarcinogenic, anti-inflammatory, and cardioprotective activities (118). Frequently quercetin occurs as aglycone, or sugarless form of rutin, a glycoside (119). 
The rapid and extensive metabolism of quercetin might be the cause of the lack of genotoxic responses in vivo (120). The gastrointestinal tract and the absorptive gastrointestinal cells are the first sites of quercetin metabolism. Quercetin is, after absorption, partially metabolised via $O$-methylation, sulphation, or glucuronidation in the intestinal epithelium $(121,122)$. Non-metabolized quercetin is conjugated in the liver to form sulphated, glucuronidated, or methylated derivatives $(123,124)$. The high degree of metabolism lowers the amount of unconjugated quercetin aglycone available in the body. In non-oral in vivo exposure and in bacterial and eukaryotic in vitro test systems quercetin aglycone levels are higher and this may help to explain the absence of quercetin-related genotoxic activity in vivo that is observed in vitro (125-134). Q shows in vitro genotoxicity in the Ames test and in the $\mathrm{MN}$ and $\mathrm{CA}$ tests. $\mathrm{Q}$ also introduced cytogenetic damage in human and rodent cells. Q is, however, shown to be nongenotoxic by the in vivo $\mathrm{MN}$ and CA tests (Table 2). 


\section{Chapter 1}

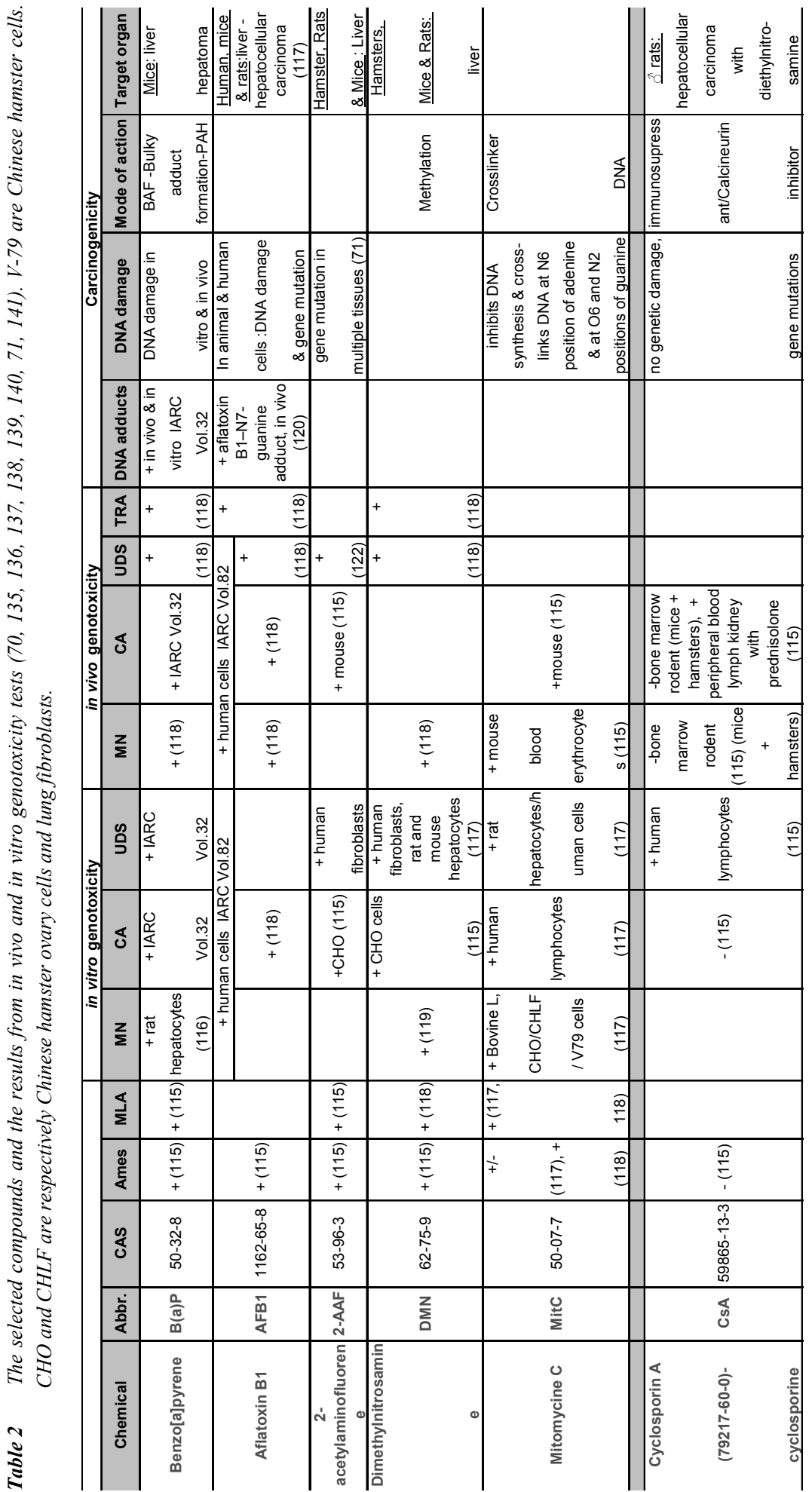




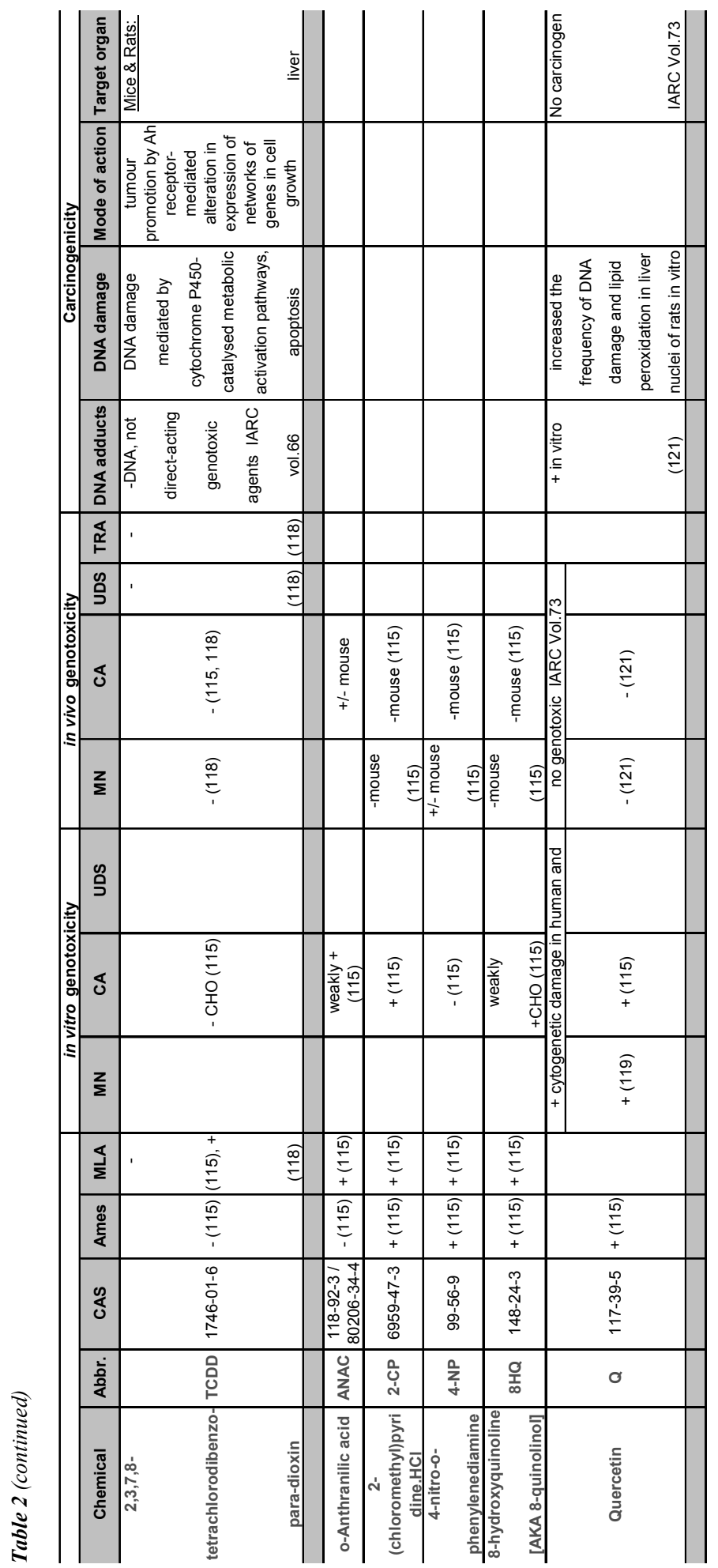




\section{OBJECTIVE AND OUTLINE OF THE THESIS}

Various test guidelines using animals have been developed for the evaluation of the toxicological responses of compounds in order to classify them for their genotoxic and carcinogenic potential in humans. These animal studies are mostly long lasting, relatively expensive and are characterized by their low throughput. Furthermore, the predictive value of these animal studies with regard to the extrapolation from animal to human risk is not very high. Combining these disadvantages with the need to assess many chemicals for genotoxicity and carcinogenicity, increases the demand for the development of high-throughput in vitro screening assays that are predictive for carcinogenicity in humans. The introduction of the microarray technology in toxicology has led to high throughput monitoring of changes in gene expression of multiple genes. Because the liver is an important organ for the metabolism of many compounds and an important organ for toxicity and carcinogenicity, hepatocyte-based systems are gaining interest in microarray-based toxicity studies. Specifically primary mouse hepatocytes can be very useful because they are metabolic competent and are of additional advantage because of the availability of the complete sequence of the mouse genome and of transgenic mouse models which allow relevant mechanistic studies (34).

Hypothetically, gene-expression fingerprints should be able to discriminate between GTX and NGTX carcinogens and between true and false positive GTX compounds, and should be negative for non-carcinogens.

The objective of this thesis therefore is to combine the use of in vitro primary mouse hepatocyte cultures with whole genome gene expression analysis through the microarray technology, in order to identify sets of gene-expression effect markers that are able to discriminate between true genotoxic and false positive genotoxic compounds. Eventually, this may result in a predictive screen which can be applied in chemical safety procedures, initially as a screening test, but eventually as alternative to current rodent testing models and may also lead to commercial applications, i.c. high-throughput systems which are more specific, dedicated, cheaper and societally more acceptable than currently available animal models.

Because gene expression profiling in HepG2 was shown to be able to discriminate GTX from NGTX compounds only at one time point, first experiments were conducted in HepG2 cells in order to investigate time-dependent changes in the cellular responses upon exposure to a well-known carcinogen and in order to further apply this in mouce primary hepatocytes. These initial experiments are described in chapter 2. Therefore, the changes in gene expression profiles of HepG2 cells caused by the model carcinogen $\mathrm{BaP}$ were investigated at 12 time points after exposure.

Next, the mouse hepatocyte isolation method was set-up and the metabolic competence of sandwich-cultured primary mouse hepatocytes was investigated in chapter 3. Pri- 
mary mouse hepatocytes were cultured for 0,42 and $90 \mathrm{~h}$ and changes in base line gene expression profiles and Cyp450 enzyme activity were investigated. Thereafter, relevance of the sandwich-cultured primary mouse hepatocyte model was further assessed in chapter 4 by comparing gene expression profiles of primary mouse hepatocytes and mouse liver in vivo after exposure to BaP. Also time- and dose-dependent effects caused by $\mathrm{BaP}$, were investigated. Gene expression profiles were generated from hepatocytes exposed to 10 or $30 \mu \mathrm{M}$ BaP for 12, 24, 36 and $48 \mathrm{~h}$ and DNA damage was phenotypically evaluated. These generated gene expression profiles were compared to those from mice exposed in vivo to $13 \mathrm{mg} / \mathrm{kg}$ bodyweight $\mathrm{BaP}$ for 7 days.

Chapter 5 focuses on the capacity of the sandwich-cultured primary mouse hepatocyte model to discriminate GTX compouds from NGTX compounds. Again, the optimal treatment time for discrimination was assessed. For that, hepatocytes were exposed to two GTX compounds, e.g. BaP and AFB1, and to two NGTX compounds, e.g. CsA and TCDD. Gene expression profiles and phenotypic measurement of DNA damage were compared between the two groups of carcinogens. PAM was used to classify the compounds and to generate a list of classifiers. For the purpose of validation, two additional GTX compounds were used as test compounds.

Finally, in chapter 6, the ability of the sandwich-cultured primary mouse hepatocyte model to discriminate GTX compounds from false-positive GTX compounds was investigated. The hepatocytes were therefore exposed to five GTX carcinogens and to five false positive GTX compounds. Also in this study gene expression profiles and phenotypic measurement of DNA damage were compared between the two groups and PAM was used to classify the compounds and to generate a list of classifiers.

Finally, chapter 7 presents the summary of the outcome of the work and a general discussion. 


\section{References}

1. Boyle, P. and J. Ferlay, Cancer incidence and mortality in Europe, 2004. Ann Oncol, 2005. 16(3): p. 481-8.

2. Le Marchand, L., The predominance of the environment over genes in cancer causation: implications for genetic epidemiology. Cancer Epidemiol Biomarkers Prev, 2005. 14(5): p. 1037-9.

3. Eun, J.W., et al., Discriminating the molecular basis of hepatotoxicity using the large-scale characteristic molecular signatures of toxicants by expression profiling analysis. Toxicology, 2008. 249(2-3): p. 17683.

4. Nioi, P., et al., Prediction of non-genotoxic carcinogenesis in rats using changes in gene expression following acute dosing. Chem Biol Interact, 2008. 172(3): p. 206-15.

5. Nesnow, S., et al., Lung tumorigenic interactions in strain A/J mice of five environmental polycyclic aromatic hydrocarbons. Environ Health Perspect, 1998. 106 Suppl 6: p. 1337-46.

6. Dambach, D.M., B.A. Andrews, and F. Moulin, New technologies and screening strategies for hepatotoxicity: use of in vitro models. Toxicol Pathol, 2005. 33(1): p. 17-26.

7. Kirkland, D., et al., Evaluation of the ability of a battery of three in vitro genotoxicity tests to discriminate rodent carcinogens and non-carcinogens I. Sensitivity, specificity and relative predictivity. Mutat Res, 2005. 584(1-2): p. 1-256.

8. Eastmond, D.A., et al., Mutagenicity testing for chemical risk assessment: update of the WHO/IPCS Harmonized Scheme. Mutagenesis, 2009. 24(4): p. 341-9.

9. Blaauboer, B.J., et al., The practical applicability of hepatocyte cultures in routine testing. EcVam workschop report $1,1994$.

10. Davila, J.C., et al., Predictive value of in vitro model systems in toxicology. Annu Rev Pharmacol Toxicol, 1998. 38: p. 63-96.

11. Schaeffner, I., et al., A microtiterplate-based screening assay to assess diverse effects on cytochrome P450 enzyme activities in primary rat hepatocytes by various compounds. Assay Drug Dev Technol, 2005. 3(1): p. 27-38.

12. van Delft, J.H., et al., Discrimination of genotoxic from non-genotoxic carcinogens by gene expression profiling. Carcinogenesis, 2004. 25(7): p. 1265-76.

13. Hong, Y., U.R. Muller, and F. Lai, Discriminating two classes of toxicants through expression analysis of HepG2 cells with DNA arrays. Toxicol In Vitro, 2003. 17(1): p. 85-92.

14. Harris, A.J., S.L. Dial, and D.A. Casciano, Comparison of basal gene expression profiles and effects of hepatocarcinogens on gene expression in cultured primary human hepatocytes and HepG2 cells. Mutat Res, 2004. 549(1-2): p. 79-99.

15. Olsavsky, K.M., et al., Gene expression profiling and differentiation assessment in primary human hepatocyte cultures, established hepatoma cell lines, and human liver tissues. Toxicol Appl Pharmacol, 2007. 222(1): p. 42-56.

16. Hockley, S.L., et al., Time- and concentration-dependent changes in gene expression induced by benzo(a)pyrene in two human cell lines, MCF-7 and HepG2. BMC Genomics, 2006. 7: p. 260.

17. Burczynski, M.E., et al., Toxicogenomics-based discrimination of toxic mechanism in HepG2 human hepatoma cells. Toxicol Sci, 2000. 58(2): p. 399-415.

18. Jover, R., et al., Re-expression of C/EBP alpha induces CYP2B6, CYP2C9 and CYP2D6 genes in HepG2 cells. FEBS Lett, 1998. 431(2): p. 227-30.

19. Rodriguez-Antona, C., et al., Cytochrome P450 expression in human hepatocytes and hepatoma cell lines: molecular mechanisms that determine lower expression in cultured cells. Xenobiotica, 2002. 32(6): p. $505-20$.

20. Gandolfi, A.J., J. Wijeweera, and K. Brendel, Use of precision-cut liver slices as an in vitro tool for evaluating liver function. Toxicol Pathol, 1996. 24(1): p. 58-61. 
21. Boess, F., et al., Gene expression in two hepatic cell lines, cultured primary hepatocytes, and liver slices compared to the in vivo liver gene expression in rats: possible implications for toxicogenomics use of in vitro systems. Toxicol Sci, 2003. 73(2): p. 386-402.

22. Glockner, R., et al., Application of cryopreserved precision-cut liver slices in pharmacotoxicology-principles, literature data and own investigations with special reference to CYP1A1-mRNA induction. Exp Toxicol Pathol, 1998. 50(4-6): p. 440-9.

23. Glockner, R., et al., Monooxygenation, conjugation and other functions in cryopreserved rat liver slices until $24 \mathrm{~h}$ after thawing. Toxicology, 2001. 161(1-2): p. 103-9.

24. Guillouzo, A., Liver cell models in in vitro toxicology. Environ Health Perspect, 1998. 106 Suppl 2: p. 511-32.

25. de Graaf, I.A., et al., Empirical validation of a rat in vitro organ slice model as a tool for in vivo clearance prediction. Drug Metab Dispos, 2006. 34(4): p. 591-9.

26. Farkas, D. and S.R. Tannenbaum, In vitro methods to study chemically-induced hepatotoxicity: a literature review. Curr Drug Metab, 2005. 6(2): p. 111-25.

27. Gomez-Lechon, M.J., et al., Long-term expression of differentiated functions in hepatocytes cultured in three-dimensional collagen matrix. J Cell Physiol, 1998. 177(4): p. 553-62.

28. Dunn, J.C., R.G. Tompkins, and M.L. Yarmush, Long-term in vitro function of adult hepatocytes in a collagen sandwich configuration. Biotechnol Prog, 1991. 7(3): p. 237-45.

29. Dunn, J.C., et al., Hepatocyte function and extracellular matrix geometry: long-term culture in a sandwich configuration. Faseb J, 1989. 3(2): p. 174-7.

30. LeCluyse, E.L., et al., Regulation of glutathione S-transferase enzymes in primary cultures of rat hepatocytes maintained under various matrix configurations. Toxicol In Vitro, 2000. 14(2): p. 101-15.

31. LeCluyse, E.L., et al., Regeneration and maintenance of bile canalicular networks in collagensandwiched hepatocytes. Toxicol In Vitro, 2000. 14(2): p. 117-32.

32. Tuschl, G. and S.O. Mueller, Effects of cell culture conditions on primary rat hepatocytes-cell morphology and differential gene expression. Toxicology, 2006. 218(2-3): p. 205-15.

33. Hoen, P.A., et al., Selective induction of cytochrome P450 3A1 by dexamethasone in cultured rat hepatocytes: analysis with a novel reverse transcriptase-polymerase chain reaction assay section sign. Biochem Pharmacol, 2000. 60(10): p. 1509-18.

34. Waterston, R.H., et al., Initial sequencing and comparative analysis of the mouse genome. Nature, 2002. 420(6915): p. 520-62.

35. Ellinger-Ziegelbauer, H., et al., Characteristic expression profiles induced by genotoxic carcinogens in rat liver. Toxicol Sci, 2004. 77(1): p. 19-34.

36. McMillian, M., et al., Inverse gene expression patterns for macrophage activating hepatotoxicants and peroxisome proliferators in rat liver. Biochem Pharmacol, 2004. 67(11): p. 2141-65.

37. Amin, R.P., et al., Genomic interrogation of mechanism(s) underlying cellular responses to toxicants. Toxicology, 2002. 181-182: p. 555-63.

38. Ruepp, S., et al., Assessment of hepatotoxic liabilities by transcript profiling. Toxicol Appl Pharmacol, 2005. 207(2 Suppl): p. 161-70.

39. Ellinger-Ziegelbauer, H., et al., Prediction of a carcinogenic potential of rat hepatocarcinogens using toxicogenomics analysis of short-term in vivo studies. Mutat Res, 2007.

40. Harries, H.M., et al., The use of genomics technology to investigate gene expression changes in cultured human liver cells. Toxicol In Vitro, 2001. 15(4-5): p. 399-405.

41. Uehara, T., et al., A toxicogenomics approach for early assessment of potential non-genotoxic hepatocarcinogenicity of chemicals in rats. Toxicology, 2008. 250(1): p. 15-26.

42. Nie, A.Y., et al., Predictive toxicogenomics approaches reveal underlying molecular mechanisms of nongenotoxic carcinogenicity. Mol Carcinog, 2006. 45(12): p. 914-33.

43. Ellinger-Ziegelbauer, H., et al., Application of toxicogenomics to study mechanisms of genotoxicity and carcinogenicity. Toxicol Lett, 2009. 186(1): p. 36-44. 
44. Hamadeh, H.K., et al., Gene expression analysis reveals chemical-specific profiles. Toxicol Sci, 2002. 67(2): p. 219-31.

45. Waters, M.D. and J.M. Fostel, Toxicogenomics and systems toxicology: aims and prospects. Nat Rev Genet, 2004. 5(12): p. 936-48.

46. Schena, M., et al., Quantitative monitoring of gene expression patterns with a complementary DNA microarray. Science, 1995. 270(5235): p. 467-70.

47. Stierum, R., et al., Toxicogenomics concepts and applications to study hepatic effects of food additives and chemicals. Toxicol Appl Pharmacol, 2005. 207(2 Suppl): p. 179-88.

48. Lockhart, D.J., et al., Expression monitoring by hybridization to high-density oligonucleotide arrays. Nat Biotechnol, 1996. 14(13): p. 1675-80.

49. Singh, R., et al., Microarray-based comparison of three amplification methods for nanogram amounts of total RNA. Am J Physiol Cell Physiol, 2005. 288(5): p. C1179-89.

50. Irizarry, R.A., et al., Exploration, normalization, and summaries of high density oligonucleotide array probe level data. Biostatistics, 2003. 4(2): p. 249-64.

51. Affymetrix, Statistical Algorithms Description Document, technical report. 2002.

52. Eisen, M.B., et al., Cluster analysis and display of genome-wide expression patterns. Proc Natl Acad Sci U S A, 1998. 95(25): p. 14863-8.

53. Tavazoie, S., et al., Systematic determination of genetic network architecture. Nat Genet, 1999. 22(3): p. 281-5.

54. Tamayo, P., et al., Interpreting patterns of gene expression with self-organizing maps: methods and application to hematopoietic differentiation. Proc Natl Acad Sci U S A, 1999. 96(6): p. 2907-12.

55. Raychaudhuri, S., J.M. Stuart, and R.B. Altman, Principal components analysis to summarize microarray experiments: application to sporulation time series. Pac Symp Biocomput, 2000: p. 455-66.

56. Brown, M.P., et al., Knowledge-based analysis of microarray gene expression data by using support vector machines. Proc Natl Acad Sci U S A, 2000. 97(1): p. 262-7.

57. Ashburner, M., et al., Gene ontology: tool for the unification of biology. The Gene Ontology Consortium. Nat Genet, 2000. 25(1): p. 25-9.

58. Currie, R.A., G. Orphanides, and J.G. Moggs, Mapping molecular responses to xenoestrogens through Gene Ontology and pathway analysis of toxicogenomic data. Reprod Toxicol, 2005. 20(3): p. 433-40.

59. GeneGo. 2008 .

60. Boorsma, A., et al., T-profiler: scoring the activity of predefined groups of genes using gene expression data. Nucleic Acids Res, 2005. 33(Web Server issue): p. W592-5.

61. Zakrzewska, A., et al., Cellular processes and pathways that protect Saccharomyces cerevisiae cells against the plasma membrane-perturbing compound chitosan. Eukaryot Cell, 2007. 6(4): p. 600-8.

62. van Leeuwen, D.M., et al., Genomic analysis suggests higher susceptibility of children to air pollution. Carcinogenesis, 2008. 29(5): p. 977-83.

63. Schuurmans, J.M., et al., Physiological and transcriptional characterization of Saccharomyces cerevisiae strains with modified expression of catabolic regulators. FEMS Yeast Res, 2008. 8(1): p. 26-34.

64. Kienhuis, A.S., et al., Parallelogram approach using rat-human in vitro and rat in vivo toxicogenomics predicts acetaminophen-induced hepatotoxicity in humans. Toxicol Sci, 2009. 107(2): p. 544-52.

65. Guo, N., et al., Global gene expression profile of Saccharomyces cerevisiae induced by dictamnine. Yeast, 2008. 25(9): p. 631-41.

66. Castillo, L., et al., Genomic response programs of Saccharomyces cerevisiae following protoplasting and regeneration. Fungal Genet Biol, 2008. 45(3): p. 253-65.

67. Subramanian, A., et al., Gene set enrichment analysis: a knowledge-based approach for interpreting genome-wide expression profiles. Proc Natl Acad Sci U S A, 2005. 102(43): p. 15545-50.

68. Ashby, J., Use of short-term tests in determining the genotoxicity or nongenotoxicity of chemicals. IARC Sci Publ, 1992(116): p. 135-64.

69. Silva Lima, B. and J.W. Van der Laan, Mechanisms of nongenotoxic carcinogenesis and assessment of the human hazard. Regul Toxicol Pharmacol, 2000. 32(2): p. 135-43. 
70. Kirkland, D., et al., Recommended lists of genotoxic and non-genotoxic chemicals for assessment of the performance of new or improved genotoxicity tests: a follow-up to an ECVAM workshop. Mutat Res, 2008. 653(1-2): p. 99-108.

71. Kirkland, D. and G. Speit, Evaluation of the ability of a battery of three in vitro genotoxicity tests to discriminate rodent carcinogens and non-carcinogens III. Appropriate follow-up testing in vivo. Mutat Res, 2008. 654(2): p. 114-32.

72. Lee, I.P., et al., Metabolism of benzo[a]pyrene 4,5-oxide by isolated perfused rat testis. Biochem Pharmacol, 1983. 32(1): p. 159-61.

73. Staal, Y.C., et al., Modulation of gene expression and DNA-adduct formation in precision-cut liver slices exposed to polycyclic aromatic hydrocarbons of different carcinogenic potency. Mutagenesis, 2007. 22(1): p. 55-62.

74. Cotty, P.J., et al., Variation in polygalacturonase production among Aspergillus flavus isolates. Appl Environ Microbiol, 1990. 56(12): p. 3885-7.

75. Horn, B.W. and J.W. Dorner, Regional differences in production of aflatoxin B1 and cyclopiazonic acid by soil isolates of aspergillus flavus along a transect within the United States. Appl Environ Microbiol, 1999. 65(4): p. 1444-9.

76. Neal, G.E., et al., Metabolism and toxicity of aflatoxins M1 and B1 in human-derived in vitro systems. Toxicol Appl Pharmacol, 1998. 151(1): p. 152-8.

77. Wild, C.P., et al., Aflatoxin B1 binding to plasma albumin and liver DNA upon chronic administration to rats. Carcinogenesis, 1986. 7(6): p. 853-8.

78. Wilson, R.H., F. De Eds, and A.J. Cox, The toxicity and carcinogenic activity of 2-acetaminofluorene. Cancer Res., 1941. 1: p. 595-608.

79. Schrenk, D., et al., Metabolic activation of 2-acetylaminofluorene is required for induction of multidrug resistance gene expression in rat liver cells. Carcinogenesis, 1994. 15(11): p. 2541-6.

80. Jenkins, G.J. and J.M. Parry, Restriction site mutation (RSM) analysis of 2-acetylaminofluorene (2$\mathrm{AAF}$ )-induced mouse liver mutations and comparison with the measurement of in vivo micronucleus induction in the bone marrows of (2-AAF)-treated mice. Teratog Carcinog Mutagen, 2000. 20(3): p. $107-$ 17.

81. Moller, M.E., I.B. Glowinski, and S.S. Thorgeirsson, The genotoxicity of aromatic amines in primary hepatocytes isolated from C57BL/6 and DBA/2 mice. Carcinogenesis, 1984. 5(6): p. 797-804.

82. Vu, V.T., et al., Association between DNA strand breaks and specific DNA adducts in murine hepatocytes following in vivo and in vitro exposure to N-hydroxy-2-acetylaminofluorene and N-acetoxy-2acetylaminofluorene. Carcinogenesis, 1985. 6(1): p. 45-52.

83. Anundi, I. and K.O. Lindros, Evidence for cytochrome P450 2E1-mediated toxicity of Nnitrosodimethylamine in cultured perivenous hepatocytes from ethanol treated rats. Pharmacol Toxicol, 1992. 70(6 Pt 1): p. 453-8.

84. Herron, D.C. and R.C. Shank, Methylated purines in human liver DNA after probable dimethylnitrosamine poisoning. Cancer Res, 1980. 40(9): p. 3116-7.

85. Reitman, F.A., et al., Calcium transport, thiol status, and hepatotoxicity following Nnitrosodimethylamine exposure in mice. J Toxicol Environ Health, 1988. 23(3): p. 321-31.

86. Dich, J., et al., Dietary intakes of nitrate, nitrite and NDMA in the Finnish Mobile Clinic Health Examination Survey. Food Addit Contam, 1996. 13(5): p. 541-52.

87. Phillipson, C.E., C. Ioannides, and D.V. Parke, Metabolic activation of dimethylnitrosamine to mutagens: role of cytochromes P-450 and P-448. Toxicol Lett, 1982. 11(1-2): p. 95-101.

88. Fournier, P., [Biotransformation of dimethylnitrosamine]. J Toxicol Clin Exp, 1990. 10(5): p. 283-96.

89. Yamazaki, H., et al., Participation of rat liver cytochrome P450 2E1 in the activation of Nnitrosodimethylamine and N-nitrosodiethylamine to products genotoxic in an acetyltransferaseoverexpressing Salmonella typhimurium strain (NM2009). Carcinogenesis, 1992. 13(6): p. 979-85. 


\section{Chapter 1}

90. Nelson, D.R., et al., Comparison of cytochrome P450 (CYP) genes from the mouse and human genomes, including nomenclature recommendations for genes, pseudogenes and alternative-splice variants. Pharmacogenetics, 2004. 14(1): p. 1-18.

91. Tomasz, M., et al., Reaction of DNA with chemically or enzymatically activated mitomycin C: isolation and structure of the major covalent adduct. Proc Natl Acad Sci U S A, 1986. 83(18): p. 6702-6.

92. Kennedy, K.A., et al., Metabolic activation of mitomycin $\mathrm{C}$ by liver microsomes and nuclei. Biochem Pharmacol, 1982. 31(11): p. 2011-6.

93. Schwartz, H.S., Pharmacology of mitomycin C. III. In vitro metabolism by rat liver. J Pharmacol Exp Ther, 1962. 136: p. 250-8.

94. Kennedy, K.A., S. Rockwell, and A.C. Sartorelli, Preferential activation of mitomycin C to cytotoxic metabolites by hypoxic tumor cells. Cancer Res, 1980. 40(7): p. 2356-60.

95. Pan, S.S., et al., Reductive activation of mitomycin $\mathrm{C}$ and mitomycin $\mathrm{C}$ metabolites catalyzed by NADPH-cytochrome P-450 reductase and xanthine oxidase. J Biol Chem, 1984. 259(2): p. 959-66.

96. Kahan, B.D., Cyclosporine. N Engl J Med, 1989. 321(25): p. 1725-38.

97. Yokoyama, I., et al., Enhancement of tumor proliferation by cyclosporine A in early phase of experimental hepatic metastasis. Jpn J Cancer Res, 1994. 85(7): p. 704-9.

98. Hojo, M., et al., Cyclosporine induces cancer progression by a cell-autonomous mechanism. Nature, 1999. 397(6719): p. 530-4.

99. Mason, G. and S. Safe, Synthesis, biologic and toxic effects of the major 2,3,7,8-tetrachlorodibenzo-pdioxin metabolites in the rat. Toxicology, 1986. 41(2): p. 153-9.

100. Poland, A. and E. Glover, Studies on the mechanism of toxicity of the chlorinated dibenzo-p-dioxins. Environ Health Perspect, 1973. 5: p. 245-51.

101. Safe, S., et al., Halogenated biphenyls: molecular toxicology. Can J Physiol Pharmacol, 1982. 60(7): p. 1057-64.

102. Birnbaum, L.S., The role of structure in the disposition of halogenated aromatic xenobiotics. Environ Health Perspect, 1985. 61: p. 11-20.

103. Davis, D. and S. Safe, Dose-response immunotoxicities of commercial polychlorinated biphenyls (PCBs) and their interaction with 2,3,7,8-tetrachlorodibenzo-p-dioxin. Toxicol Lett, 1989. 48(1): p. 35-43.

104. Viluksela, M., et al., Liver tumor-promoting activity of 2,3,7,8-tetrachlorodibenzo-p-dioxin (TCDD) in TCDD-sensitive and TCDD-resistant rat strains. Cancer Res, 2000. 60(24): p. 6911-20.

105. de Waard, P.W., et al., Influence of TCDD and natural Ah receptor agonists on benzo[a]pyrene-DNA adduct formation in the Caco-2 human colon cell line. Mutagenesis, 2008. 23(1): p. 67-73.

106. Jackson, P., M.G. Pluskal, and W. Skea, The use of polyacrylamide gel electrophoresis for the analysis of acidic glycans labeled with the fluorophore 2-aminoacridone. Electrophoresis, 1994. 15(7): p. 896902.

107. Jackson, P., The analysis of fluorophore-labeled carbohydrates by polyacrylamide gel electrophoresis. Mol Biotechnol, 1996. 5(2): p. 101-23.

108. Bigge, J.C., et al., Nonselective and efficient fluorescent labeling of glycans using 2-amino benzamide and anthranilic acid. Anal Biochem, 1995. 230(2): p. 229-38.

109. Kotake, Y. and Y. Shirai, [Formation of 5-hydroxyanthranilic acid from anthranilic acid in animals.]. Hoppe Seylers Z Physiol Chem, 1953. 295: p. 160-3.

110. Ishiguro, I., et al., Isolation and properties of protein component as activator for anthranilamide hydroxylation in rat liver. Biochim Biophys Acta, 1974. 365(1): p. 148-57.

111. Bioassay of 2-(Chloromethyl)Pyridine Hydrochloride for Possible Carcinogenicity (CAS No. 6959-473). Natl Toxicol Program Tech Rep Ser, 1979. 178: p. 1-97.

112. Dressler, W.E., et al., Carcinogenicity of N1-[tris(hydroxymethyl)]methyl-4-nitro-o-phenylenediamine fed to mated and non-mated Sprague-Dawley rats. Food Chem Toxicol, 1995. 33(8): p. 681-93.

113. Toering, S.J., G.J. Gentile, and J.M. Gentile, Mechanism of antimutagenic action of (+)-catechin against the plant-activated aromatic amine 4-nitro-o-phenylenediamine. Mutat Res, 1996. 361(2-3): p. 81-7. 
114. Wilson, L., et al., Characterization of 4-nitro-o-phenylenediamine activation by plant systems. Mutat Res, 1994. 307(1): p. 185-92.

115. Gentile, J.M., et al., In vitro enhancement of the mutagenicity of 4-nitro-o-phenylenediamine by plant S9. Environ Mutagen, 1985. 7(1): p. 73-85.

116. Andersen, A., Final amended report on the safety assessment of oxyquinoline and oxyquinoline sulfate as used in cosmetics. Int J Toxicol, 2006. 25 Suppl 1: p. 1-9.

117. Hollstein, M., R. Talcott, and E. Wei, Quinoline: conversion to a mutagen by human and rodent liver. J Natl Cancer Inst, 1978. 60(2): p. 405-10.

118. Erlund, I., et al., Consumption of black currants, lingonberries and bilberries increases serum quercetin concentrations. Eur J Clin Nutr, 2003. 57(1): p. 37-42.

119. Lamson, D.W. and M.S. Brignall, Antioxidants and cancer, part 3: quercetin. Altern Med Rev, 2000. 5(3): p. 196-208.

120. Harwood, M., et al., A critical review of the data related to the safety of quercetin and lack of evidence of in vivo toxicity, including lack of genotoxic/carcinogenic properties. Food Chem Toxicol, 2007. 45(11): p. 2179-205.

121. Murota, K., et al., Efficiency of absorption and metabolic conversion of quercetin and its glucosides in human intestinal cell line Caco-2. Arch Biochem Biophys, 2000. 384(2): p. 391-7.

122. Murota, K. and J. Terao, Quercetin appears in the lymph of unanesthetized rats as its phase II metabolites after administered into the stomach. FEBS Lett, 2005. 579(24): p. 5343-6.

123. Boersma, M.G., et al., Regioselectivity of phase II metabolism of luteolin and quercetin by UDPglucuronosyl transferases. Chem Res Toxicol, 2002. 15(5): p. 662-70.

124. Oliveira, E.J. and D.G. Watson, In vitro glucuronidation of kaempferol and quercetin by human UGT1A9 microsomes. FEBS Lett, 2000. 471(1): p. 1-6.

125. Brown, J.P. and P.S. Dietrich, Mutagenicity of plant flavonols in the Salmonella/mammalian microsome test: activation of flavonol glycosides by mixed glycosidases from rat cecal bacteria and other sources. Mutat Res, 1979. 66(3): p. 223-40.

126. Busch, D.B., J.F. Hatcher, and G.T. Bryan, Urine recovery experiments with quercetin and other mutagens using the Ames test. Environ Mutagen, 1986. 8(3): p. 393-9.

127. Crebelli, R., et al., Urinary and faecal mutagenicity in Sprague-Dawley rats dosed with the food mutagens quercetin and rutin. Food Chem Toxicol, 1987. 25(1): p. 9-15.

128. da Silva, J., et al., Evaluation of the genotoxic effect of rutin and quercetin by comet assay and micronucleus test. Food Chem Toxicol, 2002. 40(7): p. 941-7.

129. Hardigree, A.A. and J.L. Epler, Comparative mutagenesis of plant flavonoids in microbial systems. Mutat Res, 1978. 58(2-3): p. 231-9.

130. MacGregor, J.T. and L. Jurd, Mutagenicity of plant flavonoids: structural requirements for mutagenic activity in Salmonella typhimurium. Mutat Res, 1978. 54(3): p. 297-309.

131. Ochiai, M., et al., Superoxide dismutase acts as an enhancing factor for quercetin mutagenesis in rat-liver cytosol by preventing its decomposition. Mutat Res, 1984. 129(1): p. 19-24.

132. Rueff, J., et al., Oxygen species and the genotoxicity of quercetin. Mutat Res, 1992. 265(1): p. 75-81.

133. Seino, Y., et al., Identification of a mutagenic substance in a spice, sumac, as quercetin. Mutat Res, 1978. 58(2-3): p. 225-9.

134. Vrijsen, R., Y. Michotte, and A. Boeye, Metabolic activation of quercetin mutagenicity. Mutat Res, 1990. 232(2): p. 243-8.

135. http://ntp-server.niehs.nih.gov.

136. Muller-Tegethoff, K., P. Kasper, and L. Muller, Evaluation studies on the in vitro rat hepatocyte micronucleus assay. Mutat Res, 1995. 335(3): p. 293-307.

137. www.toxnet.com, in [CCRIS,HSDB, GeneTox \& ChemIDplus].

138. Lambert, I.B., et al., Detailed review of transgenic rodent mutation assays. Mutat Res, 2005. 590(1-3): p. $1-280$. 


\section{Chapter 1}

139. Cahill, P.A., et al., The GreenScreen genotoxicity assay: a screening validation programme. Mutagenesis, 2004. 19(2): p. 105-19.

140. (g-hexachlorocyclohexane), L., Health-based recommended occupational exposure limit, in report of the Dutch Expert Committee on Occupational Standards,a committee of the Health Council of The Netherlands. 2001, Health Council of the Netherlands: The Hague.

141. Kirkland, D.J., et al., Testing strategies in mutagenicity and genetic toxicology: an appraisal of the guidelines of the European Scientific Committee for Cosmetics and Non-Food Products for the evaluation of hair dyes. Mutat Res, 2005. 588(2): p. 88-105. 


\section{Chapter 2}

\section{Time Series Analysis of Benzo(a)Pyrene-Induced Transcriptome Changes Reveals Temporary Effects on DNA Repair, Metabolism and Cell Cycle}




\title{
Chapter 2
}

\begin{abstract}
Chemical carcinogens may cause a multitude of effects inside cells, thereby affecting transcript levels of genes. Such as by direct activation of transcription factors or through the formation of DNA-damage. As the profiles of these responses may be profoundly different, examining temporal changes may provide new insights in mechanisms underlying carcinogenesis. Therefore, we investigated in human hepatoma cells gene expression changes caused by the carcinogen benzo(a)pyrene at 12 time points after exposure, in relation to DNA-adduct and cell cycle. Temporal profiles, demonstrating both early and late effects in up- and downregulation, were identified. Dioxin-responsive genes show the earliest response. Most interesting are the slower effects, such as upregulation of DNA repair pathways. Expression increase for several genes in transcription-coupled nucleotide excision repair last for ca $30 \mathrm{~h}$, until $\pm 50 \%$ of the DNA adducts has been repaired, whereas for global genomic nucleotide excision repair and base excision repair upregulation is up to $60 \mathrm{~h}$. The data also indicate that when S-phase cell levels and DNA adduct levels are high, the DNA-damage responses are large, while gene expressions related to metabolism of amino acids and lipids are low. After S-phase levels decrease and those for G2/M increase, this metabolism is upregulated. Noteworthy are also the sequential periods during which several reaction pathways in gene expression, transcription and translation are upregulated. Thanks to the temporal dimension, this study of changes in gene expression profiles following exposure to a chemical carcinogen provides more and more robust insights in the affected molecular processes.
\end{abstract}




\section{Introduction}

Chemicals can cause cancer through a variety of mechanisms. Genotoxic carcinogens induce damage to the genetic material, either directly by covalently binding to DNA or indirectly by interfering with the mitotic machinery, ultimately leading to mutations in genes or large aberrations in chromosomes (1). If tumour suppressor genes are inactivated or proto-oncogenes are activated by this process, this may lead to cancer formation. The mode of action of non-genotoxic carcinogens does not imply damage to DNA or chromosomes, and, can be very diverse, ranging from stimulation of cell proliferation, suppression of apoptosis, induction of oxidative stress, to activation of biotransformation enzymes, suppression of the immune system, etc. (2).

Polycyclic aromatic hydrocarbons (PAH) comprise a large group of structurally related compounds, including many carcinogens, to which humans are daily exposed through the environment and food. PAH are well known carcinogens, especially for lung, but also for many other tissues including liver. Many carcinogenic PAH, such as benzo(a)pyrene $(\mathrm{BaP})$, share both genotoxic and non-genotoxic properties. During several enzymatic steps involving cytochrome P450 enzymes and epoxide hydroxylase, $\mathrm{BaP}$ is converted into the ultimate genotoxic carcinogen benzo(a)pyrene-7,8dihydrodiol-9,10-epoxide (BPDE). BPDE can form DNA adducts, mainly BPDEN2deoxyguanosin (BPDE-dG) (3). If not repaired, these adducts lead to mutations (4). $\mathrm{BaP}$ can also be transformed into radical cations (5) and reactive and redox-active oquinones, which also can form DNA adducts $(6,7)$. Auto-oxidation of intermediates and/or redox cycling of o-quinones generates reactive oxygen species (ROS) capable of modifying DNA, leading to oxidised nucleotides like 8-hydroxy-deoxyguanosine (8$\mathrm{OHdG}$ (8). These processes all comprise the genotoxic properties of $\mathrm{BaP}$.

The non-genotoxic properties of PAH are assumed to act through activating the transcription factor $A h R$, the aromatic hydrocarbon receptor, which thereupon dimerizes with the AhR nuclear translocator (ARNT). The AhR-ARNT complex binds to the dioxin-responsive elements (DRE) in the promoter regions of genes, thereby inducing their transcription (9). Many genes are involved in metabolism of carcinogens, including phase I enzymes like $C Y P 1 A 1, C Y P 1 A 2$ and $C Y P 1 B 1$ and several phase II enzymes (10).

In addition, PAH-mediated oxidative stress leads via the activation of transcription factor Nrf2 to the induction of multiple phase I and II biotransformation enzymes, including aldo-keto reductases, glutathione $S$-transferase-P, NAD(P)H:quinone oxireductases and UDP-glucuronosyl transferase 1A6 (11). Nrf2 protects against induction by $\mathrm{BaP}$ of DNA adducts, mutations and tumours in mice (12).

In order to protect the cells from the deleterious effects of DNA damage, cells are capable of repairing damaged DNA by many different mechanisms. In the case of BaP, the most relevant are nucleotide excision repair (NER) for the BPDE-DNA adducts and 
base excision repair (BER) for the oxidised damages $(13,14)$. In order to allow for more time for repair, cell proliferation can be blocked at several phases of the cell cycle, such as at G1-S transition, S-phase and G2-M transition. Also, in stead of this proceeding into cell cycle arrest, apoptosis can be induced, especially at high DNA damage levels (15).

Whereas exposure of cells to a full carcinogen such as $\mathrm{BaP}$ is likely to induce multiple molecular responses, their time dependencies and possible functional interactions are not well understood. Revealing successive waves of related gene expression changes linked with relevant phenotypical markers, may provide more insight into this. The objective of our study therefore is to investigate time-dependent changes in cellular responses upon exposure to a full carcinogen, thereby using $\mathrm{BaP}$ as a model compound. This is achieved by extensive time series analyses of global gene expression changes in human hepatoma cells (HepG2) in relation to phenotypic events such as DNA adduct formation and cell cycle progression. HepG2 cells represent the liver as target organ for PAH-related carcinogenesis in vivo, are metabolically competent with respect to biotransformation of mutagens and carcinogens, carry no p53 mutations, and are frequently used in toxicology and gene expression studies (16-19).

\section{Materials and methods}

\section{Cell culture and treatment}

HepG2 cells were cultured and treated with $3 \mu \mathrm{M}$ BaP (purity 97\%, CAS no. 50-32-8; Sigma-Aldich, Zwijndrecht, the Netherlands) or vehicle control (DMSO, 0.1\%) as described previously. This is the lowest $\mathrm{BaP}$ dose with a maximum accumulation of cells in S-phase (20). The cells were exposed for 3 to $60 \mathrm{~h}$ where after they were either fixed with cold methanol and stored at $-20^{\circ} \mathrm{C}$ for FACS analysis or media was removed from the culture flasks and Trizol (Gibco/BRL, Breda, The Netherlands) was added for RNA and DNA isolation. Two independent experiments were conducted.

\section{$\mathrm{BaP}$ in culture medium}

$\mathrm{BaP}$ levels in culture medium were determined following extraction with hexane, evaporation of hexane, dissolving the residue in acetonitrile, and analyses on an HPLC gradient system (Supelcosil LC-PAH (column 25cm*4.6mm, $5 \mu \mathrm{m}$ ); solvent gradient at $1.5 \mathrm{ml} / \mathrm{min}$ : $3 \mathrm{~min} 64 \%$ Acetonitril - a linear gradient to $100 \%$ acetonitril in 20 minutes - a $15 \mathrm{~min}$ hold at this) with fluorescence detection (ex/em at $280 />350 \mathrm{~nm}$ ).

$\gamma H 2 A X$ foci analysis

HepG2 cells cultured and exposed on cover slils were analysed for DNA double strand breaks by immunofluorescence staining of $\gamma \mathrm{H} 2 \mathrm{AX}$ foci as described (21). Following 
fixation, foci were stained with the anti-phospho-Histone H2A-X (ser139) Clone JBW 301 antibody (Upstate Biotechnology, Lake Placid, NY) and Alexa fluor 488 goat antimouse IgG antibody (Invitrogen, Breda, The Netherlands). Cells were scored manually using a damage score, ranging from 0 to 4 , and sample scores (100 cells/sample) are given as percentage of the maximal damage.

Flow cytometric analyses for cell cycle and apoptosis

Analyses of cell cycle profiles and apoptosis was performed as previously described using a FACSort (Becton Dickinson, Sunnyvale, USA) (20). For DNA content cells were stained with propidium iodide; apoptotic cells were visualised with the primary antibody M30 CytoDeath (Roche, Penzberg, Germany) and FITC conjugated antimouse Ig as secondary antibody (DakoCytomation, Glostrup, Denmark). For each sample 10,000 cells were analyzed. Cells in the G0-1, S or G2-M phase were expressed as a percentage of the total number of cells.

\section{RNA and DNA isolation}

RNA was isolated from the Trizol solutions according to the producer's manual and purified with the RNeasy mini kit (Qiagen Westburg bv., Leusden, The Netherlands). After isolation, the remaining phases were used for DNA isolation according to manufacturer's protocol. RNA and DNA quantity was measured on a spectrophotometer and RNA quality was determined on a BioAnalyzer (Agilent Technologies, Breda, The Netherlands). Only RNA samples which showed clear $18 \mathrm{~S}$ and $28 \mathrm{~S}$ peaks and with a RIN level higher than 8 were used.

DNA adduct analyses

DNA adduct levels were determined by ${ }^{32} \mathrm{P}$-postlabelling according to the procedure originally described by Reddy and Randerath (22) with modifications described by Godschalk et al (23).

\section{Gene expression analyses with DNA microarrays}

\section{Labelling and hybridization}

Labelling and hybridisation of RNA samples was done according to Agilent's manual for microarrays (Agilent Technologies, Breda, The Netherlands). Samples from BaP or vehicle treated cells was labelled with Cyanine 3 (Cy3) or Cyanine 5 (Cy5). cRNA of the time-matched treated and control samples was applied on the G4110B Agilent 22K Human Oligo Microarray, hybridized and washed according to Agilent's manual and slides were scanned on a ScanArrayExpress (Packard Biochip Technologies, Perkin Elmer life sciences, Boston, USA) with fixed laser power (100\%) and PMT gain (55\% for $\mathrm{Cy} 5$ and $60 \%$ for $\mathrm{Cy} 3$ ). For each biological experiment, two hybridizations per time 
point were conducted, with swapped Cy3 and Cy5 dyes. In total this resulted in 48 hybridisations.

\section{Image analysis and processing}

The images (10 micron resolution; 16 bit tiff) were processed with ImaGene 6.0 to quantify spot signals (BioDiscovery Inc., Los Angeles, USA). Irregular spots were automatically flagged and excluded from data analysis. Data from ImaGene were further processed with GeneSight 4.1.6 (BioDiscovery Inc., Los Angeles, USA). For each spot, background was subtracted and flagged spots as well as spots with a net expression level below 20 in both channels were omitted. Data were log base 2 transformed and LOWESS normalized. If for a gene more probes were on the array, replicates were averaged while omitting outliers ( $>2$ standard deviations). Raw data are available at ArrayExpress (accession numbers E-TOXM-22 and E-TOXM-23, for the first and second experiment respectively) (www.ebi.ac.uk/arrayexpress/).

\section{Gene expression data analyses and data mining}

\section{Differentially expressed genes}

First genes were selected for which all four replicate hybridizations gave an expression difference of $>0.2$ or all four $<-0.2$ (meaning all replicates in the same direction; on a normal scale, this is a $15 \%$ increase or decrease of transcript level). This resulted in 5211 genes. Second, genes were selected by ANOVA using the plug-in "Time series analysis" from BRB Array Tools (version 3.4 and $\mathrm{R}$ version 2.2.0; http://linus.nci.nih.gov/BRB-ArrayTools.html) with "Time" as descriptor. This resulted in 2808 genes with a False Discovery Rate $(F R D)<0.1$. All further analyses on significantly differentially expressed genes, start with these 2808 genes.

\section{Time series analyses}

For identification of genes, reactions, pathways or gene-sets co-regulated timedependently and correlating with a biological parameter, the software tool "Short Timeseries Expression Miner" (STEM, version 1.1.2b; http://www.cs.cmu.edu/ jernst/stem/) was used $(24,25)$. STEM finds statistically significant patterns from time series microarray experiments and can compare data sets across experiments. The clustering algorithm assigns each gene, reaction, pathway or gene-set to these profiles based on correlation coefficients (also between de two independent experiments) and permutation analyses $(n=50)$. For all parameters, log-transformed data were used, normalised such that treated-control ratios ranged from +1 to -1 , with 0 for no change.

\section{Functional interpretation of significantly differentially expressed gene sets}

Reactome (http://www.reactome.org; Version 25, November 2008) (26) is used to examine the biological processes that may be affected at the level of reactions and reaction pathways, a level of detail that cannot be obtained by gene ontology annotations, and KEGG and BioCarta pathways. Reactions are grouped into causal chains to form pathways. The tool Skypainter is used to determine per time point which events (reactions 
and/or reaction pathways) harbour differentially expressed genes (down- and upregulated genes separately), selecting only events with at least 3 genes. The proportion of these number of differentially genes per event (time point / experiment) with total numbers present in the set of 2808 genes, are calculated for each pathway.

\section{Functional interpretation of all expressed genes}

T-profiler is used for functional annotation of pathways and processes in the complete data set of genes without pre-selecting modulated genes. T-profiler uses the unpaired $t$ test to score the difference between the mean expression level of predefined sets of genes and that of all other genes within the complete data set (27). Pathways and processes included gene sets from GO terms, KEGG pathways, GenMAPP pathways, Motifs, Broad/MIT pathways, (manually curated) gene sets and gene sets retrieved from literature, i.e. lists of genes modulated by BaP or TCDD in HepG2 cells (28-30) and a set of genes with known antioxidant response elements (AREs), also known as Nrf2 binding sites (11). Per array t-values were determined for each gene set. Only gene sets with an absolute t-value $>1$ at at least 2 succeeding time points in all four replicate arrays were selected for further analyses.

\section{Results}

Effects on BaP levels, DNA adduct levels, cell cycle and apoptosis

Clearance by HepG2 cells of $\mathrm{BaP}$ from the culture medium was fast, with $1 \%$ remaining after 30-36 h, levels being not detectable after $48 \mathrm{~h}$. BaP-DNA adduct levels increased between 3-12 h, were stable until 18/30 h, where after they slowly declined (Fig. 1). For the second experiment, adduct levels reached a lower maximum and faster decreased then for the first experiment. Adduct levels stabilised to $15-25 \%$ of the highest level, even after $60 \mathrm{~h}$, suggesting a diminished repair of adducts during the last 12-30 h. Similar results were obtained by in situ staining for $\gamma \mathrm{H} 2 \mathrm{AX}$ foci, a marker for double strand DNA breaks (31). At $9 \mathrm{~h}$ this was induced, at $24 \mathrm{~h}$ it was maximal, and at $48 \mathrm{~h}$ it was decreased to ca. $25 \%$. Analyses of cell cycle distributions shows no changes upto $12 \mathrm{~h}$. At $18 \mathrm{~h} \mathrm{BaP}$ causes a drastic increase in S-phase cells with a concomitant decrease of cells in G1 and G2 phases (Fig. 1). This S-phase accumulation lasts 6-18 h, where after the number of S-phase cells decrease with a concomitant increase of G2/M-phase cells. Similar as for BaP-DNA adducts, the effects on cell cycle in the second experiment last shorter than in the first experiment. After about $54 \mathrm{~h}$, the distribution of BaP-treated cells becomes similar to that of the controls. In the control cultures, the $\%$ of cells in Sphase increases after 18-24 h together with a decrease of G1-phase cells. This may be due to depletion of the culture medium for essential compounds. Apoptotic cells levels did not increase due to BaP treatment, varied between 0.5-3\% for control and BaP cultures, and were slightly higher in the first experiment (data not shown). 


\section{Effects on gene expression}

\section{Differentially expressed genes}

Gene expression profiles were determined by DNA microarrays, which resulted in 48 hybridisations, 4 per time point. Differentially expressed genes were identified by reproducible similar changes over the 4 replicates, combined with ANOVA, resulting in 2808 differentially expressed genes. The same approach on randomised arrays resulted in not a single significantly affected gene, which indicates that few false-positives were obtained. Visualisation of the log base 2 expression ratios for these 2808 differentially expressed genes and all arrays in a heat map, shows a high reproducibility in the expression profiles between the various replicate experiments and arrays. A few genes were verified by quantitative RT-PCR, namely CYP1A1, CYP1B1 and CDKN1A. With both methods the patterns are similar, although the effects on gene expression as measured by RT-PCR are larger.

\section{Pathway analyses by Reactome}

In order to examine the responses that may occur at the level of reactions and reaction pathways, the sets of differentially expressed genes per time point were analysed in Reactome. An overview of the reaction pathways is in Fig. 2, thereby focusing on reaction pathways / processes that are considered most relevant for chemical carcinogenesis. Functional annotation based on over representation analyses using GO-terms and other gene-sets was also done using FatiGO+ (http://babelomics.bioinfo.cipf.es) (32). Results added limited knowledge and thus, are not presented.

\section{Pathway analyses by T-profiler}

T-profiler was applied to identify affected functions using the complete data set, thus without pre-selecting modulated genes. Besides gene sets based on GO annotation etc, also gene sets retrieved from literature were incorporated. Following an analysis per time point, in total 155 gene sets were identified as being modulated. Hierarchical clustering was used to group these gene sets (Fig. 3). The main functional annotations of these clusters show upregulation of TP53 and NRF2 signalling pathways, apoptosisrelated gene sets, and responses induced by genotoxic stressors. Downregulation consists of metabolisms of amines, sterols and lipids, (regulation of) transcription and nucleosome assembly. This confirms the Reactome data; although T-profiler presents less in-depth information it provides a better statistical evaluation. 

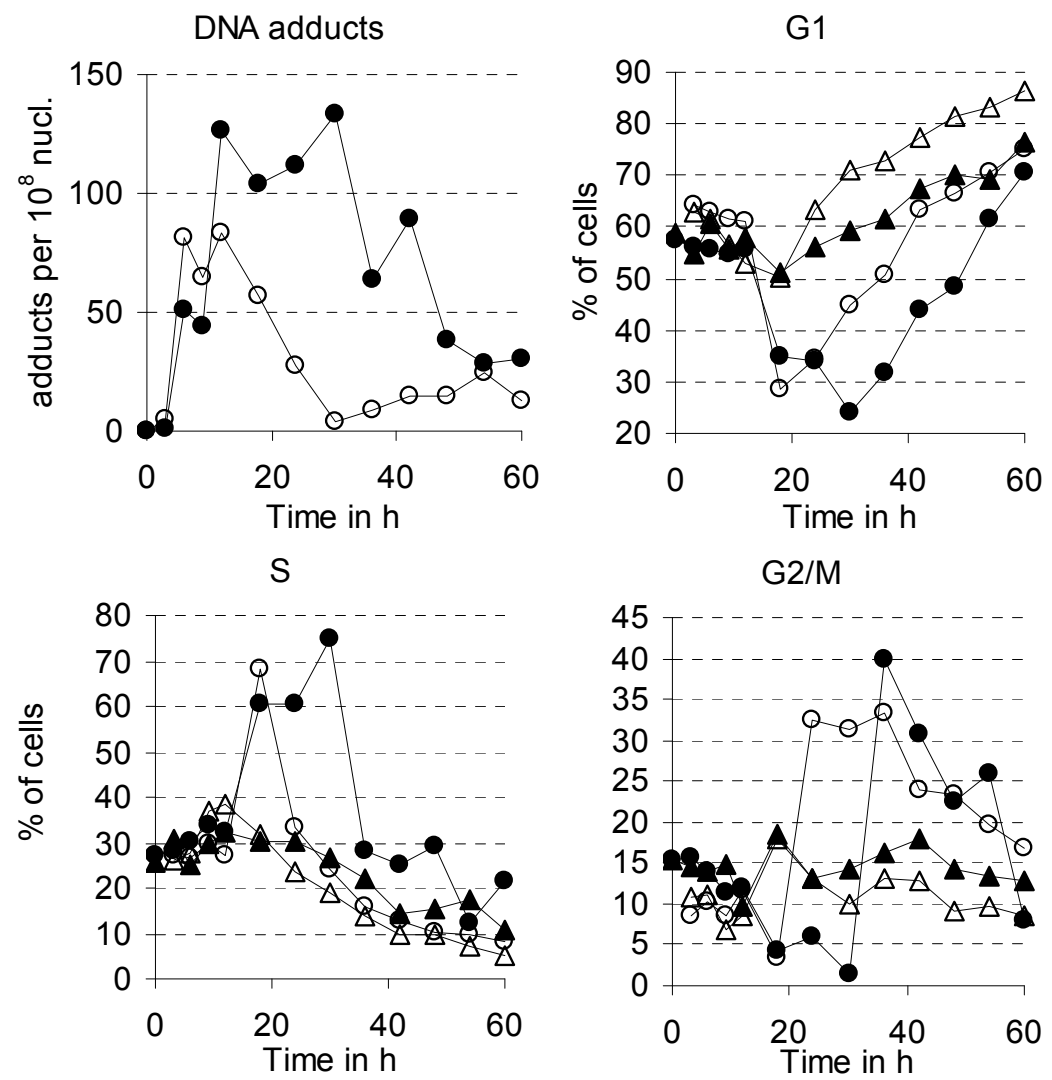

Figure 1 Levels of BaP-DNA adducts and cell cycle distribution in HepG2 cells. Cells are analysed after various exposure times in two independent experiments (Circles and triangles are for BaP treated and control cells, respectively. Closed and open symbols are for experiment 1 and 2 , respectively).

\section{Time-related effects of the functional data}

Numerous different approaches can be used to identify co-regulated genes with timerelated patterns in time series experiments on microarray studies, including hierarchical clustering, or dedicated tools such as CAGED (33), GQL (34) and STEM (24,25). All these tools have been applied on our gene expression data set. Although STEM resulted in the most comprehensible information, this mainly confirmed the data from the functional annotation analyses mentioned above which is thus not presented here.

STEM was also used to uncover time-related patterns in the reactions, pathways and biological processes as identified by Reactome and T-profiler (Fig. 2 and 3), in combination with the phenotypical parameters (BaP levels in medium, BaP-DNA adducts, and 
various phases of the cell cycle). In these analyses experiment 1 and 2 were used independently. Both positive and inverted correlations are observed, showing temporal changes in pathways and reactions in DNA repair, DNA damage response, cell cycle and general metabolisms. These are summarised in Table 1 and further discussed below.
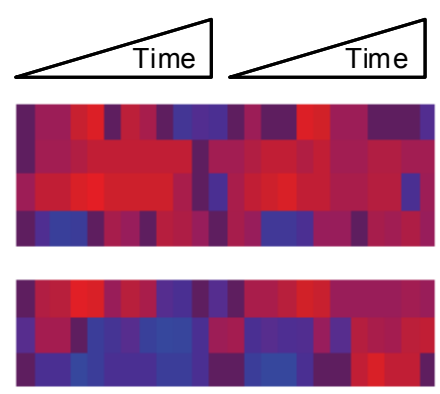

\section{Apoptos is}

Regulation of apoptosis

Extrinsic Pathway for Apoptosis

Intrinsic Pathway for Apoptosis

Apoptotic execution phase

Cell cycle checkpoints

G1/S DNA Damage Checkpoints

G2/M Checkpoints

Mitotic Spindle Checkpoint

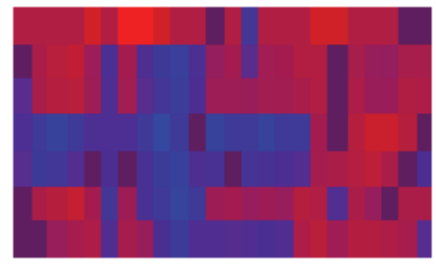

Cell cycle, mitotic

G1 Phase

G1/S Transition

S Phase

G2/M Transition

$M$ Phase

M/G1 Transition

APC/C-mediated degradation of cell cycle proteins

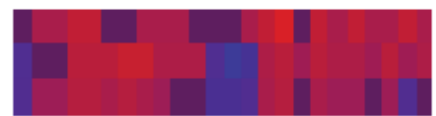

DNA repair

Base Excision Repair

Global Genomic NER (GG-NER)

Transcription-coupled NER (TC-NER)

Metabolism

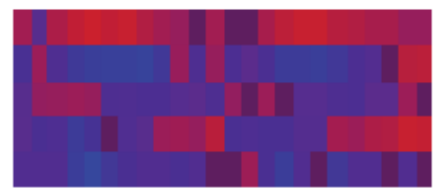

Nucleotide metabolism

Lipid and lipoprotein metabolism

Metabolism of amino acids

Metabolism of carbohydrates

Integration of energy metabolism

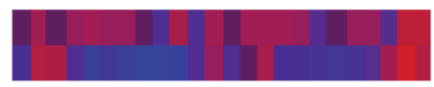

Biological oxidations

Phase 1 - Functionalization of compounds

Phase II conjugation

Gene Expression

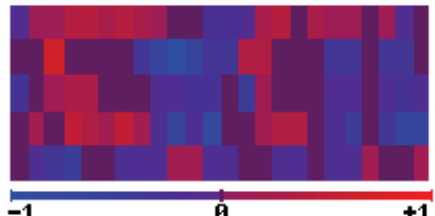

Transcription

Metabolism of non-coding RNA

mRNA Processing

Translation

Post-translational protein modification

$-1$

$+1$

Figure 2 Reactions / reaction pathways from Reactome affected in HepG2 cells by BaP treatment. Red indicates an enrichment of upregulated genes, blue of downregulated genes. Enrichment is relative to the number of genes in that pathway as present in the set of 2808 modulated genes. 


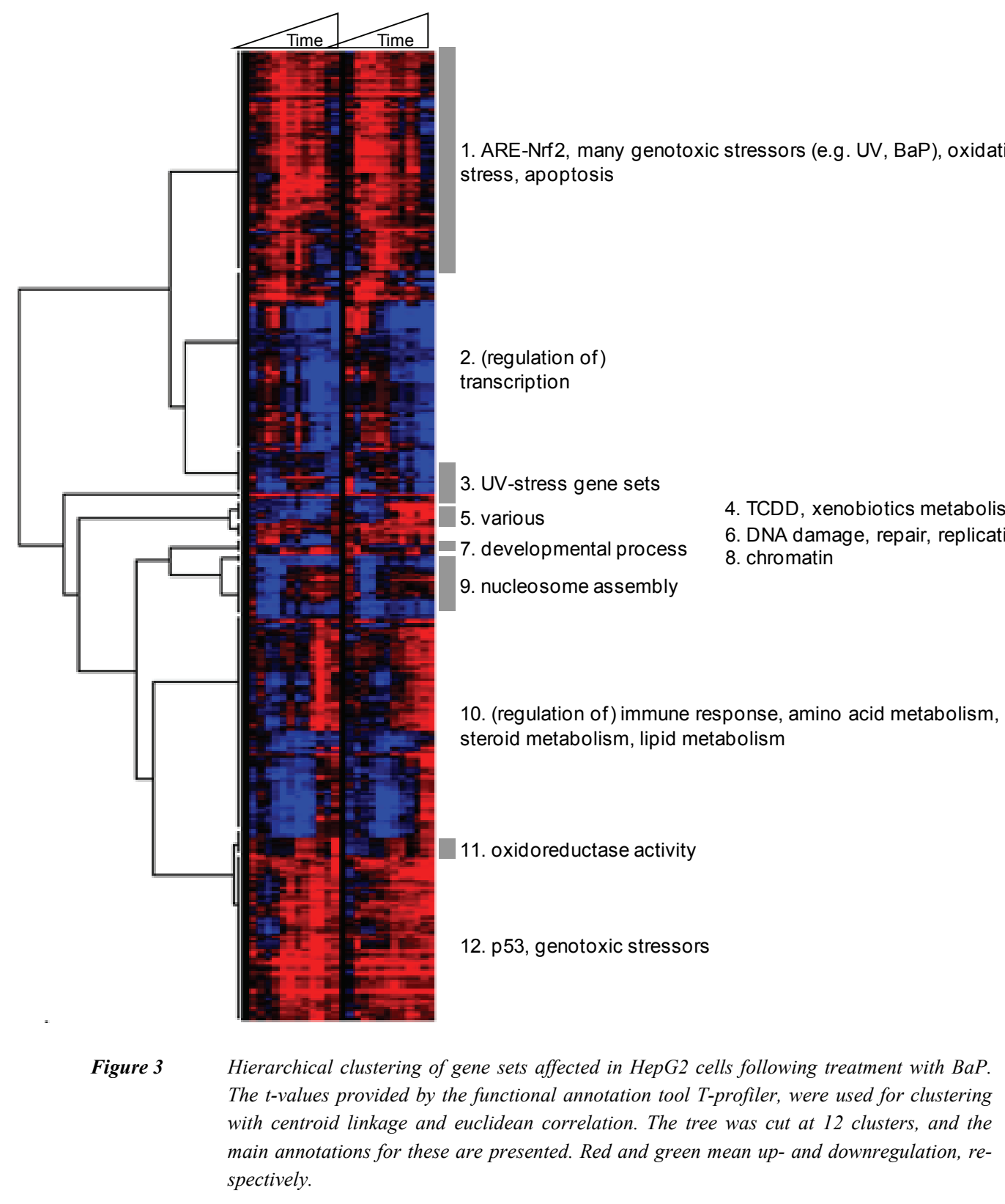


Table 1 Summary of the correlation analyses between biological parameters and pathways, processes, gene sets from the functional annotation tools T-profiler and Reactome (the data from Fig. 2 and 3) as given by the time-series analysis tool STEM.

\section{Positive correlation with BaP levels \\ T-profiler-4 - TCDD, xenobiotics metabolism}

\section{Inverted correlation with BaP levels}

React 474 - metabolism of carbohydrates

T-profiler-11 - oxidoreductase activity

T-profiler-5 - various

\section{Positive correlation with adduct levels}

React_1059 - extrinsic pathway for apoptosis

React_1104 - base excision repair

React_1628 - transcription-coupled NER (TC-NER)

React_1698 - nucleotide metabolism

React_2254 - G1/S DNA damage checkpoints

React_964 - intrinsic pathway for apoptosis

T-profiler-1 - ARE-Nrf2, many genotoxic stressors (e.g. UV, BaP), oxidative stress, apoptosis

\section{Inverted correlation with adduct levels}

T-profiler-8 - chromatin

\section{Positive correlation with G1 cells}

T-profiler-8 - chromatin

\section{Inverted correlation with G1 cells}

React_1590 - G1 phase

React_2253 - global genomic NER (GG-NER)

T-profiler-12 - p53, genotoxic stressors

\section{Positive correlation with $\boldsymbol{S}$ cells}

React 1590 - G1 phase

React_2253 - global genomic NER (GG-NER)

T-profiler-12 - p53, genotoxic stressors

\section{Inverted correlation with $S$ cells}

\section{Positive correlation with G2/M cells}

T-profiler-10 - (regulation of) immune response, amino acid metabolism, steroid metabolism, lipid metabolism

T-profiler-7 - developmental process

\section{Inverted correlation with $\mathbf{G} 2 / \mathrm{M}$ cells}

React_1014 - translation

React_11052 - metabolism of non-coding RNA

React_1725 - M/G1 transition

T-profiler-2 - (regulation of) transcription 


\section{Discussion}

Chemical carcinogens, and especially full carcinogens like $\mathrm{BaP}$ which possess both genotoxic as well as non-genotoxic properties, cause a multitude of effects in cells. These range from altering the cellular metabolic capacity, to inducing DNA damage and repair, mutagenesis, and influencing cell growth and viability. As many of these processes are exerted through changing the expression of genes at the level of mRNA, genome-wide transcriptome profiling over an extensive period and multiple time points can provide detailed insight into these processes and their regulations and interdependencies.

In our study, transcriptome responses HepG2 cells were time-dependently compared to BaP exposure levels, DNA adduct levels, distribution of cells over various phases of the cell cycle and apoptosis. We show clear temporal functional changes and temporal profiles for many genes, demonstrating both early and late effects in up- and downregulation, and for clusters of correlating genes. We delineated these gene expression changes in numerous alterations of biological pathways and processes, by several tools/approaches. Eventually, we identified by Reactome altered biological processes at the level of reactions and reaction pathways, and by T-profiler modulated biological pathways and processes.

What do all these changes teach us about the biological effects in these carcinogenexposed cells? To understand that, we finally correlated changes in phenotypi$\mathrm{cal} /$ biological parameters ( $\mathrm{BaP}$ levels in medium, BaP-DNA adducts, and various phases of the cell cycle) with those in reactions, pathways and gene sets by the timeseries analyses tool STEM (Table 1 for more detailed information).

One and three pathways/processes show a clear positive or inverted correlation, respectively, with $\mathrm{BaP}$ levels in medium (Table 1). The correlation with TCDD responsive genes is as expected, since also PAHs like BaP activate $A h R$ (9). A inverted correlation of $\mathrm{BaP}$ is observed with various diverse gene sets, namely "React_474 - metabolism of carbohydrates", "T-profiler-11 - oxidoreductase activity", and "T-profiler-5 - various". BaP-DNA adducts show a positive correlation with 7 pathways/processes/reactions (DNA repair related gene sets, many DNA damage and stress response related gene sets; Table 1), and with 1 an inverted correlation (T-profiler-8 - chromatin).

Most interesting are the effects on DNA repair pathways: both base excision repair (BER) and transcription coupled nucleotide excision repair (TC-NER) correlate with DNA adducts and are induced from 9/12h until 48h (Fig. 2). Reactive oxygen species (ROS) is expected to be formed during the metabolic activation of $\mathrm{BaP}$. ROS leads to DNA damage, such as $8-\mathrm{OHdG}$, which is repaired by BER (14). Although at $30 / 36 \mathrm{~h}$ most $\mathrm{BaP}$ has been consumed, its metabolites and intermediates are still present and thus may cause an extended oxidative stress. Indeed, the induction of BER agrees very well with the period that the gene set "T-profiler_3 - NRF2-regulated gene sets + mo- 
tifs" is induced. Through the activation of transcription factor Nrf2, ROS induces the expression of many genes with anti-oxidant responsive elements in their promoter regions (11). The BER genes modulated by BaP are FEN1, MBD4, POLD4 and SMUG1, some of which are also affected by ultraviolet light (35).

Repair of bulky DNA damages - like BaP-DNA adducts - is by NER (13) and most of that is strand-specific: the transcribed strand is faster repaired than the non-transcribed strand $(36,37)$. This is well reflected by the gene expression alterations we observed: the TC-NER reaction pathway is upregulated for a shorter period then the GC-NER reaction pathway, namely from 9-42 and 9-60h, respectively (Fig. 2). Six out of the nine NER genes modulated by $\mathrm{BaP}$ are in both GG-NER and TC-NER. DDB2 is specific for GGNER and upregulated from 9-60h; POLR2A and POLR2D are specific for TC-NER and upregulated at early time points or downregulated at late time points, respectively. Effects by BaP on DDB2 have been described before in MCF-7 cells but not in HepG2 cells $(28,38)$.

Taken together, our data suggest that the DNA damage repair system is regulated to some extent at the level of transcription. To our knowledge, this coordinated differential transcriptional regulation of various DNA damage repair pathways upon exposure to a genotoxic stressor, represents a novel finding. Till now, regulation of DNA damage repair pathways has been considered to occur mostly at post-translational level through protein modifications rather then gene expression $(39,40)$.

The correlation of BaP-DNA adducts with many pathways representing the DNA damage response, like "REACT_1059 - extrinsic pathway for apoptosis", "React_2254 G1/S DNA damage checkpoints", "React_964 - intrinsic pathway for apoptosis" and "T-profiler-1 - ARE-Nrf2, many genotoxic stressors (e.g. UV, BaP), oxidative stress, apoptosis" is as expected, since PAHs like BaP cause genotoxic damage and induce the DNA damage response pathway $(41,42)$. Although many pathways/processes/reactions related to apoptosis are induced, $\mathrm{BaP}$ causes only a marginal induction of apoptosis at the doses used here. Apparently, the apoptotic machinery is activated, but BaP-induced damages are repaired sufficiently to halt that process before execution. At higher BaP doses and by other PAHs, apoptosis is induced in HepG2 cells (20).

The set of genes identified by Hockley et al. to be affected by BaP in HepG2 cells (28), is part of "T-profiler-1 - ARE-Nrf2, many genotoxic stressors (e.g. UV, BaP), oxidative stress, apoptosis". The largest overlap in affected genes for that study with ours is at 9$30 \mathrm{~h}$.

BaP-DNA adduct levels show an inverse correlation with "T-profiler-8 - chromatin", which also shows a positive correlation with the number of cells in G1-phase. When DNA adduct levels are high, cell numbers in G1-phase are low and in this period also GO gene sets on chromatin assembly and chromosome organization are down regulated. Numbers of cells in G1-phase of the cell cycle are decreased from 18 to 24/36 h. G1-cell count shows a positive correlation with one set of pathways (see previous para- 
graph) and an inverse correlation with 3 others, namely "React_1590 - G1 phase", "React_2253 - global genomic NER (GG-NER)" and "T-profiler-12 - p53, genotoxic stressors. All of these were also found to correlate with the number of cells in S-phase, but in the positive direction. During the time that counts for S-phase cells are high and for G1-phase cell are low, also the DNA adduct levels are increased. This explains the correlations of these with gene sets for DNA damage repair and DNA damage response. Interestingly, the G1-cells show a inverted correlation with "React_1590 - G1 phase", indicating that upregulation of this reaction pathway does not necessarily agree with the actual cell cycle phase.

The concomitant increase of cells in S-phase show with a decrease of cells in G1 phase (Fig. 1) suggests an arrest of cells in S-phase and/or a stimulation of G1-cells to go into S-phase. Kinetic analyses of progression of cells into various phases of the cell cycle at various time points after $\mathrm{BaP}$ exposure are required to clarify this further. $\mathrm{BaP}$ is known to induce the G1/S-phase arrest and also to block DNA synthesis at replication forks (20,41-43).

Two pathways/processes/reactions have been shown to correlate with G2/M-cells, which are decreased from 1824/36h and then increased from ca 24/36 to 54h (Fig. 1), namely with "T-profiler-10 - (regulation of) immune response, amino acid metabolism, steroid metabolism, lipid metabolism"and "T-profiler-7 - developmental process".Within the T-profiler-10 cluster, many gene sets relate to metabolism and they also show this downregulation followed by an upregulation (see Fig. 3). This suggests that in the period when DNA adduct and numbers of cells S-phase are high and when G1 and G2/M cell levels are low, the general metabolism of the cells is downregulated. When thereafter S-phase levels decrease and G2/M increase, the demand of the cells for general metabolism is high. Once cell cycle distribution is back to baseline and DNA adducts have mostly been repaired, metabolic processes return to their normal levels.

G2/M cell levels show an inverted correlation with four pathways. Noteworthy, the inverted correlation is mainly with reactions involved in gene expression, transcription and translation. Most of these show an initial upregulation followed by a downregulation thereafter. An order is apparent: the induction period increases from $6 \mathrm{~h}$ for "React_11052 - metabolism of non-coding RNA" (such as miRNAs), ca 27h for "React_1014 - translation" and 39h for "React_1788 - transcription" (see Fig. 2). This suggests that the regulation of these reaction pathways is strictly organised. G2/M cell levels also correlate inversely with "React_1725 - M/G1 transition", which is not understood.

Our data point out that a full carcinogenic compound like BaP, with a genotoxic component through the induction of DNA adducts and mutations and a non-genotoxic component via the $A h R$ transcription factor, may also influence many other reactions / pathways that affect the carcinogenic process. Examples are the various DNA repair processes (BER, TC-NER and GG-NER), gene expression process (e.g. metabolism of non- 


\section{Chapter 2}

coding RNA, which includes miRNAs), and many signalling pathways (see Fig. 2). The factual relevance of these modulations for cancer formation is not clear yet, which thus represents a challenge for future investigations to further unravel the chemical carcinogenesis process.

Effects of $\mathrm{BaP}$ on gene expression changes as measured by DNA microarrays in HepG2 cells have been published before, but on maximally 4 time points $(19,20,28,44)$. This study, however, is the first with so many time points in a toxicogenomic evaluation of a chemical carcinogen. Therefore, our data set may serve as benchmark for others, in order to compare with responses induced by other carcinogenic compounds or in other cells or organisms, to develop new bioinformatic tools for time-series analyses, functional annotation and correlation analyses of transcriptome sets with phenotypic parameters, etc.

In the current detailed time series study, numerous temporal changes in clusters of genes upon exposure of cells to the carcinogen $\mathrm{BaP}$ have been observed, thereby providing an unprecedented insight in time-dependent interactions of the affected processes and pathways. As could be expected, TCDD responsive genes, many of them regulated through $A h R$, are those showing the earliest effect. Most interesting are the slower effects, however, such as on DNA repair. Transcription-coupled nucleotide excision repair lasts ca $18 \mathrm{~h}$, until $\pm 50 \%$ of the DNA adducts have been repaired, whereas global genomic nucleotide excision repair and base excision repair is upregulated up to $60 \mathrm{~h}$, at which time point adducts are still present. To our knowledge, this transcriptional regulation of various DNA repair pathways upon exposure to a genotoxic stressor, represents a novel finding. The data also suggest that when S-phase cell levels and DNA adduct levels are high, the metabolism of nucleotides is low. After S-phase levels decrease and those for $\mathrm{G} 2 / \mathrm{M}$ increase, this general metabolism is high. Once cell cycle distribution has returned to normal and most adducts are repaired, metabolic processes also return to normal levels. Also noteworthy are the sequential periods during which several reaction pathways in gene expression, transcription and translation are upregulated. All these new observations indicate that the cellular transcriptome is strictly regulated, with main responses once DNA damages are generated, and adapts to the changing needs of cells following acute exposure to a carcinogen.

Due to the temporal dimension, this study of changes in gene expression profiles at many time points after exposure to a chemical carcinogen provides more and more robust insight in the affected molecular processes and mechanisms then any previous study. This knowledge will aid in further understanding chemical carcinogenesis and in identifying the carcinogenic properties of chemicals. 


\section{Acknowledgments}

Part of the analyses was performed using BRB ArrayTools developed by Dr. Richard Simon and Amy Peng Lam.

Financial support by the Netherlands Genomics Initiative is gratefully acknowledged 


\section{References}

1. Hayashi, Y. (1992) Overview of genotoxic carcinogens and non-genotoxic carcinogens. Exp Toxicol Pathol, 44, 465-71.

2. Shaw, I.C. and Jones, H.B. (1994) Mechanisms of non-genotoxic carcinogenesis. Trends Pharmacol Sci, 15, 89-93.

3. Cheng, S.C., Hilton, B.D., Roman, J.M. and Dipple, A. (1989) DNA adducts from carcinogenic and noncarcinogenic enantiomers of benzo(a)pyrene dihydrodiol epoxide. Chem Res Toxicol, 2, 334-40.

4. Moriya, M., Spiegel, S., Fernandes, A., Amin, S., Liu, T., Geacintov, N. and Grollman, A.P. (1996) Fidelity of translesional synthesis past benzo(a)pyrene diol epoxide-2'-deoxyguanosine DNA adducts: marked effects of host cell, sequence context, and chirality. Biochemistry, 35, 16646-51.

5. Cavalieri, E.L. and Rogan, E.G. (1995) Central role of radical cations in metabolic activation of polycyclic aromatic hydrocarbons. Xenobiotica, 25, 677-88.

6. Penning, T.M., Burczynski, M.E., Hung, C.F., McCoull, K.D., Palackal, N.T. and Tsuruda, L.S. (1999) Dihydrodiol dehydrogenases and polycyclic aromatic hydrocarbon activation: generation of reactive and redox active o-quinones. Chem Res Toxicol, 12, 1-18.

7. Balu, N., Padgett, W.T., Lambert, G.R., Swank, A.E., Richard, A.M. and Nesnow, S. (2004) Identification and characterization of novel stable deoxyguanosine and deoxyadenosine adducts of benzo(a)pyrene-7,8-quinone from reactions at physiological pH. Chem Res Toxicol, 17, 827-38.

8. Caino, M.C., Oliva, J.L., Jiang, H., Penning, T.M. and Kazanietz, M.G. (2007) Benzo(a)pyrene-7,8dihydrodiol promotes checkpoint activation and G2/M arrest in human bronchoalveolar carcinoma $\mathrm{H} 358$ cells. Mol Pharmacol, 71, 744-50.

9. Ma, Q. (2001) Induction of CYP1A1. The AhR/DRE paradigm: transcription, receptor regulation, and expanding biological roles. Curr Drug Metab, 2, 149-64.

10. Nebert, D.W., Dalton, T.P., Okey, A.B. and Gonzalez, F.J. (2004) Role of aryl hydrocarbon receptormediated induction of the CYP1 enzymes in environmental toxicity and cancer. $J$ Biol Chem, 279, 23847-50.

11. Wang, X., Tomso, D.J., Chorley, B.N., Cho, H.Y., Cheung, V.G., Kleeberger, S.R. and Bell, D.A. (2007) Identification of polymorphic antioxidant response elements in the human genome. Hum Mol Genet, 16, 1188-200.

12. Aoki, Y., Hashimoto, A.H., Amanuma, K., Matsumoto, M., Hiyoshi, K., Takano, H., Masumura, K., Itoh, K., Nohmi, T. and Yamamoto, M. (2007) Enhanced spontaneous and benzo(a)pyrene-induced mutations in the lung of Nrf2-deficient gpt delta mice. Cancer Res, 67, 5643-8.

13. Braithwaite, E., Wu, X. and Wang, Z. (1998) Repair of DNA lesions induced by polycyclic aromatic hydrocarbons in human cell-free extracts: involvement of two excision repair mechanisms in vitro. Carcinogenesis, 19, 1239-46.

14. Izumi, T., Wiederhold, L.R., Roy, G., Roy, R., Jaiswal, A., Bhakat, K.K., Mitra, S. and Hazra, T.K. (2003) Mammalian DNA base excision repair proteins: their interactions and role in repair of oxidative DNA damage. Toxicology, 193, 43-65.

15. Bartek, J. and Lukas, J. (2007) DNA damage checkpoints: from initiation to recovery or adaptation. Curr Opin Cell Biol, 19, 238-45.

16. Knasmuller, S., Parzefall, W., Sanyal, R., Ecker, S., Schwab, C., Uhl, M., Mersch Sundermann, V., Williamson, G., Hietsch, G., Langer, T., Darroudi, F. and Natarajan, A.T. (1998) Use of metabolically competent human hepatoma cells for the detection of mutagens and antimutagens. Mutation research, 402, 185-202.

17. Wilkening, S., Stahl, F. and Bader, A. (2003) Comparison of primary human hepatocytes and hepatoma cell line Hepg2 with regard to their biotransformation properties. Drug Metab Dispos, 31, 1035-42.

18. Hsu, I.C., Tokiwa, T., Bennett, W., Metcalf, R.A., Welsh, J.A., Sun, T. and Harris, C.C. (1993) p53 gene mutation and integrated hepatitis B viral DNA sequences in human liver cancer cell lines. Carcinogenesis, 14, 987-92. 
19. Staal, Y.C., van Herwijnen, M.H., van Schooten, F.J. and van Delft, J.H. (2006) Modulation of gene expression and DNA adduct formation in HepG2 cells by polycyclic aromatic hydrocarbons with different carcinogenic potencies. Carcinogenesis, 27, 646-55.

20. Staal, Y.C., Hebels, D.G., van Herwijnen, M.H., Gottschalk, R.W., van Schooten, F.J. and van Delft, J.H. (2007) Binary PAH mixtures cause additive or antagonistic effects on gene expression but synergistic effects on DNA adduct formation. Carcinogenesis, 28, 2632-40.

21. Rothkamm, K. and Lobrich, M. (2003) Evidence for a lack of DNA double-strand break repair in human cells exposed to very low x-ray doses. Proc Natl Acad Sci U S A, 100, 5057-62.

22. Reddy, M.V. and Randerath, K. (1986) Nuclease P1-mediated enhancement of sensitivity of 32Ppostlabeling test for structurally diverse DNA adducts. Carcinogenesis, 7, 1543-51.

23. Godschalk, R.W., Maas, L.M., Van Zandwijk, N., van 't Veer, L.J., Breedijk, A., Borm, P.J., Verhaert, J., Kleinjans, J.C. and van Schooten, F.J. (1998) Differences in aromatic-DNA adduct levels between alveolar macrophages and subpopulations of white blood cells from smokers. Carcinogenesis, 19, 819-25.

24. Ernst, J. and Bar-Joseph, Z. (2006) STEM: a tool for the analysis of short time series gene expression data. BMC Bioinformatics, 7, 191.

25. Bar-Joseph, Z., Siegfried, Z., Brandeis, M., Brors, B., Lu, Y., Eils, R., Dynlacht, B.D. and Simon, I. (2008) Genome-wide transcriptional analysis of the human cell cycle identifies genes differentially regulated in normal and cancer cells. Proc Natl Acad Sci U S A, 105, 955-60.

26. Vastrik, I., D'Eustachio, P., Schmidt, E., Joshi-Tope, G., Gopinath, G., Croft, D., de Bono, B., Gillespie, M., Jassal, B., Lewis, S., Matthews, L., Wu, G., Birney, E. and Stein, L. (2007) Reactome: a knowledge base of biologic pathways and processes. Genome Biol, 8, R39.

27. Boorsma, A., Foat, B.C., Vis, D., Klis, F. and Bussemaker, H.J. (2005) T-profiler: scoring the activity of predefined groups of genes using gene expression data. Nucleic Acids Res, 33, W592-5.

28. Hockley, S.L., Arlt, V.M., Brewer, D., Giddings, I. and Phillips, D.H. (2006) Time- and concentrationdependent changes in gene expression induced by benzo(a)pyrene in two human cell lines, MCF-7 and HepG2. BMC Genomics, 7, 260.

29. Frueh, F.W., Hayashibara, K.C., Brown, P.O. and Whitlock, J.P., Jr. (2001) Use of cDNA microarrays to analyze dioxin-induced changes in human liver gene expression. Toxicol Lett, 122, 189-203.

30. Kim, W.K., In, Y.J., Kim, J.H., Cho, H.J., Kim, J.H., Kang, S., Lee, C.Y. and Lee, S.C. (2006) Quantitative relationship of dioxin-responsive gene expression to dioxin response element in Hep3B and HepG2 human hepatocarcinoma cell lines. Toxicol-Lett, 165, 174-81.

31. Zhou, C., Li, Z., Diao, H., Yu, Y., Zhu, W., Dai, Y., Chen, F.F. and Yang, J. (2006) DNA damage evaluated by gammaH2AX foci formation by a selective group of chemical/physical stressors. Mutat Res, 604, 8-18.

32. Al-Shahrour, F., Minguez, P., Vaquerizas, J.M., Conde, L. and Dopazo, J. (2005) BABELOMICS: a suite of web tools for functional annotation and analysis of groups of genes in high-throughput experiments. Nucleic Acids Res, 33, W460-4.

33. Ramoni, M.F., Sebastiani, P. and Kohane, I.S. (2002) Cluster analysis of gene expression dynamics. Proc Natl Acad Sci U S A, 99, 9121-6.

34. Costa, I.G., Schonhuth, A. and Schliep, A. (2005) The Graphical Query Language: a tool for analysis of gene expression time-courses. Bioinformatics, 21, 2544-5.

35. Garinis, G.A., Mitchell, J.R., Moorhouse, M.J., Hanada, K., de Waard, H., Vandeputte, D., Jans, J., Brand, K., Smid, M., van der Spek, P.J., Hoeijmakers, J.H., Kanaar, R. and van der Horst, G.T. (2005) Transcriptome analysis reveals cyclobutane pyrimidine dimers as a major source of UV-induced DNA breaks. Embo J, 24, 3952-62.

36. Dreij, K., Seidel, A. and Jernstrom, B. (2005) Differential removal of DNA adducts derived from antidiol epoxides of dibenzo(a,1)pyrene and benzo(a)pyrene in human cells. Chem Res Toxicol, 18, 655-64.

37. Mellon, I. (2005) Transcription-coupled repair: a complex affair. Mutat Res, 577, 155-61. 


\section{Chapter 2}

38. Mahadevan, B., Keshava, C., Musafia-Jeknic, T., Pecaj, A., Weston, A. and Baird, W.M. (2005) Altered gene expression patterns in MCF-7 cells induced by the urban dust particulate complex mixture standard reference material 1649a. Cancer Res, 65, 1251-8.

39. Branzei, D. and Foiani, M. (2008) Regulation of DNA repair throughout the cell cycle. Nat Rev Mol Cell Biol, 9, 297-308.

40. Huang, T.T. and D'Andrea, A.D. (2006) Regulation of DNA repair by ubiquitylation. Nat Rev Mol Cell Biol, 7, 323-34.

41. Hockley, S.L., Arlt, V.M., Jahnke, G., Hartwig, A., Giddings, I. and Phillips, D.H. (2008) Identification through microarray gene expression analysis of cellular responses to benzo(a)pyrene and its diol-epoxide that are dependent or independent of p53. Carcinogenesis, 29, 202-10.

42. Jeffy, B.D., Chen, E.J., Gudas, J.M. and Romagnolo, D.F. (2000) Disruption of cell cycle kinetics by benzo(a)pyrene: inverse expression patterns of BRCA-1 and p53 in MCF-7 cells arrested in S and G2. Neoplasia, 2, 460-70.

43. Bi, X., Slater, D.M., Ohmori, H. and Vaziri, C. (2005) DNA polymerase kappa is specifically required for recovery from the benzo(a)pyrene-dihydrodiol epoxide (BPDE)-induced S-phase checkpoint. $J$ Biol Chem, 280, 22343-55.

44. Hockley, S.L., Arlt, V.M., Brewer, D., Te Poele, R., Workman, P., Giddings, I. and Phillips, D.H. (2007) AHR- and DNA-damage-mediated gene expression responses induced by benzo(a)pyrene in human cell lines. Chem Res Toxicol, 20, 1797-810. 
Chapter 3

\section{Assessing the Metabolic Competence of Sandwich-Cultured Mouse Primary Hepatocytes}




\title{
Chapter 3
}

\begin{abstract}
Primary human and rat hepatocyte cultures are well established in vitro systems used in toxicological studies. However, while transgenic mouse models provide an opportunity for studying mechanisms of toxicity, mouse primary hepatocyte cultures are less well described. The potential usefulness of a mouse hepatocyte-based in vitro model was assessed in this study by investigating time-dependent competence for xenobiotic metabolism and gene expression profiles. Primary mouse hepatocytes, isolated using 2-step collagenase perfusion, were cultured in a collagen sandwich configuration. Gene expression profiles and the activities of various Cyp450 enzymes were determined after 0 $\mathrm{h}, 42 \mathrm{~h}$ and $90 \mathrm{~h}$ in culture. Principal component analysis of gene expression profiles shows that replicates per time point are quite similar. Gene expression levels of most phase I biotransformation enzymes decrease to ca $69 \%$ and $57 \%$ of the original levels at $42 \mathrm{~h}$ and $90 \mathrm{~h}$, respectively, while enzyme activities for most of the studied Cyp450s decrease to $59 \%$ and $34 \%$. The decrease for phase II gene expression is only to $96 \%$ and $92 \%$ of the original levels at $42 \mathrm{~h}$ and $90 \mathrm{~h}$, respectively. Pathway analysis reveals initial effects at the level of proteins, external signaling pathways and energy production. Later effects are observed for transcription, translation, membranes and cell cycle related gene sets. These results indicate that the sandwich-cultured primary mouse hepatocyte system is robust and appears to maintain its metabolic competence better as compared to rat hepatocytes.
\end{abstract}




\section{Introduction}

Toxicological studies designed to assess safety and possible toxicity of compounds in human populations predominantly rely on the use of animal systems. As animal experiments are expensive, time-consuming and connected with ethical drawbacks, numerous attempts have been made to find a reliable way of predicting in vivo toxicity in humans by means of in vitro models in recent years.

Traditionally, since the liver plays a major role in the metabolism of many compounds and also represents an important target organ in systemic toxicity, hepatic models are frequently used as an in vitro alternative in pharmacological, toxicological and metabolic studies $(1,2)$. Hepatic cell lines, primary hepatocyte cultures and precision-cut liver slices from various species are well established in vitro systems for these studies $(1,2,3)$. As precision-cut liver slices have a very short live span and immortalized cell lines have lost many liver specific functions, primary cultures of hepatocytes are preferentially used for in vitro studies on liver toxicity $(3,4,5)$.

Primary mammalian hepatocytes largely retain their liver-specific functions when freshly derived from the animal. Long-term cultures of functional hepatocytes however are difficult to establish. To increase the longevity and maintain differentiated functions of hepatocytes in primary cultures, cells are cultured in a sandwich configuration of collagen-collagen and in serum-free culture medium (6). Hepatocytes cultured in a sandwich configuration reorganize to form an architecture similar to that found in the liver and are able to form functional bile canalicular networks and gap junctions. In such a sandwich configuration, hepatocytes can be cultured for a longer time period compared to cultures on single layers of collagen $(7,8,9,10)$.

The use of primary human hepatocytes is preferential in order to predict in vivo toxicity in humans but is hampered by the limited availability of donor material and the large variability between the donors (3). Therefore, primary hepatocytes isolated from other mammals are used as an alternative to human tissue. However, the rapid decline in liver specific functions, in particular cytochrome P450 (Cyp450) enzyme activity, in rat liver in vitro systems limits the use of these in studies for testing chemicals for which metabolism depends on the Cyp450 enzyme system $(9,11)$. Human hepatocytes also tend to show a decrease in most Cyp450 enzymes, but some levels of Cyp450 gene expressions can be restored after a few days $(12,13)$. A mouse in vitro hepatocyte system might be an alternative to the rat and human systems, especially if the metabolic competence is preserved. In addition, since the complete sequence of the mouse genome is known (14) and transgenic mouse models are widely available, primary mouse hepatocytes are usable for the purpose of performing mechanistic investigations of liver toxicity. However, information about stability of liver specific functions in mice is scarce.

It was the aim of the current study to investigate the robustness of a mouse hepatocytebased in vitro model, especially with respect to the biotransformation functions (evalu- 
ated by assessing gene expression and enzyme activities) in order to get more insight in its potential usefulness in toxicology.

\section{Materials and Methods}

\section{Chemicals}

Dulbecco's modified Eagle's medium (DMEM), fetal calf serum (FCS), penicillin/streptomycin, Hanks' calcium- and magnesium-free buffer, insulin and Trizol were obtained from Invitrogen (Breda, The Netherlands). Glucagon, hydrocortisone (50-237), collagenase type IV, dimethylsulfoxide (DMSO; 67-68-5) and Trypan blue (72-57-1) were purchased from Sigma-Aldrich (Zwijndrecht, The Netherlands). Collagen Type I Rat Tail was obtained from BD BioSciences (Bedford, MA).

The RNeasy minikit was obtained from Qiagen, Westburg B.V. (Leusden, The Netherlands). The 5x MegaScript T7 Kit was obtained from Ambion (Austin, TX). The GeneChip $^{\circledR}$ Expression 3'-Amplification Two-Cycle cDNA Synthesis Kit and Reagents, the Hybridization, Wash and Stain Kit and the Mouse Genome 4302.0 Arrays were purchased from Affymetrix (Santa Clara, CA). The CYP450 AL4 cocktail was delivered by Advanced In Vitro Cell Technologies (Valencia, Spain).

\section{Animals}

Permission for animal studies was obtained from the Animal Ethical Committee. Adult male C57BL/6 mice (Charles River), weighing 20-25 g, were obtained from Charles River GmbH, Sulzfeld, Germany. This mouse strain was chosen because it is frequently used in toxicological and pharmacological investigations, and it is a common background for transgenic mouse strains. The animals were housed in macrolon cages with sawdust bedding at $22^{\circ} \mathrm{C}$ and $50-60 \%$ humidity. The light cycle was $12 \mathrm{~h}$ light $/ 12 \mathrm{~h}$ dark. Feed and tap water were available ad libitum.

\section{Isolation of hepatocytes}

Hepatocytes were isolated from adult male C57BL/6 mice by a two-step collagenase perfusion method according to Seglen and Casciano $(15,16)$, with modifications. The liver was perfused after cannulation of the abdominal inferior vena cava. The hepatic portal vein was cut through and the thoracic inferior vena cava was occluded with forceps. The organ was washed with Hanks' calcium- and magnesium-free buffer for 3 min. After the liver had been freed of blood the calcium-free buffer was replaced by a collagenase buffer $(0.5 \mathrm{mg} / \mathrm{ml})$ for $7-10 \mathrm{~min}$. A perfusion rate of $7 \mathrm{ml} / \mathrm{min}$ and a temperature around $39^{\circ} \mathrm{C}$ was maintained for both perfusates during the entire procedure. After the perfusion had been terminated, the liver was rapidly excised from the body cavity and transferred to a sterile Petri dish. The gall bladder and remnants of the dia- 
phragm were removed and cells were released by disrupting the liver capsule mechanically and by shaking the cells into attachment medium. The cells were separated from undigested tissue with a sterile $50-\mu \mathrm{m}$ mesh nylon filter. After washing by low-speed centrifugation at $50 \mathrm{~g}$ for $3 \mathrm{~min}$ at $4{ }^{\circ} \mathrm{C}$ several times, cell viability and yield were determined by trypan blue exclusion.

\section{Cell culture}

Cells from three independent biological replicates with viability $>85 \%$ were used and cultured on collagen gel precoated 6-well plates at a density of $6.5 \times 10^{5}$ cells $/ \mathrm{ml}(17)$. Cells were allowed to attach for $2-4 \mathrm{~h}$ at $37^{\circ} \mathrm{C}$ in a humidified chamber with $95 \% / 5 \%$ air $/ \mathrm{CO}_{2}$ in DMEM supplemented with $10 \% \mathrm{FCS}$, insulin $(0.5 \mathrm{U} / \mathrm{ml})$, glucagon $(7 \mathrm{ng} / \mathrm{ml})$ and $2 \%$ penicillin/streptomycin $(5000 \mathrm{U} / \mathrm{ml}$ penicillin; $5000 \mu \mathrm{m} / \mathrm{ml}$ streptomycin $)$. After attachment, medium containing unattached cells and debris was removed by washing and the cultures were overlaid with a second collagen layer to form a collagen-collagen sandwich culture. Primary cultures of mouse hepatocytes were cultured at $37^{\circ} \mathrm{C}$ in a humidified chamber with $95 \% / 5 \%$ air $/ \mathrm{CO}_{2}$ in serum-free culture medium supplemented with insulin $0.5 \mathrm{U} / \mathrm{ml})$, glucagon $(7 \mathrm{ng} / \mathrm{ml})$, hydrocortisone $(7.5 \mu \mathrm{g} / \mathrm{ml})$ and $2 \%$ penicillin/streptomycin (5000 U/ml penicillin; $5000 \mu \mathrm{m} / \mathrm{ml}$ streptomycin). Cells from three independent biological experiments (each from a different animal) were harvested at 0 , 42 and $90 \mathrm{~h}$ after isolation for gene expression analysis.

\section{$R N A$ isolation}

Total RNA was isolated from cultured mouse hepatocytes using Trizol reagent with the RNeasy kit according to the manufacturer's protocol. Total cellular levels were measured on a spectrophotometer and the quality of each RNA preparation was determined with a bio-analyzer (Agilent Technologies, The Netherlands). Extracted RNA was stored at $-80^{\circ} \mathrm{C}$.

\section{Target preparation and microarray hybridization}

cRNA targets were prepared according to the Affymetrix protocol. The targets were hybridized according to the manufacturer's recommended procedures on high-density oligonucleotide genechips (Affymetrix Mouse Genome 430 2.0 GeneChip arrays). The genechips were washed and stained using a fluidics station by Affymetrix and scanned in an Affymetrix GeneArray scanner.

A total of nine targets (3 time points from 3 animals) were prepared, and each preparation was analyzed using one GeneChip array. Normalization quality controls, including scaling factors, average intensities, present calls, background intensities, noise, and raw $\mathrm{Q}$ values all were within acceptable limits. Hybridization controls BioB, BioC, BioD, and CreX, were called present on all chips and yielded the expected increases in intensities. 


\section{Data analysis}

Nine datasets were obtained from this experiment. The raw data were imported into ArrayTrack (18) and converted and normalized by Robust Multi-array Average (RMA, integrated into ArrayTrack) (19). Spots of poor quality and control spots were omitted. Subsequently, the remaining probe sets $(25,084)$ were logarithm (base 2$)$ transformed. Processed and normalized gene expression values were evaluated for identifying differentially expressed probe sets with the multiclass significance analysis of microarrays (SAM, integrated into ArrayTrack; p-value < 0.05) (20). Multiclass SAM resulted in 6560 remaining differentially expressed probe sets and these were used for principal component analysis (PCA).

\section{Pathway analysis}

Gene expressions at 42 vs $0 \mathrm{~h}, 90$ vs $0 \mathrm{~h}$ and $90 \mathrm{vs} 42 \mathrm{~h}$ were uploaded in T-profiler (http://www.t-profiler.org; 21) to identify transcriptional regulation of biochemical pathways and biological processes which included genes sets from Gene Ontology (GO) terms, curated gene sets, Motifs and Kyoto Encyclopedia for Genes and Genomes (KEGG) pathways. T-profiler uses the $\mathrm{T}$ test to score the difference between the mean expression level of predefined groups of genes and that of all other genes without any statistical pre-selection of modulated genes (21). Significance was determined by generating an $\mathrm{E}$ value, a Bonferroni corrected $\mathrm{P}$ value. Pathways and processes were determined significant if $\mathrm{E}$ values were below 0.05 , and were thereupon used for hierarchical clustering and gene grouping in GenePattern (http://www.broad.mit.edu/cancer/software/genepattern/).

In order to increase specificity of the transcriptomics changes, the 6560 differentially expressed probe sets, determined by Multiclass SAM, were uploaded into MetaCore (GeneGo, San Diego, CA) for identifying the involvement of differentially expressed genes in specific cellular pathways by overrepresentation analyses compared to the total amount of genes involved in the particular pathways.

\section{Analysis of CYP450s enzyme activities}

Cyp450 activity assays at $0 \mathrm{~h}, 42 \mathrm{~h}$ and $90 \mathrm{~h}$ were conducted by the direct incubation of three independent sandwich-cultured mouse hepatocyte preparations with a cocktail of Cyp450 substrates (22). Substrates mixture stock was prepared in DMSO, and conveniently diluted in incubation media to obtain the optimal assay concentrations (Table 1). The final concentration of DMSO during incubation was $0.5 \%(\mathrm{v} / \mathrm{v})$. After $2 \mathrm{~h}$ of incubation enzymatic reactions were stopped by aspirating the incubation medium. Samples were subsequently centrifuged at $2500 \mathrm{rpm}$ for $5 \mathrm{~min}$. The supernatants were transferred to clean tubes and frozen at $-80^{\circ} \mathrm{C}$ until analysis. Sample analysis and cocktail preparation was carried out in the Unidad Mixta Hospital La Fe-Advancell, Valencia, Spain. Samples were subjected to hydrolysis before analysis by incubation with 
$\beta$-glucuronidase and arylsulfatase for $2 \mathrm{~h}$ at $37^{\circ} \mathrm{C}$. One volume of ice-cold acetonitrile was added and centrifuged samples were transferred to clean vials for further analysis. Metabolites formed and released into the culture medium were quantified by high performance liquid chromatography tandem mass spectrometry (23). Enzymatic activities were expressed as pmol of metabolite formed/incubation time/number of cells. For the statistical analysis the T-Test was used with a significance level of 5\%.

\begin{tabular}{llcl}
\hline CYP & Substrate & Concentration $(\mu \mathrm{M})$ & Metabolite \\
\hline 1A2 & Phenacetin & 10 & Acetaminophen \\
$2 \mathrm{~A} 4$ & Coumarin & 5 & 7-HO-Coumarin \\
$2 \mathrm{~B} 9 / 10 / 13 / 19 / 23$ & Bupropion & 10 & HO-Bupropion \\
$2 \mathrm{C} 37$ & Mephenytoin & 50 & 4'-HO-Mephenytoin \\
$2 \mathrm{C} 39-40 / 44 / 50 / 54-55 / 65-70$ & Diclofenac & 10 & 4'-HO-Diclofenac \\
$2 \mathrm{D} 9-13 / 22 / 26 / 34 / 40$ & Bufuralol & 10 & Hydroxybufuralol \\
$2 \mathrm{E} 1$ & Chlorzoxazone & 50 & 6-HO-Chlorzoxazone \\
$3 \mathrm{~A} 11$ & Midazolam & 5 & 1'-HO-Midazolam \\
\hline
\end{tabular}

\section{Results}

Principal component analysis of all genes

A PCA on the 6560 differentially expressed probe sets, identified with the multiclass SAM analysis ( $p$-value $<0.05$ ), was used to visualize inter-individual and timedependent differences in gene expression profiles of primary mouse hepatocytes cultured in sandwich configuration (Figure 1). PCA shows a clear discrimination between the three time groups and only limited differences between replicates of the $42 \mathrm{~h}$ and 90 $\mathrm{h}$ groups are observed, while more variance in gene expression is seen between the $0 \mathrm{~h}$ replicates.

\section{Pathway analysis}

T-profiler was used for identifying gene groups that were differentially expressed. The gene groups significantly altered in hepatocytes from at least two experiments and modified in the same direction in liver cells from all experiments were selected for each time period. In total, 384 gene sets were identified as being modulated.

Hierarchical clustering was used to generate more comprehensible groups of these genes (Figure 2). Most gene sets were either only downregulated or only upregulated. A small amount of these gene sets appeared to be upregulated during the first $42 \mathrm{~h}$, and downregulated in the period from 42 to $90 \mathrm{~h}$. 


\section{Chapter 3}

An additional analysis of affected cellular pathways was conducted using MetaCore, which showed similar results compared to the results from T-profiler (data not shown). Most prominent pathways significantly altered in MetaCore were involved in several catabolic, metabolic and biosynthetic processes, immune responses and cellular, nuclear and macromolecule related processes.

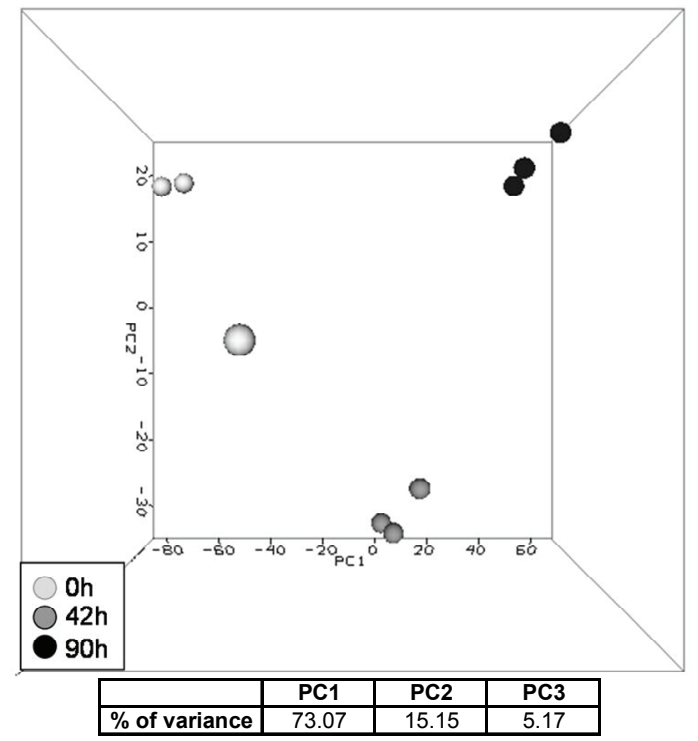

Figure $1 \quad$ Principal component analysis using the data of all differentially expressed genes from primary mouse hepatocytes at 0, 42 and 90 h cultivation.

\section{Biotransformation enzymes}

Gene expression and activity of phase I and phase II drug-metabolizing enzymes were quantified to assess the metabolic capacity of the primary mouse hepatocyte system (see Table 2 and Table 3). For the majority of the Cyp450 genes, the gene expression level decreased during culturing. For a small group of Cyp450s, however, the expression levels remained relatively constant while for an even smaller group, gene expression levels increased in all time periods.

For the phase II genes, large variations were seen in their expression levels between the different time points, even within groups of phase II genes belonging to the same family. Most phase II enzyme groups were down-regulated or hardly changed over time. Only genes involved in glutathione metabolism and $\mathrm{N}$-acetyltransferases were generally up-regulated.

Cyp450 enzyme activities of 8 selected enzymes were measured in each sample. These activities are presented as $\log 2$ mean \pm SD values in Figure 3. Enzyme activities for Cyp2a4 and Cyp2a1 were not detected. For the majority of the studied Cyp450 en- 
zymes, a significant decrease in enzyme activity was measured in both time periods. Only one group of enzymes (Cyp2B9-10/13/19/23) showed an increase in activity and expression levels. After $90 \mathrm{~h}$ in culture, all Cyp450 enzymes remained active in the primary hepatocytes.

These Cyp450 enzyme activities and their gene expression are presented in Figure 3. In all cases gene expression and enzyme activity changed in the same directions, and mostly in the same order.

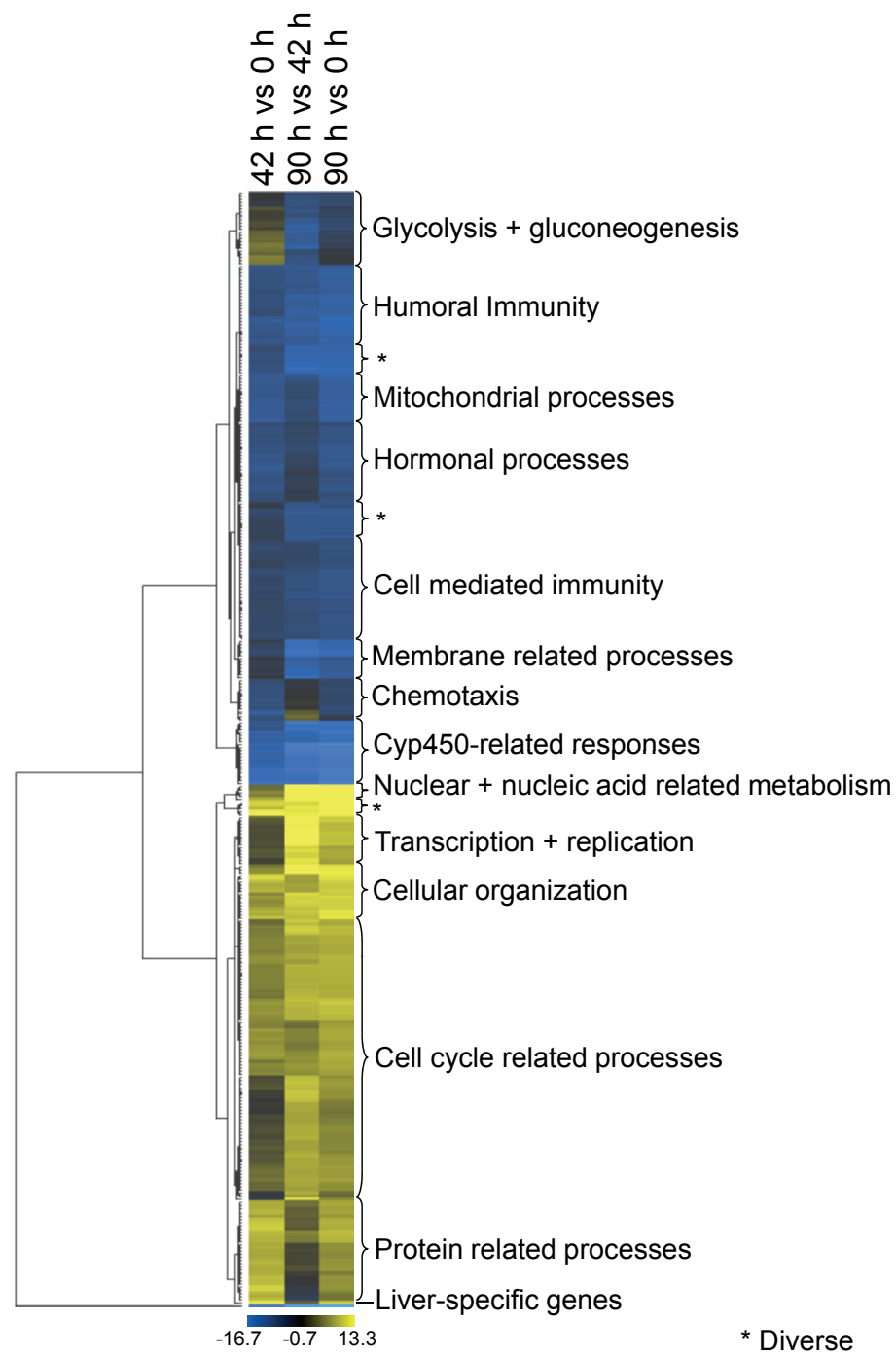

Figure 2 Hierarchical clustering of gene sets significantly modified in primary mouse hepatocytes in the time periods from 0 to $42 \mathrm{~h}$, from 42 to $90 \mathrm{~h}$ and from 0 to $90 \mathrm{~h}$. Clustering is based on the t-values, as provided by T-profiler. Yellow and blue mean up-and downregulation, respectively. 
Table 2 Expression of Cyp450 genes in primary mouse hepatocytes at 42 and $90 \mathrm{~h}$ as percentages of the expression at $0 \mathrm{~h}$.

\begin{tabular}{|c|c|c|}
\hline GENENAME & $42 \mathrm{~h}$ & $90 \mathrm{~h}$ \\
\hline Сур17a1* & 2659 & 107 \\
\hline Cyp1a1 & 119 & 117 \\
\hline Cyp1a2* & 29 & 7 \\
\hline Сyp1b1 & 109 & 104 \\
\hline Сур20a1 & 155 & 213 \\
\hline Сур21a1 & 114 & 108 \\
\hline Сyp26a1* & 24 & 10 \\
\hline Сyp27a1* & 66 & 56 \\
\hline Сур2a12* & 65 & 128 \\
\hline Сур2a4-5 & 42 & 71 \\
\hline Сyp2b10 & 1546 & 1460 \\
\hline Сyp2b13 & 102 & 95 \\
\hline Сyp2b19 & 90 & 86 \\
\hline Cyp2b9 & 126 & 110 \\
\hline Сур2c29* & 32 & 13 \\
\hline Сyp2c37 & 24 & 1 \\
\hline Сyp2c37-50-54* & 19 & 1 \\
\hline Сyp2c38 & 54 & 65 \\
\hline Сур2c44* & 27 & 2 \\
\hline Сур2c55* & 50 & 16 \\
\hline Сур2c70* & 75 & 39 \\
\hline Сур2d10* & 88 & 59 \\
\hline Cyp2d13* & 40 & 20 \\
\hline Сyp2d22* & 74 & 33 \\
\hline Сур2d26* & 69 & 56 \\
\hline Cyp2d9* & 59 & 22 \\
\hline Cyp2e1* & 56 & 3 \\
\hline Сур2f2* & 22 & 4 \\
\hline Cyp2g1* & 40 & 37 \\
\hline
\end{tabular}




\begin{tabular}{|c|c|c|}
\hline Сур2j5* & 10 & 6 \\
\hline Сyp2j6* & 99 & 83 \\
\hline Сyp2r1 & 103 & 76 \\
\hline Cyp2s $1^{*}$ & 266 & 83 \\
\hline Сур2u1 & 76 & 80 \\
\hline Сур39a1* & 197 & 421 \\
\hline Сур3a11* & 77 & 76 \\
\hline Сур3a13* & 203 & 175 \\
\hline Сур3a25* & 21 & 18 \\
\hline Сур3a41* & 66 & 65 \\
\hline Сур3a44* & 82 & 77 \\
\hline Сyp46a1* & 83 & 67 \\
\hline Сур4a10* & 32 & 38 \\
\hline Сур4a12* & 16 & 1 \\
\hline Cyp4a14* & 19 & 7 \\
\hline Cyp4b1 & 202 & 100 \\
\hline Cyp4f13 & 70 & 58 \\
\hline Cyp4f14* & 19 & 5 \\
\hline Cyp4f15* & 26 & 9 \\
\hline Cyp4f16* & 381 & 341 \\
\hline Cyp4v3* & 41 & 22 \\
\hline Cyp51 & 115 & 108 \\
\hline Сур7a1 & 76 & 42 \\
\hline Cyp7b1* & 17 & 12 \\
\hline \multirow[t]{2}{*}{ Cyp8b1* } & 109 & 7 \\
\hline & 69 & 57 \\
\hline
\end{tabular}

Significant $(p<0.05)$ in multiclass SAM 
Table 3 Expression of phase II genes in primary mouse hepatocytes at 42 and $90 \mathrm{~h}$ as percentages of the expression at $0 \mathrm{~h}$.

\begin{tabular}{|c|c|c|}
\hline GENENAME & $42 \mathrm{~h}$ & $90 \mathrm{~h}$ \\
\hline \multicolumn{3}{|c|}{ Aldo-keto reductases } \\
\hline Akr1a4 & 92 & 101 \\
\hline Akr1b3* & 208 & 321 \\
\hline Akr1b7* & 267 & 285 \\
\hline Akr1b8 & 131 & 127 \\
\hline Akr1c12 & 96 & 85 \\
\hline Akr1c13 & 103 & 107 \\
\hline Akr1c14* & 29 & 47 \\
\hline Akr1c19 & 125 & 84 \\
\hline Akr1c20* & 27 & 22 \\
\hline Akr1c21* & 86 & 71 \\
\hline Akr1c6* & 4 & 0 \\
\hline Akr1d1* & 20 & 13 \\
\hline Akr1e1 & 112 & 103 \\
\hline Akr7a5 & 93 & 83 \\
\hline \multicolumn{3}{|c|}{ Sulfotransferases } \\
\hline Chst10 & 81 & 72 \\
\hline Chst11 & 92 & 81 \\
\hline Chst4 & 83 & 80 \\
\hline Chst9 & 98 & 95 \\
\hline D4st1* & 151 & 239 \\
\hline Gal3st1 & 175 & 128 \\
\hline Gal3st4 & 96 & 81 \\
\hline Hs1bp3* & 120 & 205 \\
\hline Hs2st1* & 167 & 229 \\
\hline Hs3st1 & 93 & 88 \\
\hline Hs3st2 & 88 & 75 \\
\hline Hs3st3b1* & 88 & 76 \\
\hline Hs3st6 & 83 & 73 \\
\hline
\end{tabular}


Hs6st1*

$86 \quad 59$

Hs6st2

94

89

Ndst1

99

100

Ndst2

165

113

Ndst3

94

92

Ndst4

93

84

Sult1a1

110

119

Sult1b1*

67

18

Sult1c2

76

50

Sult1d1*

457

86

Sult1e1*

1231

397

Sult5a1*

67

60

Epoxide hydrolases

Ephx1

140

133

Ephx2*

47

35

Flavin-Containing Monooxygenase

\begin{tabular}{lcc}
\hline Fmo1* & 31 & 19 \\
Fmo2 & 102 & 96 \\
Fmo3 & 99 & 84 \\
Fmo4 & 133 & 108 \\
Fmo5 & 369 & 96 \\
\hline Glutathione reductases & & \\
\hline Gsr & 146 & 129 \\
Gss* & 153 & 329 \\
\hline Glutathione peroxidases & 70 & 47 \\
\hline Gpx1* & 139 & 161 \\
Gpx4* & 58 & 44 \\
Gpx6* $^{*}$ & 113 & 222 \\
\hline Gpx7* & & 409 \\
\hline Glutathione transferases & 526 & 142 \\
\hline Gsta1-2* & 194 & \\
Gsta2* & & \\
& & \\
\hline
\end{tabular}


Gsta3*

Gsta4*

Gstm1

Gstm2*

Gstm3*

Gstm4

Gstm5*

Gstm6

Gstm7*

Gsto1

Gsto2

Gstp1

Gstt1*

Gstt2

Gstt3

Gstz1*

Mgst1*

Mgst2*

Mgst3

$\mathrm{N}$-acetyltransferases

Gcnt1

Gcnt2

Nat10*

Nat11

Nat12

Nat2*

Nat5

Nat6

Nat9

\section{Glucuronosyl transferases}

Ugt1a1-2-5-6a-6b-7c-9-10*

Ugt2a3*
39

82

113

364

378

127

197

110

64

117

115

98

49

78

69

94

63

94

141

150

115

107

38

105

55

92

60

76

141

110

107

76

153

114

145

179

240

82

134

135

63

239

174

196

122

332

114

134

59

38

30

4 


\begin{tabular}{lcc} 
Ugt2b1* $^{*}$ & 13 & 1 \\
Ugt2b34 & 127 & 112 \\
Ugt2b35 & 99 & 147 \\
Ugt2b36* & 42 & 59 \\
Ugt2b37* $^{*}$ & 40 & 28 \\
Ugt2b38* $^{*}$ & 11 & 5 \\
Ugt2b5* $^{*}$ & 35 & 39 \\
Ugt3a1* $^{*}$ & 20 & 6 \\
Ugt3a2* $^{*}$ & 26 & 4 \\
\hline & 96 & 92
\end{tabular}

* Significant $(p<0.05)$ in multiclass SAM

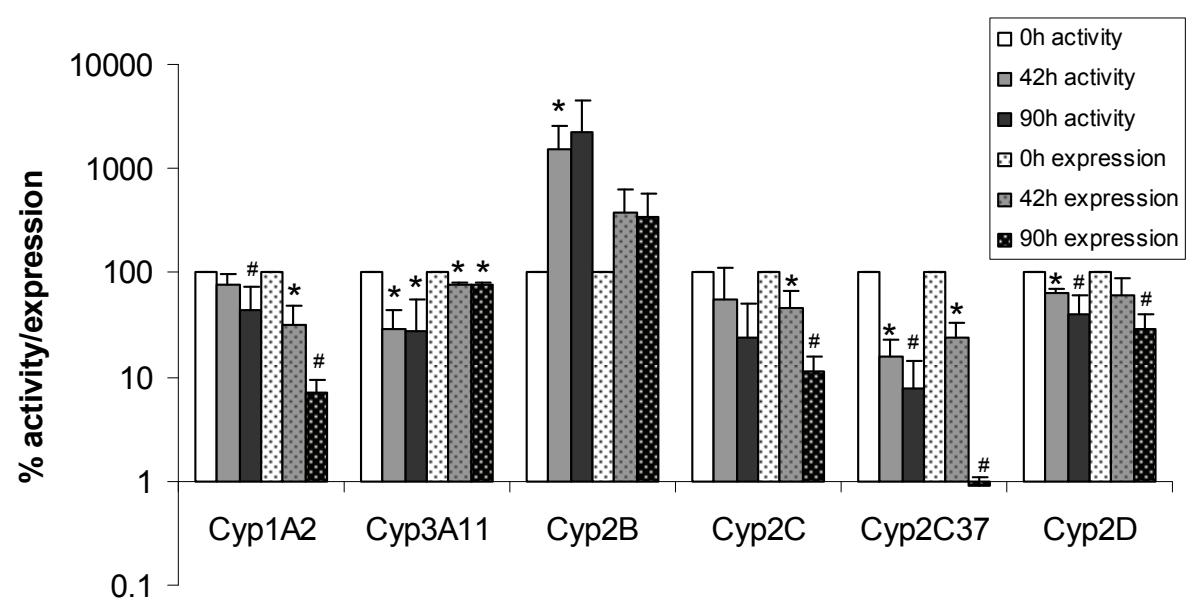

Figure $3 \quad$ Cyp450 enzyme activities and gene expression in primary mouse hepatocytes after 0, 42 and $90 \mathrm{~h}$ in culture. Values are represented as percentages from activities and gene expression 0 $h$ and as means $\pm S D$ of 3 animals for each time point.

* Significant (P value $<0.05$ ) compared to $0 \mathrm{~h}$.

${ }^{\#}$ Significant $(P$ value $<0.05)$ compared to 0 and $42 \mathrm{~h}$. 


\section{Discussion}

As human and rat sandwich-cultured hepatocytes have their disadvantages because of the limited availability of donor material and/or a rapid decline in Cyp450 enzyme activities, primary mouse hepatocytes may be an option to overcome this shortcoming (3, 11). Moreover, the growing availability of transgenic models can be a reason to use mouse primary hepatocytes. As information on the stability of liver specific functions in mouse hepatocytes is scarce, the present study investigated the stability of a mouse hepatocyte-based in vitro model, especially with respect to the biotransformation functions (gene expression and enzyme activities), in order to get more insight in its potential usefulness in toxicology.

PCA was used to elucidate changes in gene expression profiles between donor animals and between cultivation times. This revealed that profiles are very different between the three time points. These time-dependent changes can be attributed to the adaptation of the primary hepatocytes to their in vitro environment. Noteworthy, the hepatocytes at time point $0 \mathrm{~h}$ show larger inter-animal differences compared to those at later time points. This observation might be caused by initial stress induced by the enzymatic separation and isolation of hepatocytes (24). This inter-animal variability is less clear in the later time points, indicating that the stress responses are fading.

Pathway analysis, used to identify biochemical pathways and biological processes that were differentially expressed, showed again that differences exist between the two cultivation periods. Some gene sets were affected in both periods, whereas others in only the first $42 \mathrm{~h}$ or only in the $48 \mathrm{~h}$ thereafter. During only the first $42 \mathrm{~h}$ in culture, gene sets in mitochondrial processes, hormonal processes and chemotaxis were downregulated, whereas those in protein related processes are upregulated during only this period. Pathways mostly affected after the first $42 \mathrm{~h}$ are downregulation of membrane related processes, and upregulation of transcription and replication and cell cycle related processes. Gene sets that are continuously downregulated are on humoral and cell mediated immunity, CYP450 related responses and liver-specific genes. A continuous upregulation is observed in nuclear and nucleic acid related metabolism, cellular organization, and in parts of cell cycle related processes. The overall picture based on these pathway analyses, is that liver-specific functions are continuously decreasing and that gross cellular organizations are continuously upregulated. Initial effects are more at the level of protein synthesis, external signaling pathways and energy production, while later on transcription, translation, membranes and cell cycle related gene sets are affected.

Microscopic observations showed that in this $42 \mathrm{~h}$ period, cells were changing their periphery, cellular components and structures, and forming aggregates (not shown). These morphological changes at microscopic level confirm previously described studies on human hepatocytes and on the histology of rat and mouse hepatocytes. The morphological changes include attachment to the collagen layer, the remodeling of sandwich- 
cultured hepatocytes to a polygonal shape, the appearance of a clear, less granular, cytoplasm and the aggregation of the cells including the formation of gap junctions for intercellular communication $(6,25,26,27)$. Membrane and mitochondrial changes have also been demonstrated before in freshly isolated hepatocytes and hepatocytes cultured for 3 days $(28,29)$. Unfortunately, all these morphological changes were poorly represented by changes at the level of pathways as analyzed by T-profiler or MetaCore. These morphological changes were perhaps too specific and the annotation of genes with respect to that is too limited. In human and rat hepatocytes cultured in a sandwich configuration, others have found genes and pathways involved in cell structure to be highly expressed after $24 \mathrm{~h}$ in culture $(30,31,32,33)$.

To investigate the metabolic competence of sandwich-cultured mouse hepatocytes in more detail, gene expression profiles from phase I and phase II biotransformation enzymes were evaluated during the cultivation period. In general the expression values of all phase I biotransformation enzymes are decreasing over the whole cultivation period. During the first $42 \mathrm{~h}$ these phase I enzyme gene expression values are decreasing by $31 \%$ (ca $69 \%$ remaining) from the original values at $0 \mathrm{~h}$. After $90 \mathrm{~h}$ in culture the hepatocytes exhibit clearly lower levels (ca 57\%) of Cyp450s compared to the original values at $0 \mathrm{~h}$.

It was described before that many cultures of mammalian hepatocytes exhibit low levels of Cyp450 but still possess the ability to respond to Cyp450 inducers (34). The expression of Cypla1 and Cypla2 during cultivation has been studied in detail by Northern blotting (35). In primary mouse hepatocytes cultured in dishes without collagen, Cypla1 expression increased during cultivation. Cyp1a2 was constitutively expressed in these cells, but insulin suppressed this expression slightly. Our results show a steady level in Cypla1 gene expression and a down-regulation in Cyp1a2 gene expression. In human hepatocytes, most Cyp450s also showed a decrease in expression levels with the exception of a few Cyp450s which had elevated levels of expression (36). Cyp1A2 appeared to be more stable compared to the mouse model during cultivation, while Cyp2E1 and Cyp3A4, which is the homologue for Cyp3a11 in mice (37), were shown to be decreasing in time, comparable to our results (38). Most Cyp450s in conventional sandwich-cultured rat hepatocytes appeared to be decreasing in a time-dependent manner (10). Even within the short time period of $24 \mathrm{~h}$ after isolation, the expression levels of many Cyp450s decreased tremendously in rat hepatocytes (9). While in our study gene expression levels showed a slower decrease over time indicating that mouse hepatocytes remain more stable with respect to Cyp450 gene expression as compared to rat hepatocytes but not to human hepatocytes.

As several rat studies suggest that phase II enzyme activities are better preserved in culture than phase I enzyme activities, we decided to only measure enzyme activities of most important phase I enzymes involved in xenobiotic biotransformation to strengthen our gene expression results $(39,40)$. These results show a general decrease in Cyp450 


\section{Chapter 3}

enzyme activity, with only one exception. Activity levels were decreasing the first $42 \mathrm{~h}$ to $59 \%$ from the original activities. After $90 \mathrm{~h}$, activity levels were decreased to $34 \%$ in comparison to $0 \mathrm{~h}$. Compared to our results, Cyp450 enzyme activities in rat hepatocytes are decreasing very rapidly. Already after $6 \mathrm{~h}$, less than $50 \%$ of the initial Cyp 450 enzyme activity was left in rat hepatocytes $(41,42)$. These rat hepatocytes, however, were cultured on a collagen monolayer, which may affect the stability of the cells.

Phase II biotransformation enzymes demonstrate a less clear pattern. Enzymes were either up- or down-regulated or remain unchanged. Even within a group of enzymes, differences in gene expression can be seen. In general, the expression levels are decreasing to $96 \%$ and $92 \%$ as compared to levels at $0 \mathrm{~h}$ after $42 \mathrm{~h}$ and $90 \mathrm{~h}$, respectively. In rat hepatocytes, however, phase II enzymes in general showed a decrease in gene expression level after $72 \mathrm{~h}$ compared to gene expression in liver (10). For rat hepatocytes, it is known that the phase II enzymes are better preserved in culture than phase I enzymes $(39,40)$. Our data confirm these findings, thus showing that mouse hepatocytes are also stable in expression of genes encoding phase II enzymes.

An overall comparison of the gene expression levels from phase I and phase II enzymes from rat and mouse hepatocytes demonstrated that mouse hepatocytes exhibit a more stable gene expression pattern than primary rat hepatocytes.

\section{Conclusion}

In summary, our findings show that the sandwich-cultured primary mouse hepatocyte in vitro model has little or no inter-animal variations, demonstrating its reproducibility. The system is still metabolic competent even after $90 \mathrm{~h}$ culturing, despite that phase I enzyme gene expression and activity are generally decreasing. In rat hepatocytes, this decrease in phase I and II gene expression appears to be faster. Human hepatocytes, on the other hand, also show a decrease in these phase I enzymes, but are able to restore the gene expression levels of some Cyp450s. Taken together, our results indicate that the primary mouse hepatocyte system is relatively stable and might maintain its metabolic competence longer than rat hepatocytes, and roughly similar to that of human hepatocytes. Based on our gene expression data, we recommend applying a $42 \mathrm{~h}$ recovery period before using the mouse hepatocytes. 


\section{Acknowledgements}

We would like to thank Sandra Montero at Unidad Mixta Hospital La Fe-Advancell for expert technical assistance in CYP450 activities measurements. Financial support was provided by the Netherlands Genomics Initiative (NGI), the Netherlands Organisation for Scientific Research (NWO) and the CARCINOGENOMICS FP6 project sponsored by the European Union (PL037712). 


\section{References}

1. Blaauboer, B.J., et al., The practical applicability of hepatocyte cultures in routine testing. EcVam workschop report 1, 1994.

2. Davila, J.C., et al., Predictive value of in vitro model systems in toxicology. Annu Rev Pharmacol Toxicol, 1998. 38: p. 63-96.

3. Schaeffner, I., et al., A microtiterplate-based screening assay to assess diverse effects on cytochrome P450 enzyme activities in primary rat hepatocytes by various compounds. Assay Drug Dev Technol, 2005. 3(1): p. 27-38.

4. Richert, L., et al., Evaluation of the effect of culture configuration on morphology, survival time, antioxidant status and metabolic capacities of cultured rat hepatocytes. Toxicol In Vitro, 2002. 16(1): p. 8999.

5. Berry, M.N., et al., Isolated hepatocytes--past, present and future. Cell Biol Toxicol, 1997. 13(4-5): p. 223-33.

6. Tuschl, G. and S.O. Mueller, Effects of cell culture conditions on primary rat hepatocytes-cell morphology and differential gene expression. Toxicology, 2006. 218(2-3): p. 205-15.

7. LeCluyse, E.L., et al., Regulation of glutathione S-transferase enzymes in primary cultures of rat hepatocytes maintained under various matrix configurations. Toxicol In Vitro, 2000. 14(2): p. 101-15.

8. LeCluyse, E.L., et al., Regeneration and maintenance of bile canalicular networks in collagensandwiched hepatocytes. Toxicol In Vitro, 2000. 14(2): p. 117-32.

9. Boess, F., et al., Gene expression in two hepatic cell lines, cultured primary hepatocytes, and liver slices compared to the in vivo liver gene expression in rats: possible implications for toxicogenomics use of in vitro systems. Toxicol Sci, 2003. 73(2): p. 386-402.

10. Kienhuis, A.S., et al., A sandwich-cultured rat hepatocyte system with increased metabolic competence evaluated by gene expression profiling. Toxicol In Vitro, 2007. 21(5): p. 892-901.

11. Hoen, P.A., et al., Selective induction of cytochrome P450 3A1 by dexamethasone in cultured rat hepatocytes: analysis with a novel reverse transcriptase-polymerase chain reaction assay section sign. Biochem Pharmacol, 2000. 60(10): p. 1509-18.

12. Morel, F., et al., Expression of cytochrome P-450 enzymes in cultured human hepatocytes. Eur J Biochem, 1990. 191(2): p. 437-44.

13. LeCluyse, E.L., Human hepatocyte culture systems for the in vitro evaluation of cytochrome P450 expression and regulation. Eur J Pharm Sci, 2001. 13(4): p. 343-68.

14. Waterston, R.H., et al., Initial sequencing and comparative analysis of the mouse genome. Nature, 2002. 420(6915): p. 520-62.

15. Seglen, P.O., Preparation of isolated rat liver cells. Methods Cell Biol, 1976. 13: p. 29-83.

16. Casciano, D.A., Development and utilization of primary hepatocyte culture systems to evaluate metabolism, DNA binding, and DNA repair of xenobiotics. Drug Metab Rev, 2000. 32(1): p. 1-13.

17. Koebe, H.G., et al., Collagen gel immobilisation provides a suitable cell matrix for long term human hepatocyte cultures in hybrid reactors. Int J Artif Organs, 1994. 17(2): p. 95-106.

18. Tong, W., et al., ArrayTrack--supporting toxicogenomic research at the U.S. Food and Drug Administration National Center for Toxicological Research. Environ Health Perspect, 2003. 111(15): p. 1819-26.

19. Irizarry, R.A., et al., Exploration, normalization, and summaries of high density oligonucleotide array probe level data. Biostatistics, 2003. 4(2): p. 249-64.

20. Shi, L., et al., The MicroArray Quality Control (MAQC) project shows inter- and intraplatform reproducibility of gene expression measurements. Nat Biotechnol, 2006. 24(9): p. 1151-61.

21. Boorsma, A., et al., T-profiler: scoring the activity of predefined groups of genes using gene expression data. Nucleic Acids Res, 2005. 33(Web Server issue): p. W592-5.

22. Lahoz, A., et al., Strategies to in vitro assessment of major human CYP enzyme activities by using liquid chromatography tandem mass spectrometry. Curr Drug Metab, 2008. 9(1): p. 12-9. 
23. Lahoz, A., et al., Determination of major human cytochrome P450s activities in 96-well plates using liquid chromatography tandem mass spectrometry. Toxicol In Vitro, 2007. 21(7): p. 1247-52.

24. Pillar, T.M. and H.J. Seitz, Oxidative stress response induced in rat primary hepatocyte monolayers by mechanical removal of adherent cells. Cell Tissue Res, 1999. 295(2): p. 363-7.

25. Klaunig, J.E., et al., Mouse liver cell culture. I. Hepatocyte isolation. In Vitro, 1981. 17(10): p. 913-25.

26. Klaunig, J.E., et al., Mouse liver cell culture. II. Primary culture. In Vitro, 1981. 17(10): p. 926-34.

27. Lu, P., et al., Microarray analysis of gene expression of mouse hepatocytes of different ploidy. Mamm Genome, 2007. 18(9): p. 617-26.

28. Berry, M.N. and F.O. Simpson, Fine structure of cells isolated from adult mouse liver. cell biol, 1962. 15: p. 9-17.

29. Ikeda, T., et al., Change with donor age in the degradation rate of endogenous proteins of mouse hepatocytes in primary culture. Arch Gerontol Geriatr, 1992. 15(2): p. 181-8.

30. Waring, J.F., et al., Isolated human hepatocytes in culture display markedly different gene expression patterns depending on attachment status. Toxicol In Vitro, 2003. 17(5-6): p. 693-701.

31. Schuetz, E.G., et al., Regulation of gene expression in adult rat hepatocytes cultured on a basement membrane matrix. J Cell Physiol, 1988. 134(3): p. 309-23.

32. Ben-Ze'ev, A., et al., Cell-cell and cell-matrix interactions differentially regulate the expression of hepatic and cytoskeletal genes in primary cultures of rat hepatocytes. Proc Natl Acad Sci U S A, 1988. 85(7): p. 2161-5.

33. Liu, J.K., C.M. DiPersio, and K.S. Zaret, Extracellular signals that regulate liver transcription factors during hepatic differentiation in vitro. Mol Cell Biol, 1991. 11(2): p. 773-84.

34. Cervenkova, K., et al., Cell suspensions, cell cultures, and tissue slices--important metabolic in vitro systems. Biomed Pap Med Fac Univ Palacky Olomouc Czech Repub, 2001. 145(2): p. 57-60.

35. Tamaki, H., et al., Activation of CYP1A1 gene expression during primary culture of mouse hepatocytes. Toxicology, 2005. 216(2-3): p. 224-31.

36. Richert, L., et al., Gene expression in human hepatocytes in suspension after isolation is similar to the liver of origin, is not affected by hepatocyte cold storage and cryopreservation, but is strongly changed after hepatocyte plating. Drug Metab Dispos, 2006. 34(5): p. 870-9.

37. Nelson, D.R., et al., Comparison of cytochrome P450 (CYP) genes from the mouse and human genomes, including nomenclature recommendations for genes, pseudogenes and alternative-splice variants. Pharmacogenetics, 2004. 14(1): p. 1-18.

38. George, J., et al., Time-dependent expression of cytochrome P450 genes in primary cultures of welldifferentiated human hepatocytes. J Lab Clin Med, 1997. 129(6): p. 638-48.

39. Rogiers, V. and A. Vercruysse, Rat hepatocyte cultures and co-cultures in biotransformation studies of xenobiotics. Toxicology, 1993. 82(1-3): p. 193-208.

40. Kern, A., et al., Drug metabolism in hepatocyte sandwich cultures of rats and humans. Biochem Pharmacol, 1997. 54(7): p. 761-72.

41. Lopez-Garcia, M.P., Endogenous nitric oxide is responsible for the early loss of P450 in cultured rat hepatocytes. FEBS Lett, 1998. 438(3): p. 145-9.

42. Lopez-Garcia, M.P. and S.M. Sanz-Gonzalez, Peroxynitrite generated from constitutive nitric oxide synthase mediates the early biochemical injury in short-term cultured hepatocytes. FEBS Lett, 2000. 466(1): p. 187-91. 



\section{Chapter 4}

\section{The Relevance of Primary Mouse Hepatocytes for Toxicity Profiling: Responses by Benzo(a)Pyrene}

Karen Mathijs

Danyel G.J. Jennen

Andre Boorsma

Marcel H.M. van Herwijnen

Ralph W.H. Gottschalk

Harry van Steeg

Timo M. Breit

Miriam Luijten

Jos C.S. Kleinjans

Joost H.M. van Delft 


\title{
Chapter 4
}

\begin{abstract}
The availability of transgenic models has advanced mice as useful experimental models for assessing chemical safety. Consequently, mouse in vitro models are also gaining interest in the field of toxicology. Here, we aim to further determine the relevance of the sandwich-cultured primary mouse hepatocyte model for assessing genotoxic and carcinogenic properties of chemicals by investigating time- and dose-dependent effects on gene expression profiles caused by benzo(a)pyrene (BaP). Furthermore, the data were compared with transcriptomic responses in liver from mice exposed to $\mathrm{BaP}$.

Primary mouse hepatocytes from male C57BL/6 mice were treated for 12, 24, 36 or $48 \mathrm{~h}$ with various non-toxic concentrations of $\mathrm{BaP}(0,10$, or $30 \mu \mathrm{M})$. As phenotypic markers for genotoxic effects, immunostaining of $\gamma \mathrm{H} 2 \mathrm{AX}$ foci was used to detect double-strand DNA (dsDNA) breaks and ${ }^{32} \mathrm{P}$-postlabeling was applied for analyzing the presence of BaP-DNA adducts. Whole genome gene expression modifications were analyzed by means of Affymetrix mouse genome 4302.0 microarrays. Datasets were normalized using RMA and analyzed using SAM, MetaCore and T-profiler.

Levels of both DNA adducts and dsDNA breaks increased time- and dose-dependently. Furthermore, the number of significantly modulated gene expressions and pathways increased with time and dose. Genes and pathways significantly altered after exposure to BaP, appear mainly involved in biotransformation, metabolism, response to DNA and cell damage, cell survival, and tumor development and progression.

The results from this study indicate that primary mouse hepatocytes are able to generate expected transcriptomic effects of $\mathrm{BaP}$ in a time- and dose-dependent manner. In vitro in vivo comparison revealed some overlapping transcriptomic responses to $\mathrm{BaP}$, which are of interest, and suggest that primary mouse hepatocytes might represent a relevant in vitro model for toxicogenomics studies.
\end{abstract}




\section{Introduction}

Since mouse models are used frequently in toxicological studies, interest is raised in the relevance of in vitro mouse models, such as for liver. Where rodent bioassays have been accepted for the assessment of chemical toxicity, mice in particular have advantages because of the availability of transgenic models (1).

Because the liver is an important organ for the metabolism and biotransformation of many toxic compounds and consequently represents a target organ for toxicity, hepatic models are widely used as an in vitro alternative in pharmacological, toxicological and metabolic studies $(2,3)$. Well-established hepatic in vitro systems comprise hepatic cell lines, primary hepatocyte cultures and precision-cut liver slices from various species (2, $3,4)$. The use of primary human hepatocytes is considered as the "gold standard" but this is hampered by a limited availability of donor material (4). Therefore, primary mouse hepatocytes may be considered as an alternative. Sandwich-cultured hepatocytes are in favor compared to other hepatocyte-based in vitro models, because the longevity and differentiated functions of hepatocytes in primary cultures are maintained and this configuration has been shown to maintain in vivo characteristics, like cellular polarity and the distribution of actin filaments, for several weeks $(5,6,7,8)$. Furthermore, the primary mouse hepatocyte system has been proven to be robust and appears to maintain its metabolic competence better as compared to rat hepatocytes (8).

Here, we aim to investigate time- and dose-dependent effects caused by benzo(a)pyrene $(\mathrm{BaP})$, a well known carcinogen, in primary mouse hepatocytes and to determine the relevance of this hepatocyte model by comparing these results with data obtained from the liver of BaP-exposed C57BL/6 mice. The C57BL/6 mouse is a well-established mouse strain routinely used in toxicology, pharmacology and biomedical sciences.

Benzo[a]pyrene (BaP), a well-known carcinogen belonging to the class of polycyclic aromatic hydrocarbons (PAHs) with both genotoxic and non-genotoxic properties, was used in this study as the model compound. BaP binds to the Arylhydrocarbon receptor, and this complex thereupon translocates to the nucleus and induces the expression of several genes (9). An important group of these genes is represented by genes coding for Cytochrome P450 enzymes (e.g. Cyp1A1 and Cyp1A2) which are responsible for metabolizing $\mathrm{BaP}$ into its genotoxic dihydrodiol epoxide derivates (e.g. benzo[a]pyrene7,8-diol-9,10-epoxide). These intermediates can covalently bind to DNA, RNA or proteins. $(10,11)$ When these DNA adducts are not properly removed or repaired, mutations can occur during cell division and cancer development can be induced (12).

In order to protect cells from the deleterious effects of DNA damage, cells can repair the damaged DNA by a many different mechanisms, like nucleotide excision repair and base excision repair $(13,14)$. In order to allow more time for repair, cell proliferation can be blocked at several phases of the cell cycle, such as at G1-S transition, S-phase 
and G2-M transition or apoptosis can be induced, especially at high DNA damage levels (15).

For the purpose of further determining the relevance of the in vitro primary mouse hepatocyte sandwich-cultured system, we investigated such dose- and time- effects of BaP by analyzing whole genome gene expression modification, and by associating these with analysis of DNA adduct formation and $\gamma \mathrm{H} 2 \mathrm{AX}$ foci formation as relevant phenotypic parameters (16).

\section{Materials and Methods}

\section{Chemicals}

Dulbecco's modified Eagle's medium (DMEM), fetal calf serum (FCS), Hanks' calcium- and magnesium-free buffer, Alexa fluor 488 goat anti-mouse IgG antibody, insulin and Trizol were obtained from Invitrogen (Breda, The Netherlands). Glucagon, hydrocortisone, collagenase type IV, BaP, Trypan blue, dimethylsulphoxide (DMSO), bovine serum albumin (BSA), 4',6-diamidino-2-phenylindole (DAPI) and Tween-20 were purchased from Sigma-Aldrich (Zwijndrecht, The Netherlands). Triton X-100, $\mathrm{NaCl}, \mathrm{Na}_{2} \mathrm{HPO}_{4} \cdot 2 \mathrm{H}_{2} \mathrm{O}$ and $\mathrm{NaH}_{2} \mathrm{PO}_{4}$ were obtained from Merck (Darmstadt, Germany) and paraformaldehyde from ICN biomedicals (Auroro, Ohio). The anti-phosphoHistone H2A-X (ser139) Clone JBW 301 antibody was purchased by Upstate Biotechnology (Lake Placid, NY). Vectashield ${ }^{\circledR}$ Mounting Medium was supplied by Vector Labs (Burlingame, CA). Collagen Type I Rat Tail was obtained from BD BioSciences (Bedford, MA). The iScript cDNA Synthesis kit en iQ SYBR Green Supermix were purchased from BioRad (Hercules, CA). Primers were designed using Primer Express 2.0 from Applied Biosystems (Foster City, CA) and purchased from Operon (Cologne, Germany). The RNeasy minikit was obtained from Qiagen, Westburg B.V. (Leusden, The Netherlands). The 5x MegaScript T7 Kit was obtained from Ambion (Austin, TX). The GeneChip ${ }^{\circledR}$ Expression 3'-Amplification Two-Cycle cDNA Synthesis Kit and Reagents, the Hybridization, Wash and Stain Kit and the Mouse Genome 4302.0 Arrays were purchased from Affymetrix (Santa Clara, CA).

\section{Animals}

Permission for animal studies was obtained from the Animal Ethical Committee. For the in vivo study all mice were housed specific pathogen-free (SPF) in a climate-controlled room. For the in vitro study adult male C57BL/6 mice (Charles River), weighing 20-25 $\mathrm{g}$, were obtained from Charles River $\mathrm{GmbH}$, Sulzfeld, Germany. The animals were housed in macrolon cages with sawdust bedding at $22^{\circ} \mathrm{C}$ and $50-60 \%$ humidity. In both studies the light cycle was $12 \mathrm{~h}$ light/12 h dark. Feed and tap water were available $a d$ libitum. 
In vivo treatment

Eight week old male C57BL/6 mice were treated by gavage with $13 \mathrm{mg} / \mathrm{kg}$ body weight $\mathrm{BaP}$ dissolved in sunflower oil. This dose was chosen to compare results with those from previously conducted in vivo studies on carcinogenicity in wild type and $\mathrm{p} 53^{+/-}$ $\mathrm{Xpa}^{-/-}$mice (17). During 7 days four animals were treated 4 times (at start of the experiment, day 2 , day 4 , day 6 . with $\mathrm{BaP}$ or solvent. The animals were sacrificed at day 7. At autopsy, the liver was isolated from each animal and RNA was freshly isolated.

\section{Primary hepatocyte culture and treatment}

Hepatocytes were isolated from adult male C57BL/6 mice by a two-step collagenase perfusion method as described before (8). Cells were cultured in a collagen-sandwich configuration as described before (8). Prior to treatment, primary cultures of mouse hepatocytes were allowed to recover for $40-42 \mathrm{~h}$ at $37^{\circ} \mathrm{C}$ in a humidified chamber with $95 \% / 5 \%$ air $/ \mathrm{CO}_{2}$ in serum-free culture medium supplemented with insulin $0.5 \mathrm{U} / \mathrm{ml}$ ), glucagon $(7 \mathrm{ng} / \mathrm{ml})$, hydrocortisone $(7.5 \mu \mathrm{g} / \mathrm{ml})$ and $2 \%$ penicillin/streptomycin. Culture medium was refreshed every $24 \mathrm{~h}$. After the recovery period, the culture medium was replaced by culture medium containing 10 or $30 \mu \mathrm{M} \mathrm{B}(\mathrm{a}) \mathrm{P}$; the highest dose is based on a cytotoxicity assay with $80 \%$ viability (MTT test, data not shown), or $0.5 \%$ DMSO as a vehicle control. Cells were incubated with $10 \mu \mathrm{M}$ BaP for 24 or $48 \mathrm{~h}$ and with $30 \mu \mathrm{M}$ BaP for $6,12,24,36$ or $48 \mathrm{~h}$ before being used for detecting double-stranded (ds) DNA breaks or harvested for RNA and DNA isolation by adding Trizol reagent. Three independent experiments were conducted using cells from different mice.

\section{Detection of dsDNA breaks. Detection of $d s D N A$ breaks}

Double-stranded DNA breaks were detected by immunostaining of the phosphorylated histone $\mathrm{H} 2 \mathrm{AX}(\gamma \mathrm{H} 2 \mathrm{AX})$ as described before (18). Hepatocytes, used for the detection of dsDNA breaks, were cultured in a sandwich configuration on top of a cover slip. After desired exposure times, medium was aspirated and the cells were rinsed with 1x Phosphate-buffered saline (PBS) before fixation in 4\% Paraformaldehyde for $10 \mathrm{~min}$ at ambient temperature. The cells were washed again with $1 \mathrm{xPBS}$ and made permeable with $0.2 \%$ Triton $\mathrm{X}-100$ at $4^{\circ} \mathrm{C}$ for $5 \mathrm{~min}$. Thereafter cells were washed two times with 1xPBS for $5 \mathrm{~min}$ and blocked during $1 \mathrm{~h}$ at $37^{\circ} \mathrm{C}$ with blocking buffer $(1 \% \mathrm{BSA}+0.5 \%$ Tween-20 in 1X PBS). Samples were washed two times with 1xPBS for $5 \mathrm{~min}$ and incubated with the first antibody (Mouse monoclonal $\gamma \mathrm{H} 2 \mathrm{AX}$ (Ser-139)) 1:1000 in dilution buffer $(0.5 \% \mathrm{BSA}+0.5 \%$ Tween-20 in $1 \mathrm{X} \mathrm{PBS})$ during $2 \mathrm{~h}$ at $37^{\circ} \mathrm{C}$. After two washing steps with 1xPBS cells were incubated with the second antibody (Alexa 488 labelled) 1:1000 in dilution buffer during $1 \mathrm{~h}$ at $37^{\circ} \mathrm{C}$ and washed again two times with 1xPBS. Samples were incubated with DAPI for $15 \mathrm{~min}$ at room temperature, dehydrated in series of ethanol solutions (70, 90 and 100\%) for $3 \mathrm{~min}$ and air-dried. Vectashield ${ }^{\circledR}$ Mounting medium was used to stick the cover slips onto microscopic glass slides. Mi- 
croscopic photographs were taken and samples were scored manually. A damage score, ranging from 0 to 4 , determined by the grade of damage, was given to 100 cells per sample. The damage scores were multiplied by the amount of cells with that score and all together calculated to get a total percentage of damage in each sample. For the statistical analysis the T-Test was used with a significance level of $5 \%$.

DNA isolation and ${ }^{32}$ P-Postlabelling

DNA was isolated from primary mouse hepatocytes using Trizol reagent according to the manufacturer's protocol. DNA adduct levels were determined using the procedure described by Reddy and Randerath, with some modifications $(19,20)$. The DNA adduct levels were quantified by including samples with known BaP-DNA adduct levels. The detection limit was 1 adduct per $10^{8}$ nucleotides. The radio-labeled adducted nucleotide biphosphates were separated by multi-directional thin layer chromatography (TLC). The adduct spots on the chromatograms were quantified using Phosphor-Imaging technology (FLA-3000, Fuji, France) and AIDA/2D densometry software. The average and standard deviation was calculated for all three experiments and for the statistical analysis of time- and dose-dependent effects the one-way ANOVA was used with a significance level of $5 \%$.

\section{RNA isolation}

Total RNA was isolated from the livers from the in vivo study and from cultured mouse hepatocytes using Trizol reagent with the RNeasy kit according to the manufacturer's protocol. RNA concentrations were measured on a spectrophotometer and the quality of each RNA preparation was determined with a bio-analyzer (Agilent Technologies, The Netherlands). Only samples with a good quality (clear $18 \mathrm{~S}$ and $28 \mathrm{~S}$ peaks and RIN $>6$ ) were used for hybridization. Extracted RNA was stored at $-80^{\circ} \mathrm{C}$ until it was used as template for cDNA synthesis.

\section{Whole genome gene expression analysis}

\section{Target preparation and hybridization}

cRNA targets, prepared according to the Affymetrix protocol, were hybridized on highdensity oligonucleotide gene chips (Affymetrix Mouse Genome 4302.0 GeneChip arrays) according to the manufacturer's procedures. The gene chips were washed and stained using an Affymetrix fluidics station and scanned in an Affymetrix GeneArray scanner.

From the in vivo study eight samples were collected (from 4 treated animals and 4 controls) and from the in vitro study thirty samples were collected (from incubations in triplicate with 2 concentrations at 24 and $48 \mathrm{~h}$, and with 1 concentration at 12 and $36 \mathrm{~h}$ as well as from controls at each time point). 
A total of thirty-eight GeneChips was run. Normalization quality controls, including scaling factors, average intensities, present calls, background intensities, noise, and raw $\mathrm{Q}$ values, were within acceptable limits for all chips. Hybridization controls BioB, $\mathrm{BioC}$, BioD, and CreX, were identified on all chips and yielded the expected increases in intensities.

\section{Data analysis}

Thirty-eight datasets were obtained from this experiment. Raw data were imported into ArrayTrack (21) and normalized using Robust Multi-array Average (RMA, integrated into ArrayTrack) (22).

Present-Marginal-Absent calls were used to identify and omit probe sets of poor quality (23). Subsequently, the remaining probe sets (24872 in vitro and 23011 in vivo) were logarithm- (base 2) transformed and corrected for their DMSO vehicle control as described below, and used for statistical analysis. The significance analysis of microarrays (SAM, integrated into ArrayTrack) (24) was used for identifying significant changes in expression levels (paired two class, fold change 1.5) and multiclass SAM was used for identifying dose- or time-dependent differentially expressed probe sets. ArrayTrack was also used for principal component analysis (PCA) and Euclidian (complete) hierarchical clustering.

$\log 2$ of the ratios for treated-control were calculated for the in vitro data set. For the in vivo data set, the average of all controls was used as common control to calculate the $\log 2$ of the ratios for treated-common control. These two data sets were uploaded in Tprofiler (25) for identifying transcriptional up- or down-regulation of biochemical pathways and biological processes, which included genes sets from Gene Ontology (GO), curated gene sets, Motifs and Kyoto Encyclopedia for Genes and Genomes (KEGG) pathways. T-profiler uses the T-test to score the difference between the mean expression level of predefined groups of genes and that of all other genes without any pre-selection of significantly modulated genes (25). Significance was determined by generating an $\mathrm{E}$ value, a Bonferroni corrected $\mathrm{P}$ value. Pathways and processes were significant when $\mathrm{E}$ values were below 0.05 .

Interesting modulated probe sets, were further analyzed for functional annotation by MetaCore using the shortest path algorithm (GeneGo, San Diego, CA). The total list of probe sets as described before (24872 in vitro and 23011 in vivo) and were used as background list. A false discovery rate of 0.4 was used to select significant MetaCore maps.

\section{Correlation analysis}

Expressions of significantly modulated genes (as revealed by SAM), and significantly altered pathways (obtained by T-profiler) from primary mouse hepatocytes, that correlated with DNA adducts or $\gamma \mathrm{H} 2 \mathrm{AX}$ foci formation, were identified by means of the gene expression profile analysis suite (GEPAS 4.0; CIPF, Valencia, Spain). Spearman corre- 


\section{Chapter 4}

lation coefficients were calculated and correlating genes and pathways were selected by $\mathrm{P}<0.05$, a false discovery rate of 0.32 and multiple testing correction (fwer.holm 1 ) and correlating genes were further analyzed for functional annotation by MetaCore as described above. A false discovery rate of 0.4 was used to select significant MetaCore maps.

\section{Results}

\section{In vitro results}

\section{Detection of $d s D N A$ breaks}

The generation of foci of phosphorylated $\gamma \mathrm{H} 2 \mathrm{AX}$ in primary mouse hepatocytes after 24 and $48 \mathrm{~h}$ exposure to 10 and $30 \mu \mathrm{M} \mathrm{BaP}$ is shown in Figure 1. The number of foci showed a significant dose-dependent increase as more foci were formed in BaP-exposed cells compared to DMSO controls at all doses at both time points.

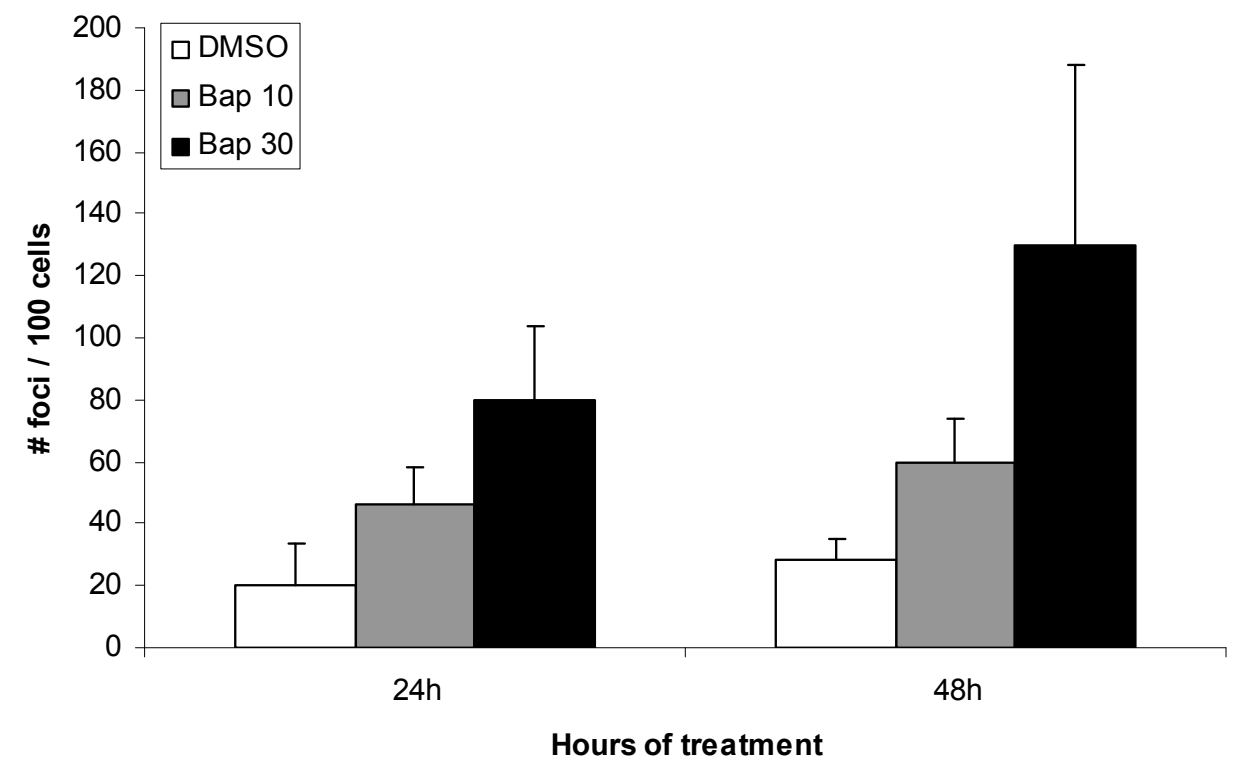

Figure $1 \quad$ Levels of dsDNA breaks ( $\gamma H 2 A X$ foci) in primary mouse hepatocytes exposed BaP or solvent after 24 or 48 h (average with $S D$ of 3 experiments)

* Significant (ANOVA, p-value < 0.05) compared to solvent controls. 


\section{BaP-DNA adduct formation}

The formation of DNA adducts in primary mouse hepatocytes treated with 10 and 30 $\mu \mathrm{M} \mathrm{BaP}$ was investigated by ${ }^{32} \mathrm{P}$-Postlabelling. At both incubation concentrations, mainly one adduct spot was observed, coinciding with the reactive metabolite antibenzo(a)pyrene-trans-7,8-dihydrodiol-9,10-epoxide (BPDE) bound to the $N^{2}$ position of guanine. As shown in Figure 2, BaP exposure resulted in significant time- and concentration-dependent increase in DNA adduct formation. Only at $6 \mathrm{~h}$ of exposure, no significant dose-dependency was detected.

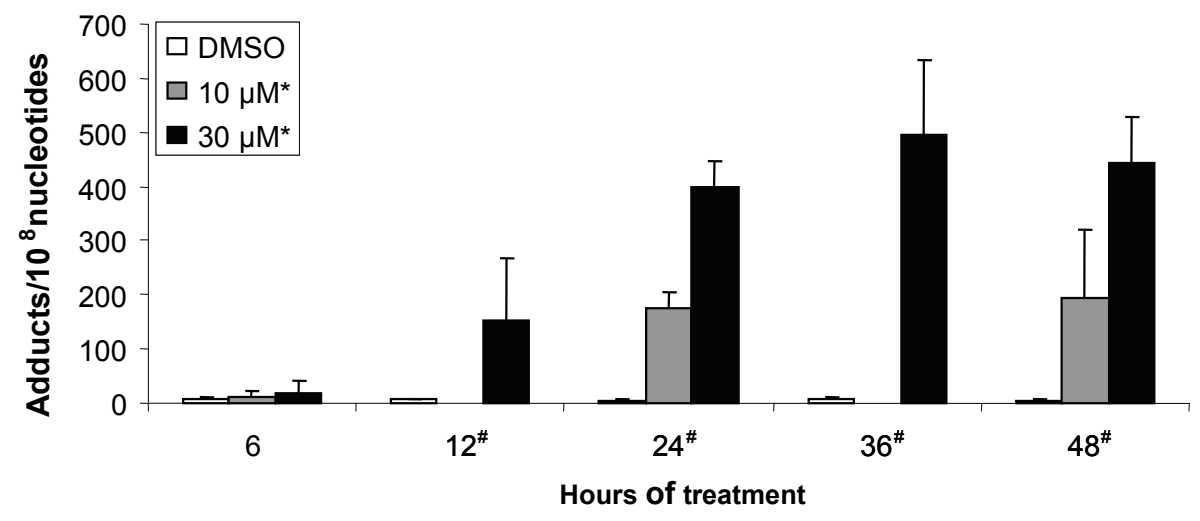

Figure 2 DNA adduct levels in primary mouse hepatocytes exposed to BaP for several periodsas measured by ${ }^{32} P$-postlabelling. The mean number of DNA adducts per $10^{8}$ nucleotides with $S D$ (3 experiments) is shown.

* Significant influence of time (ANOVA, p-value <0.05)

${ }^{*}$ Significant influence of dose (ANOVA, p-value $\left.<0.05\right)$

Gene expression analysis

Gene expression data were generated for 30 samples. Gene expression data from one of the $12 \mathrm{~h} 30 \mu \mathrm{M}$ treatments could not be discriminated from the DMSO treated samples; therefore, these results were not used for further analyses. Analysis of the data by SAM resulted in a list of differentially expressed probe sets at each time point. We found 5 altered genes after $12 \mathrm{~h}$ of exposure to $30 \mu \mathrm{M}$ BaP, 11 and 627 genes after $24 \mathrm{~h}$ of exposure to 10 and $30 \mu \mathrm{M} \mathrm{BaP}$ respectively. 10 out of 11 probe sets, differentially expressed after $24 \mathrm{~h}$ of exposure to $10 \mu \mathrm{M}$ were common with those from exposure to $30 \mu \mathrm{M}$. After $36 \mathrm{~h}$ of exposure to $30 \mu \mathrm{M}$ BaP 337 probe sets were differentially expressed. After $48 \mathrm{~h}$ of exposure to $30 \mu \mathrm{M} \mathrm{BaP} 693$ were found to be differentially expressed and 92 out of 118 probes sets which were differentially expressed after $48 \mathrm{~h}$ of exposure to $10 \mu \mathrm{M}$ were common to those from treatment with $30 \mu \mathrm{M}$ BaP. Multiclass SAM re- 


\section{Chapter 4}

sulted in 127 time-dependent probe sets, and 16 and 68 dose-dependent probe sets for respectively 24 and $48 \mathrm{~h}$. Combining all these differentially expressed probe sets at all time points resulted in a list of 1231 differentially expressed probe sets.

\section{Principal component analysis of differentially expressed genes}

To visualize time- and dose-dependent effects of $\mathrm{BaP}$ on gene expression, PCA was performed, thereby using the expression values of all 1231 differentially expressed probe sets (Figure 3a). The treated and control hepatocytes were discriminated by principal component (PC) \#2, containing a variance of $28.872 \%$. PC \#1, which contains most of the variance $(33.485 \%)$, discriminates the different time points. A minor discrimination between samples exposed to 10 or $30 \mu \mathrm{M}$ was observed. The log2 expression ratios for the differentially expressed probe sets were also analyzed by PCA (Figure $3 \mathrm{~b}$ ). Early time points, 12 and $24 \mathrm{~h}$ were discriminated from the late time points, 36 and $48 \mathrm{~h}$ by PC\#1 (37.128\%). PC\#2 (22.604\%) discriminated dose groups, with the exception of $12 \mathrm{~h}$ treatments, which were grouped together with $10 \mu \mathrm{M}$ treatments of $24 \mathrm{~h}$.

\section{Pathway analysis}

T-profiler was used for identifying BaP-induced biochemical pathways and biological processes. Pathways and processes significantly altered in hepatocytes from at least two experiments and altered in the same direction in all replicates, were considered significant and selected for each time period. 7 pathways were significantly changed after $12 \mathrm{~h}$ exposure to $30 \mu \mathrm{M} \mathrm{BaP}$, which were all overlapping with those from $24 \mathrm{~h}$ exposure to $30 \mu \mathrm{M}$ BaP. After $24 \mathrm{~h}$ treatment with $30 \mu \mathrm{M}$ BaP 98 pathways and processes appeared significantly altered. Four out of the five significantly altered pathways by $24 \mathrm{~h}$ treatment with $10 \mu \mathrm{M} \mathrm{BaP}$ were also responding at $30 \mu \mathrm{M} \mathrm{BaP}$. Exposure for $36 \mathrm{~h}$ with 30 $\mu \mathrm{M}$ BaP resulted in 60 significantly altered pathways and processes. After $48 \mathrm{~h}, 95$ and 115 pathways were significantly changed after treatment with 10 and $30 \mu \mathrm{M}$, respectively. Only 36 of these were common between both dose groups. Comparison of the treatments with $30 \mu \mathrm{M} \mathrm{BaP}$ for all time points is presented in Figure 4. This resulted in one common pathway. Both pathways significantly changed after 24 and $48 \mathrm{~h}$ exposure to $\mathrm{BaP}$ appeared to have the most time point unique pathways, and greatest overlap is observed between 36 and $48 \mathrm{~h}$ of exposure. 
A

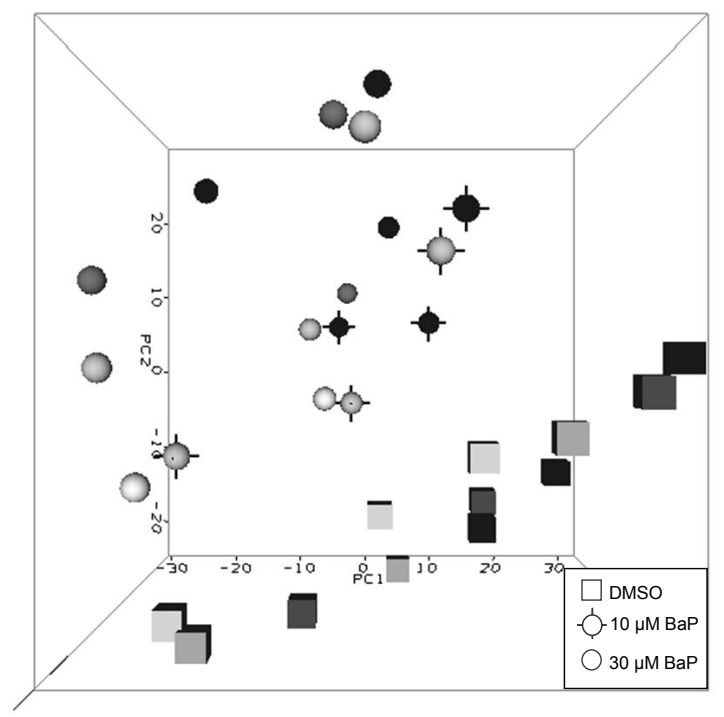

B

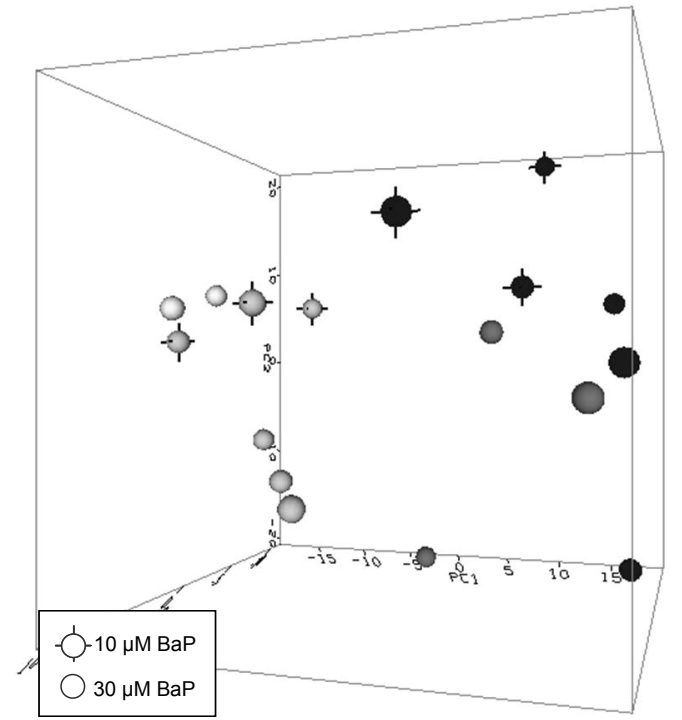

Figure 3 Principal component analysis of in vitro experiments (all 30 chips) using (A) the expression values of the differentially expressed probe and $(B)$ the $\log 2$ values of the expression ratios for the differentially expressed probe sets after exposure to BaP. The gray-scale of the symbols increases with exposure time 


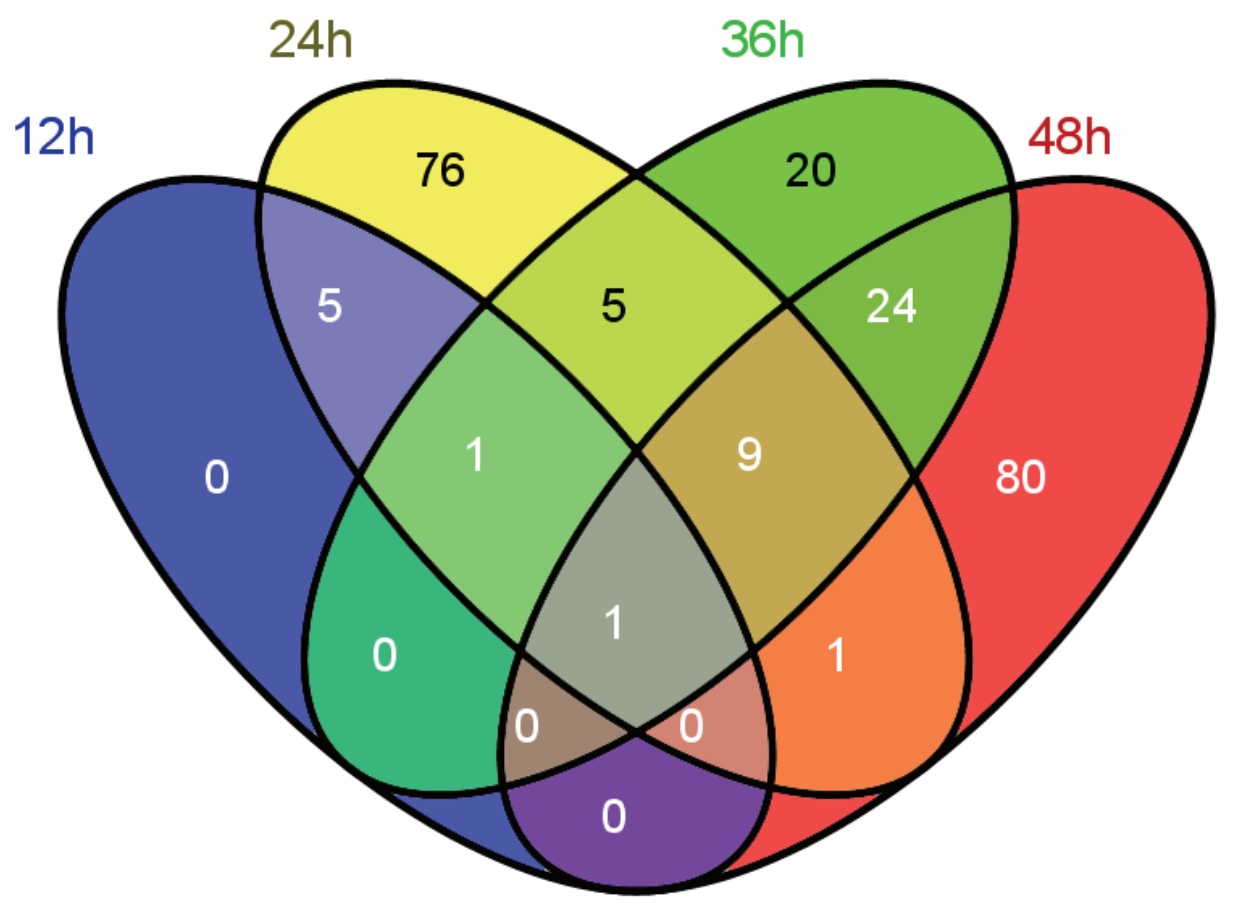

Figure $4 \quad$ Venn diagram representing the number of significantly modulated biochemical pathways and biological processes after treatment of primary mouse hepatocytes with $30 \mu \mathrm{M} \mathrm{BaP}$.

Hierarchical clustering was used to generate more comprehensible groups of these pathways (Figure 5). Pathways generated at early time points during $\mathrm{BaP}$ exposure seem to cluster separately from those at late time points, showing a certain time-dependent respons. Gene sets involved in metabolism, catabolism and membrane- and extracellular related processes and immune responses were downregulated at the early time points and upregulated at the later time points. Gene sets involved in biotransformation and metabolism are mainly continuously upregulated as treatment with $\mathrm{BaP}$ elongated. Tumor development and progression, cell damage and nucleus and nucleic acid related process were mainly upregulated during the first $24 \mathrm{~h}$ of treatment, but were downregulated at later time points. 


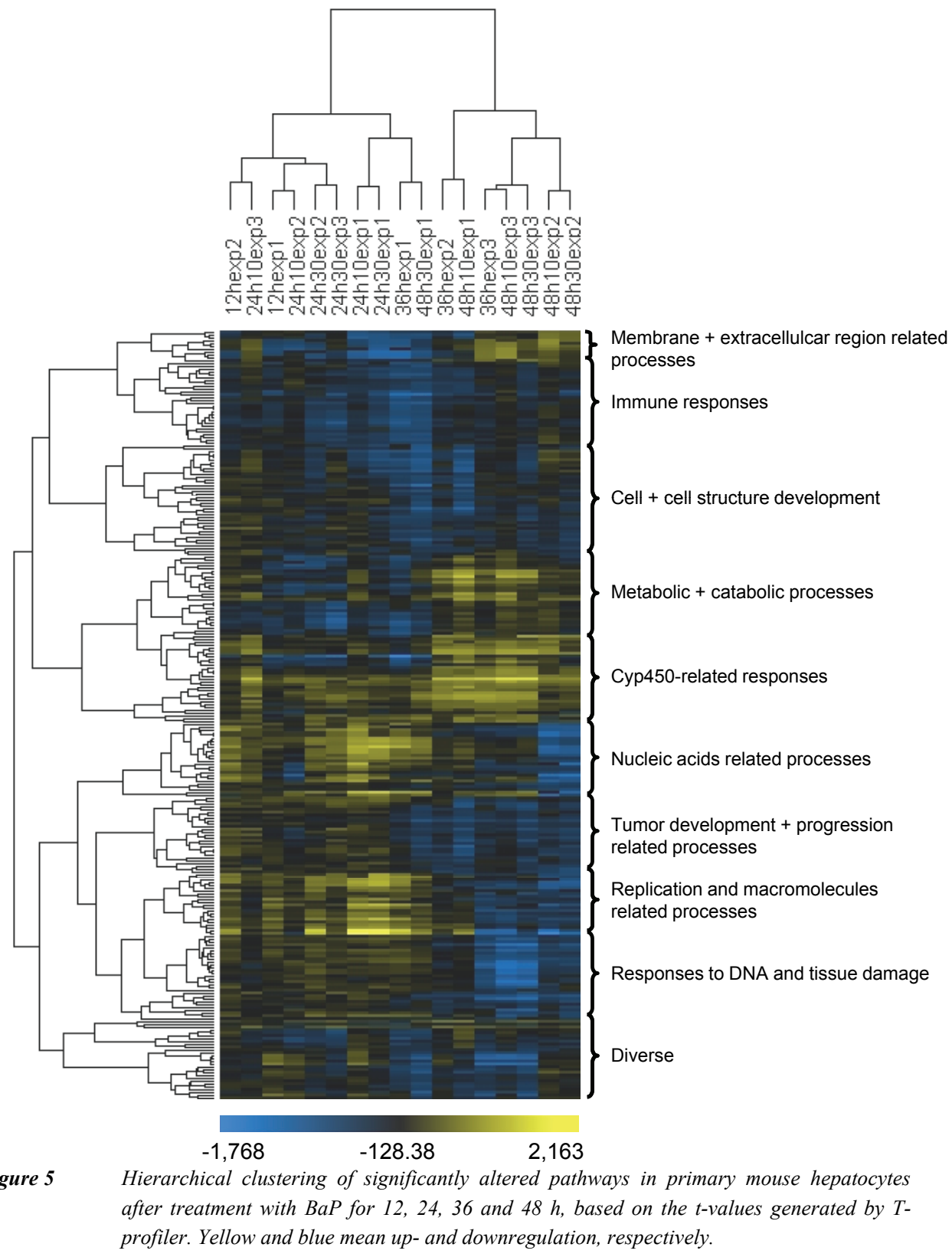




\section{Chapter 4}

\section{Correlation analysis}

In order to link gene expression changes with phenotypic effects, DNA adduct and $\gamma \mathrm{H} 2 \mathrm{AX}$ foci levels, following $\mathrm{BaP}$ exposure, we performed Spearman's correlation analyses. DNA adducts formed at all time points of exposure and all incubation concentrations were correlated with the gene expression changes of all significantly modulated probe sets (1231 probe sets). This resulted in 489 correlating probe sets at $\mathrm{P}<0.05$. Correlation analyses of the $\gamma \mathrm{H} 2 \mathrm{AX}$ foci formation at 24 and $48 \mathrm{~h}$ of $\mathrm{BaP}$ treatment for all concentrations with the gene expression changes, resulted in 189 correlating probe sets with $\mathrm{P}<0.05$. Of these, 140 probe sets were in common with that for the associations with DNA adduct levels.

These two lists of correlating probe sets were analyzed for enrichment in biological processes or pathways using MetaCore. This demonstrated that these genes are mainly involved in several metabolism processes, cell adhesion and organisation, cell signaling, responses to several stimuli, immune responses and apoptosis. 


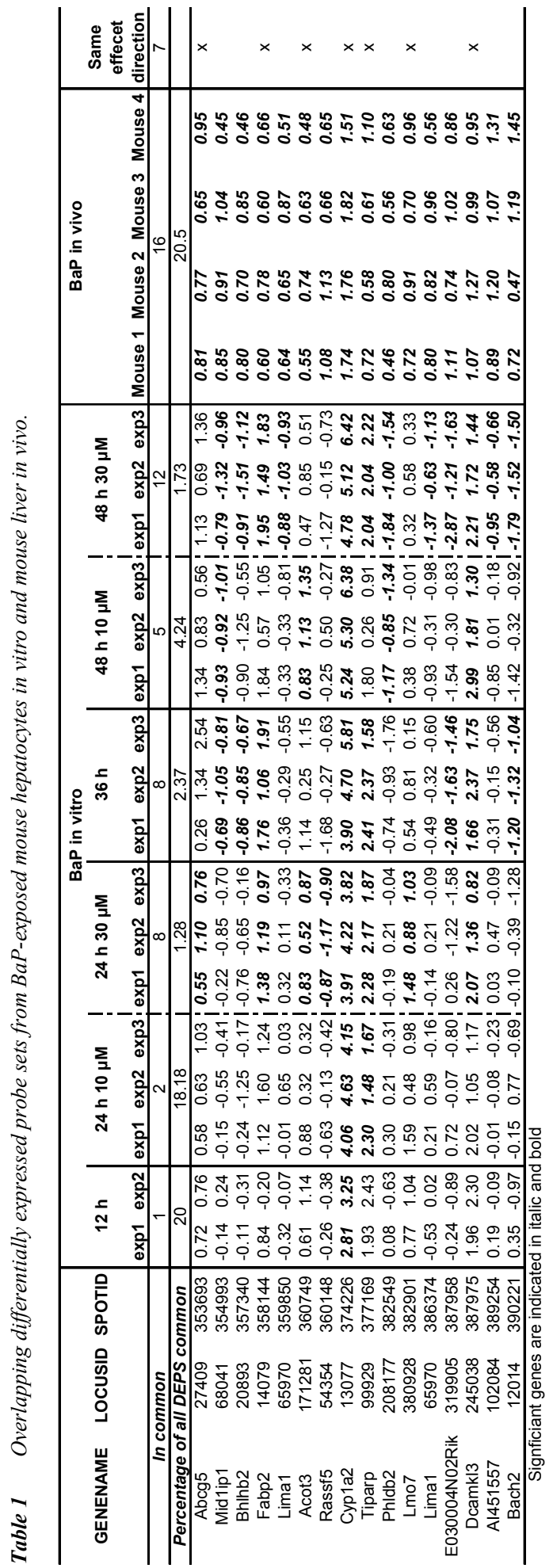




\section{In vivo results}

Gene expression analysis

Gene expression data were generated for liver samples from 8 animals. Analysis of the data by SAM resulted in a list of 78 differentially expressed probe sets.

Pathway analysis

T-profiler was again used for identifying BaP-induced alterations in biochemical pathways and biological processes. Pathways and processes significantly altered in at least two animals and in the same direction in all four replicates, were selected for each time period. Only 8 pathways were found to be significantly changed, mainly involved in liver injury and immune responses.

\section{Mouse in vivo-in vitro comparison}

Transcriptomics and T-profiler data from BaP-exposed primary mouse hepatocytes and from the livers of BaP-exposed mice in vivo were compared, both at the level of modulated genes and that of altered biochemical pathways and biological processes. Differentially expressed probe sets from BaP-exposed mouse hepatocytes in vitro (1231 probe sets) and mouse liver in vivo (78 probe sets) show an overlap of 16 probe sets (Table 1), only 7 probe sets had their effects in the same direction. Also probe sets from BaPexposed mouse hepatocytes in vitro generated by multiclass SAM (127 time-dependent probe sets, and 16 and 68 dose-dependent probe sets for respectively 24 and $48 \mathrm{~h}$ ) were compared with those from mouse liver in vivo and showed an overlap of only one probe set (Cyp1a2), with the same effect direction.

To compare the effects of $\mathrm{BaP}$ on biochemical pathways and biological processes, the T-profiler data were used. The selected gene groups from the hepatocytes ( 272 gene groups) were compared with those from the in vivo study (8 gene groups). Only 1 gene group appeared commonly expressed between $\mathrm{BaP}$-exposed hepatocytes and the in vivo study (ICHIBA_GVHD). It was, however, down-regulated in vitro system and upregulated in vivo.

Commonly shared probe sets between the two models were further analyzed for enrichment in biological processes or pathways by MetaCore. These probe sets appeared to have a predominant role in several metabolism processes, chemotaxis, chemokine related pathways, cell adhesion, immune responses and transport. 


\section{Discussion}

As mouse in vitro models are gaining interest in the field of toxicology, it was the aim to further determine the relevance of the sandwich-cultured primary mouse hepatocyte model for assessing genotoxic and carcinogenic properties of chemicals by investigating time- and dose-dependent effects on whole genome gene expression caused by benzo(a)pyrene (BaP), a well known carcinogen, and comparing obtained results in vitro with liver responses generated in mice exposed to $\mathrm{BaP}$ in vivo. Primary mouse hepatocytes were treated with two doses and analyzed at multiple time points, to identify time- and dose-dependent effects on gene expression profiling. Furthermore effects of $\mathrm{BaP}$ on primary hepatocytes were also investigated at the phenotypic level by measuring $\gamma \mathrm{H} 2 \mathrm{AX}$ foci formation and DNA adduct formation. In order to determine the relevance of the primary mouse hepatocytes, gene expression profiles were compared with those from an in vivo study.

Gene expression analysis reveals clear time- and dose-dependent effects induced by exposure to $\mathrm{BaP}$ in vitro, as visualized in the PCA plot (Fig. 2) and by the increasing number of significantly modulated genes. Time-dependent effects of $\mathrm{BaP}$ seem to have more influence on gene expression profiles compared to dose. That time- and dose have an effect on the whole genome gene expression was observed before in vitro, where time-dependent waves of gene expression changes were observed (26, 27, 28, Chapter 2). As $\mathrm{BaP}$ is known to cause cell cycle arrest in proliferating cells in order to allow for damaged DNA to be repaired, it is not surprising that effects of $\mathrm{BaP}$ differ between proliferating cells such as HepG2 cells, and non proliferating-cells like primary mouse hepatocytes $(15,26,27,28$, Chapter 2). Indeed, in primary mouse hepatocytes, hardly any cell cycle-related genes were found to be significantly altered after treatment with $\mathrm{BaP}$, but DNA damage and metabolism related genes, however, were found to be significantly altered.

In order to unravel time and dose-related effects on pathways and biological processes, T-profiler was used. Clustering of these pathways reveals that two main clusters are formed, namely early and late time points (Figure 4). Dose seems to have minor influence on clustering. T-profiler results shows that some gene groups are progressively upregulated during exposure to $\mathrm{BaP}$. These pathways are mainly involved in biotransformation and glutathione metabolism. Most likely this is due to the activation of the Aryl hydrocarbon receptor by these compound $(29,30)$. However, many gene groups are upregulated during the first $24 \mathrm{~h}$ and downregulated later on: namely tumor development and progression, responses to DNA and tissue damage and nucleus and nucleic acid and replication related process. Also many gene groups are downregulated during the first $24 \mathrm{~h}$ and upregulated later on: metabolism, catabolism and membrane- and extracellular related processes and immune responses. Responses to DNA damages and tumor development related pathways are expected to be up-regulated after treatment 
with a GTX carcinogen. They are subsequently down-regulated at later time points, indicating that $\mathrm{BaP}$ levels in the culture medium are declining and therefore the level of DNA damage is stable at later time points during incubation.

The number of $\mathrm{BaP}$-induced biochemical pathways and biological processes, considered significantly altered in vitro, increases in a time- and dose-dependent manner. At $24 \mathrm{~h}$ of $\mathrm{BaP}$ treatment four out of five pathways found after exposure to $10 \mu \mathrm{M} \mathrm{BaP}$ were also significantly altered after exposure to $30 \mu \mathrm{M}$. At $48 \mathrm{~h}$ of exposure 36 out of 95 pathways which were significantly altered after exposure to $10 \mu \mathrm{M} \mathrm{BaP}$ were also altered at $30 \mu \mathrm{M}$, thus indicating that dose-dependent effects are larger at that time point. A possible explanation for this larger dose-dependent effect at later time point is that due to metabolism, BaP levels in culture medium decrease over time, which obviously has a larger effect for the lower dose. From these results, it is difficult to decide which time point is optimal for investigating effects of compounds on transcriptomic profiles in the primary mouse hepatocyte model.

Histone H2AX is phosphorylated on Ser-139 by ATM kinase in response to damage that induces dsDNA breaks (31). Immunocytochemical detection of phosphorylated $\mathrm{H} 2 \mathrm{AX}$ foci $(\gamma \mathrm{H} 2 \mathrm{AX})$ thus reveals the presence of dsDNA breaks in chromatin and was developed by us to study the introduction of dsDNA breaks in carcinogen-treated primary mouse hepatocytes. BaP shows a time- and dose-dependent induction of DNA damage. These time- and dose-dependent effects of $\mathrm{BaP}$ on $\gamma \mathrm{H} 2 \mathrm{AX}$ were observed before in Human amnion FL and HepG2 cells (32, Chapter 2). In the Human amnion FL cells a time- and dose-dependent induction of $\gamma \mathrm{H} 2 \mathrm{AX}$ foci was observed (32). Also in the HepG2 cells a time-dependent effect on the formation of $\gamma \mathrm{H} 2 \mathrm{AX}$ foci was found, however the amount of foci increased during the first $24 \mathrm{~h}$ of exposure, but decreased again after $24 \mathrm{~h}$ due to repair of the DNA damages (Chapter 2). It is unknown whether $\mathrm{BaP}$ induces dsDNA breaks directly. The formation of dsDNA breaks can be a result of repair processes, and replication of damaged DNA in S-phase cells (32). However, in our study, the latter is less likely as primary hepatocytes are hardly dividing (33).

Formation of BaP-DNA adducts was analyzed to investigate the capability of primary mouse hepatocytes to metabolize $\mathrm{BaP}$ to its DNA reactive metabolites, which is the critical step in the initiation of chemical carcinogenesis (34). The adduct levels increased dependent on exposure time and dose, which demonstrates that these primary mouse hepatocytes are capable of metabolizing BaP to its DNA binding reactive metabolites. These results are in line with the study of Kim et al (35) for rat, where they showed the same time effect of DNA adduct formation in primary hepatocytes during $48 \mathrm{~h}$ of treatment with $\mathrm{BaP}$. Also in HepG2 cells, BaP introduced DNA adducts in a time-dependent manner (Chapter 2). Adduct levels in these HepG2 cells increased during the first $12 \mathrm{~h}$, were stable until 18-30 h, where after they slowly declined again. This was also observed in the primary hepatocytes, were adduct levels were only increasing during the first $24 \mathrm{~h}$ and stable until $48 \mathrm{~h}$. 
Upon correlating these BaP-induced DNA adduct levels and $\gamma \mathrm{H} 2 \mathrm{AX}$ foci with gene expression modifications, it is shown that processes such as metabolism processes, cell adhesion and organisation, cell signaling, responses to several stimuli, immune responses and apoptosis, are involved. Many of these pathways are related to apoptosis, which can be caused by DNA damage. This was expected because DNA adduct levels and $\gamma \mathrm{H} 2 \mathrm{AX}$ foci are phenotypic measures of DNA damage, showing the good correlation between phenotypic anchoring and gene expression patterns.

To further determine the relevance of a primary mouse hepatocyte in vitro system to test the toxicity of chemicals and drugs, transcriptomics results are compared to those from an in vivo mouse study. In the primary mouse hepatocytes 1231 probe sets were affected, whereas 78 probe sets were modulated in vivo, indicating that the effect of $\mathrm{BaP}$ on gene expression is larger in primary hepatocytes as compared to liver in vivo which is most probably related to differences in routes of exposure (direct exposure of hepatocytes in vitro, via blood flow in mice orally treated in vivo) and treatment design (once in vitro with multiple time points for sample collection, and in vivo on multiple days with one time point).

Some mouse in vivo studies with $\mathrm{BaP}$ showed that $\mathrm{BaP}$ is cleared from the blood very fast, even within a few hours, while this does not happen in primary mouse hepatocytes because cells are directly exposed to $\mathrm{BaP}(36,37)$. Exposure to $\mathrm{BaP}$ might therefore last longer in primary mouse hepatocytes which might cause more severe effects of $\mathrm{BaP}$ in vitro compared to in vivo. In several mouse in vivo studies DNA adduct level increased as exposure time elongated, and eventually reached a plateau $(37,38)$. This is comparable to our data on primary heptocytes. The adduct levels measured in these in vivo studies, however, were much lower than those from our primary mouse hepatocytes, indicating that the dose in the primary mouse hepatocytes is much higher compared to in vivo. Comparing both studies reveals that only 16 common probe sets are commonly affected, and that the number of commonly affected probe sets increases in a time- and dosedependent manner. It is therefore difficult to consider one time point as the optimal time point for comparison with the in vivo situation. From these common probe sets only 7 appeared to have the same effect direction. These were mainly genes involved in transcription and regulation of cell cycle and organisation. These genes are expected to be modulated after exposure to $\mathrm{BaP}$ because $\mathrm{BaP}$ is known to have effects on cell cycle in order to allow DNA damaged to be repaired (39).

Also the effects of $\mathrm{BaP}$ on biochemical pathways and biological processes in mice hepatocytes and mouse liver in vivo were compared. Again more gene groups are significantly modulated in the primary mouse hepatocytes (272 gene groups) compared to those from the in vivo study (8 gene groups). The amount of gene groups is increasing time- and dose-dependent in the primary mouse hepatocytes. Only 1 gene group is common between the in vitro and in vivo study. This gene group is ICHIBA_GVHD, involved in graft versus host disease in the liver. The induction of graft versus host 


\section{Chapter 4}

disease is a three-phase phenomenon (40). The first phase involves damage to host tissues by inflammation due to tissue damage. In the second phase, antigen-presenting cells as well as inflammatory cytokines triggering the activation of $\mathrm{T}$ cells, which expand and differentiate into effector cells. In the third phase, the effector phase, activated $\mathrm{T}$ cells mediate cytotoxicity against target host cells (40). Tissue damage by exposure to $\mathrm{BaP}$ might therefore induce graft versus host disease. Furthermore it is observed before in graft versus host models, that tumor necrosis factor (TNF), a cytokine produced by cells, is an important factor in graft versus host disease $(41,42)$. TNF is part of the extrinsic pathway for triggering apoptosis and can be produced by hepatocytes (43).

The significant pathways found in the in vivo study are all involved in the immune system and Cyp450 and DNA damage related pathways. Also in primary mouse hepatocytes pathways involved in the immune system and Cyp450 and DNA damage related pathways were found. Although they were not the same pathways as in vivo, most were deregulated in the same direction.

Although experimental design differences between the in vitro and the in vivo study are obvious and in vitro/in vivo extrapolation consequently have only limited value, the overlapping transcriptomic responses to the $\mathrm{BaP}$ challenges are of interest, and suggest that primary mouse hepatocytes indeed, represent a relevant in vitro model for toxicogenomics studies.

In summary, our results show that primary mouse hepatocytes are able to respond profoundly to exposure to $\mathrm{BaP}$ as the expected effects of $\mathrm{BaP}$, like DNA damage and xenobiotic metabolism, are observed. Primary mouse hepatocytes are able to metabolize $\mathrm{BaP}$, which cause DNA adducts and changes in gene expression profiles. Time appears to be a major contributor to that, whereas dose seems to have a minor contribution.

\section{Acknowledgement}

This research was financially supported by the Netherlands Genomics Initiative (NGI), the Netherlands Organisation for Scientific Research (NWO) and the CARCINOGENOMICS FP6 project sponsored by the European Union (PL037712). 


\section{References}

1. Cannon, R.E. and R.W. Tennant, Shock toxicology with transgenics. Nat Biotechnol, 1997. 15(13): p. 1349.

2. Blaauboer, B.J., et al., The practical applicability of hepatocyte cultures in routine testing. EcVam workschop report 1, 1994.

3. Davila, J.C., et al., Predictive value of in vitro model systems in toxicology. Annu Rev Pharmacol Toxicol, 1998. 38: p. 63-96.

4. Schaeffner, I., et al., A microtiterplate-based screening assay to assess diverse effects on cytochrome P450 enzyme activities in primary rat hepatocytes by various compounds. Assay Drug Dev Technol, 2005. 3(1): p. 27-38.

5. Dunn, J.C., et al., Hepatocyte function and extracellular matrix geometry: long-term culture in a sandwich configuration. Faseb J, 1989. 3(2): p. 174-7.

6. LeCluyse, E.L., et al., Regeneration and maintenance of bile canalicular networks in collagensandwiched hepatocytes. Toxicol In Vitro, 2000. 14(2): p. 117-32.

7. Boess, F., et al., Gene expression in two hepatic cell lines, cultured primary hepatocytes, and liver slices compared to the in vivo liver gene expression in rats: possible implications for toxicogenomics use of in vitro systems. Toxicol Sci, 2003. 73(2): p. 386-402.

8. Mathijs, K., et al., Assessing the metabolic competence of sandwich-cultured mouse primary hepatocytes. Drug Metab Dispos, 2009. 37: p. 1305-11.

9. Shimada, T., et al., Tissue-specific induction of cytochromes P450 1 A1 and 1 B1 by polycyclic aromatic hydrocarbons and polychlorinated biphenyls in engineered C57BL/6J mice of arylhydrocarbon receptor gene. Toxicol Appl Pharmacol, 2003. 187(1): p. 1-10.

10. Spink, D.C., et al., Induction of CYP1A1 and CYP1B1 in T-47D human breast cancer cells by benzo[a]pyrene is diminished by arsenite. Drug Metab Dispos, 2002. 30(3): p. 262-9.

11. Curfs, D.M., et al., Chronic exposure to the carcinogenic compound benzo[a]pyrene induces larger and phenotypically different atherosclerotic plaques in ApoE-knockout mice. Am J Pathol, 2004. 164(1): p. 101-8.

12. Nesnow, S., et al., Lung tumorigenic interactions in strain A/J mice of five environmental polycyclic aromatic hydrocarbons. Environ Health Perspect, 1998. 106 Suppl 6: p. 1337-46.

13. Braithwaite, E., X. Wu, and Z. Wang, Repair of DNA lesions induced by polycyclic aromatic hydrocarbons in human cell-free extracts: involvement of two excision repair mechanisms in vitro. Carcinogenesis, 1998. 19(7): p. 1239-46.

14. Izumi, T., et al., Mammalian DNA base excision repair proteins: their interactions and role in repair of oxidative DNA damage. Toxicology, 2003. 193(1-2): p. 43-65.

15. Bartek, J. and J. Lukas, DNA damage checkpoints: from initiation to recovery or adaptation. Curr Opin Cell Biol, 2007. 19(2): p. 238-45.

16. Luo, W., et al., Phenotypic anchoring of global gene expression profiles induced by N-hydroxy-4acetylaminobiphenyl and benzo[a]pyrene diol epoxide reveals correlations between expression profiles and mechanism of toxicity. Chem Res Toxicol, 2005. 18(4): p. 619-29.

17. van Steeg, H., et al., Use of DNA repair-deficient XPA transgenic mice in short-term carcinogenicity testing. Toxicol Pathol, 1998. 26(6): p. 742-9.

18. Hamer, G., et al., DNA double-strand breaks and gamma-H2AX signaling in the testis. Biol Reprod, 2003. 68(2): p. 628-34.

19. Godschalk, R.W., et al., Differences in aromatic-DNA adduct levels between alveolar macrophages and subpopulations of white blood cells from smokers. Carcinogenesis, 1998. 19(5): p. 819-25.

20. Reddy, M.V. and K. Randerath, Nuclease P1-mediated enhancement of sensitivity of 32P-postlabeling test for structurally diverse DNA adducts. Carcinogenesis, 1986. 7(9): p. 1543-51.

21. Tong, W., et al., ArrayTrack--supporting toxicogenomic research at the U.S. Food and Drug Administration National Center for Toxicological Research. Environ Health Perspect, 2003. 111(15): p. 181926. 


\section{Chapter 4}

22. Irizarry, R.A., et al., Exploration, normalization, and summaries of high density oligonucleotide array probe level data. Biostatistics, 2003. 4(2): p. 249-64.

23. Affymetrix, Statistical Algorithms Description Document, technical report. 2002.

24. Shi, L., et al., The MicroArray Quality Control (MAQC) project shows inter-and intraplatform reproducibility of gene expression measurements. Nat Biotechnol, 2006. 24(9): p. 1151-61.

25. Boorsma, A., et al., T-profiler: scoring the activity of predefined groups of genes using gene expression data. Nucleic Acids Res, 2005. 33(Web Server issue): p. W592-5.

26. Wilkening, S., F. Stahl, and A. Bader, Comparison of primary human hepatocytes and hepatoma cell line Hepg2 with regard to their biotransformation properties. Drug Metab Dispos, 2003. 31(8): p. 1035-42.

27. Wilkening, S. and A. Bader, Influence of culture time on the expression of drug-metabolizing enzymes in primary human hepatocytes and hepatoma cell line HepG2. J Biochem Mol Toxicol, 2003. 17(4): p. 207-13.

28. Hockley, S.L., et al., Time- and concentration-dependent changes in gene expression induced by benzo(a)pyrene in two human cell lines, MCF-7 and HepG2. BMC Genomics, 2006. 7: p. 260.

29. Levin, W., et al., Oxidative metabolism of polycyclic aromatic hydrocarbons to ultimate carcinogens. Drug Metab Rev, 1982. 13(4): p. 555-80.

30. Bock, K.W., Aryl hydrocarbon or dioxin receptor: biologic and toxic responses. Rev Physiol Biochem Pharmacol, 1994. 125: p. 1-42.

31. Rogakou, E.P., et al., DNA double-stranded breaks induce histone H2AX phosphorylation on serine 139. J Biol Chem, 1998. 273(10): p. 5858-68.

32. Zhou, C., et al., DNA damage evaluated by gammaH2AX foci formation by a selective group of chemical/physical stressors. Mutat Res, 2006. 604(1-2): p. 8-18.

33. Guguen-Guillouzo, C. and A. Guillouzo, Modulation of functional activities in cultured rat hepatocytes. Mol Cell Biochem, 1983. 53-54(1-2): p. 35-56.

34. Luch, A., Nature and nurture - lessons from chemical carcinogenesis. Nat Rev Cancer, 2005. 5(2): p. 113-25.

35. Kim, H.S. and B.M. Lee, Inhibition of benzo[a]pyrene-DNA adduct formation by Aloe barbadensis Miller. Carcinogenesis, 1997. 18(4): p. 771-6.

36. Arlt, V.M., et al., Metabolic activation of benzo[a]pyrene in vitro by hepatic cytochrome P450 contrasts with detoxification in vivo: experiments with hepatic cytochrome P450 reductase null mice. Carcinogenesis, 2008. 29(3): p. 656-65.

37. Uno, S., et al., Oral exposure to benzo[a]pyrene in the mouse: detoxication by inducible cytochrome P450 is more important than metabolic activation. Mol Pharmacol, 2004. 65(5): p. 1225-37.

38. de Vries, A., et al., Induction of DNA adducts and mutations in spleen, liver and lung of XPAdeficient/lacZ transgenic mice after oral treatment with benzo[a]pyrene: correlation with tumour development. Carcinogenesis, 1997. 18(12): p. 2327-32.

39. Hockley, S.L., et al., Identification through microarray gene expression analysis of cellular responses to benzo(a)pyrene and its diol-epoxide that are dependent or independent of p53. Carcinogenesis, 2008. 29(1): p. 202-10.

40. Ferrara, J.L., R. Levy, and N.J. Chao, Pathophysiologic mechanisms of acute graft-vs.-host disease. Biol Blood Marrow Transplant, 1999. 5(6): p. 347-56.

41. Schmaltz, C., et al., Donor T cell-derived TNF is required for graft-versus-host disease and graft-versustumor activity after bone marrow transplantation. Blood, 2003. 101(6): p. 2440-5.

42. Eibl, B., et al., Evidence for a graft-versus-tumor effect in a patient treated with marrow ablative chemotherapy and allogeneic bone marrow transplantation for breast cancer. Blood, 1996. 88(4): p. 1501-8.

43. Santos, S.A., D.R. Andrade, and D.R. Andrade Junior, Rat hepatocyte invasion by Listeria monocytogenes and analysis of TNF-alpha role in apoptosis. Rev Inst Med Trop Sao Paulo, 2005. 47(2): p. 73-80. 


\section{Discrimination for Genotoxic and} Non-genotoxic Carcinogens by Gene Expression Profiling in Primary Mouse Hepatocytes Improves with Exposure Time 


\title{
Chapter 5
}

\begin{abstract}
Assessing the potential carcinogenicity of chemicals for humans represents an ongoing challenge. Chronic rodent bioassays predict human cancer risk at only limited reliability while simultaneously being expensive and long-lasting. In order to seek for alternatives, the ability of a transcriptomics-based primary mouse hepatocyte model to classify carcinogens by their modes of action was evaluated. As it is obvious that exposure will induce a cascade of gene expression modifications, in particular, the influence of exposure time in vitro on discriminating genotoxic (GTX) carcinogens from non-genotoxic (NGTX) carcinogens class discrimination was investigated. Primary mouse hepatocytes from male C57BL/6 mice were treated for 12, 24, 36 and $48 \mathrm{~h}$ with two GTX and two NGTX carcinogens. For validation, two additional GTX compounds were studied at 24 and $48 \mathrm{~h}$. Immunostaining of $\gamma \mathrm{H} 2 \mathrm{AX}$ foci was applied in order to phenotypically verify DNA damage. It confirmed significant induction of DNA damage after treatment with GTX compounds but not with NGTX compounds. Whole genome gene expression modifications were analyzed by means of Affymetrix microarrays. When using differentially expressed genes from datasets normalized by RMA, the two classes and various compounds were better separated from each other by hierarchical clustering when increasing the treatment period. Discrimination of GTX and NGTX carcinogens by Prediction Analysis of Microarray improved with time, and resulted in correct classification of the validation compounds. The present study shows that gene expression profiling in primary mouse hepatocytes is promising for discriminating GTX from NGTX compounds and that this discrimination improves with increasing treatment period.
\end{abstract}




\section{Introduction}

The carcinogenic potential of chemical compounds is currently evaluated through application of chronic rodent bioassays. This strategy, however, generates a high false positive rate and is therefore not quite reliable (1) while simultaneously being expensive and time-consuming, as it requires the use of many animals and large quantities of the test compound during what is usually a 2-year period of study. Therefore, the usefulness of in vitro assays for predicting human carcinogenicity in vivo is increasingly explored (2). As the liver is the main organ for metabolism of many compounds including procarcinogens, and also represents a major target organ for chemical carcinogens in vivo, in vitro models based on hepatocyte systems are frequently considered for the prediction of toxicity. Among these, primary hepatocytes, precision cut liver slices and hepatic cell lines are well established in vitro models $(2,3,4)$. Combining such in vitro models with powerful genomic-based methods might provide high throughput screening methods for predicting toxic risks in humans. The application of DNA microarray technology enables examining differential gene expression for many genes simultaneously. These DNA microarray technologies have the potential to both enhance our understanding of the mechanism underlying a compound's carcinogenic effects and to identify a characteristic set of genes from a database of reference profiles, which may allow the prediction of an unknown compound's mode of action $(5,6)$.

Based on their mechanisms of action, chemical carcinogens are classified as genotoxic (GTX) or non-genotoxic (NGTX) carcinogens (7). A genotoxic compound may covalently bind with DNA and cause direct damage to DNA by adduct formation. These lesions may not or incorrectly be repaired which leads to mutations and ultimately to the formation of tumors (6). A non-genotoxic compound, on the other hand, lacks the ability to induce DNA damage directly or indirectly. Because NGTX compounds have different features from GTX compounds, it may be hypothesized that GTX and NGTX induce distinct gene expression profiles which consequently may be used for mechanism-based classifying unknown compounds as $\operatorname{GTX}$ or $\operatorname{NGTX}(8,9)$.

Length of exposure has a major influence on gene expression profiles in cells in vitro, and this appears to have a higher impact than compound's dose $(10,11)$. Therefore, it may be hypothesized that the exposure period affects class discrimination based on transcriptomics data.

The current study therefore aimed to investigate whether incorporating timedependency as a parameter improves mechanism-based classification models to discriminate GTX and NGTX carcinogens. For this, we apply whole genome gene expression analysis to sandwich-cultured primary mouse hepatocytes. Primary mouse hepatocytes are metabolic competent and are of additional advantage because of the availability of the complete sequence of the mouse genome (12) and of transgenic mouse models which allow relevant mechanistic studies. Gene expression profiles generated at four 
time points from primary mouse hepatocytes treated with four model compounds, were used in the training phase. From these, a classification model was derived, which was subsequently validated by using a set of two additional compounds. The functionality of the resulting classifiers was analyzed by MetaCore. Because histone H2AX is phosphorylated on serine-139 by ataxia telangiectasia mutated (ATM) kinase in response to DNA damage, particularly double strand breaks $(13,14)$, we analyzed the formation of phosphorylated $\mathrm{H} 2 \mathrm{AX}(\gamma \mathrm{H} 2 \mathrm{AX})$ foci in order to confirm GTX properties of the compounds.

\section{Materials and Methods}

\section{Chemicals}

Dulbecco's modified Eagle's medium (DMEM), fetal calf serum (FCS), Hanks' calcium- and magnesium-free buffer, Alexa fluor 488 goat anti-mouse IgG antibody, insulin and Trizol were obtained from Invitrogen (Breda, The Netherlands). Glucagon, hydrocortisone, collagenase type IV, Benzo(a)pyrene (BaP), Aflatoxin B1 (AFB1), Cyclosporine A (CsA), Dimethylnitrosamine (DMN), Mitomycin C (MitC), Trypan blue, dimethylsulphoxide (DMSO), bovine serum albumin (BSA), 4',6-diamidino-2phenylindole (DAPI) and Tween-20 were purchased from Sigma-Aldrich (Zwijndrecht, The Netherlands) and 2,3,7,8-tetrachlorodibenzo-p-dioxin (TCDD) from C.N. Schmidt BV (Amsterdam, The Netherlands). Triton X-100, NaCl, $\mathrm{Na}_{2} \mathrm{HPO}_{4} \cdot 2 \mathrm{H}_{2} \mathrm{O}$ and $\mathrm{NaH}_{2} \mathrm{PO}_{4}$ were obtained from Merck (Darmstadt, Germany) and paraformaldehyde from ICN biomedicals (Auroro, Ohio). The anti-phospho-Histone H2A-X (ser139) Clone JBW 301 antibody was purchased by Upstate Biotechnology (Lake Placid, NY). Vectashield ${ }^{\circledR}$ Mounting Medium was supplied by Vector Labs (Burlingame, CA). Collagen Type I Rat Tail was obtained from BD BioSciences (Bedford, MA). The iScript cDNA Synthesis kit en iQ SYBR Green Supermix were purchased from BioRad (Hercules, CA). Primers were designed using Primer Express 2.0 from Applied Biosystems (Foster City, CA) and purchased from Operon (Cologne, Germany). The RNeasy minikit was obtained from Qiagen, Westburg B.V. (Leusden, The Netherlands). The 5x MegaScript T7 Kit was obtained from Ambion (Austin, TX). The GeneChip ${ }^{\circledR}$ Expression 3'Amplification Two-Cycle cDNA Synthesis Kit and Reagents, the Hybridization, Wash and Stain Kit and the Mouse Genome 430 2.0 Arrays were purchased from Affymetrix (Santa Clara, CA).

\section{Animals and isolation of hepatocytes}

Permission for isolating primary hepatocytes from mice was obtained from the Animal Ethical Committee. Adult male C57BL/6 mice (Charles River), weighing 20-25 g, were obtained from Charles River GmbH, Sulzfeld, Germany. This mouse strain was chosen 
because it is frequently used in toxicological and pharmacological investigations, and it is a common background for transgenic mouse strains. The animals were housed in macrolon cages with sawdust bedding at $22^{\circ} \mathrm{C}$ and $50-60 \%$ humidity. The light cycle was $12 \mathrm{~h}$ light $/ 12 \mathrm{~h}$ dark. Feed and tap water were available ad libitum.

Hepatocytes were isolated by a two-step collagenase perfusion method according to Seglen (15), with modifications as described before (16).

\section{Cell culture and treatment}

Cells with viability $>85 \%$, determined by trypan blue exclusion, were cultured in a collagen-collagen sandwich formation as described before $(16,17)$. Prior to treatment, primary cultures of mouse hepatocytes were allowed to recover for $40-42 \mathrm{~h}$ at $37^{\circ} \mathrm{C}$ in a humidified chamber with $95 \% / 5 \% \mathrm{air} / \mathrm{CO}_{2}$ in serum-free culture medium supplemented with insulin $0.5 \mathrm{U} / \mathrm{ml})$, glucagon $(7 \mathrm{ng} / \mathrm{ml})$, hydrocortisone $(7.5 \mu \mathrm{g} / \mathrm{ml})$ and $2 \%$ penicillin/streptomycin (5000 U/ml penicillin; $5000 \mu \mathrm{m} / \mathrm{ml}$ streptomycin). Culture medium was refreshed every $24 \mathrm{~h}$. After the recovery period, the culture medium was replaced by culture medium containing one of the selected four compounds, or with vehicle control (Table 1). Cells were incubated for 12, 24, 36 or $48 \mathrm{~h}$ before being used for detecting double-stranded (ds) DNA breaks or harvested for RNA isolation by adding Trizol reagent. These time points were chosen as they are regularly used in genotoxicity tests and because stability of the cells until $48 \mathrm{~h}$ has been demonstrated (16). Three independent replicate biological experiments were conducted for each compound.

\section{Detection of dsDNA breaks}

Double-stranded DNA breaks were detected by immunostaining of the phosphorylated histone $\mathrm{H} 2 \mathrm{AX}(\gamma \mathrm{H} 2 \mathrm{AX})$ as described before (18). Hepatocytes, used for the detection of dsDNA breaks, were cultured in a sandwich configuration on top of a cover slip. After desired exposure times, medium was aspirated and the cells were rinsed with 1x Phosphate-buffered saline (PBS) before fixation in 4\% Paraformaldehyde for $10 \mathrm{~min}$ at ambient temperature. The cells were washed again with $1 \mathrm{xPBS}$ and made permeable with $0.2 \%$ Triton $\mathrm{X}-100$ at $4^{\circ} \mathrm{C}$ for $5 \mathrm{~min}$. Thereafter cells were washed two times with $1 \times$ PBS for $5 \mathrm{~min}$ and blocked during $1 \mathrm{~h}$ at $37^{\circ} \mathrm{C}$ with blocking buffer $(1 \% \mathrm{BSA}+0.5 \%$ Tween-20 in 1X PBS). Samples were washed two times with 1xPBS for $5 \mathrm{~min}$ and incubated with the first antibody (Mouse monoclonal $\gamma \mathrm{H} 2 \mathrm{AX}$ (Ser-139)) 1:1000 in dilution buffer $(0.5 \% \mathrm{BSA}+0.5 \%$ Tween-20 in $1 \mathrm{X} \mathrm{PBS})$ during $2 \mathrm{~h}$ at $37^{\circ} \mathrm{C}$. After two washing steps with 1xPBS cells were incubated with the second antibody (Alexa 488 labelled) 1:1000 in dilution buffer during $1 \mathrm{~h}$ at $37^{\circ} \mathrm{C}$ and washed again two times with 1xPBS. Samples were incubated with DAPI for $15 \mathrm{~min}$ at room temperature, dehydrated in series of ethanol solutions (70, 90 and 100\%) for 3 min and air-dried. Vectashield ${ }^{\circledR}$ Mounting medium was used to stick the cover slips onto microscopic glass slides. Microscopic photographs were taken and samples were scored manually. A damage score, 
ranging from 0 to 4 , determined by the grade of damage, was given to 100 cells per sample. The damage scores were multiplied by the amount of cells with that score and all together calculated to get a total percentage of damage in each sample. For the statistical analysis the T-Test was used with a significance level of $5 \%$.

\section{$R N A$ isolation}

Total RNA was isolated from cultured mouse hepatocytes using Trizol and the RNeasy kit according to the manufacturer's protocol. RNA concentrations were measured by means of a spectrophotometer and the quality of each RNA preparation was determined using a bio-analyzer (Agilent Technologies, The Netherlands). Extracted RNA was stored at $-80^{\circ} \mathrm{C}$ until further analysis.

\section{Whole genome gene expression analysis}

Targets were prepared according to the Affymetrix protocol. The cRNA targets were hybridized according to the manufacturer's recommended procedures on high-density oligonucleotide gene chips (Affymetrix Mouse Genome 430 2.0 GeneChip arrays). The gene chips were washed and stained using an Affymetrix fluidics station and scanned by means of an Affymetrix GeneArray scanner.

A total of sixty GeneChips was run. Normalization quality controls, including scaling factors, average intensities, present calls, background intensities, noise, and raw Q values, were within acceptable limits, according to the manufacturer, for all chips. Hybridization controls BioB, BioC, BioD, and CreX, were identified on all chips and yielded the expected increases in intensities.

\section{Data analysis}

\section{Selection of differentially expressed probe sets}

Sixty datasets were obtained from this experiment. Raw data were imported into ArrayTrack (19) and normalized using Robust Multi-array Average (RMA, integrated into ArrayTrack) (20). Present-Marginal-Absent calls were used to identify and omit probe sets of poor quality (21). Subsequently, the total remaining probe sets for each time point (12 h: 22986; 24 h: 23606; 36 h: 23811; 48 h: 24358; total: 26666), were logarithmically (base 2) transformed and corrected for their DMSO vehicle control. For each time point probe sets were then filtered for those for which expression was in at least one compound up- or downregulated by a minimum of 1.2-fold in at least two out of three experiments with expressions altered in the same direction in all replicate and with a mean fold up- or downregulated of 1.5 (22). The generated list with differentially expressed genes ( $\log 2$ ratios) was used for hierarchical clustering (HCA) with the Ward's minimum variance method (23) and prediction analysis of microarray (PAM). 


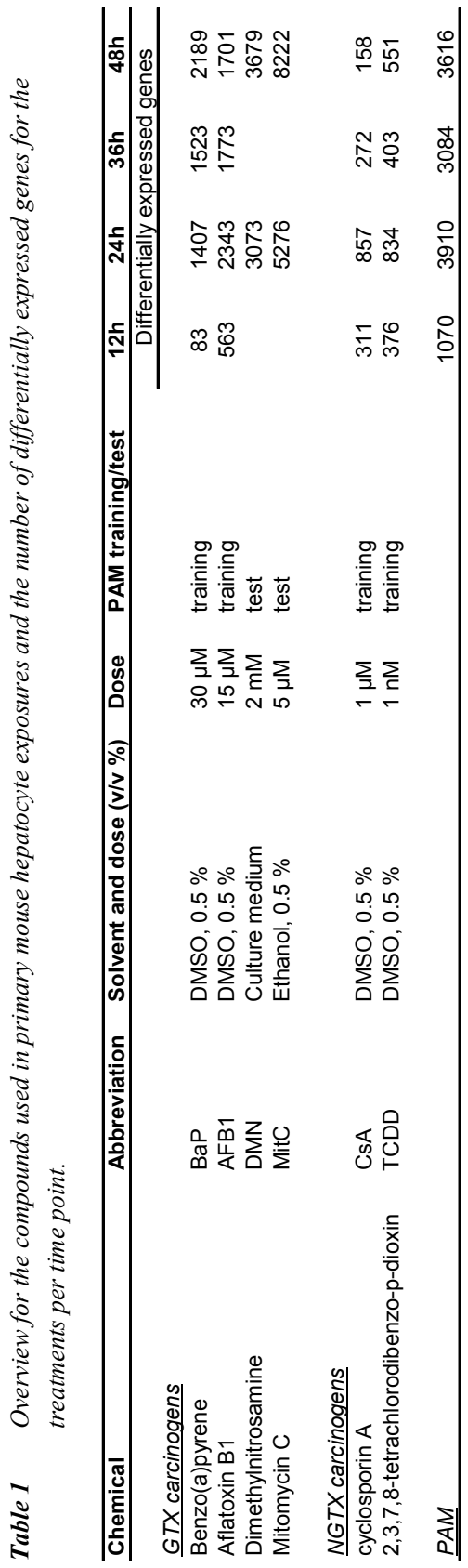




\section{Correlation analysis}

Genes that correlated with $\gamma \mathrm{H} 2 \mathrm{AX}$ foci formation were identified with the gene expression profile analysis suite (GEPAS 4.0; CIPF, Valencia, Spain). The values for $\gamma \mathrm{H} 2 \mathrm{AX}$ foci formation, corrected by subtracting the values for the DMSO from the values for the exposed samples and log (base 2) transformed, were correlated with the log (base 2) transformed expression changes of the filtered probe sets (24 h: 23606; 48 h: 24358). Spearman correlation coefficients were calculated and correlating genes were selected by $\mathrm{P}<0.05$ for Prediction Analysis of Microarray software (PAM).

\section{Pathway analysis}

The complete data sets of genes from all compounds of all experiments ( $\log 2$ of the ratios for treated-control) were uploaded in T-profiler (24) to identify transcriptional regulation of biochemical pathways and biological processes in the complete data set of genes without any pre-selection of genes. T-profiler uses the T-test to score the difference between the mean expression level of predefined groups of genes and that of all other genes without any pre-selection of modulated genes (24). Significance was determined by generating an E value, a Bonferroni corrected $\mathrm{P}$ value. Pathways and processes were significant when E values were below 0.05 and used for hierarchical clustering GenePattern (25) using Pearson correlation with pairwise complete-linkage.

\section{Class discrimination and functional analyses of classifiers}

The Prediction Analysis of Microarray software (PAM) was used for identifying genomic classifiers and for discrimination of GTX and NGTX carcinogens (26). PAM uses gene expression data to identify a subset of genes that best characterize each class by using the method of "nearest shrunken centroids" (26).

For this analysis, the gene list with differentially expressed probe sets (Table 1) was used. Ten-fold cross validation was applied in all time points, using each treatment as an independent experiment. For each time point, a set of genes (classifiers) was generated by using the smallest estimated misclassification error rate and a $>80 \%$ test probability. Additionally, two well-known GTX compounds were used to validate the classification. Genes correlating with $\gamma \mathrm{H} 2 \mathrm{AX}$ foci formation at 24 and $48 \mathrm{~h}$ were also used for PAM to investigate if this improves the classification. The classifiers from the differentially expressed probe sets from the each time point were further analyzed for functional annotation by MetaCore using the shortest path algorithm (GeneGo, San Diego, CA). Again, data derived at $12 \mathrm{~h}$ were omitted. The total list of probe sets, without probe sets of poor quality, were selected for each time point as described before ( $24 \mathrm{~h}: 23606 ; 36$ h: 23811; 48 h: 24358) and used as background list in MetaCore. A false discovery rate of 0.2 was used to select significant MetaCore maps. MetaCore was also used to generate biological networks. 


\section{Results}

\section{Time-dependent gene expression profiles}

We selected four compounds in order to examine time-dependent differences in class discrimination performance by mouse hepatocyte gene expression changes which might be induced by GTX or NGTX carcinogens. Only non-cytotoxic doses as determined by the MTT assay (ca 80\% viability), were used (Table 1). Only one dose was investigated, as several studies have shown that in in vitro models, treatment time has a much larger impact on chemically induced gene expression modifications than dose $(10,11)$. In total, 60 gene chips were run. No overt outliers appeared between the three replicates, as investigated by hierarchical clustering analysis (HCA). For each compound and time point, the differentially expressed probe sets were retrieved (Table 1).

To visualize variability and time-dependent effects on gene expression profiles from GTX and NGTX compounds, HCA for each time point was done by including only modulated gene expressions from that treatment period (Figure 1). For all compounds, the clustering of replicates improved with treatment time: at $12 \mathrm{~h}$ it was quite poor while at $48 \mathrm{~h}$ for all compounds, replicates grouped together. Furthermore, only at $48 \mathrm{~h}$ the GTX and NGTX classes were completely separated from each other.

\section{Detection of $d s D N A$ breaks}

The generation of phosphorylation of $\gamma \mathrm{H} 2 \mathrm{AX}$ (forming of $\gamma \mathrm{H} 2 \mathrm{AX}$ foci), which is a signature for dsDNA damage $(27,14)$, after 24 and $48 \mathrm{~h}$ exposure to the four compounds is shown in Figure 2. Only one dose and two time points were investigated. At $48 \mathrm{~h}$, levels of $\gamma \mathrm{H} 2 \mathrm{AX}$ foci in cells treated with GTX compounds were significantly increased as compared to DMSO controls, while at $24 \mathrm{~h}$ only AFB1 had induced a significant increase compared to DMSO controls. Cells treated with the NGTX compounds, on the other hand, showed no changes in levels of $\gamma \mathrm{H} 2 \mathrm{AX}$ foci compared to the controls, except for CsA at $48 \mathrm{~h}$ when a significant decrease compared to the DMSO controls was shown. Time had only a significant effect on the cells treated with BaP, where more $\gamma \mathrm{H} 2 \mathrm{AX}$ foci were detected as exposure time elongated. 

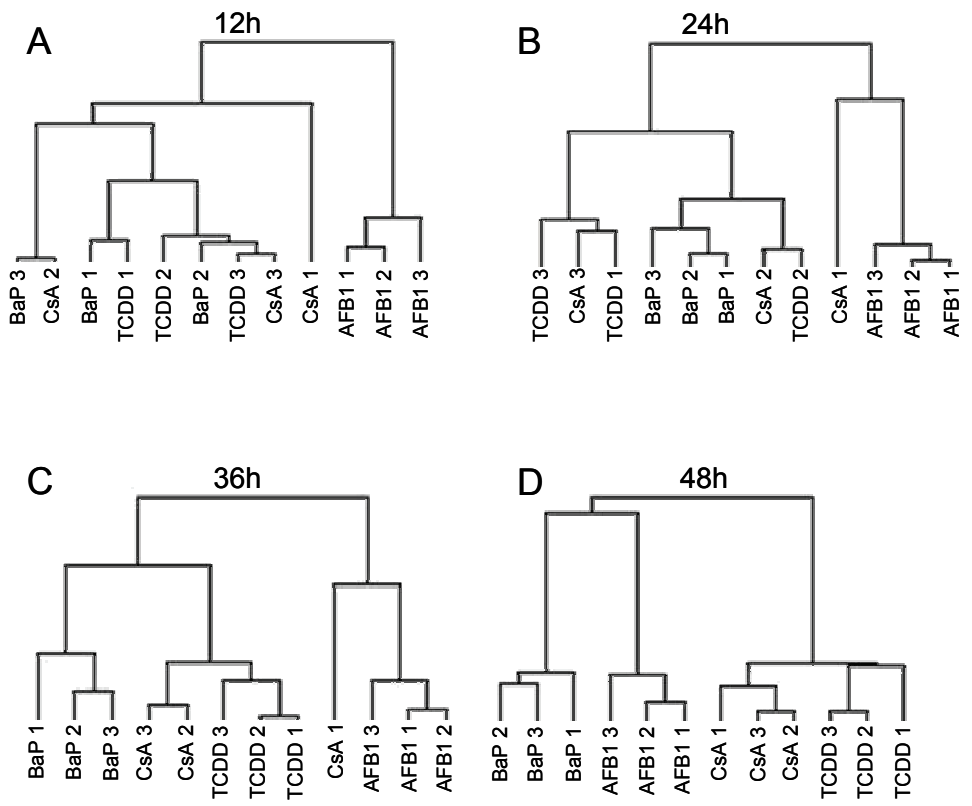

Figure $1 \quad$ Hierarchical clustering per time point of treatments using genes differentially expressed in primary mouse hepatocytes after exposure to BaP, AFB1, TCDD or CsA for (A) 12, (B) 24, (C) 36 and (D) $48 \mathrm{~h}$ (all in triplicate experiments).

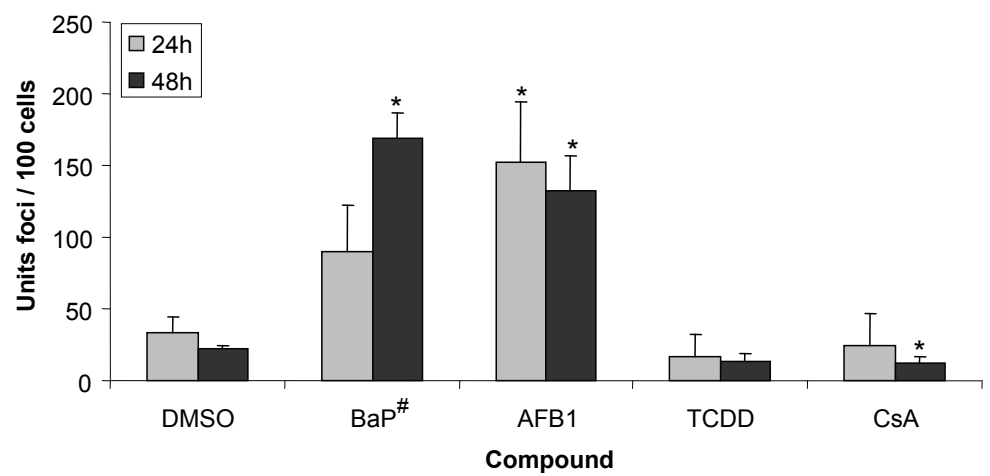

Figure 2 Levels of $\gamma H 2 A X$ foci, a measure for dsDNA breaks, in primary mouse hepatocytes exposed to BaP, AFB1, TCDD, CsA or solvent for 24 or 48 h (average with SD of 3 experiments).

* Significant $(p$-value $<0.05)$ compared to solvent controls

\# Significant ( $p$-value $<0.05$ ) over time 
Pathway analysis

Pathways and processes significantly altered in hepatocytes in at least two experiments and altered in the same direction in all three replicates, were considered significant. For each compound and each time point significantly altered pathways were selected (in total 471 pathways). Only 5 pathways were significantly altered at 12 h. At 24 h, 215 pathways were significantly altered, 175 at $36 \mathrm{~h}$ and 382 pathways at $48 \mathrm{~h}$. More pathways were significantly changed after treatment of hepatocytes with a GTX compound. Hierarchical clustering of these pathways with GenePattern (25) is presented in Figure 3 , showing distinct patterns for groups of pathways. Processes related to macromolecules, cellular organisation and regulation are mostly upregulated by all compounds at $24 \mathrm{~h}$ and signal transduction is only upregulated by the NGTX compounds at $24 \mathrm{~h}$. Immune responses, extracellular, membrane and cytoplasm processes, lipid-related processes and metabolic and biosynthetic processes are downregulated by GTX compounds and upregulated by NGTX compounds at later time points. P53-related gene groups are upregulated by GTX compounds at $36 \mathrm{~h}$. Cytochrome P450-related pathways were clearly triggered by treatment with BaP and TCDD.

\section{Class discrimination}

For each time point, the $\log 2$ of the ratio's for the differentially expressed genes upon treatments with BaP, AFB1, TCDD or CsA was uploaded into PAM in order to identify molecular classifiers, e.g. a subset of genes, that can best discriminate GTX from NGTX carcinogens. PAM generates a misclassification error rate curve based on crossvalidation reducing the number of genes (data not shown). The misclassification error rate reached $<0.1$ for all time points, except for $12 \mathrm{~h}$ where the misclassification was always $>0.4$. Therefore, data sampled at $12 \mathrm{~h}$, were not further analyzed. For each time point, a set of classifiers was generated by using a threshold with a misclassification error rate of 0 and a probability for classification of $>80 \%$ for the training set data. This resulted in 15 genes after $24 \mathrm{~h}$ of exposure, 16 genes after $36 \mathrm{~h}$ and 26 genes after $48 \mathrm{~h}$ : scores generated by PAM for all classifiers are presented in Table 2. Classifiers upregulated in GTX compounds were downregulated in NGTX compounds and vice versa.

To investigate whether gene expression changes correlating with $\gamma \mathrm{H} 2 \mathrm{AX}$ foci formation after exposure to BaP, AFB1, CsA or TCDD, are also capable of discriminating GTX from NGTX compounds, Spearman correlation coefficients were calculated and correlating genes were selected at $\mathrm{P}<0.05$. This resulted in 683 correlating genes after $24 \mathrm{~h}$ of exposure and 374 genes after $48 \mathrm{~h}$ of exposure. These genes were also uploaded into PAM. A misclassification error rate of 0 was reached after exposure periods of 24 and $48 \mathrm{~h}$. Classifiers were again generated by using a threshold with a misclassification error rate of 0 and a classification probability of $>80 \%$ for the training set data, resulting 19 classifiers after $24 \mathrm{~h}$ of exposure and 22 classifiers after $48 \mathrm{~h}$, presented in Table 2. 
From these classifiers, 6 genes were common between exposure periods of 24 and $48 \mathrm{~h}$. From the classifiers found after $24 \mathrm{~h}$ of exposure 10 were common with classifiers found from the differentially expressed genes. After $48 \mathrm{~h}$ of exposure 8 were common with classifiers found from the differentially expressed genes.

For the purpose of validating class discrimination profiles, primary hepatocytes were treated with two additional genotoxic compounds, DMN and MitC, or vehicle control for the apparently optimal exposure periods of 24 or $48 \mathrm{~h}$. A sampling time of $12 \mathrm{~h}$ was not included as the classification was not successful at that early time point. Also after $36 \mathrm{~h}$ of exposure, no analysis was performed as classifiers found at this particular time point, were barely different from those at 24 and $48 \mathrm{~h}$. The classifiers generated by PAM from the differentially expressed probe sets and from the significantly modulated pathways by the training set, were then applied for classifying these two additional GTX compounds. After both exposure periods, all independent triplicate treatments of both compounds were classified correctly as GTX with a predicted test probability of $100 \%$. Additionally, the list of classifiers generated from the genes correlating with $\gamma \mathrm{H} 2 \mathrm{AX}$ foci formation by PAM was validated by evaluating these new compounds. Only after $48 \mathrm{~h}$ of exposure, however, the independent triplicate treatments of both compounds were classified correctly as GTX with, though with a predicted test probability $>90 \%$. After $24 \mathrm{~h}$ the predicted test probability was lower but both compounds were again classified correct (data not shown).

\section{Functional analyses of classifiers}

Because the classifiers generated by PAM after $36 \mathrm{~h}$ of exposure were barely different from those at 24 and $48 \mathrm{~h}$, only classifiers after 24 and $48 \mathrm{~h}$ of exposure were used for over-representation analysis in MetaCore maps. Classifiers appeared to have a predominant role in transcription, responses to extracellular stimuli, DNA damage, cell cycle and apoptosis and survival and also in aminoacid, carbohydrate, lipid, nucleotide and steroid metabolism. One classifier, namely Mdm2, was present in a large number of MetaCore maps. A network was generated using shortest path algorithm to visualize possible interactions between the major classifiers based on literature text mining (Figure 4). Again, this network demonstrated the pivotal role of Mdm2. Mdm2 appeared upregulated in GTX, and downregulated in NGTX compounds. FHIT, which was downregulated in GTX compounds, had an inhibiting role on Mdm2, while XPG, which as Figure 4 shows, was indirectly upregulated in GTX, was induced by Mdm2. Esr1, inhibited by Mdm2, had an inhibiting role on C10orf11 and on NCKX3, which were both downregulated in GTX compounds. Esr1 had a stimulating role on C3orf26, Lactoferrin and PDK4, but only C3orf26 was downregulated in GTX compounds. Mdm2 had also an inhibiting role on P53 and indirectly on SERA and MRCK $\gamma$. But only SERA appeared downregulated in GTX compounds. This network plays a role in cellular proliferation and tumor suppression. 
AFB1 BaP TCDD CsA

12-24-36-48-h 12-24-36-48-h 12-24-36-48-h 12-24-36-48-h

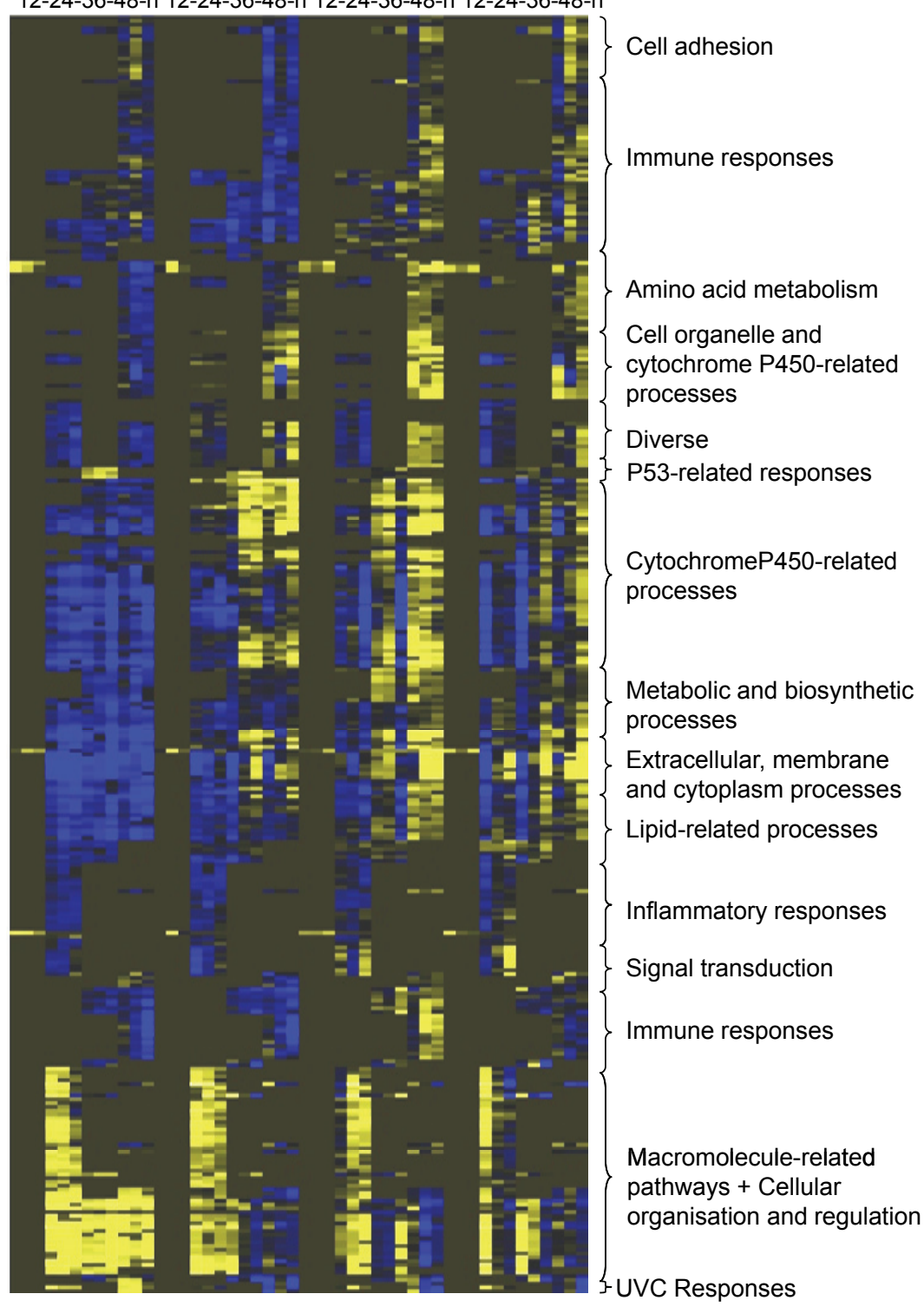

$-2.5$

$-0.06$

1.7

Figure 3 Hierarchical clustering of all significantly altered pathways after treatment with $A F B 1, B a P$, TCDD or CsA for 12, 24, 36 and $48 \mathrm{~h}$, based on the t-values generated by T-profiler. Yellow and blue mean up- and downregulation, respectively. 
Table 2

Genes selected by PAM for class discrimination and their GTX and NGTX scores.

\begin{tabular}{|c|c|c|c|c|c|c|c|c|c|c|c|}
\hline \multirow{2}{*}{\multicolumn{2}{|c|}{ GENEBANKACC Genename }} & \multicolumn{6}{|c|}{ Differentially expressed genes } & \multicolumn{4}{|c|}{ Genes correlating with $\gamma \mathrm{H} 2 \mathrm{AX}$} \\
\hline & & \multicolumn{2}{|c|}{24} & \multicolumn{2}{|c|}{36} & \multicolumn{2}{|c|}{48} & \multicolumn{3}{|c|}{24} & \multirow[t]{2}{*}{48} \\
\hline & & \multicolumn{6}{|c|}{ Score } & \multicolumn{3}{|c|}{ Score } & \\
\hline & & GTX & NGTX & GTX & NGTX & GTX & NGTX & GTX & NGTX & GTX & NGTX \\
\hline NM_008522 & Ltf & 0.05 & -0.05 & 0.33 & -0.33 & 0.35 & -0.35 & 0.16 & -0.16 & 0.51 & -0.51 \\
\hline AK005731 & 1700007K13Rik & 0.32 & -0.32 & 0.25 & -0.25 & 0.23 & -0.23 & 0.42 & -0.42 & 0.34 & -0.34 \\
\hline BI651416 & Cdc42bpg & 0.25 & -0.25 & 0.16 & -0.16 & 0.14 & -0.14 & 0.37 & -0.37 & 0.28 & -0.28 \\
\hline BE956581 & Cpt1c & & & 0.16 & -0.16 & 0.10 & -0.10 & & & 0.26 & -0.26 \\
\hline X58876 & Mdm2 & 0.01 & -0.01 & & & 0.09 & -0.09 & 0.11 & -0.11 & 0.25 & -0.25 \\
\hline BB463610 & 4632434I11Rik & & & & & & & 0.02 & -0.02 & 0.18 & -0.18 \\
\hline BB043558 & 9230114K14Rik & & & 0.11 & -0.11 & 0.05 & -0.05 & & & 0.17 & -0.17 \\
\hline AF297615 & Ggta1 & & & & & 0.04 & -0.04 & & & 0.16 & -0.16 \\
\hline AK004719 & Mdm2 & & & & & & & & & 0.11 & -0.11 \\
\hline AF335325 & Ddit4I & & & & & & & & & 0.11 & -0.11 \\
\hline BM198879 & Ercc5 & 0.09 & -0.09 & & & & & 0.18 & -0.18 & 0.11 & -0.11 \\
\hline BC008105 & Polk & & & & & & & & & 0.10 & -0.10 \\
\hline BC003267 & BC003267 & & & & & & & & & 0.10 & -0.10 \\
\hline AV327248 & Zfp365 & & & & & & & & & 0.09 & -0.09 \\
\hline AV246296 & Eda2r & & & & & & & & & 0.07 & -0.07 \\
\hline BC021352 & Plod2 & & & & & & & & & 0.07 & -0.07 \\
\hline AK014608 & 4632434I11Rik & & & & & & & & & 0.07 & -0.07 \\
\hline AF033112 & Siva & & & & & & & & & 0.06 & -0.06 \\
\hline AK007854 & 1810053B23Rik & & & & & & & & & 0.06 & -0.06 \\
\hline BG797099 & Ddit4I & & & & & & & & & 0.02 & -0.02 \\
\hline AV273409 & Wnt9a & & & & & & & & & 0.00 & 0.00 \\
\hline NM_030697 & Ankrd47 & 0.19 & -0.19 & 0.16 & -0.16 & & & 0.29 & -0.29 & & \\
\hline AV377066 & 9130221J18Rik & 0.11 & -0.11 & & & & & 0.17 & -0.17 & & \\
\hline BM200015 & Hsdl2 & 0.05 & -0.05 & & & & & 0.14 & -0.14 & & \\
\hline NM_013743 & Pdk4 & 0.04 & -0.04 & & & & & 0.13 & -0.13 & & \\
\hline BM2̄̄30508 & A030007D23Rik & & & & & & & 0.08 & -0.08 & & \\
\hline NM_011316 & Saa4 & 0.00 & 0.00 & & & & & 0.07 & -0.07 & & \\
\hline NM_011388 & Slc10a2 & & & & & & & 0.07 & -0.07 & & \\
\hline BB414224 & Tmprss2 & & & & & & & 0.05 & -0.05 & & \\
\hline NM_019976 & Psrc1 & & & & & & & 0.02 & -0.02 & & \\
\hline BC025198 & Rap2a & & & & & & & 0.02 & -0.02 & & \\
\hline Al451920 & C530044N13Rik & & & & & & & 0.01 & -0.01 & & \\
\hline AV009441 & Ivl & & & & & & & 0.00 & 0.00 & & \\
\hline BB821363 & Scfd2 & -0.18 & 0.18 & & & 0.05 & -0.05 & & & & \\
\hline BC026831 & Fads1 & & & & & 0.00 & 0.00 & & & & \\
\hline BC024358 & Tpm2 & & & & & 0.00 & 0.00 & & & & \\
\hline AA561726 & Phgdh & & & & & -0.01 & 0.01 & & & & \\
\hline NM_008935 & Prom1 & & & & & -0.02 & 0.02 & & & & \\
\hline BB454777 & 4930579E17Rik & & & -0.01 & 0.01 & -0.03 & 0.03 & & & & \\
\hline AK003186 & Tpm2 & & & & & -0.03 & 0.03 & & & & \\
\hline AV213379 & Oxct1 & & & & & -0.03 & 0.03 & & & & \\
\hline NM_024188 & Oxct1 & & & & & -0.05 & 0.05 & & & & \\
\hline BB458460 & Chchd6 & & & & & -0.05 & 0.05 & & & & \\
\hline BB246912 & 1700112E06Rik & & & & & -0.06 & 0.06 & & & & \\
\hline BC024120 & Tat & & & & & -0.07 & 0.07 & & & & \\
\hline AF055573 & Fhit & & & -0.11 & 0.11 & -0.11 & 0.11 & & & & \\
\hline Al747296 & Gmds & -0.04 & 0.04 & -0.24 & 0.24 & -0.14 & 0.14 & & & & \\
\hline $\mathrm{BI} 247584$ & Fdps & & & & & -0.14 & 0.14 & & & & \\
\hline NM_053122 & Immp2I & & & -0.16 & 0.16 & -0.16 & 0.16 & & & & \\
\hline L21027 & Phgdh & & & & & -0.16 & 0.16 & & & & \\
\hline AF000969 & Cadps2 & -0.21 & 0.21 & -0.58 & 0.58 & -0.29 & 0.29 & & & & \\
\hline BC017615 & Slc24a3 & & & -0.11 & 0.11 & -0.35 & 0.35 & & & & \\
\hline Al596632 & Ptprg & -0.24 & 0.24 & -0.16 & 0.16 & & & & & & \\
\hline AK010447 & Smyd3 & & & -0.04 & 0.04 & & & & & & \\
\hline AK019979 & 2610528E23Rik & & & -0.10 & 0.10 & & & & & & \\
\hline NM_012006 & Acot1 & 0.06 & -0.06 & & & & & & & & \\
\hline NM_026517 & Rpl22I1 & & & 0.00 & 0.00 & & & & & & \\
\hline
\end{tabular}




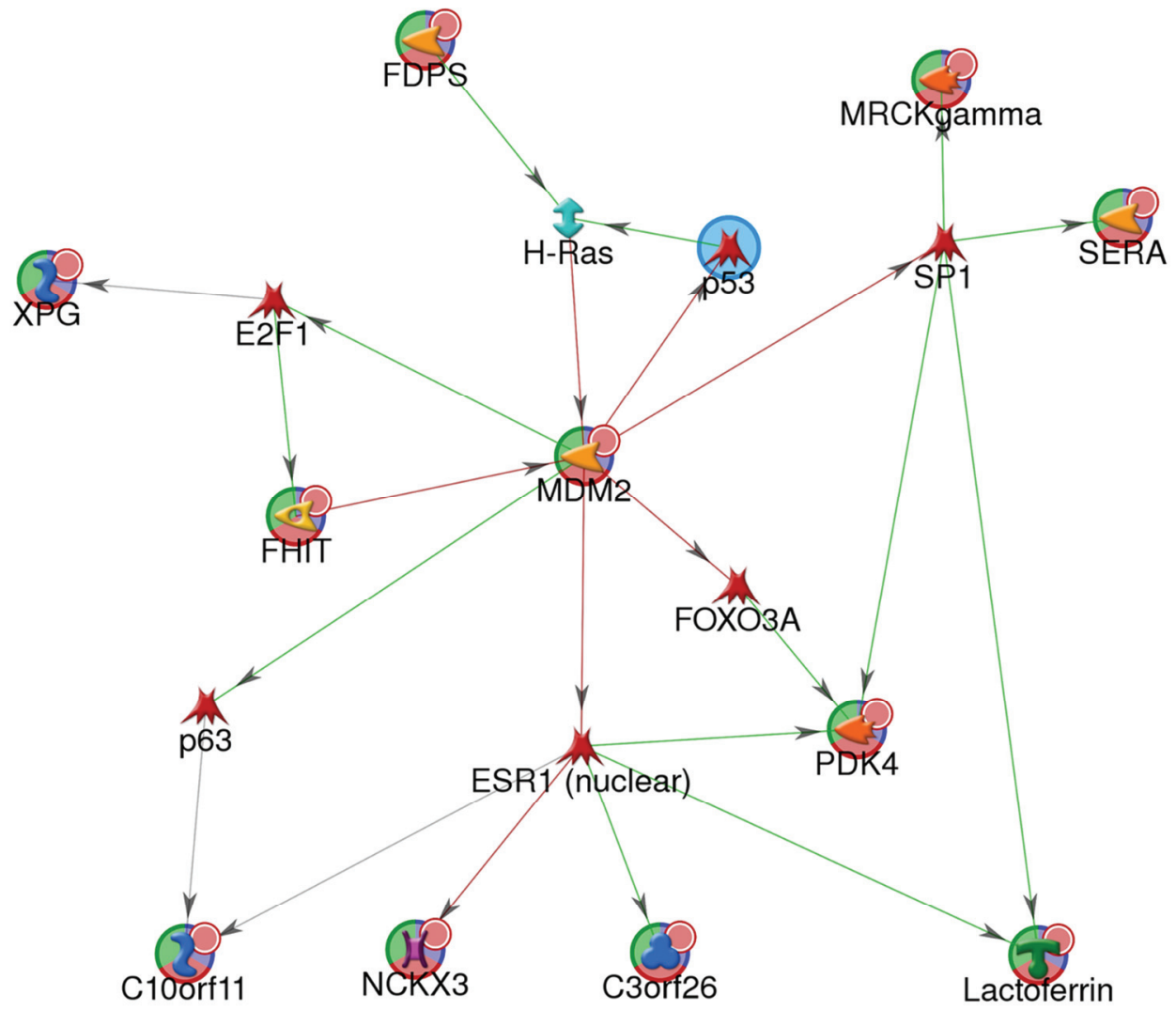

Figure 4 Biological network generated in MetaCore, to map interactions between the classifiers selected in primary mouse hepatocytes after 24, 36 and 48 h exposure to BaP, AFB1, TCDD or CsA. Those genes that have expression values are labelled with circles/disks of different shades of red or blue, according to the corresponding levels of up- or down-regulation, respectively. A green arrow indicates activation, a red arrow indicates inhibition. 


\section{Discussion}

With the aim to find alternatives for expensive and long-lasting chronic rodent bioassays, primary mouse hepatocytes were used to evaluate the time-dependence of this in vitro assay to classify carcinogens by their modes of action using gene expression profiling.

Evaluation of $\gamma \mathrm{H} 2 \mathrm{AX}$ foci formation confirmed the correct selection of GTX and NGTX compounds. Induction of $\gamma \mathrm{H} 2 \mathrm{AX}$ foci is a measure for the formation of dsDNA breaks in human cell lines and in the liver of mice $(13,14)$, but this has, to our knowledge, not previously been demonstrated in primary mouse hepatocytes. The two GTX carcinogens appeared clearly capable of inducing $\gamma \mathrm{H} 2 \mathrm{AX}$ foci formation, while the two NGTX carcinogens, on the other hand, were not able to cause $\gamma \mathrm{H} 2 \mathrm{AX}$ foci formation. These results are in line with findings on cell lines done by Zhou et al. (28), who found comparable results in human amnion FL and Chinese hamster CHL cells after $24 \mathrm{~h}$ of exposure to $\mathrm{BaP}$ and other GTX compounds. NGTX compounds CsA and azathioprine did not show an induction in $\gamma \mathrm{H} 2 \mathrm{AX}$ foci formation in human amnion FL and Chinese hamster CHL cells in the study of Zhou et al. (28).

To discriminate GTX and NGTX compounds based on gene expression profiles, we used a supervised clustering approach, namely PAM. Because length of exposure has been shown to have a major influence on gene expression profiles in cells in vitro (10, 11) it may be hypothesized that exposure period affects class discrimination based on transcriptomics data. In the current study class discrimination is indeed dependent on exposure time. At $12 \mathrm{~h}$ the two classes could not be discriminated in the training set. After longer exposure times, however, class discrimination was successful. At the $12 \mathrm{~h}$ time point, a high misclassification error rate was shown. At the other time points, misclassification errors were 0 and therefore these incubation periods all seem suited for class discrimination.

The lists of classifiers sampled at 24, 36 and $48 \mathrm{~h}$ of exposure were compared. Only 1 classifier at $36 \mathrm{~h}$ of exposure was unique, all the other classifiers at $36 \mathrm{~h}$ were also present in the list of classifiers at 24 or $48 \mathrm{~h}$. Six classifiers were present in the lists for 24 and $48 \mathrm{~h}$. Consequently, transcriptomic response at $36 \mathrm{~h}$ of exposure have not been evaluated in the subsequent validation.

The PAM classification models based on classifiers generated at 24 and $48 \mathrm{~h}$ of exposure were validated in a study with two additional compounds, DMN and MitC. Based on their gene expression profiles, both compounds were correctly classified as GTX, demonstrating that the obtained classifiers following exposure to carcinogens may indeed be able to discriminate between GTX and NGTX classes. At both time points, classification was perfect, although the classifiers lists were quite different. Gene expression modifications correlating with $\gamma \mathrm{H} 2 \mathrm{AX}$ foci formation as induced by the four model compounds, were also used in PAM as a training set. Generated classifiers were vali- 
dated again by using the additional compounds and both compounds were classified correct only at $48 \mathrm{~h}$, but with lower test probabilities as compared to class discrimination with all differentially expressed probe sets. This suggests that DNA damage-related genes are an important, but not the only contributor in discriminating GTX from NGTX. The applicability of class discrimination for carcinogens by gene expression profiling was shown in several mouse and rat in vivo studies (6, 29-31). Furthermore the reliability of classification methods similar to the one we used, were previously successfully demonstrated in in vivo and in vitro (HepG2 cells) systems to discriminate GTX from NGTX carcinogens $(6,7,32,33)$. Most of these studies did not focus on time-dependent discrimination, but evaluated changes at only one time point. The study from Uehara et al. showed time-dependent increase in discrimination scores by PAM in rats treated with NGTX (33). The in vivo study from Ellinger-Ziegelbauer et al. demonstrated that more differences between GTX and NGTX compounds were observed after treatment for 7 day compared to 1 or 3 days (34).

Since it is known that DNA damage is induced by GTX compounds, it is not surprising that many of the classifiers for GTX are involved in cell cycle checkpoints, repair mechanism and response to DNA damage. The induction of $\gamma \mathrm{H} 2 \mathrm{AX}$ foci formation confirms that also in these primary hepatocytes cultures the GTX compounds induce DNA damage. Predominantly, the formation of these foci is a result of double-strand DNA damage, which can be caused by repair mechanisms deleting DNA adducts (27, 28).

Analysis by MetaCore demonstrated that the murine double minute (Mdm2) oncogene is the most prominent classifier is, which is a regulator of $\mathrm{p} 53$, but also has some p53independent activities (35). The Mdm2 oncoprotein binds to p53 and thereby blocks its ability to inhibit cellular proliferation or to induce cell death (36). Mdm2 mediates the ubiquitination of p53 and promotes the degradation of p53 by the proteasome (37). Overexpression of $\mathrm{Mdm} 2$ is related to the increase of tumorigenic potential and can overcome the suppression of growth activity of p53 $(38,39,40)$. This p53 is related to DNA damage responses as levels of p53 are increasing vary fast in cells sustaining DNA damage (41). Mdm2 and P53 form a feedback loop which plays a role in cell cycle arrest and apoptosis (42). GTX compounds might therefore be able to induce overexpression of this Mdm2 oncogene. In our study treatment with GTX compounds clearly increases the Mdm2 gene expression.

Furthermore, the gene expression of the Mdm2 oncogene is suppressed by FHIT, which is a tumor suppressor gene (40). Treatment with GTX compounds caused a downregulation of this FHIT gene in our study, leading to stimulation of Mdm2. Other classifiers linked to $\mathrm{Mdm} 2$ gene in the network from MetaCore are involved in response to DNA damage and metabolism. Furthermore, Mdm2 was previously detected as a classifier that could discriminate between GTX and NGTX in rat livers (33). Although the other classifiers found in that study are different from our classifiers, the affected 
responses to DNA damage and cell cycle regulation-related processes, are comparable. More in vivo class discrimination studies found classifiers involved in metabolism, cell cycle-related and DNA damage responses $(31,29)$. An HepG2 in vitro study detected classifiers mainly involved in apoptosis-related pathways; however, also some p53related DNA damage responses were detected (7).

Pathway analysis was used to visualize compound- and time-related effects. At $12 \mathrm{~h}$ of treatment hardly any effects are observed on pathways. This is in agreement with the effects on genes, indicating that this time point is not suitable for further transcriptomics experiments. The biggest effects on pathways, however, are observed at $48 \mathrm{~h}$ of treatment. At $24 \mathrm{~h}$ of treatment an upregulation of most gene sets related to macromolecules, cellular organisation and regulation by all compounds is observed. These processes might be naturally occurring in primary hepatocytes in culture as it was shown before in untreated hepatocytes that cellular organisation and macromolecule related gene groups are mainly upregulated during culture (16). Besides these common processes triggered by all compounds, differences between the GTX and NGTX compounds are observed. Signal transduction gene groups are only upregulated by the NGTX compounds at $24 \mathrm{~h}$. Gene groups involved in immune responses, extracellular, membrane and cytoplasm processes, lipid-related processes and metabolic and biosynthetic processes are mainly downregulated by GTX compounds an upregulated by NGTX compounds at later time points. The few P53-related gene groups are mainly upregulated by GTX compounds, especially at $36 \mathrm{~h}$. Treatment of primary mouse hepatocytes with CsA triggered only a small number of pathways in these cells and more pathways were significantly altered at $48 \mathrm{~h}$ of treatment. CsA is a well-known human carcinogen, but showed no tumor development before in wild-type male C57BL/6 mice (43); this might explain the observed minor effects on pathways in this mouse hepatocyte model. Also treatment of primary mouse hepatocytes with TCDD led to a small number of significantly modulated pathways, with most pathways modulated at $48 \mathrm{~h}$ of treatment, showing that both NGTX compounds have less pronounced effects on primary mouse hepatocytes and their effects are observed at a later stage as compared to GTX compounds. The major differences between GTX and NGTX compounds at the level of pathways were detected in P53-related processes and immune responses. Furthermore cytochromeP450-related gene groups are mostly upregulated by $\mathrm{BaP}$ and TCDD at 36 and $48 \mathrm{~h}$. Most likely this is due to the activation of the Aryl hydrocarbon receptor by these compounds $(44,45)$.

In summary, the present study demonstrates that in primary mouse hepatocytes, exposure length is of major importance for classifying GTX and NGTX compounds based on gene expression profiling. $12 \mathrm{~h}$ of exposure appeared too short, and a treatment period of $48 \mathrm{~h}$ seems optimal. 
These findings may be used to further develop an in vitro assay of mouse primary hepatocytes using gene expression profiling to predict possible carcinogens, and thus that the use of mouse primary hepatocytes is a specific and promising in vitro model.

\section{Acknowledgements}

Financial support was provided by the Netherlands Genomics Initiative (NGI), the Netherlands Organisation for Scientific Research (NWO) and the CARCINOGENOMICS FP6 project sponsored by the European Union (PL037712). 


\section{References}

1. Roe, F.J., A brief history of the use of laboratory animals for the prediction of carcinogenic risk for man with a note on needs for the future. Exp Toxicol Pathol, 1998. 50(4-6): p. 271-6.

2. Dambach, D.M., B.A. Andrews, and F. Moulin, New technologies and screening strategies for hepatotoxicity: use of in vitro models. Toxicol Pathol, 2005. 33(1): p. 17-26.

3. Butterworth, B.E., et al., Use of primary cultures of human hepatocytes in toxicology studies. Cancer Res, 1989. 49(5): p. 1075-84.

4. Groneberg, D.A., C. Grosse-Siestrup, and A. Fischer, In vitro models to study hepatotoxicity. Toxicol Pathol, 2002. 30(3): p. 394-9.

5. Le Fevre, A.C., et al., Characterization of DNA reactive and non-DNA reactive anticancer drugs by gene expression profiling. Mutat Res, 2007. 619(1-2): p. 16-29.

6. Eun, J.W., et al., Discriminating the molecular basis of hepatotoxicity using the large-scale characteristic molecular signatures of toxicants by expression profiling analysis. Toxicology, 2008. 249(2-3): p. 17683.

7. van Delft, J.H., et al., Discrimination of genotoxic from non-genotoxic carcinogens by gene expression profiling. Carcinogenesis, 2004. 25(7): p. 1265-76.

8. Ashby, J., Use of short-term tests in determining the genotoxicity or nongenotoxicity of chemicals. IARC Sci Publ, 1992(116): p. 135-64.

9. Silva Lima, B. and J.W. Van der Laan, Mechanisms of nongenotoxic carcinogenesis and assessment of the human hazard. Regul Toxicol Pharmacol, 2000. 32(2): p. 135-43.

10. Hockley, S.L., et al., Time- and concentration-dependent changes in gene expression induced by benzo(a)pyrene in two human cell lines, MCF-7 and HepG2. BMC Genomics, 2006. 7: p. 260.

11. Lambert, C.B., et al., Dose- and time-dependent effects of phenobarbital on gene expression profiling in human hepatoma HepaRG cells. Toxicol Appl Pharmacol, 2009. 234(3): p. 345-60.

12. Waterston, R.H., et al., Initial sequencing and comparative analysis of the mouse genome. Nature, 2002. 420(6915): p. 520-62.

13. Koike, M., et al., Histone H2AX Phosphorylation Independent of ATM after X-irradiation in Mouse Liver and Kidney in situ. J Radiat Res (Tokyo), 2008.

14. Rogakou, E.P., et al., DNA double-stranded breaks induce histone H2AX phosphorylation on serine 139. J Biol Chem, 1998. 273(10): p. 5858-68.

15. Seglen, P.O., Preparation of isolated rat liver cells. Methods Cell Biol, 1976. 13: p. 29-83.

16. Mathijs, K., et al., Assessing the metabolic competence of sandwich-cultured mouse primary hepatocytes. Drug Metab Dispos, 2009. 37: p. 1305-11.

17. Beken, S., et al., Collagen-gel cultures of rat hepatocytes: collagen-gel sandwich and immobilization cultures. Methods Mol Biol, 1998. 107: p. 303-9.

18. Hamer, G., et al., DNA double-strand breaks and gamma-H2AX signaling in the testis. Biol Reprod, 2003. 68(2): p. 628-34.

19. Tong, W., et al., ArrayTrack--supporting toxicogenomic research at the U.S. Food and Drug Administration National Center for Toxicological Research. Environ Health Perspect, 2003. 111(15): p. 1819-26.

20. Irizarry, R.A., et al., Exploration, normalization, and summaries of high density oligonucleotide array probe level data. Biostatistics, 2003. 4(2): p. 249-64.

21. Affymetrix, Statistical Algorithms Description Document, technical report. 2002.

22. Shi, L., et al., The MicroArray Quality Control (MAQC) project shows inter- and intraplatform reproducibility of gene expression measurements. Nat Biotechnol, 2006. 24(9): p. 1151-61.

23. Ward, J.H., Hierarchical grouping to optimize an objective function. Journal of the American Statistical Association 1963. 58: p. 236-244.

24. Boorsma, A., et al., T-profiler: scoring the activity of predefined groups of genes using gene expression data. Nucleic Acids Res, 2005. 33(Web Server issue): p. W592-5.

25. Reich, M., et al., GenePattern 2.0. Nat Genet, 2006. 38(5): p. 500-1. 
26. Tibshirani, R., et al., Diagnosis of multiple cancer types by shrunken centroids of gene expression. Proc Natl Acad Sci U S A, 2002. 99(10): p. 6567-72.

27. Fernandez-Capetillo, O., et al., H2AX: the histone guardian of the genome. DNA Repair (Amst), 2004. 3(8-9): p. 959-67.

28. Zhou, C., et al., DNA damage evaluated by gammaH2AX foci formation by a selective group of chemi$\mathrm{cal} /$ physical stressors. Mutat Res, 2006. 604(1-2): p. 8-18.

29. Iida, M., et al., Unique patterns of gene expression changes in liver after treatment of mice for 2 weeks with different known carcinogens and non-carcinogens. Carcinogenesis, 2005. 26(3): p. 689-99.

30. Ellinger-Ziegelbauer, H., et al., Prediction of a carcinogenic potential of rat hepatocarcinogens using toxicogenomics analysis of short-term in vivo studies. Mutat Res, 2007.

31. Nioi, P., et al., Prediction of non-genotoxic carcinogenesis in rats using changes in gene expression following acute dosing. Chem Biol Interact, 2008. 172(3): p. 206-15.

32. van Delft, J.H., et al., Comparison of supervised clustering methods to discriminate genotoxic from nongenotoxic carcinogens by gene expression profiling. Mutat Res, 2005. 575(1-2): p. 17-33.

33. Uehara, T., et al., A toxicogenomics approach for early assessment of potential non-genotoxic hepatocarcinogenicity of chemicals in rats. Toxicology, 2008. 250(1): p. 15-26.

34. Ellinger-Ziegelbauer, H., et al., Comparison of the expression profiles induced by genotoxic and nongenotoxic carcinogens in rat liver. Mutat Res, 2005. 575(1-2): p. 61-84.

35. Daujat, S., H. Neel, and J. Piette, MDM2: life without p53. Trends Genet, 2001. 17(8): p. 459-64.

36. Momand, J., H.H. Wu, and G. Dasgupta, MDM2--master regulator of the p53 tumor suppressor protein. Gene, 2000. 242(1-2): p. 15-29.

37. Haupt, Y., et al., Mdm2 promotes the rapid degradation of p53. Nature, 1997. 387(6630): p. 296-9.

38. Finlay, C.A., The mdm-2 oncogene can overcome wild-type p53 suppression of transformed cell growth. Mol Cell Biol, 1993. 13(1): p. 301-6.

39. Bueso-Ramos, C.E., et al., The human MDM-2 oncogene is overexpressed in leukemias. Blood, 1993. 82(9): p. 2617-23

40. Schlott, T., et al., Different gene expression of MDM2, GAGE-1, -2 and FHIT in hepatocellular carcinoma and focal nodular hyperplasia. Br J Cancer, 1999. 80(1-2): p. 73-8.

41. Lakin, N.D. and S.P. Jackson, Regulation of p53 in response to DNA damage. Oncogene, 1999. 18(53): p. 7644-55.

42. Jiang, Y., et al., Up-regulation of murine double minute clone 2 (MDM2) gene expression in rat brain after morphine, heroin, and cocaine administrations. Neurosci Lett, 2003. 352(3): p. 216-20.

43. van Kreijl, C.F., et al., Xpa and Xpa/p53+/- knockout mice: overview of available data. Toxicol Pathol, 2001. 29 Suppl: p. 117-27.

44. Levin, W., et al., Oxidative metabolism of polycyclic aromatic hydrocarbons to ultimate carcinogens. Drug Metab Rev, 1982. 13(4): p. 555-80.

45. Bock, K.W., Aryl hydrocarbon or dioxin receptor: biologic and toxic responses. Rev Physiol Biochem Pharmacol, 1994. 125: p. 1-42. 



\section{Chapter 6}

\section{Gene Expression Profiling in Primary Mouse Hepatocytes Discriminates Between True and False Genotoxic Compounds}




\title{
Chapter 6
}

\begin{abstract}
Since well-established in vitro methods for testing the genotoxic potency of chemicals such as the Ames/Salmonella test, the mouse lymphoma assay, the micronucleus test and the chromosomal aberration test - show an extremely high false positive rate in that they wrongly predict in vivo genotoxicity and carcinogenicity, there is an urgent need for more reliable assays. Within this context, we investigated whether gene expression profiling in metabolically competent primary mouse hepatocyte cultures is capable of discriminating true genotoxic compounds (GTX) from false positive genotoxic compounds (FP GTX). Sandwich-cultured primary hepatocytes from male C57BL/6 mice were treated for 24 and $48 \mathrm{~h}$ with five true GTX and five false GTX compounds. Immunostaining of $\gamma \mathrm{H} 2 \mathrm{AX}$ foci was used to verify the induction of DNA damage by these compounds. Whole genome gene expression modifications were analyzed by means of Affymetrix mouse genome 4302.0 microarrays. Selected differentially expressed genes were subjected to hierarchical clustering and class prediction methods. The $\gamma \mathrm{H} 2 \mathrm{AX}$ assay revealed significant induction of DNA damage by treatment with all true GTX compounds, whereas false GTX compounds were not able to increase $\gamma \mathrm{H} 2 \mathrm{AX}$ formation, except for 4-Nitro-o-phenylenediamine (4-NP). Only after $48 \mathrm{~h}$, replicates for each compound cluster perfectly together. Class prediction resulted in a correct classification for 9 out of 10 compounds at both time points; only 2-Acetylaminofluorene (2-AAF) was misclassified. The 76 classifiers at $24 \mathrm{~h}$ of exposure and 97 classifiers at $48 \mathrm{~h}$ of exposure were mostly involved in several metabolic and biosynthetic processes, immune responses and apoptosis. The present study shows that gene expression profiling in primary mouse hepatocytes is capable of discriminating between true GTX compounds and false positive GTX compounds.
\end{abstract}




\section{Introduction}

Well-established in vitro systems frequently used to identify the genotoxic potency of chemicals are the bacterial Ames test, the mouse lymphoma assay, the micronucleus test and the chromosomal aberration test (1). These classic in vitro genotoxicity tests, however, have been shown to generate an extremely high false positive rate in terms of erroneously predicting carcinogenicity in vivo (1). The specificity of the bacterial Ames test, for example, is $73.9 \%$, while the mouse lymphoma assay, the micronucleus test and the chromosomal aberration test have a specificity even below $45 \%$. However, a positive outcome from the in vitro test battery requires subsequent in vivo testing for genotoxicity (2). In case of a false positive outcome, this implies that without reason animals are subject to such additional in vivo testing. This leads to costs and animal burden, based on the wrong arguments. Therefore, novel in vitro systems need to be developed which are capable of reliably discriminating genotoxins and non-genotoxins Chemical compounds, which are are capable of causing gene mutations or chromosomal damage in vitro are defined as genotoxins (GTX). In most cases this is by covalent binding with DNA $(3,4)$. Formed damage may be not or incorrectly repaired which leads to mutations accumulating in time and - in a worst case - ultimately inducing the formation of tumors $(3,4)$.

The liver is the principal organ involved in the biotransformation of xenobiotic substances, with its capacity to convert hydrophobic compounds into water-soluble products that can be readily secreted from the body. This transformation first involves activation to intermediates which are often highly reactive and can bind to DNA, causing DNA damage (5). The liver also represents a major target organ for chemical carcinogens in vivo $(6,7)$. The use of in vitro liver systems is therefore relevant to screen potential carcinogenic compounds.

Additionally, the application of global gene expression analysis has the potential of providing new biomarkers for predicting the toxic risks of chemicals for humans. Simultaneously to identifying a characteristic set of genes from a database of reference profiles in order to predict a compound's unknown toxicity, these methodologies may enhance our understanding of the mechanisms underlying the compound's toxic effects $(8,3)$. Gene expression profiling analysis is shown to be a valuable tool for investigating mechanisms of toxicity in several in vitro liver systems and in vivo (9-13).

In this context, the current study focuses on the application of chemically-induced altered gene expression profiling to primary mouse hepatocytes as an in vitro system for the purpose of discriminating GTX compounds from false positive GTX compounds. The false positive GTX compounds are defined as non-carcinogens, demonstrating only genotoxicity in in vitro tests, but not in vivo in rodent bioassays..

Primary mouse hepatocytes are applied in this study as an in vitro system to discriminate false positive GTX compounds from true GTX compounds, because (A) they are 
metabolic competent, (B) the complete sequence of the mouse genome is available (14) , and (C) transgenic mouse models may allow relevant mechanistic follow-up studies. Gene expression profiles of primary mouse hepatocytes, were challenged with five true GTX compounds and five false positive GTX compounds, and were compared in order to generate a list of classifiers which may be able to discriminate these two classes. The formation of phosphorylated $\mathrm{H} 2 \mathrm{AX}(\gamma \mathrm{H} 2 \mathrm{AX})$ foci, which particularly monitor double strand breaks as histone H2AX becomes phosphorylated on serine-139 by ataxia telangiectasia mutated (ATM) kinase and accumulates at the breaks $(15,16)$, was assessed in order to phenotypically discriminate these two classes.

\section{Materials and Methods}

\section{Chemicals}

Dulbecco's modified Eagle's medium (DMEM), fetal calf serum (FCS), Hanks' calcium- and magnesium-free buffer, Alexa fluor 488 goat anti-mouse IgG antibody, insulin and Trizol were obtained from Invitrogen (Breda, The Netherlands). Glucagon, hydrocortisone, collagenase type IV, Benzo(a)pyrene (BaP), Aflatoxin B1 (AFB1), 2Acetylaminofluorene (2-AAF), Dimethylnitrosamine (DMN), Mitomycin C (MitC), oAnthranilic acid (ANAC), 2-(Chloromethyl)pyridine.HCl (2-CP), 4-Nitro-ophenylenediamine (4-NP), Quercetin (Q), 8-Hydroxyquinoline (8-HQ), Trypan blue, dimethylsulphoxide (DMSO), bovine serum albumin (BSA), 4',6-diamidino-2phenylindole (DAPI) and Tween-20 were purchased from Sigma-Aldrich (Zwijndrecht, The Netherlands). Triton X-100, NaCl, $\mathrm{Na}_{2} \mathrm{HPO}_{4} \cdot 2 \mathrm{H}_{2} \mathrm{O}$ and $\mathrm{NaH}_{2} \mathrm{PO}_{4}$ were obtained from Merck (Darmstadt, Germany) and paraformaldehyde from ICN biomedicals (Auroro, Ohio). The anti-phospho-Histone H2A-X (ser139) Clone JBW 301 antibody was purchased by Upstate Biotechnology (Lake Placid, NY). Vectashield® Mounting Medium was supplied by Vector Labs (Burlingame, CA). Collagen Type I Rat Tail was obtained from BD BioSciences (Bedford, MA). The RNeasy minikit was obtained from Qiagen, Westburg B.V. (Leusden, The Netherlands). The 5x MegaScript T7 Kit was obtained from Ambion (Austin, TX). The GeneChip ${ }^{\circledR}$ Expression 3'-Amplification Two-Cycle cDNA Synthesis Kit and Reagents, the Hybridization, Wash and Stain Kit and the Mouse Genome 430 2.0 Arrays were purchased from Affymetrix (Santa Clara, CA).

\section{Animals}

Permission for performing animal studies was obtained from the Animal Ethical Committee. Adult male C57BL/6 mice (Charles River), weighing 20-25 g, were obtained from Charles River GmbH, Sulzfeld, Germany. This mouse strain was chosen because it is frequently used in toxicological and pharmacological investigations, and it is a com- 
mon background for transgenic mouse strains. The animals were housed in macrolon cages with sawdust bedding at $22^{\circ} \mathrm{C}$ and $50-60 \%$ humidity. The light cycle was $12 \mathrm{~h}$ light/12 h dark. Feed and tap water were available ad libitum.

\section{Isolation of hepatocytes}

Hepatocytes were isolated from adult male C57BL/6 mice by a two-step collagenase perfusion method according to Seglen and Casciano $(17,18)$, with modifications as described before (19). Cell viability and yield were determined by trypan blue exclusion.

\section{Cell culturing and treatments}

Cells with viability $>85 \%$, were cultured in a collagen-collagen sandwich formation as described before $(19,20,21)$. Prior to treatment, primary cultures of mouse hepatocytes were allowed to recover for $40-42 \mathrm{~h}$ at $37^{\circ} \mathrm{C}$ in a humidified chamber with $95 \% / 5 \%$ air $/ \mathrm{CO}_{2}$ in serum-free culture medium supplemented with insulin $0.5 \mathrm{U} / \mathrm{ml}$ ), glucagon ( $7 \mathrm{ng} / \mathrm{ml})$, hydrocortisone $(7.5 \mu \mathrm{g} / \mathrm{ml})$ and $2 \%$ penicillin/streptomycin $(5000 \mathrm{U} / \mathrm{ml}$ penicillin; $5000 \mu \mathrm{m} / \mathrm{ml}$ streptomycin). Culture medium was refreshed every $24 \mathrm{~h}$. After the recovery period, the culture medium was replaced by culture medium containing one of the selected ten compounds, or with vehicle control. Only non-cytotoxic doses were used for each compound, which were determined by the MTT assay (ca $80 \%$ viability after $24 \mathrm{~h}$ incubation) and are presented in Table 1. Cells were incubated for 24 or $48 \mathrm{~h}$ before being used for detecting double-stranded (ds) DNA breaks or harvested for RNA isolation by adding Trizol reagent. Three independent replicate biological experiments with hepatocytes from different mice were conducted for each compound.

\section{Detection of dsDNA breaks}

Double-stranded DNA breaks were detected by immunostaining of the phosphorylated histone $\mathrm{H} 2 \mathrm{AX}(\gamma \mathrm{H} 2 \mathrm{AX})$ as described before (22, Chapter 5). Samples were corrected for their vehicle control and for the statistical analysis of dose-dependent effects the $t$ test was used ( $\mathrm{p}$-value $<0.05)$.

\section{RNA isolation}

Total RNA was isolated from cultured mouse hepatocytes using Trizol and by means of the RNeasy kit according to the manufacturer's protocol. RNA concentrations were measured by means of a spectrophotometer and the quality of each RNA preparation was determined by means of a bio-analyzer (Agilent Technologies, The Netherlands). Only samples with a good quality (clear $18 \mathrm{~S}$ and $28 \mathrm{~S}$ peaks and $\mathrm{RIN}>6$ ) were used for hybridization. Extracted RNA was stored at $-80^{\circ} \mathrm{C}$ until further analysis. 
Whole genome gene expression analysis

Targets were prepared according to the Affymetrix protocol. cRNA targets were hybridized according to the manufacturer's recommended procedures on high-density oligonucleotide gene chips (Affymetrix Mouse Genome 430 2.0 GeneChip arrays). The gene chips were washed and stained using an Affymetrix fluidics station and scanned by means of an Affymetrix GeneArray scanner.

A total of eighty-two GeneChips was run (ArrayExpress nummers volgen nog). Normalization quality controls, including scaling factors, average intensities, present calls, background intensities, noise, and raw $\mathrm{Q}$ values, were within acceptable limits for all chips. Hybridization controls BioB, BioC, BioD, and CreX, were identified on all chips and yielded the expected increases in intensities.

\section{Data analysis}

\section{Selection of differentially expressed probe sets}

Eighty-two datasets were obtained from this experiment. Raw data were imported into ArrayTrack $(23,24)$ and normalized using Robust Multi-array Average (RMA, integrated into ArrayTrack) (25).

Present-Marginal-Absent calls were used to identify and omit probe sets of poor quality (26). Subsequently, the remaining probe sets were logarithmically (base 2) transformed, corrected for vehicle control, and subjected to all further analyses ( $24 \mathrm{~h}: 26100 ; 48 \mathrm{~h}$ : 26690; total: 27363). Probe sets for which expression was up- or down-regulated by at least one compound at a minimum of 1.2-fold in at least two out of three experiments with expressions altered in the same direction in all replicates and with a mean fold upor down-regulation of 1.5 were selected (27). This was repeated for each time point. The generated list with differentially expressed probe sets (log 2 ratios) was used for hierarchical clustering (HCA) and prediction analysis of microarray (PAM) (10776 probe sets at $24 \mathrm{~h}$ and 12180 probe sets at $48 \mathrm{~h}$ ).

\section{Correlation analysis}

Genes that correlated with $\gamma \mathrm{H} 2 \mathrm{AX}$ foci formation were identified using the gene expression profile analysis suite (GEPAS 4.0; CIPF, Valencia, Spain). The values for $\gamma \mathrm{H} 2 \mathrm{AX}$ foci formation, corrected by subtracting the values for DMSO control from the log (base 2) transformed values for the exposed samples, were correlated with the expression changes of differentially expressed probe sets. Spearman correlation coefficients were calculated and correlating genes $(\mathrm{P}<0.05)$ were selected for PAM.

\section{Pathway analysis}

The complete data sets of genes from all compounds of all experiments ( $\log 2$ of the ratios for treated-control) were uploaded in T-profiler (28) to identify transcriptional regulation of biochemical pathways and biological processes in the complete data set of genes without any pre-selection of genes. T-profiler uses the T-test to score the differ- 
ence between the mean expression level of predefined groups of genes and that of all other genes without any pre-selection of modulated genes (28). Significance was determined by generating an E value, a Bonferroni corrected $\mathrm{P}$ value. Pathways and processes were significant when E values were below 0.05 and used for hierarchical clustering GenePattern (29) using Pearson correlation with pairwise complete-linkage.

\section{Class prediction and functional analysis of classifiers}

The software tool "prediction analysis of microarray" (PAM) was used for discriminating true GTX compounds from false positive GTX compounds (30). PAM uses gene expression data to calculate the shrunken centroid for each class and identifies the specific genes that determine the centroid most. Based on the nearest shrunken centroid, PAM is also capable of predicting to which class an unknown sample belongs (30). Class prediction was performed after $24 \mathrm{~h}$ and $48 \mathrm{~h}$ of exposure.

For this analysis, the gene list with differentially expressed probe sets was used. For each exposure period, 3 sets of genes (classifiers) were generated by PAM, using all ten treatments, based on the smallest estimated misclassification error rate (generated by 10 -fold cross-validation) and a $>80 \%$ predicted test probability. This was done by using 2 experiments as training set and the third experiment for validation. This was done for all 3 possible combinations, each time leaving out another experiment. For each time point, the classifiers that were in common between the three training sets, were set as the final classifier set for that time point and were further analyzed for functional annotation by MetaCore using the shortest path algorithm (GeneGo, San Diego, CA). In total, 76 classifiers from $24 \mathrm{~h}$ and 97 classifiers from $48 \mathrm{~h}$ were analyzed by MetaCore. The total list of probe sets, without probe sets of poor quality, were selected for each time point as described before (24 h: 26100; 48 h: 26690; total: 27363) and used as background list in MetaCore. A false discovery rate of 0.3 was used to select significant MetaCore maps. 


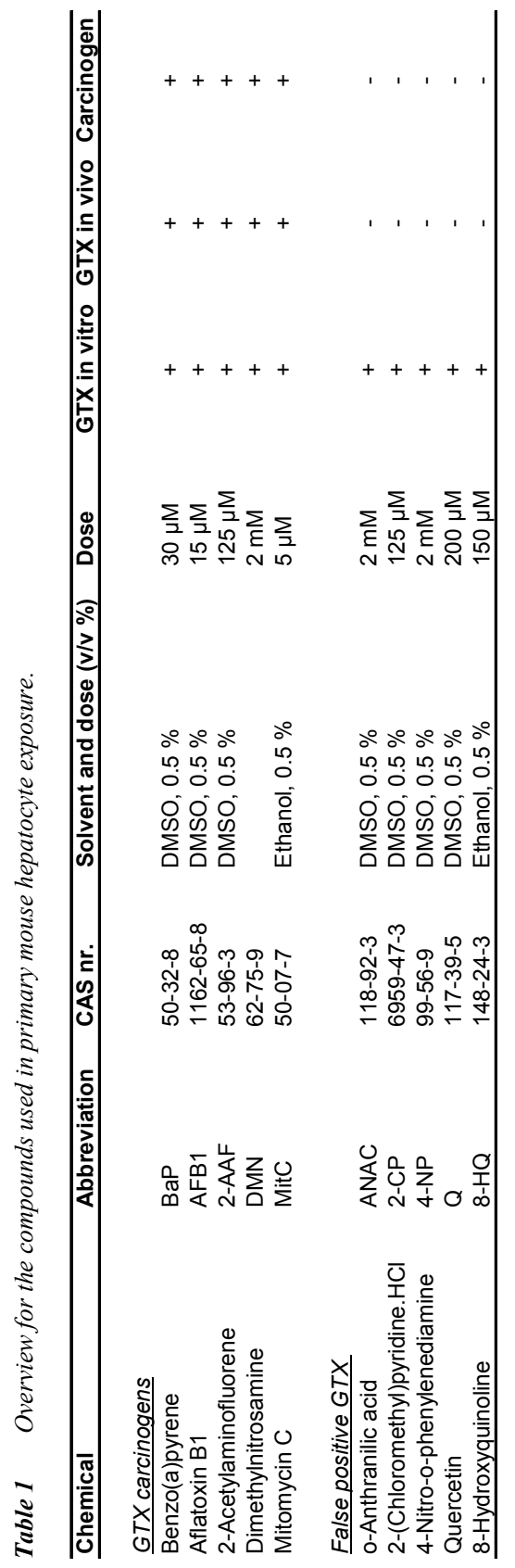




\section{Results}

Ten compounds were selected to examine the usefulness of sandwich-cultured primary mouse hepatocytes for discriminating true GTX compounds from their false positive GTX compounds. All true GTX compounds, chosen for this study, were shown to be GTX in vitro and in vivo and to be carcinogenic in mouse liver. The false positive GTX compounds are all GTX in at least 3 in vitro tests, non-GTX in in vivo tests and they are non-carcinogens (1). Non-cytotoxic doses were used for all compounds, determined by the MTT assay (ca 80\% viability after $24 \mathrm{~h}$ incubation) (Table 1).

\section{Detection of dsDNA breaks}

The formation of phosphorylated $\gamma \mathrm{H} 2 \mathrm{AX}$ foci, which is a signature for dsDNA breaks $(31,16,32)$, in relation to exposure to ten compounds in comparison to vehicle controls for 24 and $48 \mathrm{~h}$ is shown in Figure 1. dsDNA break frequencies in cells treated with true GTX compounds were significantly increased. Cells treated with false positive GTX compounds, with exception of 4-NP, showed no significant increase in $\gamma \mathrm{H} 2 \mathrm{AX}$ foci formation. Time had only a significant effect following treatment with $\mathrm{BaP}$. A significant increase in $\gamma \mathrm{H} 2 \mathrm{AX}$ foci formation was detected in these cells as exposure time elongated. The results for Q-treated cells, however, are less reliable as non-specific staining of the collagen layer was detected in these samples (data not shown).

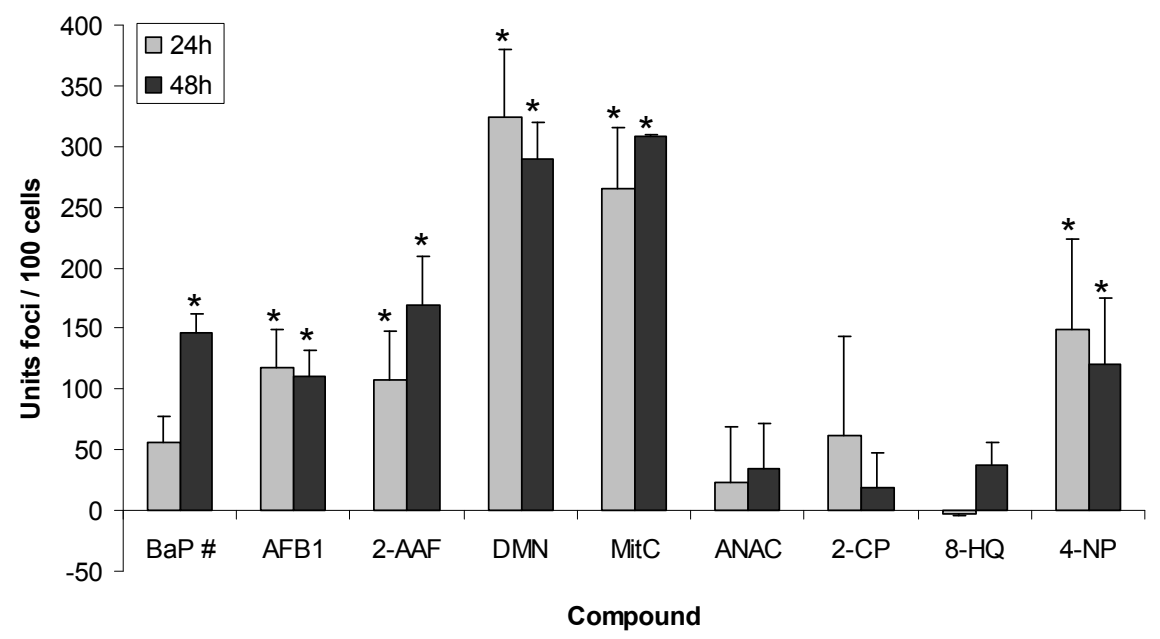

Figure $1 \quad$ Levels of dsDNA breaks ( $\gamma H 2 A X$ foci) in primary mouse hepatocytes exposed to GTX and FP GTX compounds for 24 or $48 \mathrm{~h}$ (average with SD of 3 experiments and corrected for solvent control)

* Significant (p-value <0.05) compared to solvent controls

\# Significant ( $p$-value $<0.05)$ over time 


\section{Chapter 6}

\section{Hierarchical clustering analyses}

To visualize possible similarities and differences between gene expression profiles from all compounds, HCA was performed by including only differentially expressed genens in samples from the $24 \mathrm{~h}$ and $48 \mathrm{~h}$, respectively (10776 probe sets at $24 \mathrm{~h}$ and 12180 probe sets at $48 \mathrm{~h}$ ) (Figure 2). Only after $48 \mathrm{~h}$ of exposure, replicates from each compound cluster perfectly together, not at $24 \mathrm{~h}$. At none of the time points a clear clustering occurs of true or false positive GTX compounds. At $48 \mathrm{~h}$ MitC and DMN cluster separately from all the other compounds. All false positive GTX compounds cluster together, with the exception of 4-NP which is clustered separately from all compounds.
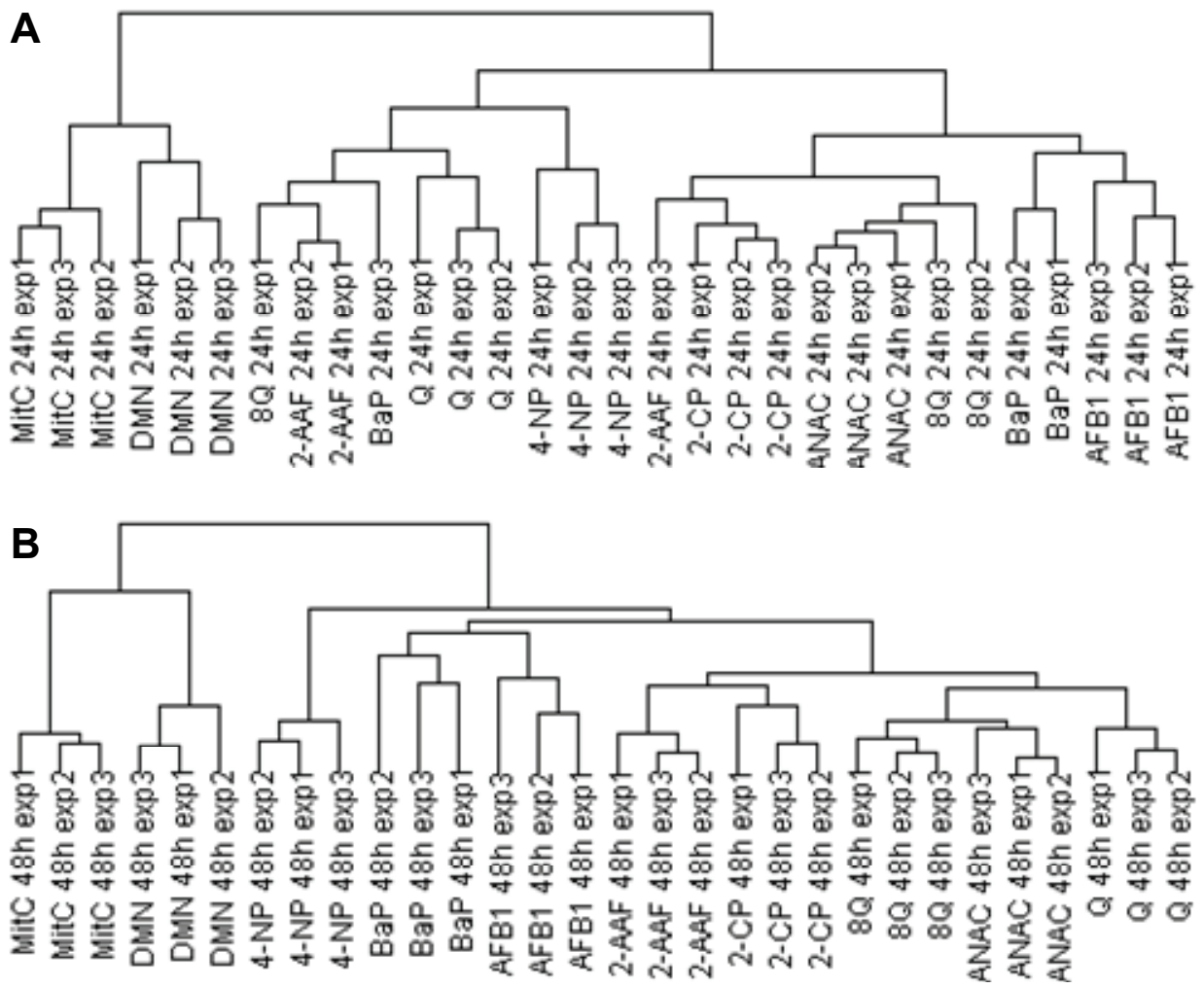

Figure 2 Hierarchical clustering of treatments with differentially expressed genes in primary mouse hepatocytes after exposure to GTX and FP GTX compounds at (A) $24 \mathrm{~h}$ and (b) $48 \mathrm{~h}$. 
Pathway analysis

Pathways and processes significantly altered in hepatocytes in at least two experiments and changed in the same direction in all three replicates, were considered affected. For each compound and each time point significantly altered pathways were selected (in total 1422 pathways). Hierarchical clustering of these pathways with GenePattern (29) is presented in Figure 3, showing distinct patterns for groups of pathways. Differences between the two time points are especially observed after treatment with 2-CP or 8-HQ. The effects on pathways after treatment with 2-AAF are clearly different from the other true GTX compounds, especially in pathways related to metabolic and biosynthetic processes, immune responses, glycolysis and gluconeogenesis, mitochondrial and cell energy related processes and ribosomal and translation processes.

\section{Class prediction}

In order to identify classifier genes whose expression changes best discriminate true GTX compounds from the false positive GTX compounds, the class prediction software tool PAM was used. For each time point, initially 3 lists of classifiers were generated, based on analyses by PAM of the data from 2 experiments and leaving out the third. The experiment left out (consisting of 10 treatments), was used for validation. Ultimately, the classifiers from each time point which were in common between these three training sets were selected. This resulted in 76 classifiers after $24 \mathrm{~h}$ of exposure and 97 classifiers after $48 \mathrm{~h}$, presented in Table 2.34 classifiers were in common between exposure periods of 24 and $48 \mathrm{~h}$.

The results for each validation are presented in Table 3. Each validation test resulted in a perfect classification of 9 out of the 10 compounds. Only 2-AAF was misclassified in all validation tests and for all experiments at both time points.

In an attempt to improve class discrimination, genes correlating with $\gamma \mathrm{H} 2 \mathrm{AX}$ foci formation were also fed into PAM; this resulted in a similar outcome (data not shown).

\section{Functional analyses of classifiers}

The classifiers as selected by PAM from the differentially expressed probe sets from the each time point were used for over-representation analysis in MetaCore maps. Classifiers appeared to have a predominant role in several metabolic processes, immune and damage responses and apoptosis at both time points. 
BaP AFB1 2-AAF DMN MitC ANAC 2-CP 4-NP 8-HQ Q 24-48h 24-48h 24-48h 24-48h 24-48h 24-48h 24-48h 24-48h 24-48h 24-48h

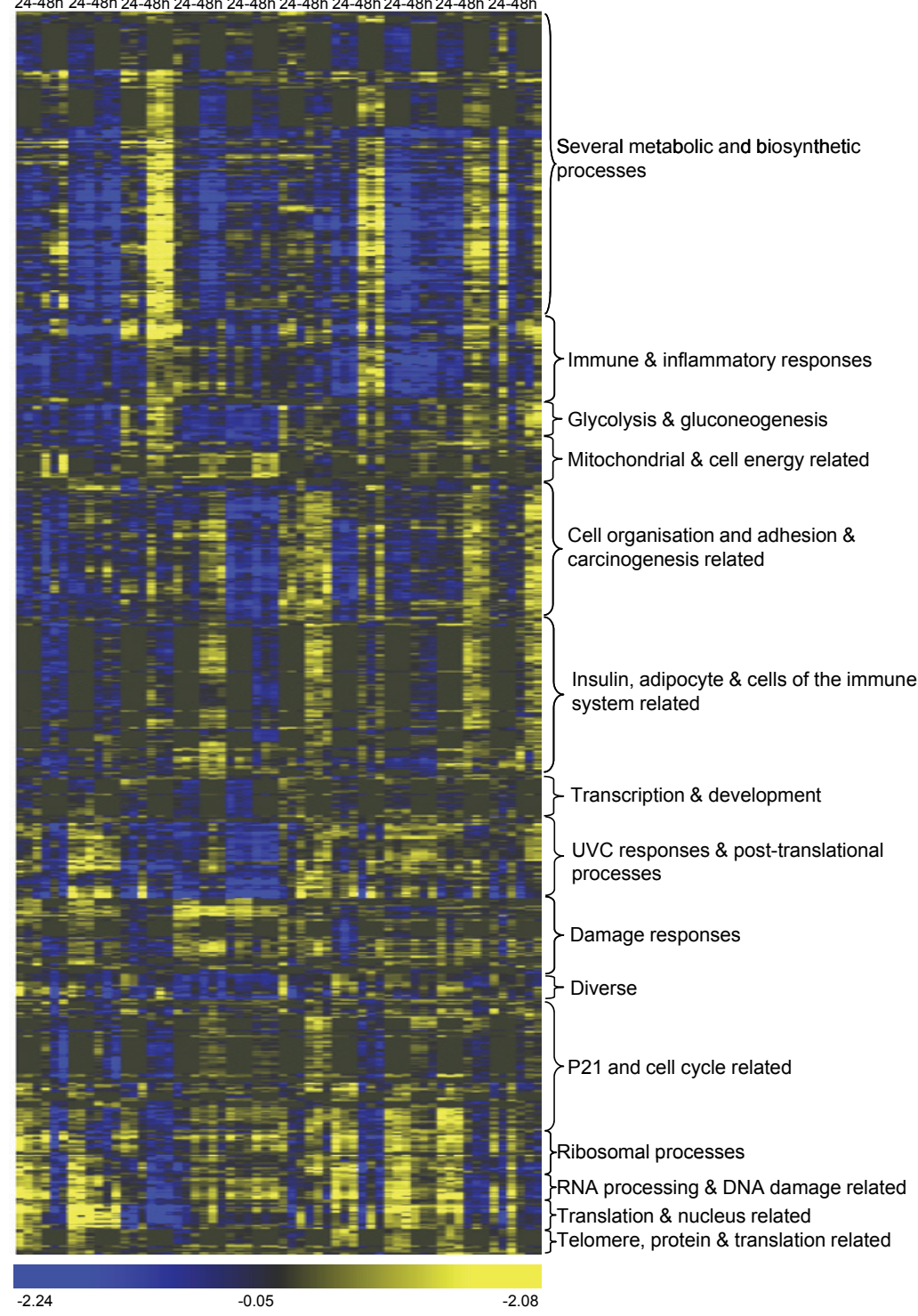

Figure 3 Hierarchical clustering of all significantly altered pathways after treatment with true GTX and false positive GTX compounds for 24 and $48 \mathrm{~h}$, based on the t-values generated by $T$ profiler. Yellow and blue mean up- and downregulation, respectively. 
Table 2 Genes selected by PAM, which were common in all validation sets, for class discrimination and their true GTX compound and FP GTX compound scores.

\begin{tabular}{|c|c|c|c|c|c|}
\hline \multirow[t]{3}{*}{ GENEBANKACC } & \multirow[t]{3}{*}{ Gene Symbol } & \multicolumn{2}{|c|}{24} & \multicolumn{2}{|c|}{48} \\
\hline & & \multicolumn{2}{|c|}{ Score } & \multicolumn{2}{|c|}{ Score } \\
\hline & & GTX & NGTX & GTX & NGTX \\
\hline AA561726 & 382244 & & & 0.05 & -0.05 \\
\hline AF000969 & 375800 & -0.05 & 0.05 & 0.19 & -0.19 \\
\hline AF022072 & 365836 & 0.00 & 0.00 & 0.08 & -0.08 \\
\hline AF033112 & 376872 & & & -0.10 & 0.10 \\
\hline AF055573 & 366751 & & & 0.21 & -0.21 \\
\hline AF065917 & 357372 & 0.05 & -0.05 & & \\
\hline AF069954 & 356166 & & & -0.02 & 0.02 \\
\hline AF204959 & 364872 & 0.03 & -0.03 & & \\
\hline AF297615 & 358267 & 0.05 & -0.05 & -0.14 & 0.14 \\
\hline AF335325 & 376288 & & & 0.00 & 0.00 \\
\hline Al594683 & 387405 & 0.09 & -0.09 & -0.17 & 0.17 \\
\hline Al596632 & 383599 & -0.06 & 0.06 & & \\
\hline Al747296 & 383239 & & & 0.01 & -0.01 \\
\hline Al987929 & 374725 & -0.03 & 0.03 & & \\
\hline AK004419 & 378573 & -0.02 & 0.02 & & \\
\hline AK005731 & 372301 & 0.19 & -0.19 & -0.39 & 0.39 \\
\hline AK007766 & 378303 & -0.03 & 0.03 & & \\
\hline AK007854 & 378379 & 0.11 & -0.11 & -0.02 & 0.02 \\
\hline AK009736 & 374461 & -0.03 & 0.03 & & \\
\hline AK010447 & 378452 & -0.13 & 0.13 & 0.13 & -0.13 \\
\hline AK010738 & 378971 & & & 0.00 & 0.00 \\
\hline AK014608 & 374420 & 0.04 & -0.04 & -0.14 & 0.14 \\
\hline AK017734 & 371811 & & & -0.03 & 0.03 \\
\hline AK018383 & 353878 & & & -0.04 & 0.04 \\
\hline AK019979 & 371961 & -0.11 & 0.11 & 0.02 & -0.02 \\
\hline AV095209 & 386153 & -0.11 & 0.11 & 0.02 & -0.02 \\
\hline AV141095 & 382253 & -0.06 & 0.06 & 0.01 & -0.01 \\
\hline AV173571 & 384913 & -0.02 & 0.02 & & \\
\hline AV173869 & 384058 & & & 0.07 & -0.07 \\
\hline AV216768 & 390175 & & & 0.02 & -0.02 \\
\hline AV219418 & 383896 & 0.03 & -0.03 & -0.01 & 0.01 \\
\hline AV221299 & 392995 & & & 0.03 & -0.03 \\
\hline AV223474 & 390168 & -0.03 & 0.03 & & \\
\hline AV246296 & 394849 & & & -0.06 & 0.06 \\
\hline AV251625 & 393625 & & & -0.01 & 0.01 \\
\hline AV254764 & 386766 & & & -0.03 & 0.03 \\
\hline AV298304 & 384191 & 0.04 & -0.04 & & \\
\hline AV327248 & 382034 & 0.03 & -0.03 & -0.17 & 0.17 \\
\hline AV377066 & 365590 & 0.00 & 0.00 & & \\
\hline AW240761 & 360689 & -0.01 & 0.01 & & \\
\hline AW543460 & 384409 & -0.03 & 0.03 & & \\
\hline AW543723 & 396735 & 0.04 & -0.04 & & \\
\hline AW986246 & 372263 & -0.06 & 0.06 & & \\
\hline
\end{tabular}




\begin{tabular}{|c|c|c|c|c|c|}
\hline BB009155 & 389978 & & & -0.08 & 0.08 \\
\hline BB027848 & 392880 & 0.03 & -0.03 & -0.03 & 0.03 \\
\hline BB043558 & 386143 & 0.12 & -0.12 & -0.29 & 0.29 \\
\hline BB046347 & 370831 & & & -0.01 & 0.01 \\
\hline BB140436 & 387651 & & & 0.00 & 0.00 \\
\hline BB204486 & 385734 & & & 0.04 & -0.04 \\
\hline BB223872 & 389580 & & & -0.15 & 0.15 \\
\hline BB246912 & 376663 & & & 0.15 & -0.15 \\
\hline BB275142 & 390167 & 0.16 & -0.16 & -0.07 & 0.07 \\
\hline BB308836 & 390965 & -0.01 & 0.01 & & \\
\hline BB318221 & 392210 & -0.12 & 0.12 & & \\
\hline BB463610 & 383399 & 0.10 & -0.10 & & \\
\hline BB458460 & 392250 & & & 0.02 & -0.02 \\
\hline BB463610 & 383399 & & & -0.19 & 0.19 \\
\hline BB526605 & 386240 & -0.04 & 0.04 & & \\
\hline BB730977 & 386916 & & & 0.05 & -0.05 \\
\hline BB743970 & 388064 & & & -0.11 & 0.11 \\
\hline BB770528 & 377524 & 0.06 & -0.06 & -0.02 & 0.02 \\
\hline BB781615 & 390898 & & & -0.09 & 0.09 \\
\hline BB821363 & 382138 & -0.07 & 0.07 & & \\
\hline BC003284 & 364436 & & & -0.09 & 0.09 \\
\hline BC004827 & 374892 & -0.01 & 0.01 & 0.06 & -0.0 \\
\hline BC005552 & 375001 & & & 0.01 & -0.0 \\
\hline BC006713 & 358440 & & & -0.08 & 0.0 \\
\hline BC008626 & 363008 & 0.17 & -0.17 & & \\
\hline BC010318 & 366153 & & & 0.04 & -0.04 \\
\hline BC010462 & 364901 & 0.11 & -0.11 & & \\
\hline BC012247 & 353835 & 0.06 & -0.06 & -0.13 & 0.13 \\
\hline BC012260 & 363632 & 0.04 & -0.04 & & \\
\hline BC012955 & 367082 & & & 0.05 & -0.0 \\
\hline BC013893 & 376296 & & & -0.09 & 0.0 \\
\hline BC015270 & 359187 & 0.02 & -0.02 & & \\
\hline BC016073 & 362815 & -0.07 & 0.07 & & \\
\hline BC016265 & 363619 & -0.03 & 0.03 & & \\
\hline BC017615 & 363489 & & & 0.15 & -0.15 \\
\hline BC019379 & 371844 & & & 0.08 & -0.0 \\
\hline BC019882 & 363791 & 0.10 & -0.10 & -0.19 & 0.1 \\
\hline BC021352 & 354685 & & & -0.03 & 0.0 \\
\hline BC022148 & 369161 & & & -0.20 & 0.20 \\
\hline BC025169 & 375604 & & & 0.04 & -0.0 \\
\hline BC025501 & 375599 & 0.01 & -0.01 & & \\
\hline BC025837 & 375175 & 0.00 & 0.00 & & \\
\hline BC025915 & 376116 & -0.01 & 0.01 & & \\
\hline BC026131 & 357954 & & & 0.04 & -0.0 \\
\hline BC026422 & 375638 & 0.01 & -0.01 & & \\
\hline BC027026 & 355021 & & & -0.14 & 0.14 \\
\hline BC027121 & 363139 & & & -0.11 & 0.1 \\
\hline BC027185 & 364867 & & & -0.10 & 0.1 \\
\hline BE956581 & 385458 & & & -0.16 & 0.1 \\
\hline BF719766 & 392437 & 0.00 & 0.00 & -0.11 & 0.11 \\
\hline BG065754 & 372817 & 0.01 & -0.01 & -0.09 & 0.09 \\
\hline
\end{tabular}




\begin{tabular}{|c|c|c|c|c|c|}
\hline BG066491 & 385964 & & & 0.21 & -0.21 \\
\hline BG066903 & 373044 & -0.01 & 0.01 & & \\
\hline BG069873 & 396155 & 0.03 & -0.03 & & \\
\hline BG070887 & 383449 & -0.04 & 0.04 & & \\
\hline BG076151 & 383144 & 0.00 & 0.00 & -0.02 & 0.02 \\
\hline BG076333 & 353474 & & & 0.02 & -0.02 \\
\hline BG261907 & 356202 & -0.11 & 0.11 & & \\
\hline BG797099 & 361167 & & & -0.11 & 0.11 \\
\hline BG967046 & 386449 & & & -0.08 & 0.08 \\
\hline BI651416 & 387321 & 0.18 & -0.18 & -0.36 & 0.36 \\
\hline Bl660702 & 397278 & 0.07 & -0.07 & & \\
\hline BI966443 & 362070 & & & -0.02 & 0.02 \\
\hline BM198879 & 374683 & 0.03 & -0.03 & -0.04 & 0.04 \\
\hline BM200015 & 368650 & & & -0.15 & 0.15 \\
\hline BM230508 & 389864 & 0.07 & -0.07 & -0.17 & 0.17 \\
\hline BM936480 & 385793 & & & -0.05 & 0.05 \\
\hline BQ174991 & 383555 & & & 0.03 & -0.03 \\
\hline L21027 & 368225 & & & 0.04 & -0.04 \\
\hline NM_007556 & 374349 & & & 0.06 & -0.06 \\
\hline NM_007980 & 358144 & & & -0.01 & 0.01 \\
\hline NM_007987 & 393266 & 0.07 & -0.07 & -0.27 & 0.27 \\
\hline NM_008522 & 372809 & 0.13 & -0.13 & -0.31 & 0.31 \\
\hline NM_008576 & 357701 & -0.04 & 0.04 & & \\
\hline NM_008935 & 354314 & & & 0.00 & 0.00 \\
\hline NM_009897 & 355477 & & & -0.02 & 0.02 \\
\hline NM_011075 & 359047 & & & -0.08 & 0.08 \\
\hline NM_011176 & 357469 & 0.09 & -0.09 & -0.16 & 0.16 \\
\hline NM_011316 & 353539 & 0.06 & -0.06 & -0.01 & 0.01 \\
\hline NM_012006 & 370922 & 0.15 & -0.15 & -0.14 & 0.14 \\
\hline NM_013642 & 370453 & & & 0.03 & -0.03 \\
\hline NM_013738 & 371675 & & & -0.06 & 0.06 \\
\hline NM_013866 & 359040 & 0.05 & -0.05 & & \\
\hline NM_013929 & 358083 & & & -0.02 & 0.02 \\
\hline NM_018770 & 356065 & 0.00 & 0.00 & & \\
\hline NM_018881 & 360649 & & & -0.05 & 0.05 \\
\hline NM_019738 & 354279 & & & 0.01 & -0.01 \\
\hline NM_021451 & 357674 & 0.01 & -0.01 & & \\
\hline NM_025770 & 353067 & -0.01 & 0.01 & & \\
\hline NM_028803 & 356267 & -0.06 & 0.06 & & \\
\hline NM_030697 & 370462 & 0.03 & -0.03 & -0.07 & 0.07 \\
\hline NM_053122 & 353952 & & & 0.21 & -0.21 \\
\hline NM_053168 & 354166 & 0.02 & -0.02 & & \\
\hline NM_134147 & 354301 & & & 0.06 & -0.06 \\
\hline NM_134188 & 360821 & 0.01 & -0.01 & 0.00 & 0.00 \\
\hline Y15910 & 370060 & -0.11 & 0.11 & & \\
\hline X62701 & 377843 & & & 0.01 & -0.01 \\
\hline
\end{tabular}


Table 3 Class prediction by PAM of GTX and FP GTX compounds at 24 and $48 \mathrm{~h}$ in primary mouse hepatocytes.

Data from 2 experiments were used for training, followed by validation of the classifiers with data from the remaining experiment.

\begin{tabular}{|c|c|c|c|c|c|c|c|}
\hline \multirow[b]{2}{*}{ Compound } & \multirow[b]{2}{*}{ Carcinogenic class } & \multicolumn{3}{|c|}{$24 \mathrm{~h}$ validation } & \multicolumn{3}{|c|}{$48 \mathrm{~h}$ validation } \\
\hline & & $\exp 1$ & $\exp 2$ & $\exp 3$ & $\exp 1$ & $\exp 2$ & $\exp 3$ \\
\hline AFB1 & GTX & GTX & GTX & GTX & GTX & GTX & GTX \\
\hline $\mathrm{BaP}$ & GTX & GTX & GTX & GTX & GTX & GTX & GTX \\
\hline 2-AAF & GTX & FP GTX & FP GTX & FP GTX & FP GTX & FP GTX & FP GTX \\
\hline DMN & GTX & GTX & GTX & GTX & GTX & GTX & GTX \\
\hline MitC & GTX & GTX & GTX & GTX & GTX & GTX & GTX \\
\hline 2-CP & FP GTX & FP GTX & FP GTX & FP GTX & FP GTX & FP GTX & FP GTX \\
\hline 4-NP & FP GTX & FP GTX & FP GTX & FP GTX & FP GTX & FP GTX & FP GTX \\
\hline ANAC & FP GTX & FP GTX & FP GTX & FP GTX & FP GTX & FP GTX & FP GTX \\
\hline $\mathbf{Q}$ & FP GTX & FP GTX & FP GTX & FP GTX & FP GTX & FP GTX & FP GTX \\
\hline $8 Q$ & FP GTX & FP GTX & FP GTX* & FP GTX & FP GTX & FP GTX & FP GTX \\
\hline
\end{tabular}

\section{Discussion}

The well-established in vitro test battery for genotoxicity has an extremely high false positive rate for genotoxicity and carcinogenicity (1). The predictive value of in vitro experiments is poor and this implies that a large number of chemicals are unnecessarily subjected to subsequent in vivo testing, thereby increasing the amount of animal studies. Therefore, there is a need for novel in vitro systems for discriminating genotoxic from non-genotoxic compounds, which demonstrates a relative low false positive rate, thereby generating a realistic and not longer over-estimated demand for genotoxicity and carcinogenicity testing in long-term rodent bioassays.

Therefore, in the current study, the application of gene expression profiles from primary mouse hepatocytes as an in vitro tool for discriminating false positive GTX compounds from true GTX compounds was assessed.

For the purpose of phenotypically discriminating true GTX from false positive GTX compounds, we evaluated differences in $\gamma \mathrm{H} 2 \mathrm{AX}$ foci formation. Some true GTX carcinogens, like $\mathrm{BaP}, 2-\mathrm{AAF}$ and $\mathrm{MitC}$, are shown before to be able to induce $\gamma \mathrm{H} 2 \mathrm{AX}$ foci formation in different human cells (33-35). It is therefore to be expected that this $\gamma \mathrm{H} 2 \mathrm{AX}$ foci formation can also be detected in primary mouse hepatocytes treated with true GTX compounds. All true GTX compounds are significantly capable of inducing the formation of $\gamma \mathrm{H} 2 \mathrm{AX}$ foci in both time points, while the false positive GTX, with the exception of 4-NP, do no. This demonstrates the metabolic competence of the primary mouse hepatocytes, as all true GTX compounds are not directly active but need to be transformed to their ultimate carcinogenic metabolite. Only one false positive GTX compound, namely 4-NP, a very powerful direct-acting in vitro mutagen, is able to induce $\gamma \mathrm{H} 2 \mathrm{AX}$ foci formation. This indicates that 4-NP might in fact be a true GTX 
agent, but it may also confirm our test for $\gamma \mathrm{H} 2 \mathrm{AX}$ foci as it is also in vitro. Only in cells treated with $\mathrm{BaP}$, a significant influence of exposure duration on $\gamma \mathrm{H} 2 \mathrm{AX}$ foci formation has been detected, indicating that both time points might be optimal for the phenotypical discrimination of true GTX compounds from the false positive GTX compounds.

Gene expression data were analyzed with PAM as a method for class prediction. PAM is a supervised clustering tool designed for class prediction analyses based on microarray data. The training sets generated a list of genes, called classifiers, that appeared to be able to discriminate between classes, and these were validated by using the test sets. By using PAM, only 2-AAF is misclassified as a false positive GTX compound, in all experiments and at both time points, while all the other compounds are always correctly classified. The obtained classifiers therefore seem to reliably discriminate between true and false positive GTX compounds both at 24 and $48 \mathrm{~h}$ of exposure, showing for this data set a specificity of $90 \%$. This high percentage proves the principle that gene expression profiles in primary mouse hepatocytes can classify compounds according to their GTX potential, with the compounds used in this study. Both $24 \mathrm{~h}$ and $48 \mathrm{~h}$ treatment seem to be fit for this purpose. Comparable results were found in some in vivo and in vitro studies on gene expression profiles, but these studies were based on discriminating GTX from NGTX carcinogens, DNA damaging from non-DNA damaging GTX compounds, or discriminating compounds according to their carcinogenic potential (13, $36-39,40,41)$. For the well-established in vitro test battery specificity appeares to be extremely low. The specificity of the Ames test was within a reasonable $73.9 \%$, but all mammalian cell tests had very low specificity, even below $45 \%$. The current study can, therefore, be the basis for developing a new predictive screen, which can, as alternatives to current rodent genotoxicity testing models, be applied in chemical safety procedures. The next step for that, would be to include more chemicals.

The classifiers generated by PAM from the each time point were used for overrepresentation analysis in MetaCore maps. It is not surprising that many of these classifiers are involved in apoptosis-related processes at both time points. It is well documented that the DNA damage responses involves induction of apoptosis (42). Many in vivo and in vitro studies on gene expression profiles of GTX compounds have found also genes involved in apoptosis, but these were however not the same genes (13, 36-39, 40, 41). Further, groups of classifiers from our study appear involved in metabolism and biosynthesis. Many similar metabolism-related genes were previously found in rat in vivo studies on gene expression modifications by GTX and NGTX compounds, but also these were not the same genes $(37,38)$. This overlap between our in vitro model with the standard rodent bioassays indicates that our classifiers are specific and reliable and thus both exposure periods are suitable for discrimination of true and false positive GTX compounds.

After evaluating classification at the single gene level, we also analyzed data at a more generic level. Pathway analysis was used to visualize time-related effects. Time appears 
to have some effects on pathways, especially after treatment with 2-CP and 8-HQ. Most striking, however, is that the effects on pathways after treatment with 2-AAF are clearly different from the other true GTX compounds.

Thus treatments with 2-AAF, a well-known true GTX compound that causes liver tumors in C57BL/6 male mice and has proven to be genotoxic in the mouse in several in vivo and in vitro studies $(43,44)$, are misclassified by PAM using gene expression changes. The level of $\gamma \mathrm{H} 2 \mathrm{AX}$ foci formation induced in vitro by 2-AAF, however, is comparable to that from other true GTX compounds BaP and AFB1. Apparently, in mice hepatocytes, differences between 2-AAF and the other true GTX are only pronounced at the gene expression level. Because it is known that DNA damage induced by GTX compounds, leads to stimulation of apoptosis and suppression of the cell cycle, we tried to find an explanation for the misclassification of 2-AAF by particularly evaluating genes related to apoptosis and cell cycle $(45,46)$. Around $16 \%$ of the differentially expressed probe sets and almost one third of the classifiers generated by PAM appeared to be reversely expressed by treatment with 2-AAF compared to the other GTX compounds, especially genes involved in apoptosis (Ahr, Bax, Serpinb2 and several Caspases) and cell cycle (Cdkn1a). Because 2-AAF has this reversed effect on genes involved in apoptosis and cell cycle, and because precisely these genes are important for the classification of GTX compounds, 2-AAF is misclassified by using gene expression profiles. But because 2-AAF is able to introduce DNA damage, it is correctly classified as a true GTX compound by the evaluation of $\gamma \mathrm{H} 2 \mathrm{AX}$ foci formation.

In summary, this study demonstrates that true GTX compounds can be reliably discriminated from false positive GTX compounds in primary mouse hepatocytes by gene expression profiling, when using PAM. We provide proof of the principle that primary mouse hepatocytes may represent a novel in vitro system with the capacity to screen compounds for their true genotoxic potential.

\section{Acknowledgements}

Financial support was provided by the Netherlands Genomics Initiative (NGI), the Netherlands Organisation for Scientific Research (NWO) and the CARCINOGENOMICS FP6 project sponsored by the European Union (PL037712). 


\section{References}

1. Kirkland, D., et al., Evaluation of the ability of a battery of three in vitro genotoxicity tests to discriminate rodent carcinogens and non-carcinogens I. Sensitivity, specificity and relative predictivity. Mutat Res, 2005. 584(1-2): p. 1-256.

2. Eastmond, D.A., et al., Mutagenicity testing for chemical risk assessment: update of the WHO/IPCS Harmonized Scheme. Mutagenesis, 2009. 24(4): p. 341-9.

3. Eun, J.W., et al., Discriminating the molecular basis of hepatotoxicity using the large-scale characteristic molecular signatures of toxicants by expression profiling analysis. Toxicology, 2008. 249(2-3): p. 17683.

4. Nioi, P., et al., Prediction of non-genotoxic carcinogenesis in rats using changes in gene expression following acute dosing. Chem Biol Interact, 2008. 172(3): p. 206-15.

5. Chhabra, R.S., Intestinal absorption and metabolism of xenobiotics. Environ Health Perspect, 1979. 33: p. 61-9.

6. Blaauboer, B.J., et al., The practical applicability of hepatocyte cultures in routine testing. EcVam workschop report 1, 1994.

7. Davila, J.C., et al., Predictive value of in vitro model systems in toxicology. Annu Rev Pharmacol Toxicol, 1998. 38: p. 63-96.

8. Le Fevre, A.C., et al., Characterization of DNA reactive and non-DNA reactive anticancer drugs by gene expression profiling. Mutat Res, 2007. 619(1-2): p. 16-29.

9. Aubrecht, J., et al., Molecular genotoxicity profiles of apoptosis-inducing vanadocene complexes. Toxicol Appl Pharmacol, 1999. 154(3): p. 228-35.

10. Ellinger-Ziegelbauer, H., et al., Application of toxicogenomics to study mechanisms of genotoxicity and carcinogenicity. Toxicol Lett, 2009. 186(1): p. 36-44.

11. Ellinger-Ziegelbauer, H., et al., Prediction of a carcinogenic potential of rat hepatocarcinogens using toxicogenomics analysis of short-term in vivo studies. Mutat Res, 2007.

12. Ellinger-Ziegelbauer, H., et al., Characteristic expression profiles induced by genotoxic carcinogens in rat liver. Toxicol Sci, 2004. 77(1): p. 19-34.

13. Ellinger-Ziegelbauer, H., et al., Comparison of the expression profiles induced by genotoxic and nongenotoxic carcinogens in rat liver. Mutat Res, 2005. 575(1-2): p. 61-84.

14. Waterston, R.H., et al., Initial sequencing and comparative analysis of the mouse genome. Nature, 2002. 420(6915): p. 520-62.

15. Koike, M., et al., Histone H2AX Phosphorylation Independent of ATM after X-irradiation in Mouse Liver and Kidney in situ. J Radiat Res (Tokyo), 2008.

16. Rogakou, E.P., et al., DNA double-stranded breaks induce histone H2AX phosphorylation on serine 139. J Biol Chem, 1998. 273(10): p. 5858-68.

17. Seglen, P.O., Preparation of isolated rat liver cells. Methods Cell Biol, 1976. 13: p. 29-83.

18. Casciano, D.A., Development and utilization of primary hepatocyte culture systems to evaluate metabolism, DNA binding, and DNA repair of xenobiotics. Drug Metab Rev, 2000. 32(1): p. 1-13.

19. Mathijs, K., et al., Assessing the metabolic competence of sandwich-cultured mouse primary hepatocytes. Drug Metab Dispos, 2009. 37: p. 1305-11.

20. Koebe, H.G., et al., Collagen gel immobilisation provides a suitable cell matrix for long term human hepatocyte cultures in hybrid reactors. Int J Artif Organs, 1994. 17(2): p. 95-106.

21. Beken, S., et al., Collagen-gel cultures of rat hepatocytes: collagen-gel sandwich and immobilization cultures. Methods Mol Biol, 1998. 107: p. 303-9.

22. Hamer, G., et al., DNA double-strand breaks and gamma-H2AX signaling in the testis. Biol Reprod, 2003. 68(2): p. 628-34.

23. Tong, W., et al., ArrayTrack--supporting toxicogenomic research at the U.S. Food and Drug Administration National Center for Toxicological Research. Environ Health Perspect, 2003. 111(15): p. 1819-26. 


\section{Chapter 6}

24. Tong, W., et al., Development of public toxicogenomics software for microarray data management and analysis. Mutat Res, 2004. 549(1-2): p. 241-53.

25. Irizarry, R.A., et al., Exploration, normalization, and summaries of high density oligonucleotide array probe level data. Biostatistics, 2003. 4(2): p. 249-64.

26. Affymetrix, Statistical Algorithms Description Document, technical report. 2002.

27. Shi, L., et al., The MicroArray Quality Control (MAQC) project shows inter- and intraplatform reproducibility of gene expression measurements. Nat Biotechnol, 2006. 24(9): p. 1151-61.

28. Boorsma, A., et al., T-profiler: scoring the activity of predefined groups of genes using gene expression data. Nucleic Acids Res, 2005. 33(Web Server issue): p. W592-5.

29. Reich, M., et al., GenePattern 2.0. Nat Genet, 2006. 38(5): p. 500-1.

30. Tibshirani, R., et al., Diagnosis of multiple cancer types by shrunken centroids of gene expression. Proc Natl Acad Sci U S A, 2002. 99(10): p. 6567-72.

31. Fernandez-Capetillo, O., et al., H2AX: the histone guardian of the genome. DNA Repair (Amst), 2004. 3(8-9): p. 959-67.

32. Rogakou, E.P., et al., Megabase chromatin domains involved in DNA double-strand breaks in vivo. J Cell Biol, 1999. 146(5): p. 905-16.

33. Mladenov, E., I. Tsaneva, and B. Anachkova, Activation of the S phase DNA damage checkpoint by mitomycin C. J Cell Physiol, 2007. 211(2): p. 468-76.

34. Yamamoto, K., et al., Upregulated ATM gene expression and activated DNA crosslink-induced damage response checkpoint in Fanconi anemia: implications for carcinogenesis. Mol Med, 2008. 14(3-4): p. $167-74$.

35. Zhou, C., et al., DNA damage evaluated by gammaH2AX foci formation by a selective group of chemi$\mathrm{cal} /$ physical stressors. Mutat Res, 2006. 604(1-2): p. 8-18.

36. Iida, M., et al., Unique patterns of gene expression changes in liver after treatment of mice for 2 weeks with different known carcinogens and non-carcinogens. Carcinogenesis, 2005. 26(3): p. 689-99.

37. Tsujimura, K., et al., Prediction of carcinogenic potential by a toxicogenomic approach using rat hepatoma cells. Cancer Sci, 2006. 97(10): p. 1002-10.

38. Uehara, T., et al., A toxicogenomics approach for early assessment of potential non-genotoxic hepatocarcinogenicity of chemicals in rats. Toxicology, 2008. 250(1): p. 15-26.

39. van Delft, J.H., et al., Discrimination of genotoxic from non-genotoxic carcinogens by gene expression profiling. Carcinogenesis, 2004. 25(7): p. 1265-76.

40. Aardema, M.J. and J.T. MacGregor, Toxicology and genetic toxicology in the new era of "toxicogenomics": impact of "-omics" technologies. Mutat Res, 2002. 499(1): p. 13-25.

41. Aubrecht, J. and E. Caba, Gene expression profile analysis: an emerging approach to investigate mechanisms of genotoxicity. Pharmacogenomics, 2005. 6(4): p. 419-28.

42. Sionov, R.V. and Y. Haupt, The cellular response to p53: the decision between life and death. Oncogene, 1999. 18(45): p. 6145-57.

43. Hoogervorst, E.M., et al., 2-AAF-induced tumor development in nucleotide excision repair-deficient mice is associated with a defect in global genome repair but not with transcription coupled repair. DNA Repair (Amst), 2005. 4(1): p. 3-9.

44. http://ntp-server.niehs.nih.gov.

45. Levine, A.J., p53, the cellular gatekeeper for growth and division. Cell, 1997. 88(3): p. 323-31.

46. Adimoolam, S. and J.M. Ford, p53 and regulation of DNA damage recognition during nucleotide excision repair. DNA Repair (Amst), 2003. 2(9): p. 947-54. 
Chapter 7

\section{Summary and General Discussion}


The research described in this thesis focused on a toxicogenomics approach toward developing alternatives for animal testing with regard to genotoxicity testing. The main goal was to identify a set of gene-expression effect markers that is able to screen compounds for their true genotoxic potential in an relevant in vitro model. At the same time the gene-expression data was used to study the underlying molecular mechanisms associated with chemical carcinogenesis.

Hepatic in vitro models are used frequently in toxicological studies because the liver plays a major role in the metabolism of many compounds and also represents an important target organ in systemic toxicity $(1,2)$. Hepatic cell lines, primary hepatocyte cultures and precision-cut liver slices from various species are well established in vitro systems for these studies $(1,2,3)$. As precision-cut liver slices have a very short live span and immortalized cell lines have lost many liver specific functions, primary cultures of hepatocytes are preferentially used for in vitro studies on liver toxicity $(3,4,5)$. Primary human and rat hepatocyte cultures are well established alternative in vitro systems used in toxicological studies. Mouse primary hepatocyte cultures are less well described, however, while mouse models gain importance in toxicology as transgenic mouse models provide an opportunity for studying mechanisms of toxicity. Furthermore, liver cancer in the mouse is the most frequently observed cancer in this species. For these reasons, primary mouse hepatocytes were explored in this research.

In the strategy to identify possible carcinogenic properties of chemical compounds, a tiered approach is used. First in vitro and if deemed necessary in vivo genotoxicity tests are conducted, followed by animal carcinogenicity tests. The classic 2 year rodent bioassay used to assess chemical compounds for their carcinogenic potential, is very expensive and time-consuming as it requires the use of many animals and large quantities of the test compound and also has several ethical drawbacks. Furthermore the reliability, relevance and effectiveness of these in vivo assays are subjected to many uncertainties with regard to the extrapolation from animal to human risk. Therefore the use of in vitro models for predicting in vivo carcinogenicity in humans is increasingly considered (6). Earlier in vitro systems used for the identification of the genotoxic and thus possible carcinogenic potency of chemicals are the bacterial Ames test, the mouse lymphoma assay, the micronucleus test and the chromosomal aberration test (7). These systems have the benefit of being relatively simple and cheap. An important disadvantage of these in vitro genotoxicity tests, however, is the generation of an extremely high false positive rate when compared with in vivo genotoxicity and carcinogenicity results (7). This calls for better in vitro assays for predicting genotoxicity and carcinogenicity, generating less false positives.

Genomics-based technologies enable to investigate the function of the complete genome by expression analyses at the level of transcription (transcriptomics), translation (proteomics) and metabolism (metabonomics). Combining these technologies with the re- 
quired bio-informatics tools will cause a revolution in current hazard and risk assessment practices.

Hypothetically, toxicogenomics will lead to the identification of "fingerprints", a set of gene-expression effect markers which able to test compounds for their carcinogenic potential, in that gene-expression fingerprints should be positive for chemical carcinogens while being able to discriminate between GTX and NGTX carcinogens and between true and false positive GTX compounds, and should be negative for noncarcinogens. These "fingerprints" should be highly similar between a laboratory animal model and man.

Eventually, this may lead to the development of a predictive high-throughput screen which can be used for chemical safety procedures as an alternative to current rodent testing models which is more specific, dedicated, cheaper and socially more acceptable than currently available animal models.

The objective of this thesis is to evaluate and to optimize the use of in vitro primary mouse hepatocyte cultures to identify sets of gene-expression effect markers that are able to discriminate between true genotoxic and false positive genotoxic carcinogens.

\section{HepG2 study}

In order to determine the optimal time points for gene expression profiling in cells in vitro, first time-dependent changes in the cellular responses upon exposure to a wellknown carcinogen were investigated with the intention to further apply this in primary mouse hepatocytes $(8,9)$. In our lab it was shown before that gene expression profiling could be used to discriminate genotoxic from non-genotoxic carcinogens (10). Timedependent effects, however, were not investigated and therefore first experiments were conducted in human hepatoma (HepG2) cells, described in Chapter 2. The changes in gene expression profiles of HepG2 cells caused by the model carcinogen Benzo(a)pyrene (BaP) were investigated at 12 time points after exposure, in relation to DNA adduct levels and cell cycle distribution.

In this detailed time series study, numerous temporal changes in clusters of genes upon exposure of cells to the carcinogen $\mathrm{BaP}$ have been observed, thereby providing an unprecedented insight in time-dependent interactions of the affected processes and pathways.

The most interesting effects were observed with regard to DNA repair. Both base excision repair and global genomic repair correlated with DNA adducts and were induced from $9 / 12 \mathrm{~h}$ until $60 \mathrm{~h}$, when adducts were still present.

Furthermore, the results from this study also suggest that when the levels of cells in the G1-phase are low and DNA adduct levels are high, the metabolism of the cells is mainly directed towards that of nucleotides, while metabolism of amino acids and lipids is 
downregulated. Once cell cycle distribution has normalized and most DNA adducts have been repaired, metabolic processes return to control levels. Furthermore, several reaction pathways in gene expression, transcription and translation are upregulated in sequential periods.

All these observations indicate that the cellular transcriptome is strictly regulated and adapts to the changing needs of cells following acute exposure to a carcinogen. Timedependent effects of $\mathrm{BaP}$ on gene expression profiling is observed indicating that more time points should be evaluated for gene expression profiling in next studies with primary mouse hepatocytes.

\section{Mouse hepatocyte-based in vitro model}

So far, primary mouse hepatocytes have not been used frequently in toxicology. Therefore, the potential usefulness of a mouse hepatocyte-based in vitro model for toxicology was assessed by investigating time-dependent competence for xenobiotic metabolism and stability of gene expression profiles in Chapter 3. Gene expression profiles turned out to be very different between the three time points $(0,42$ and $90 \mathrm{~h})$ analyzed. These time-dependent changes can be attributed to the adaptation of the primary hepatocytes to their in vitro environment. The gene expression profiles of the replicates, however, turned out to be quite similar per time point, despite that larger inter-animal variations were observed immediately after the isolation of the cells. This observation might be caused by variation in initial stress induced by the enzymatic separation and isolation of hepatocytes (11). This inter-animal variability is less clear in the later time points, indicating that the stress responses are fading.

Pathway analysis, used to identify biochemical pathways and biological processes that were differentially expressed, revealed initial effects at the level of external signalling pathways and energy production gene sets. Later effects were observed for gene sets related to transcription, translation, membranes and cell cycle related. The overall picture based on these pathway analyses, was that liver-specific functions were continuously decreasing and that gross cellular organizations were continuously upregulated.

To investigate the metabolic competence of sandwich-cultured mouse hepatocytes in more detail, gene expression profiles from phase I and phase II biotransformation enzymes were evaluated during the cultivation period. In general the expression values of all phase I biotransformation enzymes are decreasing over the whole cultivation period. Also enzyme activities of most Cyp450 enzymes are decreasing over the whole time period, only Cyp2B9-10/13/19/23 showed an increase in activity and expression levels. After $90 \mathrm{~h}$ in culture, all Cyp450 enzymes were still active in the primary hepatocytes. Most Cyp450s in conventional sandwich-cultured rat hepatocytes appeared to be decreasing very rapidly, even within the short time period of $24 \mathrm{~h}$ after isolation $(12,13)$. 
While in our study gene expression levels showed a slower decrease over time indicating that mouse hepatocytes remain more stable with respect to Cyp450 gene expression as compared to rat hepatocytes but not to human hepatocytes.

The decrease for phase II enzyme gene expression was only to $92 \%$ of the original levels in the end. This is in line with several rat studies who suggest that phase II enzyme activities are better preserved in culture than phase I enzyme activities $(14,15)$.

An overall comparison of the gene expression levels from phase I and phase II enzymes from rat and mouse hepatocytes demonstrated that mouse hepatocytes exhibit a more stable gene expression pattern than primary rat hepatocytes.

All these results indicate that the sandwich-cultured primary mouse hepatocyte in vitro system has little or no inter-animal variations, demonstrating its reproducibility. It was shown to be robust and it appears to maintain its metabolic competence better as compared to rat hepatocytes. Based on our gene expression data, we recommend applying a $42 \mathrm{~h}$ recovery period before using the mouse hepatocytes to reduce stress responses caused by the perfusion method.

Next, in Chapter 4, the primary mouse hepatocyte model was further characterised by evaluating gene expression profiles after exposure to a model carcinogen, namely $\mathrm{BaP}$. Because we observed in Chapter 2, that, in HepG2 cells, time has a major influence on gene expression profiles after exposure to $\mathrm{BaP}$, time-dependent effects on DNA damage and gene expression profile changes caused by $\mathrm{BaP}$ in primary mouse hepatocytes were investigated. Also dose-dependent effects were investigated in this model. Therefore the hepatocytes were, after a recovery period of $42 \mathrm{~h}$, as recommended in Chapter 3, treated for several time points with various non-toxic concentrations of $\mathrm{BaP}$.

Gene expression analysis revealed that primary mouse hepatocytes show clear time- and dose-dependent effects induced by exposure to $\mathrm{BaP}$. Time-dependent effects of $\mathrm{BaP}$ seemed to be more important compared to dose-dependent effects. These time effects, however, are very different from those found in Chapter 2, as a continuous up- or down-regulation was observed in the primary mouse hepatocytes, while more variation was observed in HepG2 cells. As $\mathrm{BaP}$ is known to cause cell cycle arrest in dividing cells in order to allow for damaged DNA to be repaired, it is not surprising that effects of $\mathrm{BaP}$ differ between proliferating cells such as HepG2 cells, and non proliferatingcells such as primary mouse hepatocytes $(8,16,17,18)$.

To further determine the relevance of the primary mouse in vitro system, gene expression results were compared to an in vivo mouse study which evaluated genomics responses to $\mathrm{BaP}$ in the liver. Some similarities between these two systems were revealed. However both more differentially expressed probe sets and significantly modulated gene groups were found in primary hepatocytes. However, it has to be noted that the used doses and dosing regimes in both models, are not comparable, with one high dose in vitro and multiple low doses in vivo. 
The effects of BaP on DNA damage in primary mouse hepatocytes, as marker of genotoxic effects, were also studied in Chapter 4. The staining of $\gamma \mathrm{H} 2 \mathrm{AX}$ foci was used to detect double-strand DNA (dsDNA) breaks, and DNA was isolated to determine BaP-DNA adducts. Both DNA adducts and dsDNA breaks appeared to increase timeand dose-dependently. This time- and dose-dependent influence was also observed upon gene expression analysis. The results in Chapter 4 show that primary mouse hepatocytes are able to sensitively respond to exposure to BaP: they are able to metabolize $\mathrm{BaP}$, which causes DNA adducts and well-characterized changes in gene expression profiles.

\section{Class discrimination}

Because research described in the previous chapters demonstrated primary mouse hepatocytes to be robust, to maintain its metabolic competence during the culturing period and to respond as expected after exposure to a well-known genotoxic carcinogen, in Chapter 5, we investigated the competence of primary mouse hepatocytes to discriminate genotoxic (GTX) carcinogens from non-genotoxic (NGTX) carcinogens. As duration of exposure has a major influence on gene expression profiles, shown in Chapter 2 and Chapter 4, it was hypothesized that exposure period also affects class discrimination based on transcriptomics data. Primary mouse hepatocytes were therefore analyzed at several time points during exposure to two GTX and two NGTX carcinogens. Discrimination of GTX and NGTX compounds based on gene expression profiles, was performed by the Prediction Analysis of Microarray software (PAM), which represents a supervised clustering approach. In the study described in Chapter 5, class discrimination indeed appears dependent on exposure time. The use of PAM resulted in successful class discrimination only in the later time points, while after $12 \mathrm{~h}$ of treatment the compounds were misclassified. The classifiers generated by PAM were compared and those generated after $36 \mathrm{~h}$ of exposure turned out to show much overlap with those at 24 or 48 $\mathrm{h}$. Therefore only these two time points were investigated in a validation study with two extra GTX compounds. Based on their gene expression profiles, both compounds were correctly classified as GTX, thus demonstrating that the obtained classifiers following exposure to carcinogens may indeed be able to discriminate between GTX and NGTX classes.

Immunostaining of $\gamma \mathrm{H} 2 \mathrm{AX}$ foci was again used to phenotypically verify DNA damage. The $\gamma \mathrm{H} 2 \mathrm{AX}$ assay confirmed significant induction of damage by treatment with GTX compounds, whereas NGTX compounds were not able to induce that.

The study described in Chapter 5 showed that gene expression profiling in primary mouse hepatocytes has the potential of discriminating between GTX and NGTX compounds and that this classification improved with increasing treatment time. 
In Chapter 6 we thereupon investigated whether a primary mouse hepatocyte in vitro system is capable of discriminating GTX compounds from false-positive GTX compounds by applying the toxicogenomics approach. The false-positive GTX compounds, chosen for this study, are considered to be non-carcinogens, showing only genotoxicity in in vitro tests while not inducing genotoxicity in vivo.

Because in Chapter 5 we found that 24 and $48 \mathrm{~h}$ are the optimal time points for class discrimination, primary mouse hepatocytes were treated for 24 and $48 \mathrm{~h}$ with five true GTX and five false-positive GTX compounds. Clustering of true and false-positive GTX compound-induced gene expression changes by HCA revealed a much better clustering at $48 \mathrm{~h}$ compared to $24 \mathrm{~h}$, demonstrating that $48 \mathrm{~h}$ is more optimal for classification of true and false-positive GTX compounds.

Upon applying PAM for each time point analyzed for gene expression changes, gene classifiers could be selected resulting in a correct classification for 9 compounds at both time points. Only 2-Acetylaminofluorene (2-AAF) was misclassified as a false-positive GTX compound. This might be explained by the particular gene expression profiles of genes involved in apoptosis and cell cycle. These genes are normally stimulated by DNA damage induced by GTX compounds $(19,20)$ and are reversely expressed after treatment with 2-AAF compared to the other true GTX compounds. And because these genes are involved in the classification of GTX compounds, 2-AAF might misclassified by using gene expression profiles.

The obtained classifiers from PAM seem to reliably discriminate true from falsepositive GTX compounds both at 24 and $48 \mathrm{~h}$. Both time points are in this case optimal for classification of true and false-positive GTX compounds.

In an attempt to phenotypically discriminate true GTX from false-positive GTX compounds, the differences in $\gamma \mathrm{H} 2 \mathrm{AX}$ foci formation were also evaluated in Chapter 6. All true GTX carcinogens were significantly capable of inducing the formation of $\gamma \mathrm{H} 2 \mathrm{AX}$ foci in both time points and only one false-positive GTX compound, namely 4-NP, seemed to be able to induce $\gamma \mathrm{H} 2 \mathrm{AX}$ foci formation.

Only in cells treated with $\mathrm{BaP}$ a significant influence of time was detected, indicating again that both time points might be optimal for the discrimination of true GTX compounds from the false-positive GTX compounds.

The study described in Chapter $\mathbf{6}$ demonstrates that true GTX carcinogens can be reasonably well discriminated from false-positive GTX compounds in primary mouse hepatocytes by gene expression profiling, depending on the method used. The most successful discrimination was generated by using PAM. Although the discrimination is not perfect, gene expression profiling in primary mouse hepatocyte can be new in vitro system with the capacity to discriminate true GTX from false positive GTX compounds. The applicability of class discrimination for GTX compounds by gene expression profiling was previously shown in several in vivo and in vitro studies (7, 10, 21-37). Compared to the frequently used chronic rodent bioassays the use of primary mouse hepato- 
cytes for the screening of the genotoxic potential of chemical compounds is clearly an improvement as it requires much less animals and it is less time-consuming. Compared to some well-established in vitro systems, like the Ames test, the mouse lymphoma assay, the micronucleus test and the chromosomal aberration test, the primary mouse hepatocyte model might generate a lower false positive rate as the false-positive GTX compounds used in this research all showed genotoxicity in some well-established in vitro systems frequently used to identify the carcinogenic potency, but were clearly classified separately from the true GTX carcinogens in primary mouse hepatocytes. Therefore this model can be the basis for developing predictive screens, which can, as alternatives to current rodent genotoxicity testing models, be applied in chemical safety procedures. In combination with phenotypic anchoring this model can lead to the use of a specific in vitro system that predict specific in vivo toxicity.

\section{Limitations and recommendations}

The primary mouse in vitro model used in this research has some limitations regarding to its use for the evaluation of the genotoxic potential of chemical compounds.

The isolation of primary mouse hepatocytes by the two-step collagenase perfusion is a technically elaborated procedure and requires some practice. The hepatocytes need to be freshly derived from the animal in order to retain their liver-specific functions. Longterm cultures of functional hepatocytes are difficult to establish, but in a sandwich configuration, hepatocytes can be cultured for a longer time period $(38,39)$.

Furthermore, the mouse hepatocyte model used in this research only relies on one liver cell type, namely hepatocytes, whereas other liver cells are absent. Comparison with the in vivo situation can also be limited because in the mouse hepatocyte model exchanges between cells and their environment are less well present because of the absence of the blood flow.

Therefore the use of primary human hepatocytes can be appropriate in order to predict in vivo toxicity in humans, but is, however, hampered by the large variability between the donors and the limited availability of donor material $(3,4,5)$. Rat hepatocytes are an alternative to human hepatocytes, also frequently used but, a rapid decline in liver specific functions, in particular cytochrome P450 (Cyp450) enzyme activity is observed. Therefore a mouse in vitro hepatocyte system might still be the best alternative for the human situation. In addition, since the complete sequence of the mouse genome is known (40) and transgenic mouse models are widely available, primary mouse hepatocytes are better fit for the purpose of performing mechanistic investigations of liver toxicity.

Class prediction described in this research was based on the use of some model compounds and turned out to be time-dependent. Therefore, it is recommended to study 
class prediction based on gene expression profiles at more than one time point. Based on gene expression profiles 11 out of 12 (92\%) compounds were classified correct. In order to increase the reliability of the system and to decrease the false positive rate, the research described in this research should be expanded by using much more compounds.

Class discrimination also turned out to be dependent on the classification methods used. Not all methods result in a correct classification and therefore several methods should be applied in order to generate the optimal class discrimination.

\section{Conclusion}

In conclusion, the research described in this thesis, indicates that the sandwich-cultured primary mouse hepatocyte in vitro model has little or no inter-animal variations, it is relatively stable and maintains its metabolic competence longer than rat hepatocytes, while being almost similar in stability to that of human hepatocytes. Based on our gene expression data, we recommend applying a $42 \mathrm{~h}$ recovery period before exposing the mouse hepatocytes. Primary mouse hepatocytes appear also able to metabolize BaP, which cause DNA adducts and changes in gene expression profiles.

This research also shows that gene expression profiles derived from primary mouse hepatocytes exposed to classes of genotoxins can be applied for class discrimination. A successful classification of GTX and NGTX compounds may be generated, with an increased performance at longer exposure time to the chemical compounds. Also true GTX carcinogens may be successfully discriminated from false-positive GTX compounds by gene expression profiling. Although this discrimination is not perfect, primary mouse hepatocytes may represent a novel in vitro system with the capacity of profiling compounds for their genotoxic potential.

This research has thus laid a fundament for further developing an in vitro assay of mouse primary hepatocytes by using gene expression profiling for the ultimate purpose of predicting possible carcinogens. This model may be applied in chemical safety procedures as it has the potential of providing detailed understanding of the mode of action of toxicants. By linking this information to the parameters studied in routine toxicity tests (phenotypic anchoring) this may eventually lead to the use of specific in vitro systems that predict specific in vivo toxicity. 


\section{References}

1. Blaauboer, B.J., et al., The practical applicability of hepatocyte cultures in routine testing. EcVam workschop report 1, 1994.

2. Davila, J.C., et al., Predictive value of in vitro model systems in toxicology. Annu Rev Pharmacol Toxicol, 1998. 38: p. 63-96.

3. Schaeffner, I., et al., A microtiterplate-based screening assay to assess diverse effects on cytochrome P450 enzyme activities in primary rat hepatocytes by various compounds. Assay Drug Dev Technol, 2005. 3(1): p. 27-38.

4. Richert, L., et al., Evaluation of the effect of culture configuration on morphology, survival time, antioxidant status and metabolic capacities of cultured rat hepatocytes. Toxicol In Vitro, 2002. 16(1): p. 8999.

5. Berry, M.N., et al., Isolated hepatocytes--past, present and future. Cell Biol Toxicol, 1997. 13(4-5): p. 223-33.

6. Dambach, D.M., B.A. Andrews, and F. Moulin, New technologies and screening strategies for hepatotoxicity: use of in vitro models. Toxicol Pathol, 2005. 33(1): p. 17-26.

7. Kirkland, D., et al., Evaluation of the ability of a battery of three in vitro genotoxicity tests to discriminate rodent carcinogens and non-carcinogens I. Sensitivity, specificity and relative predictivity. Mutat Res, 2005. 584(1-2): p. 1-256.

8. Hockley, S.L., et al., Time- and concentration-dependent changes in gene expression induced by benzo(a)pyrene in two human cell lines, MCF-7 and HepG2. BMC Genomics, 2006. 7: p. 260.

9. Lambert, C.B., et al., Dose- and time-dependent effects of phenobarbital on gene expression profiling in human hepatoma HepaRG cells. Toxicol Appl Pharmacol, 2009. 234(3): p. 345-60.

10. van Delft, J.H., et al., Discrimination of genotoxic from non-genotoxic carcinogens by gene expression profiling. Carcinogenesis, 2004. 25(7): p. 1265-76.

11. Pillar, T.M. and H.J. Seitz, Oxidative stress response induced in rat primary hepatocyte monolayers by mechanical removal of adherent cells. Cell Tissue Res, 1999. 295(2): p. 363-7.

12. Kienhuis, A.S., et al., A sandwich-cultured rat hepatocyte system with increased metabolic competence evaluated by gene expression profiling. Toxicol In Vitro, 2007. 21(5): p. 892-901.

13. Boess, F., et al., Gene expression in two hepatic cell lines, cultured primary hepatocytes, and liver slices compared to the in vivo liver gene expression in rats: possible implications for toxicogenomics use of in vitro systems. Toxicol Sci, 2003. 73(2): p. 386-402.

14. Rogiers, V. and A. Vercruysse, Rat hepatocyte cultures and co-cultures in biotransformation studies of xenobiotics. Toxicology, 1993. 82(1-3): p. 193-208.

15. Kern, A., et al., Drug metabolism in hepatocyte sandwich cultures of rats and humans. Biochem Pharmacol, 1997. 54(7): p. 761-72.

16. Bartek, J. and J. Lukas, DNA damage checkpoints: from initiation to recovery or adaptation. Curr Opin Cell Biol, 2007. 19(2): p. 238-45.

17. Wilkening, S., F. Stahl, and A. Bader, Comparison of primary human hepatocytes and hepatoma cell line Hepg2 with regard to their biotransformation properties. Drug Metab Dispos, 2003. 31(8): p. 1035-42.

18. Wilkening, S. and A. Bader, Influence of culture time on the expression of drug-metabolizing enzymes in primary human hepatocytes and hepatoma cell line HepG2. J Biochem Mol Toxicol, 2003. 17(4): p. 207-13.

19. Levine, A.J., p53, the cellular gatekeeper for growth and division. Cell, 1997. 88(3): p. 323-31.

20. Adimoolam, S. and J.M. Ford, p53 and regulation of DNA damage recognition during nucleotide excision repair. DNA Repair (Amst), 2003. 2(9): p. 947-54.

21. van Delft, J.H., et al., Comparison of supervised clustering methods to discriminate genotoxic from nongenotoxic carcinogens by gene expression profiling. Mutat Res, 2005. 575(1-2): p. 17-33.

22. Uehara, T., et al., A toxicogenomics approach for early assessment of potential non-genotoxic hepatocarcinogenicity of chemicals in rats. Toxicology, 2008. 250(1): p. 15-26. 
23. Tweats, D.J., et al., Determination of genetic toxicity and potential carcinogenicity in vitro--challenges post the Seventh Amendment to the European Cosmetics Directive. Mutagenesis, 2007. 22(1): p. 5-13.

24. Thomas, R.S., et al., A comparison of transcriptomic and metabonomic technologies for identifying biomarkers predictive of two-year rodent cancer bioassays. Toxicol Sci, 2007. 96(1): p. 40-6.

25. Nioi, P., et al., Prediction of non-genotoxic carcinogenesis in rats using changes in gene expression following acute dosing. Chem Biol Interact, 2008. 172(3): p. 206-15.

26. Kirkland, D.J., et al., Testing strategies in mutagenicity and genetic toxicology: an appraisal of the guidelines of the European Scientific Committee for Cosmetics and Non-Food Products for the evaluation of hair dyes. Mutat Res, 2005. 588(2): p. 88-105.

27. Iida, M., et al., Unique patterns of gene expression changes in liver after treatment of mice for 2 weeks with different known carcinogens and non-carcinogens. Carcinogenesis, 2005. 26(3): p. 689-99.

28. Hu, T., et al., Identification of a gene expression profile that discriminates indirect-acting genotoxins from direct-acting genotoxins. Mutat Res, 2004. 549(1-2): p. 5-27.

29. Eun, J.W., et al., Discriminating the molecular basis of hepatotoxicity using the large-scale characteristic molecular signatures of toxicants by expression profiling analysis. Toxicology, 2008. 249(2-3): p. 17683.

30. Ellinger-Ziegelbauer, H., et al., Comparison of the expression profiles induced by genotoxic and nongenotoxic carcinogens in rat liver. Mutat Res, 2005. 575(1-2): p. 61-84.

31. Ellinger-Ziegelbauer, H., et al., Prediction of a carcinogenic potential of rat hepatocarcinogens using toxicogenomics analysis of short-term in vivo studies. Mutat Res, 2007.

32. Ellinger-Ziegelbauer, H., et al., Application of toxicogenomics to study mechanisms of genotoxicity and carcinogenicity. Toxicol Lett, 2009. 186(1): p. 36-44.

33. da Silva, J., et al., Evaluation of the genotoxic effect of rutin and quercetin by comet assay and micronucleus test. Food Chem Toxicol, 2002. 40(7): p. 941-7.

34. Aubrecht, J., et al., Molecular genotoxicity profiles of apoptosis-inducing vanadocene complexes. Toxicol Appl Pharmacol, 1999. 154(3): p. 228-35.

35. Ashby, J., Use of short-term tests in determining the genotoxicity or nongenotoxicity of chemicals. IARC Sci Publ, 1992(116): p. 135-64.

36. Aubrecht, J. and E. Caba, Gene expression profile analysis: an emerging approach to investigate mechanisms of genotoxicity. Pharmacogenomics, 2005. 6(4): p. 419-28.

37. Aardema, M.J. and J.T. MacGregor, Toxicology and genetic toxicology in the new era of "toxicogenomics": impact of "-omics" technologies. Mutat Res, 2002. 499(1): p. 13-25.

38. LeCluyse, E.L., et al., Regulation of glutathione S-transferase enzymes in primary cultures of rat hepatocytes maintained under various matrix configurations. Toxicol In Vitro, 2000. 14(2): p. 101-15.

39. LeCluyse, E.L., et al., Regeneration and maintenance of bile canalicular networks in collagensandwiched hepatocytes. Toxicol In Vitro, 2000. 14(2): p. 117-32.

40. Waterston, R.H., et al., Initial sequencing and comparative analysis of the mouse genome. Nature, 2002. 420(6915): p. 520-62. 

Nederlandse Samenvatting 
Het onderzoek, beschreven in deze thesis, is voornamelijk gericht op het ontwikkelen van alternatieven voor dierproeven op gebied van genotoxiciteitstesten met behulp van toxicogenomics. Het voornaamste doel was het identificeren van een set merkers die een effect hebben op de genexpressie en die in staat zijn verbindingen te toetsen op hun genotoxisch vermogen in een relevant in vitro model. Daarnaast werd de genexpressie data gebruikt om de onderliggende moleculaire mechanismen, die gepaard gaan met chemische carcinogenese, te bestuderen.

In vitro levermodellen worden frequent gebruikt in toxicologische studies omdat de lever een belangrijke rol speelt in het metabolisme van vele verbindingen en omdat, in systemische toxiciteit, de lever een belangrijk doel-orgaan is $(1,2)$. Levercellijnen, primaire hepatocyten culturen en lever coupes van verschillende diersoorten zijn goed ingeburgerd als in vitro systemen voor dergelijke studies (1, 2, 3). Aangezien lever coupes een zeer korte levensduur hebben en cellijnen een groot deel van de leverspecifieke functies verloren hebben worden primaire hepatocyt culturen bij voorkeur gebruikt voor in vitro studies op gebied van lever toxiciteit $(3,4,5)$. Primaire hepatocyten culturen van de mens en rat zijn veelgebruikte in vitro systemen in toxicologische studies. Primaire hepatocyten culturen van de muis zijn echter minder goed beschreven, maar muizen modellen worden steeds belangrijker in de toxicologie omdat transgene muizen modellen de mogelijkheid geven om de mechanismen van toxiciteit te bestuderen. Bovendien is leverkanker de meest voorkomende kanker in muizen. Om deze redenen werden, in dit onderzoek, primaire muizen hepatocyten onderzocht.

Als strategie om de mogelijke kankerverwekkende eigenschappen van chemische verbindingen te identificeren werd een gedifferentieerde aanpak gebruikt. Ten eerste werden in vitro en, indien noodzakelijk, in vivo genotoxiciteitstesten uitgevoerd, gevolgd door carcinogeniciteitstesten in dieren. De klassieke 2 jaar durende knaagdier bioassay, gebruikt om chemische stoffen te beoordelen op hun carcinogeen vermogen, is erg duur en tijdrovend omwille van het gebruik van een groot aantal dieren en grote hoeveelheden van de teststof en heeft daarnaast ook een aantal ethische bezwaren. Bovendien wordt de betrouwbaarheid, de relevantie en de doeltreffendheid van deze in vivo testen onderworpen aan tal van onzekerheden met betrekking tot de risico- extrapolatie van dier naar mens. Daarom wordt het gebruik van in vitro modellen voor het voorspellen van de in vivo carcinogeniciteit bij de mens steeds meer overwogen (6). Eerdere in vitro systemen die gebruikt werden voor de identificatie van het genotoxische, en dus mogelijk kankerverwekkend vermogen van chemische stoffen, zijn de bacteriële Ames test, de muislymfoom test, de micronucleus test en de chromosoom aberratie test (7). Deze systemen hebben het voordeel relatief eenvoudig en goedkoop te zijn. Een belangrijk nadeel van deze in vitro genotoxiciteitstesten zijn echter de van extreem veel valspositieven die uit deze test komen ten opzichte van de in vivo genotoxiciteit en carci- 
nogeniteit resultaten (7). Dit vraagt om betere in vitro testen voor het voorspellen van genotoxiciteit en carcinogeniteit die minder valse positieven voortbrengen.

Genomics-technologieën zijn in staat de functie van het complete genoom te onderzoeken met behulp van expressie analyses op het niveau van transcriptie (transcriptomics), translatie (proteomics) en metabolisme (metabonomics). De combinatie van deze technologieën met de benodigde bio-informatica hulpmiddelen, zal leiden tot een revolutie in de huidige risico- en gevaren-evaluatie.

Hypothetisch gezien zal de toxicogenomica leiden tot de identificatie van zogeheten "fingerprints", een reeks van genexpressie-effect merkers die in staat zijn om verbindingen te testen op hun carcinogeen vermogen. Deze genexpressie "fingerprints" zouden negatief moeten zijn voor niet-kankerverwekkende stoffen en positief moeten zijn voor de chemische kankerverwekkende stoffen, terwijl ze in staat moeten zijn een onderscheid te maken tussen de GTX en NGTX carcinogenen en tussen echte en valse positieve GTX verbindingen. Bovendien zouden ze zeer vergelijkbaar moeten zijn tussen het proefdier model en de mens.

Uiteindelijk zou dit kunnen leiden tot de ontwikkeling van een voorspellende highthroughput test die meer specifiek, toegewijd, goedkoper en sociaal meer aanvaardbaar is dan de momenteel beschikbare diermodellen en die, bovendien, gebruikt kan worden in procedures voor chemische veiligheid als een alternatief voor de huidige testen in knaagdieren.

Het doel van dit proefschrift is het evalueren en optimaliseren van het gebruik van in vitro primaire hepatocyt culturen van de muis om sets van genexpressie-effect merkers te identificeren die in staat zijn onderscheid te maken tussen echte en valse positieve genotoxische kankerverwekkende stoffen.

\section{HepG2 studie}

Om de optimale tijdstippen voor profilering van genexpressie in cellen in vitro te bepalen werden eerst tijdsafhankelijke veranderingen in de cellulaire respons na blootstelling aan een bekend carcinogeen onderzocht, met de bedoeling om dit verder toe te passen in de primaire muizen hepatocyten $(8,9)$. Het is reeds in ons laboratorium aangetoond dat genexpressie-profielen gebruikt kunnen worden om genotoxische van niet-genotoxische carcinogenen te dicrimineren (10). Tijdsafhankelijke effecten werden echter nog niet onderzocht en daarom werden de eerste experimenten uitgevoerd in de menselijke hepatoom (HepG2) cellen, beschreven in Hoofstuk 2. De veranderingen in de genexpressieprofielen van HepG2-cellen, veroorzaakt door het model carcinogeen Benzo(a)pyreen $(\mathrm{BaP})$, werden, met betrekking tot DNA-adduct niveaus en celcyclus distributie, onderzocht op 12 tijdstippen na de blootstelling. 
In deze gedetailleerde tijdsreeks studie werden, na blootstelling van de cellen aan de kankerverwekkende stof $\mathrm{BaP}$, talrijke tijdelijke veranderingen in genenclusters waargenomen. Dit levert daarmee een ongekend inzicht in de tijdsafhankelijke interacties van de betrokken processen en pathways. De meest interessante effecten werden waargenomen met betrekking tot DNA-herstel. Zowel base excisie herstel als globaal genomisch herstel correleerde met DNA-adducten en werden veroorzaakt vanaf 9/12 u tot $60 \mathrm{u}$, wanneer de adducten nog steeds aanwezig zijn.

De resultaten van deze studie suggereren bovendien ook dat wanneer de celniveaus in de G1-fase laag zijn en DNA adduct niveaus hoog zijn, het metabolisme van de cellen voornamelijk gericht is op die van de nucleotiden, terwijl het metabolisme van aminozuren en lipiden omlaag gereguleerd is. Zodra de celcyclus distributie weer normaal is en de meeste DNA-adducten hersteld zijn, keren de metabole processen terug tot het controle niveau. Bovendien zijn verscheidene reactie pathways in genexpressie, transcriptie en translatie in opeenvolgende perioden omhoog gereguleerd.

Al deze waarnemingen wijzen erop dat de cellulaire transcriptoom strikt gereguleerd is en dat het zich aanpast aan de veranderende behoeften van de cellen na acute blootstelling aan een carcinogeen. Tijdsafhankelijke effecten van $\mathrm{BaP}$ op genexpressie-profielen werden waargenomen, waaruit blijkt dat er verschillende tijdstippen moeten worden geëvalueerd op genexpressie-profilering in de volgende studies met primaire muis hepatocyten.

\section{Hepatocyt-gebaseerd muizen in vitro model}

Tot nu toe werden de primaire muizen hepatocyten niet vaak gebruikt in de toxicologie. Daarom werd het potentiële nut van een in vitro muizen hepatocyten model voor toxicologie beoordeeld door de tijdsafhankelijke bevoegdheid tot het metabolisme van xenobiotica en de stabiliteit van genexpressie-profielen te onderzoeken in Hoofdstuk 3. Genexpressie-profielen bleken zeer verschillend zijn tussen de drie geanalyseerde tijdstippen ( 0,42 en 90 uur). Deze tijdsafhankelijke veranderingen kunnen worden toegeschreven aan de aanpassing van de primaire hepatocyten aan hun in vitro omgeving. Maar de genexpressie-profielen van de replica's echter, bleken zeer vergelijkbaar te zijn per tijdstip, ondanks dat er, onmiddellijk na de isolatie van de cellen, grotere verschillen tussen de dieren werden waargenomen. Dit kan worden veroorzaakt door variatie in de initiële stress veroorzaakt door de enzymatische scheiding en isolatie van hepatocyten (11). Deze inter-dier variabiliteit is minder duidelijk in de latere tijdstippen, wat aangeeft dat de stress responsen vervagen.

Pathway analyse, gebruikt voor de identificatie van de biochemische pathways en biologische processen die differentieel tot expressie werden gebracht, onthulde initiële effecten op het niveau van de externe signalerings pathways en energieproductie genen- 
sets. Latere effecten werden waargenomen voor genensets die verband houden met transcriptie, translatie en membraan- en celcyclus-gerelateerde effecten. Het algemene beeld op basis van deze pathway analyses, was dat de leverspecifieke functies continu afnamen en dat, in het algemeen, cellulaire organisaties voortdurend omhoog gereguleerd werden.

Om de metabole bevoegdheid van sandwich-gekweekte muizen hepatocyten meer in detail te onderzoeken, werden genexpressie-profielen van fase I en fase II biotransformatie-enzymen geëvalueerd tijdens de kweekperiode. In het algemeen nemen de expressiewaarden van alle fase I biotransformatie-enzymen af gedurende de gehele kweekperiode. Ook de enzym-activiteiten van de meeste Cyp450 enzymen nemen af gedurende de gehele tijdsperiode, alleen Сyp2B9-10/13/19/23 vertoonde een toename van de activiteit en expressie niveaus. Na 90 uur in kweek bleken alle Cyp450 enzymen nog steeds actief in de primaire hepatocyten. De meeste Cyp450s bleken in conventionele sandwich-gekweekte ratten hepatocyten zeer snel te verminderen, zelfs binnen de korte periode van 24 uur na isolatie $(12,13)$. Terwijl in onze studie de genexpressieniveaus een tragere afname in de tijd vertoonde, wat aangeeft dat de muizen hepatocyten meer stabiel blijven op gebied van Cyp450 genexpressie ten opzichte van ratten hepatocyten, maar niet ten opzichte van menselijke hepatocyten.

De genexpressie van fase II enzymen was, op het einde, slechts afgenomen tot $92 \%$ van de oorspronkelijke niveaus. Dit is in overeenstemming met verschillende studies bij ratten die suggereren dat, in kweek, fase II enzym-activiteiten beter bewaard worden dan fase I enzym-activiteiten $(14,15)$.

Een globale vergelijking van de genexpressie-niveaus van fase I en fase II enzymen van hepatocyten van ratten en muizen heeft aangetoond dat de muizen hepatocyten een stabieler genexpressie-patroon vertonen dan de primaire ratten hepatocyten.

Al deze resultaten geven aan dat het in sandwich-gekweekte primaire muizen hepatocyten in vitro systeem weinig of geen inter-dier variaties heeft, wat de reproduceerbaarheid aantoont. Er werd aangetoond dat het systeem robuust is en dat het de metabole bevoegdheid beter lijkt te behouden ten opzichte van ratten hepatocyten. Op basis van onze genexpressie gegevens, adviseren wij een herstel periode van 42 u toe te passen alvorens de muizen hepatocyten te gebruikten om stress responsen, veroorzaakt door de perfusie-methode, te verminderen.

Vervolgens wordt in Hoofdstuk 4 het primaire muizen hepatocyt model verder gekarakteriseerd door de evaluatie van genexpressie-profielen na blootstelling aan een model carcinogeen, namelijk BaP. Omdat we, in Hoofdstuk 2, waargenomen hebben dat de tijd een grote invloed heeft op genexpressie-profielen in HepG2 cellen na blootstelling aan $\mathrm{BaP}$, werden tijdsafhankelijke effecten op DNA schade en verandering in genexpressie-profielen ten gevolge van $\mathrm{BaP}$ in primaire muizen hepatocyten onderzocht. Ook de dosis-afhankelijke effecten werden onderzocht in dit model. Daarvoor werden de hepatocyten, na een herstel periode van 42 uur, zoals aanbevolen in Hoofdstuk 3, gedu- 
rende verschillende tijdsperioden behandeld met verschillende niet-toxische concentraties van $\mathrm{BaP}$.

Uit genexpressie analyse bleek dat de primaire muizen hepatocyten duidelijke tijds-en dosis-afhankelijke effecten, geïnduceerd door blootstelling aan BaP, vertonen. Tijdsafhankelijke effecten van BaP bleken belangrijker te zijn vergeleken met de dosisafhankelijke effecten. Deze tijdseffecten, echter, waren zeer verschillend van die beschreven in Hoofdstuk 2, aangezien een continue omhoog-of omlaag-regulatie werd waargenomen in de primaire muizen hepatocyten, terwijl meer variatie werd waargenomen in HepG2 cellen. Aangezien BaP gekend is voor het veroorzaken van een halt in de celcyclus in delende cellen, om beschadigd DNA te repareren, is het niet verwonderlijk dat de effecten van $\mathrm{BaP}$ verschillen tussen delende cellen, zoals HepG2 cellen, en niet-delende cellen, zoals primaire muizen hepatocyten $(8,16,17,18)$.

Om de relevantie van het primaire muizen in vitro systeem verder te bepalen, werden genexpressie resultaten vergeleken met een muizen in vivo studie die genomische responsen aan $\mathrm{BaP}$ in de lever beoordeelde. Enkele gelijkenissen tussen deze twee systemen werden aangetoond. Maar, in de primaire hepatocyten, echter, werden meer genen differentieel tot expressie gebracht en werden meer gemoduleerde groepen genen gevonden. Toch moet worden opgemerkt dat de gebruikte doses en dosering regimes in beide modellen, niet vergelijkbaar zijn, aangezien enkel één hoge dosis in vitro en meerdere lage dosissen in vivo gebruikt werden.

Ook de effecten van BaP op DNA-schade, als marker van genotoxische effecten, werden in primaire muizen hepatocyten bestudeerd in Hoofdsuk 4. De kleuring van $\gamma \mathrm{H} 2 \mathrm{AX}$ foci werd gebruikt om dubbel streng DNA (dsDNA) breuken op te sporen en DNA werd geïsoleerd om BaP-DNA-adducten te bepalen. Zowel DNA-adducten en dsDNA breuken bleken tijds-en dosis-afhankelijk toe te nemen. Deze tijds-en dosisafhankelijke invloed werd ook waargenomen in de analyse van genexpressie. De resultaten in Hoofdstuk 4 tonen aan dat de primaire muizen hepatocyten in staat zijn om gevoelig te reageren op blootstelling aan $\mathrm{BaP}$ : ze zijn in staat om $\mathrm{BaP}$ te metaboliseren, wat DNA-adducten en goed gekarakteriseerde veranderingen in genexpressie-profielen veroorzaakt.

\section{Klasse discriminatie}

Omdat het onderzoek beschreven in de vorige hoofdstukken aangetoond heeft dat primaire muizen hepatocyten robuust zijn, in staat zijn de metabole bevoegdheid te handhaven gedurende de hele kweekperiode en in staat zijn te reageren zoals verwacht na blootstelling aan een bekende genotoxische kankerverwekkende stof, onderzochten we, in Hoofdstuk 5, de bevoegdheid van de primaire muizen hepatocyten om genotoxische (GTX) kankerverwekkende stoffen van niet-genotoxische (NGTX) carcinogenen te 
onderscheiden. Omdat de duur van blootstelling een grote invloed heeft op genexpressie-profielen, zoals aangetoond in Hoofdstuk 2 en Hoofdstuk 4, werd verondersteld dat de blootstellingsperiode ook van invloed zou kunnen zijn op klasse discriminatie gebaseerd op transcriptomics gegevens. Primaire muizen hepatocyten werden derhalve geanalyseerd op verschillende tijdstippen na blootstelling aan twee GTX en twee NGTX kankerverwekkende stoffen. Discriminatie van GTX en NGTX verbindingen op basis van genexpressie-profielen, werd uitgevoerd door de 'Prediction Analysis of Microarray' software (PAM), waarbij een 'supervised clustering' methode toegepast wordt. In de studie beschreven in Hoofdstuk 5 blijkt klasse discriminatie inderdaad afhankelijk te zijn van de blootstellingstijd. Het gebruik van PAM resulteerde enkel in een succesvolle klasse discriminatie op de latere tijdstippen, terwijl na 12 uur van de behandeling de verbindingen onjuist geclassificeerd werden. De zogenaamde 'classifiers', gegenereerd door PAM, werden vergeleken met elkaar en de 'classifiers' die na 36 uur van de blootstelling verkregen werden bleken veel overlap te vertonen met die van 24 of 48 uur. Daarom werden alleen deze twee tijdstippen onderzocht in een validatie studie met twee extra GTX verbindingen. Op basis van hun genexpressie-profielen werden beide verbindingen correct geclassificeerd als GTX, waaruit blijkt dat de verkregen 'classifiers' na blootstelling aan kankerverwekkende stoffen inderdaad in staat zijn onderscheid te maken tussen de GTX en NGTX klassen.

Immunokleuring van $\gamma \mathrm{H} 2 \mathrm{AX}$ foci werd gebruikt om fenotypisch DNA-schade te controleren. De $\gamma \mathrm{H} 2 \mathrm{AX}$ test bevestigde significante inductie van schade door de behandeling met GTX verbindingen, terwijl NGTX verbindingen niet in staat waren om schade te induceren.

De studie beschreven in Hoofdstuk 5 toonde aan dat genexpressie-profilering in de primaire muizen hepatocyten het potentieel heeft om de GTX van de NGTX verbindingen te onderscheiden en dat de classificatie verbeterde met toenemende behandelingstijd.

In Hoofdstuk 6 hebben we vervolgens onderzocht of een primaire muizen hepatocyten in vitro systeem in staat is onderscheid te maken tussen GTX verbindingen en valspositieve GTX verbindingen met behulp van een toxicogenomics aanpak. De valspositieve GTX verbindingen, gekozen voor deze studie, worden beschouwd als nietkankerverwekkende stoffen die slechts genotoxiciteit vertonen in in vitro testen, maar niet in vivo.

Omdat we in Hoofdstuk 5 vonden dat 24 en 48 uur de optimale tijdstippen zijn voor klasse discriminatie werden primaire muizen hepatocyten gedurende 24 en 48 uur behandeld met vijf echte GTX en vijf vals-positieve GTX verbindingen. Clustering van veranderingen in genexpressie, veroorzaakt door echte en vals-positieve GTX verbindingen, met behulp van HCA, bleek een veel betere clustering op te leveren na 48 uur vergeleken met 24 uur, waaruit blijkt dat 48 uur meer optimaal is voor de indeling van waar en vals-positieve GTX verbindingen. 
$\mathrm{Na}$ de toepassing van PAM voor elk geanalyseerd tijdstip voor de veranderingen in genexpressie, konden 'classifiers' geselecteerd worden wat resulteerde in een juiste indeling voor 9 verbindingen op beide tijdstippen. Enkel 2-Acetylaminofluorene (2AAF) werd ten onrechte aangezien voor een vals-positieve GTX compound. Dit kan worden verklaard door de specifieke genexpressie-profielen van genen die betrokken zijn bij apoptose en celcyclus. Deze genen worden gewoonlijk gestimuleerd door DNAschade veroorzaakt door GTX verbindingen $(19,20)$ en worden omgekeerd tot expressie gebracht na behandeling met 2-AAF in vergelijking met de andere echte GTX verbindingen. En omdat deze genen betrokken zijn bij de indeling van de GTX verbindingen, wordt 2-AAF wellicht onjuist geclassificeerd op basis van genexpressie-profielen.

De 'classifiers' verkregen uit PAM lijken een betrouwbaar onderscheid te maken tussen echte en vals-positieve GTX verbindingen, zowel op 24 en 48 uur. Beide tijdstippen zijn in dit geval optimaal voor de indeling van echte en vals-positieve GTX verbindingen.

In een poging om fenotypisch een onderscheid te maken tussen echte en vals-positieve GTX verbindingen werden de verschillen in $\gamma \mathrm{H} 2 \mathrm{AX}$ foci vorming ook geëvalueerd in

Hoofdstuk 6. Alle echte GTX verbindingen waren significant in staat om $\gamma \mathrm{H} 2 \mathrm{AX}$ foci te vormen op beide tijdstippen en enkel één vals-positieve GTX verbinding, namelijk 4$\mathrm{NP}$, leek $\gamma \mathrm{H} 2 \mathrm{AX}$ foci te kunnen vormen.

Alleen in de cellen die behandeld werden met BaP werd een significante invloed van de tijd waargenomen, waaruit nogmaals blijkt dat beide tijdstippen optimaal kunnen zijn voor de discriminatie van de echte GTX verbindingen van de vals-positieve GTX verbindingen.

De studie beschreven in Hoofdstuk 6 laat zien dat, afhankelijk van de gebruikte methode, echte GTX carcinogenen redelijk goed onderscheiden kunnen worden van valspositieve GTX verbindingen in primaire muizen hepatocyten door genexpressieprofilering. De meest succesvolle discriminatie werd met behulp van PAM verkregen. Hoewel de discriminatie niet perfect is, kan genexpressie-profilering in primaire muizen hepatocyten dienen als een nieuw in vitro systeem met de capaciteit om echte GTX van vals-positieve GTX verbindingen te onderscheiden.

De toepassing van klasse discriminatie van GTX verbindingen met genexpressieprofilering werd al eerder aangetoond in verschillende in vivo en in vitro studies (7, 10, 21-37). Vergeleken met de vaak gebruikte chronische knaagdier bioassays, is het gebruik van primaire muizen hepatocyten voor de screening van de genotoxische effecten van chemische verbindingen duidelijk een verbetering omdat het veel minder dieren vergt en minder tijdrovend is. Vergeleken met een aantal gerenommeerde in vitro systemen, zoals de Ames-test, de muis lymfoomtest, de micronucleus test en de chromosoom aberratie test, kan het primaire muizen hepatocyten model een lager percentage vals positieve teweegbrengen aangezien alle vals-positieve GTX verbindingen, gebruikt in dit onderzoek, genotoxiciteit vertoonde in een aantal goed gevestigde in vitro syste- 
men die vaak gebruikt worden om het kankerverwekkende potentieel van verbindingen te identificeren, maar in primaire muizen hepatocyten duidelijk apart van de echte GTX kankerverwekkende stoffen ingedeeld werden. Daarom kan dit model de basis vormen voor de ontwikkeling van een voorspellende test, die als alternatief voor de huidige knaagdier genotoxiciteit testen kan worden toegepast in chemische veiligheidstesten. In combinatie met fenotypische verankering kan dit model leiden tot het gebruik van een specifiek in vitro systeem dat specifieke in vivo toxiciteit kan voorspellen.

\section{Beperkingen en aanbevelingen}

Het primaire muizen in vitro model dat gebruikt werd in dit onderzoek heeft een aantal beperkingen met betrekking tot het gebruik ervan voor de beoordeling van de genotoxische effecten van chemische verbindingen.

De isolatie van de primaire muizen hepatocyten met behulp van de twee-stap collagenase perfusie is een technisch ingewikkelde procedure en vereist enige oefening. De hepatocyten moeten vers uit het dier verkregen worden om hun leverspecifieke functies te behouden. Lange-termijn culturen van functionele hepatocyten zijn moeilijk te behouden, maar in een sandwich-configuratie kunnen hepatocyten voor een langere periode gekweekt worden $(38,39)$.

Bovendien is het muizen hepatocyt model dat gebruikt werd in dit onderzoek slechts berust op één lever-cel type, namelijk hepatocyten, terwijl andere lever cellen afwezig zijn. Vergelijking met de in vivo situatie kan ook beperkt zijn, omdat in het muizen hepatocyten model uitwisselingen tussen cellen en hun omgeving minder goed aanwezig zijn vanwege de afwezigheid van de bloedstroom.

Daarom wordt het gebruik van primaire humane hepatocyten als meer geschikt geacht om in vivo toxiciteit te voorspellen bij de mens, maar wordt echter gehinderd door de grote variabiliteit tussen de donoren en de beperkte beschikbaarheid van donormateriaal $(3,4,5)$. Ratten hepatocyten zijn een alternatief voor de menselijke hepatocyten en worden ook vaak gebruikt, maar een snelle daling in de leverspecifieke functies, met name cytochroom P450 (Cyp450) enzym activiteit, wordt waargenomen. Daarom kan een muizen in vitro hepatocyten systeem nog het beste alternatief zijn voor de menselijke situatie. Daarnaast zijn, aangezien de volledige sequentie van het muizen genoom bekend is (40) en transgene muizen modellen op grote schaal beschikbaar zijn, primaire muizen hepatocyten zijn beter geschikt zijn voor het verrichten van mechanistische onderzoeken van de lever toxiciteit.

Klasse voorspelling, beschreven in dit onderzoek, was gebaseerd op het gebruik van bepaalde model verbindingen en bleek tijdsafhankelijk te zijn. Daarom wordt aanbevolen om klasse voorspelling op basis van gen-expressie profielen op meer dan een tijdstip te bestuderen. Op basis van genexpressie-profielen werden 11 van de 12 (92\%) verbin- 
dingen juist ingedeeld. Om het systeem meer betrouwbaar te maken en om het aantal vals positieven te verminderen zou het onderzoek, beschreven in deze thesis, uitgebreid moeten worden door veel meer van deze verbindingen te gebruiken.

Klasse discriminatie bleek ook afhankelijk te zijn van de gebruikte classificatie methoden. Niet alle methoden resulteren in een juiste classificatie en dus moeten verschillende methoden worden toegepast om een optimale klasse discriminatie te verkrijgen.

\section{Conclusie}

Het onderzoek beschreven in dit proefschrift geeft aan dat het sandwich-gekweekte primaire muizen hepatocyten in vitro model weinig of geen inter-dier variatie heeft, relatief stabiel is en haar metabole bevoegdheid langer handhaaft dan ratten hepatocyten, terwijl het bijna gelijk in stabiliteit is met die van de humane hepatocyten. Op basis van onze genexpressie gegevens adviseren wij de toepassing van een herstel periode van $42 \mathrm{u}$ alvorens de muizen hepatocyten bloot te stellen. Primaire muizen hepatocyten lijken ook in staat om BaP te metaboliseren, wat vorming van DNA-adducten en veranderingen in genexpressie-profielen veroorzaakt.

Dit onderzoek toont ook aan dat genexpressie-profielen, afkomstig van primaire muizen hepatocyten blootgesteld aan klassen van genotoxines, gebruikt kunnen worden voor klasse discriminatie. Een succesvolle indeling van de GTX en NGTX verbindingen kan verkregen worden met een verbetering in classificatie op langere blootstellingstermijn. Ook echte GTX carcinogenen kunnen met succes worden gediscrimineerd van valspositieve GTX verbindingen door genexpressie-profilering. Hoewel deze discriminatie niet perfect is, kunnen de primaire muizen hepatocyten een nieuw in vitro systeem vertegenwoordigen dat de capaciteit heeft om verbindingen te profileren voor hun genotoxisch potentieel.

Dit onderzoek heeft dus een fundament gelegd voor de verdere ontwikkeling van een in vitro assay met primaire muizen hepatocyten door genexpressie-profilering te gebruikten om, als uiteindelijke doel, mogelijke kankerverwekkende stoffen te voorspellen. Dit model kan toegepast worden in de chemische veiligheid procedures aangezien zij de mogelijkheden hebben om gedetailleerde inzichten in het werkingsmechanisme van toxische stoffen te verstrekken. Door deze informatie te koppelen aan de parameters die in routine toxiciteit onderzocht worden (fenotypisch ankers), kan dit uiteindelijk leiden tot het gebruik van specifieke in vitro systemen die specifieke in vivo toxiciteit voorspellen. 


\section{Referenties}

1. Blaauboer, B.J., et al., The practical applicability of hepatocyte cultures in routine testing. EcVam workschop report 1, 1994.

2. Davila, J.C., et al., Predictive value of in vitro model systems in toxicology. Annu Rev Pharmacol Toxicol, 1998. 38: p. 63-96.

3. Schaeffner, I., et al., A microtiterplate-based screening assay to assess diverse effects on cytochrome P450 enzyme activities in primary rat hepatocytes by various compounds. Assay Drug Dev Technol, 2005. 3(1): p. 27-38.

4. Richert, L., et al., Evaluation of the effect of culture configuration on morphology, survival time, antioxidant status and metabolic capacities of cultured rat hepatocytes. Toxicol In Vitro, 2002. 16(1): p. 8999.

5. Berry, M.N., et al., Isolated hepatocytes--past, present and future. Cell Biol Toxicol, 1997. 13(4-5): p. 223-33.

6. Dambach, D.M., B.A. Andrews, and F. Moulin, New technologies and screening strategies for hepatotoxicity: use of in vitro models. Toxicol Pathol, 2005. 33(1): p. 17-26.

7. Kirkland, D., et al., Evaluation of the ability of a battery of three in vitro genotoxicity tests to discriminate rodent carcinogens and non-carcinogens I. Sensitivity, specificity and relative predictivity. Mutat Res, 2005. 584(1-2): p. 1-256.

8. Hockley, S.L., et al., Time- and concentration-dependent changes in gene expression induced by benzo(a)pyrene in two human cell lines, MCF-7 and HepG2. BMC Genomics, 2006. 7: p. 260.

9. Lambert, C.B., et al., Dose- and time-dependent effects of phenobarbital on gene expression profiling in human hepatoma HepaRG cells. Toxicol Appl Pharmacol, 2009. 234(3): p. 345-60.

10. van Delft, J.H., et al., Discrimination of genotoxic from non-genotoxic carcinogens by gene expression profiling. Carcinogenesis, 2004. 25(7): p. 1265-76.

11. Pillar, T.M. and H.J. Seitz, Oxidative stress response induced in rat primary hepatocyte monolayers by mechanical removal of adherent cells. Cell Tissue Res, 1999. 295(2): p. 363-7.

12. Kienhuis, A.S., et al., A sandwich-cultured rat hepatocyte system with increased metabolic competence evaluated by gene expression profiling. Toxicol In Vitro, 2007. 21(5): p. 892-901.

13. Boess, F., et al., Gene expression in two hepatic cell lines, cultured primary hepatocytes, and liver slices compared to the in vivo liver gene expression in rats: possible implications for toxicogenomics use of in vitro systems. Toxicol Sci, 2003. 73(2): p. 386-402.

14. Rogiers, V. and A. Vercruysse, Rat hepatocyte cultures and co-cultures in biotransformation studies of xenobiotics. Toxicology, 1993. 82(1-3): p. 193-208.

15. Kern, A., et al., Drug metabolism in hepatocyte sandwich cultures of rats and humans. Biochem Pharmacol, 1997. 54(7): p. 761-72.

16. Bartek, J. and J. Lukas, DNA damage checkpoints: from initiation to recovery or adaptation. Curr Opin Cell Biol, 2007. 19(2): p. 238-45.

17. Wilkening, S., F. Stahl, and A. Bader, Comparison of primary human hepatocytes and hepatoma cell line Hepg2 with regard to their biotransformation properties. Drug Metab Dispos, 2003. 31(8): p. 1035-42.

18. Wilkening, S. and A. Bader, Influence of culture time on the expression of drug-metabolizing enzymes in primary human hepatocytes and hepatoma cell line HepG2. J Biochem Mol Toxicol, 2003. 17(4): p. 207-13.

19. Levine, A.J., p53, the cellular gatekeeper for growth and division. Cell, 1997. 88(3): p. 323-31.

20. Adimoolam, S. and J.M. Ford, p53 and regulation of DNA damage recognition during nucleotide excision repair. DNA Repair (Amst), 2003. 2(9): p. 947-54.

21. van Delft, J.H., et al., Comparison of supervised clustering methods to discriminate genotoxic from nongenotoxic carcinogens by gene expression profiling. Mutat Res, 2005. 575(1-2): p. 17-33.

22. Uehara, T., et al., A toxicogenomics approach for early assessment of potential non-genotoxic hepatocarcinogenicity of chemicals in rats. Toxicology, 2008. 250(1): p. 15-26. 
23. Tweats, D.J., et al., Determination of genetic toxicity and potential carcinogenicity in vitro--challenges post the Seventh Amendment to the European Cosmetics Directive. Mutagenesis, 2007. 22(1): p. 5-13.

24. Thomas, R.S., et al., A comparison of transcriptomic and metabonomic technologies for identifying biomarkers predictive of two-year rodent cancer bioassays. Toxicol Sci, 2007. 96(1): p. 40-6.

25. Nioi, P., et al., Prediction of non-genotoxic carcinogenesis in rats using changes in gene expression following acute dosing. Chem Biol Interact, 2008. 172(3): p. 206-15.

26. Kirkland, D.J., et al., Testing strategies in mutagenicity and genetic toxicology: an appraisal of the guidelines of the European Scientific Committee for Cosmetics and Non-Food Products for the evaluation of hair dyes. Mutat Res, 2005. 588(2): p. 88-105.

27. Iida, M., et al., Unique patterns of gene expression changes in liver after treatment of mice for 2 weeks with different known carcinogens and non-carcinogens. Carcinogenesis, 2005. 26(3): p. 689-99.

28. $\mathrm{Hu}, \mathrm{T}$., et al., Identification of a gene expression profile that discriminates indirect-acting genotoxins from direct-acting genotoxins. Mutat Res, 2004. 549(1-2): p. 5-27.

29. Eun, J.W., et al., Discriminating the molecular basis of hepatotoxicity using the large-scale characteristic molecular signatures of toxicants by expression profiling analysis. Toxicology, 2008. 249(2-3): p. 17683.

30. Ellinger-Ziegelbauer, H., et al., Comparison of the expression profiles induced by genotoxic and nongenotoxic carcinogens in rat liver. Mutat Res, 2005. 575(1-2): p. 61-84.

31. Ellinger-Ziegelbauer, H., et al., Prediction of a carcinogenic potential of rat hepatocarcinogens using toxicogenomics analysis of short-term in vivo studies. Mutat Res, 2007.

32. Ellinger-Ziegelbauer, H., et al., Application of toxicogenomics to study mechanisms of genotoxicity and carcinogenicity. Toxicol Lett, 2009. 186(1): p. 36-44.

33. da Silva, J., et al., Evaluation of the genotoxic effect of rutin and quercetin by comet assay and micronucleus test. Food Chem Toxicol, 2002. 40(7): p. 941-7.

34. Aubrecht, J., et al., Molecular genotoxicity profiles of apoptosis-inducing vanadocene complexes. Toxicol Appl Pharmacol, 1999. 154(3): p. 228-35.

35. Ashby, J., Use of short-term tests in determining the genotoxicity or nongenotoxicity of chemicals. IARC Sci Publ, 1992(116): p. 135-64.

36. Aubrecht, J. and E. Caba, Gene expression profile analysis: an emerging approach to investigate mechanisms of genotoxicity. Pharmacogenomics, 2005. 6(4): p. 419-28.

37. Aardema, M.J. and J.T. MacGregor, Toxicology and genetic toxicology in the new era of "toxicogenomics": impact of "-omics" technologies. Mutat Res, 2002. 499(1): p. 13-25.

38. LeCluyse, E.L., et al., Regulation of glutathione S-transferase enzymes in primary cultures of rat hepatocytes maintained under various matrix configurations. Toxicol In Vitro, 2000. 14(2): p. 101-15.

39. LeCluyse, E.L., et al., Regeneration and maintenance of bile canalicular networks in collagensandwiched hepatocytes. Toxicol In Vitro, 2000. 14(2): p. 117-32.

40. Waterston, R.H., et al., Initial sequencing and comparative analysis of the mouse genome. Nature, 2002. 420(6915): p. 520-62. 
Dankwoord 
Eindelijk, na vele uren, dagen, weken en maanden zwoegen, is het dan zover: het laatste hoofdstuk schrijven. Het laatst geschreven hoofdstuk dat, zoals de ervaring mij leert, waarschijnlijk het eerst gelezen hoofdstuk zal zijn.

Dit laatste hoofdstuk zou er natuurlijk nooit geweest zijn zonder alle voorafgaande hoofdstukken. En die hoofdstukken zouden er dan weer niet geweest zijn zonder de hulp, medewerking en steun van een heel aantal mensen. Hoog tijd dus om deze mensen eens te bedanken voor hun bijdrage.

Om te beginnen wil ik twee mensen bedanken die mij gedurende mijn hele AIO-periode met raad en daad hebben bijgestaan, namelijk mijn promotor Jos Kleinjans en mijn copromotor Joost van Delft.

Jos, tijdens de eerste jaren waren onze contacten redelijk beperkt. Maar naarmate het einde van mijn AIO-periode naderde, werd jouw rol steeds belangrijker. Je had vaak scherpe, maar altijd rechtvaardige en opbouwende kritiek waarmee je mij telkens weer opnieuw wist te motiveren. En vooral die laatste, loodzware dagen ben ik doorgekomen dankzij jouw aanmoedigingen. Mijn oprechte dank hiervoor.

Joost, in het begin bleken jouw open Hollandse houding en mijn bescheiden Belgische mentaliteit nogal eens te botsen. Maar gelukkig konden we geleidelijk aan steeds beter samenwerken. Jij had altijd een andere kijk op de zaken en stelde me vaak vele 'lastige' vragen waardoor ik kritischer naar mijn resultaten leerde kijken. En vooral in het laatste jaar kon ik enorm veel beroep doen op jouw rijke ervaring, waarvoor ik je graag wil bedanken.

Maar iemand die ik, op praktisch gebied dan, misschien nog meer dankbaar moet zijn is Anne Kienhuis. Toen ik wilde starten met mijn experimenten met muizen hepatocyten bleek er helemaal niemand ervaring te hebben met muizenperfusies en leek ik er helemaal alleen voor te staan. Maar gelukkig kon ik altijd beroep doen op jouw ervaringen met rattenperfusies. Jouw praktische hulp tijdens de perfusies was van enorme waarde en ik was dan ook vereerd dat je mijn hulp vroeg bij de humane perfusies. Lieve Anne, zonder jou was het mij nooit gelukt om de muizenperfusies te doen slagen.

Mijn allereerste muizenperfusie deed ik echter bij Biopredic International in Rennes. Cher Christophe Chesne, merci de m'avoir permis de visiter Biopredic International. Christine Boissier et Claire Guyomard, grâce à vous j'ai passé une semaine agréable et instructive à la fois. Bien que j'aie adapté quelque peu la procédure de perfusion, ce que vous m'avez appris a été la base de mes recherches.

Toen de muizenperfusies eindelijk op punt stonden en ik de hepatocyten had blootgesteld, kon ik gelukkig ook nog op de hulp van Ralph Gottschalk, Marcel van Herwijnen en Karen Brauers rekenen. Jullie hielpen me niet enkel bij mijn RT-PCR's en arrays of 
bij het verzamelen van samples, maar namen me ook veel werk uit handen door adducten te meten en $\gamma \mathrm{H} 2 \mathrm{AX}$ kleuringen uit te voeren. Ik had het nooit allemaal alleen kunnen doen.

En toen het werk in het lab afgerond was, moest het echte werk nog beginnen, namelijk de data-analyses. In het begin leek het mij een onmogelijke opdracht om zoveel data te verwerken, maar met de vele uurtjes hulp van Danyel Jennen kon ik toch de bomen weer door het bos zien.

Danyel, ik ben je enorm dankbaar dat ik jou als vraagbaak mocht gebruiken. Hoewel je het zelf ook vaak heel druk had, maakte je toch steeds tijd voor mij als ik weer eens elke 5 minuten kwam aankloppen met mijn 'vervelende' vragen. En daarmee samenhangend moet ik ook nog Jacco Briede bedanken. Niet alleen probeerde je mij te helpen indien Danyel er niet was, maar ik ben je vooral dankbaar om je geduld en begrip als ik weer eens kwam storen. En ook Andre Boorsma en Peter Hendriksen verdienen een bedankje voor alle hulp bij het analyseren van de eerste array's.

Voor de administratieve kant van mijn onderzoek wil ik graag Marie-Claire van der Voort, Anneloes Melman, René Reijnders en Rob Schlooz bedanken. Marie-Claire, je hebt me meer dan eens uit de nood geholpen als ik weer eens niets begreep van de hele papierhandel of andere administratieve hulp nodig had. Anneloes, bedankt voor de belangrijke bijdrage die je geleverd hebt, vooral tijdens het laatste jaar. De nodige formulieren voor mijn papers in orde maken, hulp bij mijn thesis en de nodige brieven schrijven, je deed het allemaal met de glimlach. En René en Rob, bedankt voor alle goede raad en adviezen waarmee jullie meermaals mijn twijfels wegnamen.

Naast al dat experimenteren, analyseren en schrijven was er ook tijd voor ontspanning, bijvoorbeeld onder de vorm van het 'Generic Riskful Animation Team' (G.R.A.T.) waarbij Sabine Langie en ik samen ons creatief ei kwijt konden.

Sabine, wat was het plezant om ons samen in dit avontuur te storten. Ik zal ons eerste kerstfeestje en onze ballonnenavond niet snel vergeten. Later kwam daar ook Joost Linschooten bij. Joost en Sabine, bedankt voor de vele fijne brainstorms die we samen hadden en om telkens weer nieuwe uitjes, survival weekendjes en andere gezelligheden te organiseren. De herinnering aan ons avondje t-shirts schilderen en al onze opnameavonden voor de kerstfeestjes toveren nog steeds een glimlach op mijn gezicht. We hebben toen met ons drietjes nogal wat afgelachen. En daarbij kregen we natuurlijk af en toe de hulp van Pascal Kempers.

Pascal, wat waren we blij als je weer eens wilden verschijnen als 'foute' Kerstman of tekstjes wilden inspreken. Maar ook buiten het G.R.A.T. kon ik altijd op je rekenen als ik weer eens computerproblemen had en vooral wanneer ik behoefte had aan een goede babbel of een luisterend oor. Je bent meer dan eens een steun geweest in moeilijke tijden! 


\section{Dankwoord}

Ook Lucien Beckers, Stijn Lumeij en Marlon Jetten, bedankt om jullie bij het G.R.A.T. aan te sluiten om Sabine en mij te vervangen. Nog veel succes en plezier met het organiseren van allerhande leuke activiteiten.

Verder ben ik ook mijn kamergenootjes Nejla Güngör, Nicole Verhofstad, Sabine Langie en later ook Marlon Jetten enorm dankbaar om het leven op GRAT zo aangenaam te maken. Ik kon vaak bij jullie terecht voor hulp met zinsconstructies, Excel probleempjes, papers submitten en nog veel meer van dat. En vooral onze gezellige babbelmomenten zorgden zo vaak voor de nodige afleiding. Nog veel succes met het afronden van jullie onderzoek.

En ook de andere collega-AIO's verdienen zeker een bedankje voor alle fijne momenten samen. Ik kon altijd wel bij mijn lotgenoten terecht voor tal van vragen en problemen. Dennie Hebels, Joyce Houben, Marieke Quaak, Joost Linschooten, Kevin Hochstenbach, Kristina Magkoufopoulou, Marten Schults, Joep van Berkel, Kimberly VanHees en Jonathan de Jonge, ook jullie wens ik nog veel succes met het afronden van jullie onderzoek. En alle AIO's die mij voorgegaan zijn, wil ik bedanken voor raad en hulp in de eerste jaren van mijn onderzoek.

Ook alle andere collega's van GRAT, bedankt voor alle fijne momenten zowel tijdens als na de werkuren.

I also would like to thank Savi Rangarajan. Savi, we became such good friends at the Gordon Research Conference. Thanks for all the support and for the great time together.

En nu het proefschrift eindelijk af is, wil ik toch in het bijzonder mijn twee paranimfen Karen Brauers en Veerle Mathijs bedanken. Het is voor mij een hele geruststelling dat jullie twee me tijdens de promotie zullen ondersteunen.

Karen, wat het je enorm veel tijd aan mij gespendeerd! Zeker toen ik je opzadelde met al die gamma-kleuringen en array's. Daarom leek het mij ook terecht om jou als paranimf te vragen en ik ben je enorm dankbaar dat je 'ja' gezegd hebt.

Veerle, mijn lieve zus, wie anders kon ik vragen voor deze 'zware' taak als paranimf. $\mathrm{Na}$ meer dan 28 jaar kennen we elkaar dan ook door en door en ik ben blij dat jij op zo'n belangrijk moment in mijn leven naast mij wil staan.

En daarbij verdienen ook Jan en Myrte de Keyser een bedankje. Jan, merci dat ge uw madam efkes wil afstaan aan uw schoonzusje. Myrte, mijn liefste metekindje, bedankt dat tanti op jou mocht letten als mama en papa er niet waren, zo kon ik toch regelmatig 'verplicht' ontspannen. 
Ben Mathijs, mijn broerke, jammer dat er maar twee paranimfen naast mij kunnen staan tijdens de promotie, anders had ik het je zeker gevraagd. Bedankt dat je regelmatig interesse had in mijn onderzoek en in het leven als doctoraatsstudent. Ik hoop dat ik een inspiratie geweest ben en dat je jouw weg zal vinden in je eigen vakgebied.

Mama en papa, ik weet dat jullie trots zijn op jullie dochter, maar ik wil jullie bedanken om altijd voor mij klaar te staan. Zelfs als ik mijn frustraties weer eens de vrije loop liet, waren jullie er om mij op te vangen. Dat verdient een super dankjewel.

En tenslotte bompa, mijn opa, jij was uiteindelijk diegene die mij stimuleerde om mijn $\mathrm{PhD}$ te halen. Jammer dat je deze dag niet meer mag meemaken, want ik weet dat je enorm fier geweest zou zijn op je kleindochter...

Merci iedereen!

Karen 

Curriculum Vitae 


\section{Curriculum Vitae}

Karen Mathijs was born on April $6^{\text {th }} 1981$ in Neerpelt, Belgium. After finishing secondary school in the discipline 'Mathematics \& Sciences' at the WICO Campus Salvator in Hamont-Achel, she started in 1999 to study 'Biomedical Sciences' at the Limburg University Centre (currently University Hasselt) in Diepenbeek. After her first two years, she continued her study at the transnational University Limburg (tUL; collaboration between Diepenbeek and Maastricht), where she obtained in 2003 her diploma of 'Licentiate in the Biomedical Sciences / Master of Health Sciences'. During her study she ran an internship at the Biomedical Research Institute (BIOMED) in Diepenbeek, conducting proteomics research on primary rat oligodendrocytes in multiple sclerose. Thereafter she started in 2003 to study the specialisation in 'Molecular Medical Biotechnology' at the University of Ghent, were she obtained in 2004 her academic degree. During this study she ran an internship at the Flemisch Institute for Biotechnology (VIB) in Zwijnaarde, conducting in vivo research on the role of matrixmetalloproteinases in TNF-related pathologies and tumor development.

Subsequently, from November 2004 until March 2009, she worked as a PhD student at the department of Health Risk Analysis \& Toxicology (GRAT) at the Maastricht University. The research conducted during these years and presented in this thesis, occurred under supervision of Prof. Dr. Jos CS Kleinjans and Dr. Joost HM van Delft. Next to conducting research, she attended several courses on handling laboratory animals (according to art.9 of the Dutch law on experimental animals), and for several modules as part of the Postgraduate Education in Toxicology in favour of the registration as a toxicologist.

After obtaining her $\mathrm{PhD}$ title Karen, likes to become a teacher in sciences. 
Karen Mathijs werd geboren op 6 april 1981 te Neerpelt, België. Na het behalen van haar secundair diploma in Wiskunde-wetenschappen aan de WICO Campus Salvator the Hamont-Achel, startte ze in 1999 aan de studie 'Biomedische Wetenschappen' aan het Limburgs Universitair Centrum (tegenwoordig Universiteit Hasselt) te Diepenbeek. Na de kandidatuurjaren, zette zij haar studie verder aan de transnationale Universiteit Limburg (tUL; samenwerking tussen Diepenbeek en Maastricht), waar zij in 2003 haar diploma 'Licentiaat in de Biomedische Wetenschappen / Doctorandus in de Gezondheidswetenschappen' behaalde. Tijdens deze studie deed ze een stageonderzoek in het Biomedisch Onderzoeksinstituut (BIOMED), waar ze een proteoomstudie deed op primaire ratten oligodendrocyten in relatie to multiple sclerose.

Vervolgens startte ze in 2003 de specialisatiestudie in 'Moleculaire Medische Biotechnologie' aan de Universiteit van Gent, waar ze in 2004 haar diploma behaalde. Tijdens deze studie deed ze een stageonderzoek aan het Vlaams Instituut voor Biotechnologie (VIB) te Zwijnaarde, waar ze, in een in vivo studie, onderzoek deed naar de rol van matrix-metalloproteinasen in TNF-gerelateerde pathologieën en tumor ontwikkeling. Daarna was Karen, van november 2004 tot en met maart 2009, werkzaam als promovenda bij de capaciteitsgroep GezondheidsRisico Analyse en Toxicology (GRAT) aan de Universiteit Maastricht

Haar promotie onderzoek, dat beschreven is in dit proefschrift, gebeurde onder begeleiding van Prof. Dr. Jos CS Kleinjans and Dr. Joost HM van Delft. Naast het uitvoeren van onderzoek, heeft ze ook verscheidene cursussen gevolgd; waaronder 'Proefdierkunde op grond van art. 9 van de Wet van Dierproeven' en verschillende modules van de 'Postdoctorale Opleiding Toxicologie' ten behoeve van registratie als toxicoloog.

$\mathrm{Na}$ het behalen van haar doctors titel wil Karen Mathijs aan de slag in het onderwijs. 



\section{List of Publications}




\section{FULL PAPERS}

Mathijs K., Kienhuis A.S., Brauers K.J.J., Jennen D.G.J., Lahoz A., Kleinjans J.C.S., van Delft J.H.M.: Assessing the metabolic competence of sandwich-cultured Mouse primary hepatocytes. Drug Metab Dispos, 2009. 38: p. 1305-11.

Mathijs K., Brauers K.J.J., Jennen D.G.J., Boorsma A., van Herwijnen M.H.M., Gottschalk R.W.H., Kleinjans J.C.S., van Delft J.H.M.: Discrimination for genotoxic and non-genotoxic carcinogens by gene expression profiling in primary mouse hepatocytes improves with exposure time. Submitted in Toxicol Sci.

Mathijs K., Jennen D.G.J., Boorsma A., van Herwijnen M.H.M., Gottschalk R.W.H., van Steeg H., Breit T.M., Luijten M., Kleinjans J.C.S., van Delft J.H.M.: "Omics"based validation of a primary mouse hepatocyte model for the purpose of genotoxicity profiling using Benzo(a)pyrene as a reference. In preparation.

Mathijs K., Brauers K.J.J., Jennen D.G.J., Kleinjans J.C.S., van Delft J.H.M.: Gene expression profiling in primary mouse hepatocytes discriminates between true and false genotoxic compounds. In preparation.

Hockley S.L., Mathijs K., Staal Y.C.M., Brewer D., Giddings I., van Delft J.H.M., Philips D.H.: Interlaboratory and Interplatform Comparison of Microarray Gene Expression Analysis of HepG2 Cells Exposed to Benzo(a)pyrene. Omics, 2009. 13(2): p. 115-25.

Van Delft J.H.M., Mathijs K., Staal Y.C.M., van Herwijnen M.H.M., Brauers K.J.J, Boorsma A., Kleinjans J.C.S: Time Series Analysis of Benzo[A]Pyrene-Induced Transcriptome Changes Reveals Temporary Effects on DNA Repair, Metabolism and Cell Cycle. In preparation. 


\section{ABSTRACTS}

Mathijs K., Van Delft J.H.M., Kleinjans J.C.S: Successive gene expression changes in HepG2 cells after B[a]P exposure. Annual PhD student meeting of the Netherlands Society of Toxycology (NVT), Wageningen, The Netherlands, June 2006.

Mathijs K., Kienhuis A.S., Brauers K.J., Jennen D.G., Kleinjans J.C.S., van Delft J.H.M.: Sandwich-cultured mouse hepatocytes: Stability, metabolic competence and limitations. Annual PhD student meeting of the Netherlands Society of Toxycology (NVT), Wageningen, The Netherlands, June 2008.

Mathijs K., van Herwijnen M.H.M., van Delft J.H.M.: Time- and concentrationdependent changes in gene expression induced by B(a)P in primary mouse hepatocytes. Gordon Research Conference Toxicogenomics, New London, United States, June 2007.

Mathijs K., van Herwijnen M.H.M., van Delft J.H.M.: Time- and concentrationdependent changes in gene expression induced by B(a)P in primary mouse hepatocytes. Annual PhD student meeting of the Netherlands Society of Toxycology (NVT), Wageningen, The Netherlands, June 2007.

Mathijs K., van Herwijnen M.H.M., van Delft J.H.M.: Time- and concentrationdependent changes in gene expression induced by B(a)P in primary mouse hepatocytes. Work in Progress Meeting of the Netherlands Toxicogenomics Centre (NTC), Wageningen, The Netherlands, June 2007.

Mathijs K., van Herwijnen M.H.M., van Delft J.H.M.: Time- and concentrationdependent changes in gene expression induced by B(a)P in primary mouse hepatocytes. ECNIS Annual Meeting, Maastricht, The Netherlands, February 2007. 
